\title{
WestVirginiaUniversity
}

THE RESEARCH REPOSITORY @ WVU

Graduate Theses, Dissertations, and Problem Reports

2005

\section{Handcuffed hegemony: International restraint in unbalanced systems}

\author{
Mark E. Schaefer \\ West Virginia University
}

Follow this and additional works at: https://researchrepository.wvu.edu/etd

\section{Recommended Citation}

Schaefer, Mark E., "Handcuffed hegemony: International restraint in unbalanced systems" (2005).

Graduate Theses, Dissertations, and Problem Reports. 2330.

https://researchrepository.wvu.edu/etd/2330

This Dissertation is protected by copyright and/or related rights. It has been brought to you by the The Research Repository @ WVU with permission from the rights-holder(s). You are free to use this Dissertation in any way that is permitted by the copyright and related rights legislation that applies to your use. For other uses you must obtain permission from the rights-holder(s) directly, unless additional rights are indicated by a Creative Commons license in the record and/ or on the work itself. This Dissertation has been accepted for inclusion in WVU Graduate Theses, Dissertations, and Problem Reports collection by an authorized administrator of The Research Repository @ WVU.

For more information, please contact researchrepository@mail.wvu.edu. 
Handcuffed Hegemony: International Restraint in Unbalanced Systems

\author{
Mark E. Schaefer
}

Dissertation submitted to the Eberly College of Arts and Sciences
at West Virginia University
in partial fulfillment of the requirements
for the degree

Doctor of Philosophy

in

Political Science

\author{
Approval by \\ Joe Hagan, Ph.D., Committee Co-Chairperson \\ Jamie Elizabeth Jacobs, Ph.D., Committee Co-Chairperson \\ Scott R. Crichlow, Ph.D. \\ John C. Kilwein, Ph.D. \\ Jason Parker, Ph.D. (Department of History)
}

Department of Political Science

Morgantown, West Virginia

2005

Key Words: Hegemony, International Regimes, Domestic Politics, and Restraint Copyright: 2005 Mark E. Schaefer 


\begin{abstract}
Handcuffed Hegemony: International Restraint in Unbalanced Systems
\end{abstract}

\title{
Mark E. Schaefer
}

This work contends that the current systemic view of hegemonic systems is incorrect. On one hand hegemonic actors are conceptualized as omnipotent actors that can mold the system to best reflect its goals. Still, others illustrate that such unipolar systems can never be achieved, or at best exist for a short time as other powers move to rebalance the international system. Mearsheimer illustrates a more realistic approach, that unbalanced multipolar systems can exist, in which a larger state is present in a traditional multipolar system, not a traditional vertical authority structure. He contends that such a system is transient, for this larger power will eventually be reined in by other actors. This piece contends that these unbalanced systems are reality, and that current thought relies only on systemic notions and does not realize other constraints that can maintain system stability for significant durations of time.

The theory developed in this work is based upon a series of three hegemonic constraints: international regime constraints, domestic political constraints, and the degree of hegemonic power concentration. This work maintains that these "hegemonic handcuffs" can restrain the actions of the dominant state in the international system so as to preclude traditional balancing behavior by the remaining great powers in the system, until a point in time in which the hegemonic actor begins to cast off its shackles. It is at this point in a hegemons life that the remaining great powers begin to balance the power of the dominant state, hence signaling the end of the hegemonic actor's supremacy. The work utilizes the cases of Spain under Philip II, France under Napoleon III, and Germany under Bismarck in a structured focus framework to delve in to the theory in question. 


\section{Acknowledgements}

As my graduate career draws to a close there are many individuals that I must thank for their support and comfort throughout this process. First, I would like to express my eternal thanks to my wife Natalie Schaefer whose love, kindness, and support kept me on this path. Truly without her I would never have reached this point. I must next thank the Schaefer family, my father Paul E. Schaefer, my mother Nancy Schaefer, my grandmother Sally "Bay" Beatty, as well as my brother Todd E. Schaefer and his family for all of their support. I must also thank the Chapin family for their support and for accepting me into the fold: Dr. Charles Chapin, Carol Ann Chapin, and Charlie Chapin. Finally, I would be remiss not to thank our cat, Kitty, who provided numerous distractions during the writing of this dissertation.

I also need to thank my departmental family for all of their assistance and support. First, I must thank my dissertation committee co-chairs: Dr. Joe Hagan and Dr. Jamie Elizabeth Jacobs. They have no idea how much their council and friendship have meant to me as well as how much they have shaped my life, not merely this dissertation. I must also thank the other members of my dissertation committee for their aid and for shaping such a monstrous work: Dr. Scott R. Crichlow, Dr. John C. Kilwein, and Dr. Jason Parker. I would also like to thank the professors in the West Virginia University Department of Political Science who have provided me with an invaluable education: Dr. Robert E. DiClerico, Dr. Robert D. Duval, Dr. Allan S. Hammock, Dr. Susan Hunter, Dr. Kevin M. Leyden, Dr. Donley T. Studlar, and Dr. Jeffrey S. Worsham. Additionally, I need to thank the other bosses of the WVU Department of Political Science for their assistance and support: Rebecca Digman, Lee Ann Greathouse, and Donna MacIsaac. Donna must also be thanked for expertise in scheduling as well as her formatting skills.

I must also express my thanks to Dr. Neil Berch and the members of the WVU Debate Team. Dr. Berch helped put me on this path and was their as a friend throughout. My friends on the Debate Team provided me with argument partners, helped Natalie and I find each other, and gave me places to rest as a began my life as a commuting teacher. Finally, I must thank my students at both West Virginia University and Marietta College. You all have taught me more than I could ever teach you.

Finally, the author must thank his beloved West Virginia University Mountaineers and Chicago Cubs for providing needed diversions.

Nevertheless, all mistakes and omissions in this work are solely my own. 


\section{Table of Contents}

Chapter One: Handcuffing the Hegemon...................................................................... 1

Traditional Views of Hegemony and their Limitations ......................................................

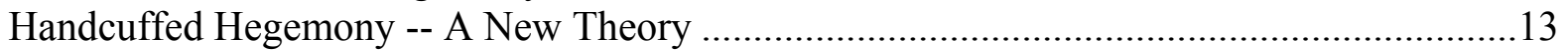

Chapter Two: The Thoughts behind the Handcuffs..................................................20

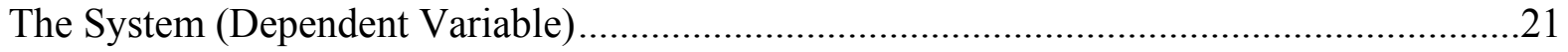

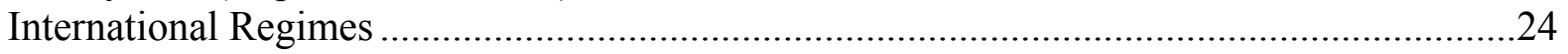

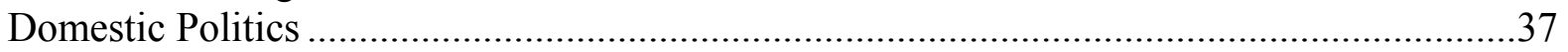

Concentration of Hegemonic Power.............................................................................44

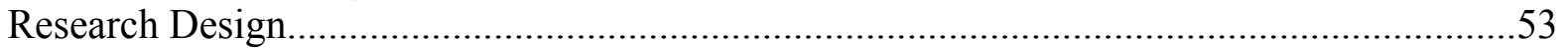

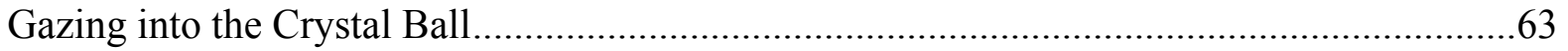

Chapter Three: The Accidental Hegemon: the Case of Spain............................................66

International Regimes - If Only Spain had Some Self-Restraint ......................................69

The Impact of Spain's International Regimes ................................................................... 77

The Handcuff of Domestic Politics (or the Key to Hegemonic Failure) ...............................78

The Impact of Spain's Domestic Politics.........................................................................97

The Handcuff of Hegemonic Power Concentration (or Did Spain Really Borrow Power) ....98

The Impact of Spain's Hegemonic Power ................................................................... 117

The Dependent Variable - The Balancing of Spain .....................................................118

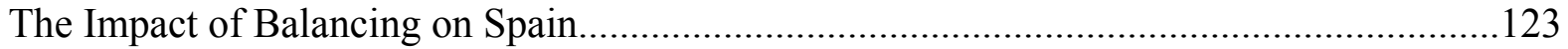

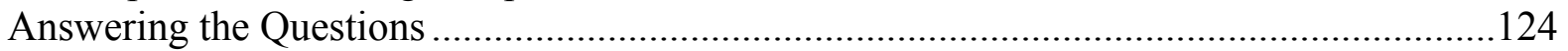

When Hegemony Goes Wrong ................................................................................ 143

Chapter Four: France under Napoleon III - Hoping to be Handcuffed ...........................145

International Regimes and France - The Hope for a Restraining Hand .............................148

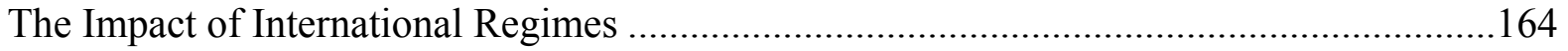

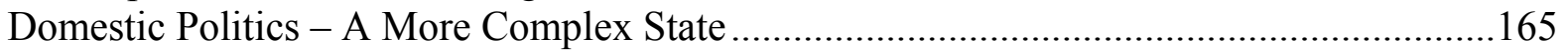

The Impact of French Domestic Politics .......................................................................... 178

The Handcuff of Hegemonic Power Concentration

(Being in the Right Place at the Right Time)............................................................179

The Impact of France's Hegemonic Power Concentration..............................................187

The Dependent Variable - The Balancing of France.........................................................188

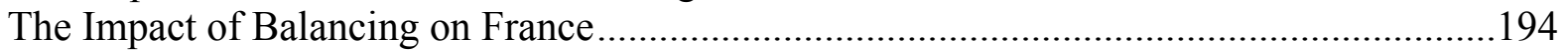

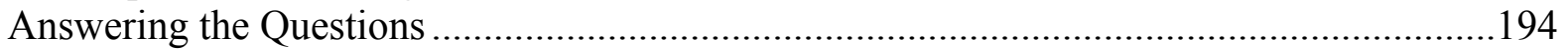

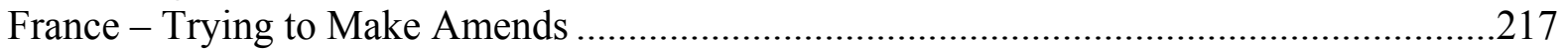

Chapter Five: Germany under Bismarck -

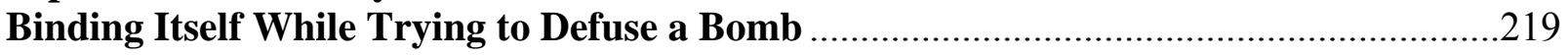

German International Regimes - The Ties that Bind .............................................221

The Impact of German International Regimes.............................................................234

The Domestic Politics of Germany - Trying to Keep the Monster Tucked Away................234

The Impact of Domestic Politics on German Dominance .................................................249

German Hegemonic Power - Powerful at the Right Time ...............................................250

The Impact of German Hegemonic Power Concentration...............................................254

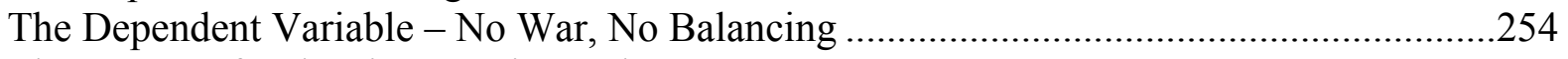

The Impact of Balancing on Bismarck's Germany.....................................................261

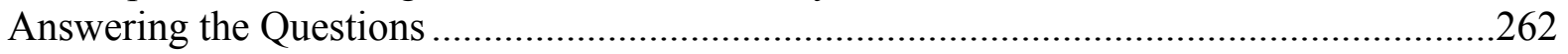




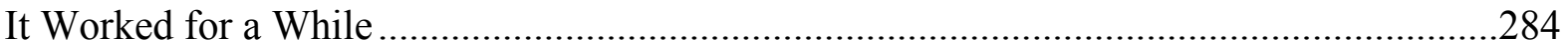

Chapter Six: However, In Conclusion and Moreover ....................................................286

Hypotheses Revisited..........................................................................................28

Historical Intelligence: Implications for the United States ............................................295

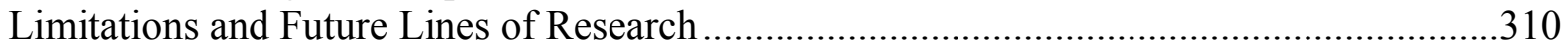

Making a Contribution - Building on the Past ....................................................... 313

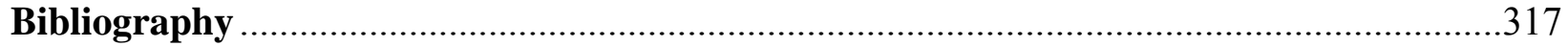




\section{List of Tables}

Table 3-1: Spanish Imports of Wealth from the Americas ......................................................102

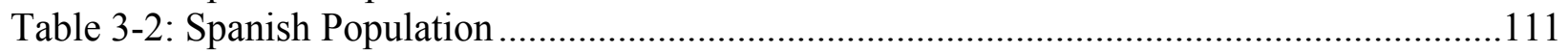

Table 3-3: European Increases in Military Manpower .........................................................112

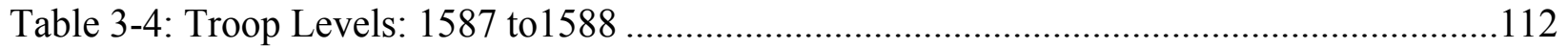

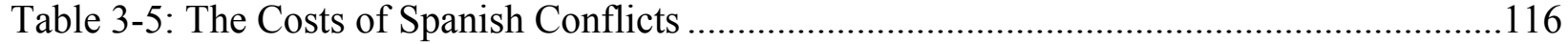

Table 3-6: The Great Powers in the Time of Philip II ........................................................124

Table 3-7: Spanish Interest Group Activity ....................................................................... 134

Table 3-8: Spanish Population and Distribution................................................................139

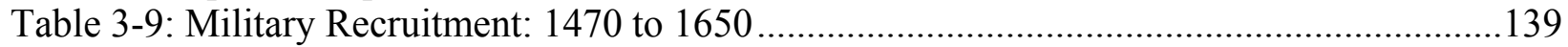

Table 4-1: Great Power Strengths following the Napoleonic Wars ........................................180

Table 4-2: The Great Powers in the Time of Napoleon III....................................................195

Table 4-3: French Interest Group Activity........................................................................203

Table 4-4: Great Power Population Size during the Rule of Napoleon III ...............................211

Table 4-5: Great Power Economic Indicators in the Case of France......................................212

Table 4-6: Great Power Military Comparisons for the Case of France ...................................213

Table 5-1: The Great Powers in the Time of Bismarck .........................................................263

Table 5-2: Interest Group Activity in the Time of Bismarck................................................271

Table 5-3: Bismarck's International Regimes ..................................................................274

Table 5-4: Great Power Population Numbers in the German Case .......................................279

Table 5-5: Great Power Economic Indicators in the Time of Bismarck...................................279

Table 5-6: Great Power Military Comparisons in the German Case ........................................280 


\section{Chapter One Handcuffing the Hegemon}

In recent years a large question has arisen in the international relations community. It can be seen in the Summer 2000 issue of Foreign Policy simply entitled "What Comes after the PostCold War World?" It seems that everyone sees something new dominating the international landscape. Is it a system of complex interdependence (Keohane and Nye)? Is it a new system of multipolarity? Or is it possible that the death of a hegemon has been misstated (Russett)? A deeper question exists, that being have we correctly identified what a hegemonic system looks like? It is my contention that the United States remains hegemonic in the international system, but that in order to correctly view the hegemony of the United States we must reconceptualize our view of these systems. Moreover, this new form of hegemony is nothing new for international politics. Past views of hegemony have been unable to fully explain the complex reality of hegemons. This piece will lay groundwork for a new theory of hegemony, and will study hegemony throughout several historical periods, while considering several hegemonic actors. The study will use case studies of the Spain under Philip II; France under the rule of Napoleon III; and Bismarck's Germany to study this new conceptualization of hegemonic power. These three case studies will then be used in a lesson drawing framework to provide possible intelligence through history to prescribe courses of potential action for the United States. This research will begin to explore constraints that exist in the world of great powers.

Actors face constraints from several different sides. Such constraints can also be found in the most dominant actor. These constraints appear very interesting when hegemonic powers are considered, because the notions of restricted or governed action are not traditionally ascribed to the hegemon. This work contends that hegemonic constraints can be tested through the use of balancing behavior as the dependent variable. Layne (1998) provides a telling description of 
balancing behavior against hegemonic actors. He argues that hegemonic actors are threatening to other states in the international system, not merely because of their size but as a result of their potential to dominate the system, thus the presence of a hegemon or potential hegemon triggers states to access their latent power or seek out balancing partners as a response. (Layne 1998 1315) Thus, while considering the work of Layne, how can any actor ever reach the point of hegemony? The theory advanced in this research will argue that hegemony can be reached without triggering balancing behavior if a state is able to operate within three levels of constraint: domestic politics, international institutions in the form of international regimes and laws, and the constraint of the power distribution throughout a given system. It is my contention that hegemonic actors cannot be seen as all powerful dominant states, but rather these dominant actors must be seen in conjunction with the hegemonic handcuffs that serve to restrain their actions and make their preponderance of power more palatable to the other powers present in each given system. Dominant actors that do not tolerate or seek to remove their handcuffs will soon find themselves balanced by other states seeking to decrease the discrepancies of power distribution.

The very nature of a great power's state governmental structure can be seen as a potential source of constraint. The domestic politics of a given state can be seen to limit certain state actions, or to force the hand of the state in a manner that would not be considered in the optimal interest of a given state. These domestic constraints can be argued to arise from a number of different sources. It could be seen that the domestic institutions present in a given state could be a source of constraint. Moreover, the presence of interests within a state or its government may cause a state to take certain actions and limit other actions. The economic needs of a state may cause or constrain still other actions. 
International regimes of varying levels of institutionalization throughout time may be seen to further limit, constrain, or encourage state actions in the powers in question. At a very minimal level previous treaties and international agreements could be shown to limit state actions. If a state feels that a given action may be in violation of an agreement that action may be taken out of the considered possibilities to meet an existing problem or policy goal. At a more institionalized extreme agreements such as those in made in an international body may also cause a higher degree of compliance and thus constraint. One could imagine that breaking an agreement of the magnitude of the WTO or a modern free trade agreement may cause even more fallout than the breaking of an agreement in the 1700s to preserve trading rights.

The degree of hegemonic power dispersion is also important to how such an international system functions. Traditionally hegemonic actors are assumed to have a preponderance of all forms of power, including both hard and soft power. Though, the case can be made for systems in which two different powers each hold a preponderance of one of the sources of hegemonic power. Such a dispersion of power would tend to add additional instability to a system, as one power may posses a disproportionate amount of military strength while another state may control a larger share of economic or trading power. However, before we delve deeper into potential sources of constraint on hegemonic actors, we must first come to terms with exactly what type of actors we are considering, and in what systemic arrangement these types of actors actually operate.

\section{Traditional Views of Hegemony and their Limitations}

Gilpin (1981) seeks to explain how change takes place in the international system. He is also interested in what circumstances affect change in the system. The author is attempting to create a framework where the concept of war and change can be analyzed. Gilpin seeks to use 
economic theories in order to better understand the international system. His work seems to challenge the balance of power theorists, while maintaining his place in the realist structure. He does not see the balance of power theory as systemic as the real world demands. (Gilpin)

Gilpin offers a cyclical view of world politics, whereby states rise, become overextended, and thus fall to a rising power. States become overextended when they attempt to stretch their international involvement past the point that their economic strength and resources can sustain. Gilpin argues that each state must be aware of its limitations, and thus avoid actions that can cause such strategic overstretches that leave the hegemonic actor vulnerable to other states, particularly the rising hegemon. The author states that there are economic determents to state actions. All states seek to increase their control over the international system, therefore states use cost/benefit analysis to determine moves in the international system. Each state must decide whether it is profitable to gain more weapons or make a strategic move against a neighboring country. States are encouraged or discouraged by specific factors to attempt to change the international system As the power of a state increases it seeks to control more land, resources, and eventually the international system, for that countries which becomes the hegemonic actor can shape the system to best suit the state's goals and needs. States will seek to expand until the cost of expansion is more than the benefits of such a move. Gilpin then explains that as costs and benefits of expansion and system change are reached economic costs to maintain the current power level increase at a higher rate than the country's economy can support. Thus, the hegemonic power is in decline. Now that the key power faces decline, another state has risen to a position capable of challenging it for supremacy. The hegemon is faced with three choices. It can make an offensive strike against the challenging power, hence a hegemonic war, the most favored reaction. It can seek to reduce its costs of maintaining its power; however this may lead 
to an overextension of commitments. Or the state can move towards a more isolationist foreign policy. With each of these choices a change in the international system will occur, and a new power will rise only to face the same fate as its predecessor. (Gilpin)

Gilpin cites three sources of hegemonic power. First, Gilpin argues that the hegemonic actor gains power by gaining dominance in both economic and military realms. He argues that in order to act as the hegemon a state must gain a preponderance of power in the international system. This dominance of power allows the hegemon to maintain political and economic relations with the other states in the system, additionally this power allows the hegemon to create spheres of influence within the system. Second, a hegemon must gain the highest level of international prestige among the other states in the system. Prestige is defined as a willingness to take action despite the resistance of other states in the international system. Third, a hegemon must create a system of international control, whereby sets of rules and norms are put in place by the hegemon. Additionally, Gilpin illustrates how the hegemon further perpetuates its dominant position in the international system. The author argues that hegemon provides certain public goods to the other states in the international system in order to continue and further its hegemony. Gilpin argues that the United States has been the hegemon following the end of the Second World War; however he argues that the United States is facing a hegemonic decline. (Gilpin)

Gilpin's theory of hegemonic stability dismisses the state as a viable and real actor in the international system. The author's work moves in the same tradition of Waltz in which the only property of a state that is needed to determine foreign policy action is the relative power resources of the state, and the movements of the international system will control the remainder of state action. Additionally, Gilpin's work is not strengthened through the use of a historical 
survey of the actions and impacts of previous hegemonic actors. It is as if we are to assume that U.S. and British hegemony are the absolute model of such actions and such a system. These oversights completely moot out any notion of state dynamics, as well as notions of the dynamics of the international system over time. Additionally, Gilpin's work creates a view of hegemony in which a perfectly vertical authority structure is formed, and in such a view it is often argued that the hegemon has the ability to completely control the actions of the other states in the system.

Layne (1993) provides a compelling counterpoint to some of the contentions of Gilpin. The author argues that no matter the benevolence of U.S. actions the unipolarity that the state currently possess will be fleeting as new states will rise to challenge and balance the preponderance of power which the United States enjoys. He argues that power balances power in a Waltzian framework, as he contends that no matter how gently the U.S. walks it will still manage to step on the toes of some states. The author argues that differential growth rates will certainly move in a way disadvantageous to any hegemon, and thus a challenger will rise. (Layne 1993)

Layne's work provides a typical neorealist response to those that argue that hegemony can be sustained, though the work does not act to counter notions that a challenger potentially exist within the system. He does illustrate that challengers must make the decision to take on the role of a hegemonic challenger or balancer (Layne 134). Thus, it seems possible to argue that though other states may achieve the potential to act as balancers they may choose not to take such action, as they may see other structure that provide suitable constraints for their largest global neighbor. It seems possible to argue that such actors can remain latent within a system as 
other constraints take their course, yet holding onto the possibility that action may be necessitated in the future to counter the actions of a dominant power.

Kaplan (1957) illustrates the potential for several variants of international systems to exist, though in this work it is his notions of the balance of power systems that are of most interest. The author's work can be seen as an attempt to add additional structure to the study of international relations. His work is shown to bring structural soundness to the notions of a systemic level of analysis of the relations of states. It can be argued that it is the work of Kaplan that has laid the groundwork for future systems scholars such as Waltz, Walt, and Schweller.

Kaplan's first system is labeled the "balance of power" system. He illustrates that in this system the international system lacks any institutionalized governmental system. He depicts a traditional system in which the main actors in the system are socialized to understand the rules of the structure without the presence of a central authority figure. Kaplan illustrates that six primary rules exist within this structural form: states are argued to take actions that can increase their share of international power; actors will move into a conflict phase rather than give up on a potential source of additional power if negotiations fail to bring resolution in the best interest of a power seeking state; states will stop a conflict if it becomes aware that such a conflict will remove a losing state from the ranks of the systems great powers; states within the structure will act to balance any single or group of actors that seek to gain hegemony over the remaining members of the system; other states within the system will seek to constrain any actor that supports structural guidelines that could introduce an organization or regime that would seek to constrain the remaining actors within the system; and in a system of balanced power the victorious actors in any conflict will seek to allow the return of the defeated power or powers to their original position within the system. (Kaplan 21-36) Essentially, Kaplan's first system 
appears to provide a rule centered model of the traditional notions of a multipolar world, in which actors seek to gain power at the expense of other actors within the system, yet with the ultimate end being the maintenance of stability among the system members unless hegemony can be achieved by each state.

The work of Kaplan goes a long way in illustrating potential international structures and in providing potential systemic explanations of state actions. It is the work of Kaplan that appears to foreshadow the more contemporary notions of multipolarity, in which such balances of power are constantly sought by those in the system. Yet, the work still compartmentalizes the impact of the system on state action, thus segregating other forms of constraint on state action rather than undertaking a more holistic understanding of the relations of large powers. Additionally, Kaplan's hierarchical system resembles that of Gilpin's in that the largest actor, the hegemon, is provided with a blank check for action. In the worlds of both scholars the largest actor appears to have the ability to take action in an unfettered manner. This seems to ignore the reality of the international world, in that all states may face constraints both internally and externally, no matter the amount of capabilities held by such a state.

Mearsheimer (2001) provides us with a glimpse of a system in which a larger state actor still may have to deal with the constraints of other actors within the system. The author's work is aimed at the creation of a new form of realist thought, what he terms offensive realism. Mearsheimer argues that offensive realism differs from traditional realism, or what he terms defensive realism. He contends that states are socialized by the system to see the international system as one of self-help, which in turn causes states to seek offensive advantages. This is comparatively different than the notions of defensive realism, for states do not seek to maintain a balance of power and negotiate first in instances of disagreement, conversely he argues that 
states seek to make offensive gains in a zero-sum fashion in relation to other states in the international system. Moreover, Mearsheimer claims that the ultimate goal of each great power in the system is to gain and maintain hegemony. Though, he contends that hegemony is largely a dream of empire, as opposed to a geopolitical reality for several reasons. (Mearsheimer)

The author sees what he terms true hegemony to be nothing more than a hopeful wish for states in the modern era. Mearsheimer argues that several realties present themselves to states seeking the ultimate endgame of offensive realism. He assumes that a hegemon would need to extend its power throughout the entire globe, thus controlling all aspects of state action throughout the system. Hence, he argues that such a massive amount of capabilities centralized within one power would not typically be feasible for a state seeking to gain hegemony. Additionally, Mearsheimer contends that the oceans of the world create a barrier to true hegemony, for armies represent the true basis of hegemonic power and oceans present a large problem for adequate hegemonic power projection. Ultimately he concludes that given these constraints in today's strategic environment a hegemon would have to create and maintain a viable first strike capability in order to truly be hegemonic. (Mearsheimer)

However, Mearsheimer's work does allow for two variants of what can be termed quasihegemons. He illustrates that regional hegemons can survive in today's international system, though their hegemony is contained to a given region. The author's prime example of such a regional hegemon is the United States as its power relates to the remainder of the Western Hemisphere. Hence, regional hegemons are able to circumvent the "blocking power of water" by focusing their military capabilities throughout a region not divided by water, thus water barriers do not dilute the manpower of their land armies. (Mearsheimer) 
Mearsheimer creates a second form of multipolarity to rival Kaplan's singular balance of power system. The author illustrates that such systems as Kaplan references have the potential for existence as does what he terms to be unbalanced multipolarity. Mearsheimer's unbalanced form of this structure is argued to exist when a multipolar system is present, yet one power within the system is on the verge of hegemony. The author argues that this unbalanced system is the most unstable variant of modern systems theory, for the chance for great power wars are at there highest in this system, as compared to the moderately stable balanced multipolar world or what he terms to be the most stable potential system, that being a bipolar system. The author contends that this unbalanced system is the most unstable system in that balancing against the rising or larger power is certain to happen, and for the potential hegemon is certain to realize the how close it has come to the endgame of offensive realism. (Mearsheimer)

However, Mearsheimer's assumption that hegemonic actors would need to militarily control all other actors within a system is still troubling. The author seems to dismiss the notion that hegemons can create regimes and norms that further extend their means of control. He appears to be consumed with notions of military hegemony and thus ignores economic and cultural considerations that may be of importance. Additionally, his omission of other forms of constraints such as domestic politics and international regimes are also troubling.

Kennedy (1987) created a work that details the interaction of economic power and great power strategy. However, he contends that the work should not be taken as a general international relations theory on the rise and fall of great powers, but rather as a historical work that seeks to understand the relationship of power overextension and economic growth or decline. Essentially, Kennedy contends that great powers will tend to reach a point of decline either as a result of their own overuse of power that outstrips a given states economic power 
resources or a decline that is the result of differential rates of growth. He shows that these differential rates of growth are based upon varying rates of industrial, military, and strategic innovation. The work concerns itself with great power politics without taking a systemic approach to great power politics, but instead focuses the work on historical changes in such powers over time. It seems that if Kennedy was put to the task of explaining hegemonic decline his historical work would lend support to the work of Gilpin, as his basic thesis is economic long-cycles that show the economic rise and decline of such dominant actors. (Kennedy)

The piece, as a work of history, is exceptional in the amount of information and depth that he was able to convey to readers, however as a theoretical work the author himself places the onus of deeper theoretical understandings upon the readers. Kennedy's work does a wonderful job of illustrating the interplay between economic power and military might, while using historical depth to show the involvement of domestic political concerns and thus with this in mind the work will be very useful as a historical work. But, Kennedy ignores other great power resources that can be used to prevent balancing actions by other great powers. It must be seen that it was not his intent to explain such balancing actions, rather to explain the interaction of economic development and great power status. This work, while grounded in similar historical case studies, will attempt to look into means in which dominant actors can prevent balancing by making their power more palatable to other great powers in each respective international system. Specifically, the work will argue that international regimes can be used to prevent such balancing and hegemonic decline; as such regimes can be created by handcuffed hegemons to restrain themselves and other actors in the system.

Grunberg (1990) provides a critical look at notions of hegemonic stability theory. The writer's largest criticism is aimed primarily against the work of Gilpin. She contends that the 
presence of the Cold War during the height of Gilpin's assertions of U.S. hegemony severely weaken his case. The author illustrates that it seems difficult for the U.S. to be viewed as a dominant unipolar actor, for during this time period it can be seen that the United States was balanced by the Soviet Union. Grunberg contends that Gilpin conflates hegemony with the United States' dominance during the bipolar, Cold War period. Additionally, the author illustrates that other forms of hegemony throughout time periods in Europe can also be called into question, as other states existed that could have balanced or checked the powers of a potential hegemon. (Grunberg)

Grunberg shows some considerable and basic flaws of hegemonic stability theory. It seems that both the problems Grunberg finds with the theory can be minimized, if not erased, if one begins to consider a hegemonic or potentially hegemonic system in a different light. The main criticism appears to exist in the systemic view of a unipolar world, that being a vertical authority structure, in which the hegemonic actor sits above all actors in the system and is capable of imposing its will upon all other actors in the system. This view may be corrected if one looks at the structure without its implied vertical ordering. It seems possible that a hegemon or a potentially dominant actor could exist in a system that appeared visually similar to one of a multipolar structure. Moreover, this view would seem to be more realistic, as most structural diagrams tend to portray a multipolar system as a system of several symmetrical players. Yet, it seems that asymmetry constantly exists in the system as one or more actors would tend to have more power capabilities, as it appears fictitious to assume that all states in a given multipolar system exist in a complete balance. However, if one were to envision such a system the problem of system stability would seem to arise, as traditional neorealist theory would show that such a system would be transient as other actors would move to balance a non-symmetrical power. 
One goal of this work is to illustrate that this systemic asymmetry is the norm, and that contrary to the works above the integrity and stability of such a system that contains several large powers yet with one larger power can find stability. It is the contention of this work that this stability is found through the constraints, or handcuffs, that are placed upon the largest international actor.

\section{Handcuffed Hegemony -- A New Theory}

The first step in the creation of any new theoretical pursuit is to place it within the existing body of literature. Currently, a great deal of theories in the realm of international relations are compartmentalized. Theorists tend to approach theory generalization with levels of analysis problem. It seems that most of the theoretical underpinnings that exist today come from three distinct views of international relations, those being the systemic, the state, and the individual. Each body of theoretical literature has made enormous contributions to the study of the relations of international actors. Yet, most of the works face the problem of tunnel vision. By this it is meant that these three levels of analysis have become distinct views of the international world. Moreover, these views have great explanatory powers individually, however individually they tend to miss a great deal of the changes that take place within the international environment.

This work will attempt to create a more holistic, or blended, approach to the study of international relations. It appears that if one were to use multiple levels of analysis, and bring them to bear upon one area of international relations more understanding and more explanation will be found. This work will strive to create a view of the actions of hegemonic states through the use of both domestic level variables as well as through the use of systemic variables. While, 
the road may become difficult and taxing, some new theories are necessitated to attempt to move towards a more complete view of the world.

Next, it must be illustrated exactly what type of international systems is being considered in this work. Gilpin, a main proponent of the theory of hegemonic stability, has attempted to show that when hegemonic system exists a vertical authority structure is present in the international system. The author contends that in such a system the hegemon through the creation of norms and rules for the international system creates a means of stabilizing the power of the hegemonic actor. This view seems to perpetuate the belief that in such a system the hegemonic actor has a preponderance of power, and is thus able to control the entirety of the system and the actors within the system. This view is further illustrated through the work of Nye, as he contends that the United States currently exists as such a power. Moreover, Nye argues that in such a system the United States is capable of maintaining its dominance and moving unbalanced throughout the world through a diligent use of its soft power as opposed to the sole use of hard power.

However, other works suggest that such unipolar visions are merely transient in nature as other powers will begin to rise to challenge an actor that has either achieved or sits poised to achieve hegemony. Layne's work attempts to describe the current situation that is faced by the United States. He argues that no matter how softly and quietly the U.S. moves other states will rise to balance a state that has a preponderance of military power. Such views of balancing are foreshadowed by the works of Waltz, Walt, and Mearsheimer.

Waltz, both in his seminal work that sets the foundations of structural realism and in latter works that have discussed the relevance of the work in the Post-Cold War era, has discussed notions of balancing in which powers that attempt to maintain preponderances of 
power find themselves in the face of alliance formations that seek to check this great power. These notions of balancing can be traced to the Waltz's notions of the rules of the balance of power, as it has long been articulated that such balances occur through a socialized process that seeks to maintain the status quo within a system. Moreover, these very balancing behaviors can be seen in Kaplan's balance of power system, as other states within a given international system seek to ensure that no state is able to gain a dominance of power in the system.

The work of Walt further illustrates these balancing notions, as the author contends that it is not power that is balanced, but threat. Walt argues that states tend to balance threats, for these threats represent real or perceived dangers to the other states in a system. The work of Mearsheimer goes a step further in this regard, as he contends that states in the international system constantly seek to gain hegemony. Though, he argues that this notion of hegemony is really nothing more than an imperial dream. He contends that when a state begins to reach towards hegemony through a rapid growth rate or new technology the international system becomes unbalanced. He illustrates that such an unbalanced system can be viewed as a typical multipolar system with one larger pole. Mearsheimer contends that it is these unbalanced multipolar systems that are the most unstable, as other powers will eventually seek to balance against the larger pole.

It seems that the theoretical works that surround notions of hegemony have worked in divergent paths. First, the Gilpin camp argues that hegemony exists in this perfect vertical model in which the hegemon has seemingly total power until its economic demise and replacement by another rising power. While, structural realists appear to argue that such notions of hegemony are mere flights of fantasy as balancing will always take place. It is the position of this work that neither camp accurately portrays reality. The hegemonic stability writers appear to set the bar 
too high for a state to ever reach, that being the notion that a hegemon exists in a perfect authority structure over the remaining members of the system. Structuralists seek to explain away hegemony only through systemic variables of alliance formation. Nevertheless, it seems possible to argue that Mearsheimer's unbalanced multipolar system is the norm and a more accurate representation of reality, as multipolar systems tend to exist in which one power that is larger than the remaining powers in the system. It seems that current depictions of the system have been taken to a high degree of abstraction, in which all powers are viewed as roughly equal until a time of systemic conflict. Hence, it seems that the true puzzle exists when such an unbalanced system remains stable and durable for some period of time. This work will argue that a more holistic international relations theory is necessitated to understand why such seemingly unstable and transient systems are actually durable and stable for some period of time.

It seems that a system of hegemonic constraints may exist that act to check the power of the largest and most powerful state in the system, thus preventing the need for all out balancing and devolution to war for some period of time. It is possible to argue that a hegemonic state will perceive the potential for balancing by other states in the system, and thus a wise hegemon will seek to ensure that balancing behavior is not triggered. Hence, such a hegemonic state would seek to minimize its threat to other states in the system, and would seek to provide public goods, as shown in the work of Gilpin, that would appear to pacify the other major powers in the system. Additionally, balancing would always be a potential strategy that could be undertaken by the other states in the system. Thus, the nature of balancing present in a given international system can be used as the dependent variable in this study. The argument being that if a hegemonic state were to attempt to cast off one or more of its hegemonic constraints that traditional balancing behavior would then be seen. 
The first handcuff may be seen in the very international regimes that hegemonic states are argued to create. Hass illustrates that hegemonic states tend to create regimes that provide public goods to the remainder of the system, while the hegemonic actor shoulders more of the costs though still gaining additional long-term payoffs. Krasner illustrates that these regimes are systems of rules that actually normalize behavior. These normalized behaviors would tend to set the rules and parameters of the actions of the largest systemic actor. Moreover, Pachula and Hopkins illustrate that norms act as constraints upon the states involved in a regime, as states make gains from their inclusion in international regimes that they would otherwise not obtain without the regime. The work of Jervis shows that one such gain can be security. He contends that in such security regimes military concerns are normalized and expectations are set. Thus, it seems possible to argue that these institutionalized understandings could seek to prevent balancing behavior as long as the hegemonic state meets the criteria and expectations of its regime partners. Furthermore, Pachula and Hopkins show that regimes take place in both formal and informal settings, hence it can be hoped that even more historical systems may still posses these informal regimes.

The second hegemonic handcuff is the domestic politics of the largest state in the system. However, this handcuff may appear to be reversible in nature, as domestic politics may constrain actions in some instances while in other instances demand action that could be seen to destroy the constraint of regimes and eventually trigger the feared alliance formation that foretell the end for a given hegemon in an unbalanced system. Skocpol reminds us that state level variables are often left out of international relations. While, the work of Olson illustrates the power that is present within domestic interests can move policy. Additionally, the works of Snyder and Kupchan depict just how interests and elites can shape and pull foreign policy action in ways that 
can both strive to protect the status quo, that being system stability, and move policy in manners that can create self-encirclement. It seems that domestic politics can be isolated as the lynchpin for either system insurance of system stasis or dynamism.

Finally, hegemonic actors can be constrained by the varying degrees of power concentration or dispersion that exists in a given system over a period of time. A more stable and durable system would tend to exist when all hegemonic powers are centralized within one power, that is to say when one power possesses a preponderance of both hard and soft power at a given time point. However, systems can be envisioned in which such powers are divided between two states. That is to say that one power may have the majority of hard power, while another power may posses the highest level of soft power. Such a divided unbalanced multipolar system would then be less stable and durable than a system that exists with unified power, for in such a divided system the two powers would appear to challenge one another for dominance within the system. Such divisions of power would then be a potential explanation for the relationship that existed between Germany and Great Britain prior to World War I and the relationship between the United States and the Soviet Union during the Cold War period. Thus, with these three groups of hegemonic constraints the following model can be seen:

$$
\text { Balancing Behavior }=\beta_{1}+\beta_{\text {Regime }}+\beta_{\text {Domestic Politics }}+\beta_{\text {Hegemonic Power }}+\mathrm{u}
$$

This holistic theory of hegemonic stability lends itself to the testing of several hypotheses. H1: Unbalanced systems have existed with stability and durability over time. H2: Hegemonic states tend to seek to prevent balancing and thus attempt to function within their constraints under optimal circumstances. H3: Regimes act as a means of conveying norms throughout a system, hence further constraining the actions of hegemonic actors. H4: Domestic 
politics exist as a proximate cause of system and regime stability or instability. H5: Systems with divided hegemony will be less stable as higher degrees of tension will be found.

This chapter has set up an alternate manner in which we can view hegemonic systems. It is the hope of this work that a more complete view of great power politics can be found with the realization that not all hegemonic systems must be unipolar in nature. The next chapter will turn our attention towards the literature that frames the restraints of handcuffed hegemonic action, as well as the works that detail balancing in the international system and thus the dependent variable in this study. Through the use of a case study methodology we will be able test the above mentioned hypothesis and generate valuable insights that will allow us to draw important lessons so as to better illustrate the importance of restraint even in times of disparate distributions of power, for while these unbalanced systems can be maintained they can also be seen as extremely sensitive to systemic and domestic effects. 


\section{Chapter Two \\ The Thoughts behind the Handcuffs}

When viewing hegemonic systems as unbalanced multipolar systems the understanding of a system of restraints becomes key, as it is argued that these are the ties that make a handcuffed hegemons power more tolerable to the remaining great powers in the system. This chapter will begin with a review of the literature surrounding both the dependent variable, balancing within the international system, and then move onto a review of the major works surrounding the three theorized handcuffs: international regimes, domestic politics, and the concentration of hegemonic power. The success of a restrained hegemonic actor's foreign policy is argued to be seen in the balancing behavior present in a given international system, as states that successfully navigate the restraints of hegemony are argued to face little in the way of balancing in the international system and states that are unsuccessful will see their period of dominance marred by encircling alliances and direct military challenges. This work contends that international regimes can be the binding glue that can tie and restrain a hegemonic actor and thus allow durability and stability within an unbalanced system. Domestic politics are seen as the lynchpin variable that will either allow a hegemonic actor to remain constrained or the same forces may push a state to break its restraints, thus triggering balancing or warfare in the system. The concentration of hegemonic power is a basic determination of the power of the dominant actor in comparison to other great powers in the international system. It is thought that power levels will illustrate not only the distribution of power in a given system but also lend explanatory power towards the stability of a system. The chapter then moves to a review of case study methodology as well as a discussion of the lesson drawing framework. The chapter concludes with the designing of not only case selection criteria but also discussions of the 
particular structured focus questions that will be utilized across the three case studies. This section is key in adding methodological rigor to the research.

\section{The System (Dependent Variable)}

Waltz (1979) attempts to create a theory of international relations whereby states can be shown to react solely to the movements of other states within the international system. This theory depicts states as black boxes, in which the inner workings of each particular state are of little importance. Waltz sees the international system as the key driving force behind the relations of states. He moves to illustrate that even if a state undergoes a political change it will still continue to behave in the same manner in the international system, for the structure of the system has not been altered. While each actor remains sovereign they each have a specific relation to the other states in the system. (Waltz 1979)

Waltz follows the typical realist perspective in seeing the international system as a dark and dangerous place in which states act in their own self-interest. Balance of power is the result of the socialization and competition of states in the international system. These two factors illustrate how the balance functions. Each actor attempts to ensure its security, thus the others are socialized to react and compete in such a fashion so that one state does not become dominant. When one state or a group of states becomes dominant a system change occurs and conflict arises. (Waltz 1979)

Waltz's work is seen as the jumping point for the balancing versus bandwagoning debate that has raged within the international relations community. The author begins the debate by contending that states within a system do not bandwagon, but rather balance against rising powers. He argues that such actions take place for this is how the system socializes powers to behave when facing such a problem. Waltz contends that such actions are induced for states do 
not seek to maximize power, but conversely to maintain their place in the international system. Thus, you cannot lose what you do not put in the middle. (Waltz 1979)

With the end of the Cold War, and its bipolar system, Waltz (2000) has clarified his work to further illustrate that his theory of international relations remains relevant in today's international world. He contends that with the collapse of the Soviet Union and the bipolar system a brief period of hegemony, or unipolarity, by the United States can be expected. Though, he argues that the United States will not remain long without true balancers, as the international system will seek to return itself to a place of balance. Waltz illustrates that regardless of how benevolent the U.S. may behave, it can still expect that balancers will rise into positions of power in order to check the power of the remaining great power, for no matter how quietly the state acts it will still be seen as a potential threat to some states that exist in the system. (Waltz 2000)

Waltz presents a detailed and clear model of the international system, however, his model is not without its shortcomings. This structural model of international relations fails to come to grips with notion of change in the international system. Waltz assumes that change occurs in the international system when balancing fails and war erupts, however his notion of change appears to be limited to the players in the grand game of balance of power politics. Waltz assumes that the international system remains constant in its degree of anarchy and rule by force. This appears to be over stated when one considers today's international system.

The work of Walt (1988) takes a different look at the notion of balances of power. He contends that such balances are really balances of threat. He illustrates that states do not balance shifts in power, but that such states truly balance their perceptions of threats. The author identifies four potential sources of threats. First, threat is a function of capabilities, thus the first 
essence of a threat is really Waltz's notion of power. However, Walt contends that capabilities are a necessary but not sufficient condition for balancing to occur. He depicts such balancing occurring when two other factors are met. This second factor is termed geographical proximity. The threat from capabilities must be geographically placed in such a manner as to pose a true threat to a given state. The third source of threat is offensive capability, for the author determines that for such a threat to arise the capabilities must also be offensive in nature. Hence, defensive capabilities will not typically be perceived in such a manner as to constitute a threat upon a potential balancer. The final confounding factor that Walt considers is one of intent. He illustrates that for a threat to be considered valid a state must perceive a hostile intent from the state in question in order to balance the threat. (Walt 1998)

Walt's work provides a different perspective as to what triggers balancing. His contentions that threats supersede power as the instigator of a balancing appears provides a potential explanation as to why states of the hegemonic or potentially hegemonic variety may be able to escape an eventual downfall as a result of balancing. Still, his reliance upon perceptions of threats may still prove to be problematic, as one states intended perception may be another states misperception.

Christensen and Snyder (1990) provide another view of alliance formation strategy within a multipolar system. The authors draw upon the work of Jervis, as they utilize defensive and offensive perceptions as a means of deterring causes of alliance formation. The researchers ultimately conclude that two distinct forms of alliance strategy are created depending on a states view of the current state of offensive or defensive advantages. Christensen and Snyder articulate that if a defensive advantage is perceived states will tend to "buck-pass." The authors illustrate that an alliance strategy in which a rising power is not balanced by a given state, but rather such 
a state would attempt to free-ride off of the actions of other states in the system. They argue that this is done either if a state does not wish to invest in the costs of such balancing, or if such a state expects to make power gains as the expanding state and the balancing state mutually drain each others capabilities. Thus, it is possible that in such an instance that an aggressive or revisionist state may go unbalanced for some time and destabilize the system. The authors use Germany during World War II as an example of such a case. Christensen and Snyder also contend that if a state perceives that an offensive advantage exists in a given time point states will "chain gang." They argue that such a strategy takes place when a number of states act in unison to balance a growing power, hence leading to a large imbalance in the system and heighten chances for war, as the researchers illustrate took place in the First World War. (Christensen and Snyder)

This work provides an example of the notion of state perceptions being drawn into the systemic realm. Moreover, it potentially provides a partial explanation for why hegemonic or potentially hegemonic states may exist unbalanced through a time period, as states seek to shirk their balancing duties as a defensive advantage is perceived.

\section{International Regimes}

Krasner (1983) presents an overview to the study of regimes. His work provides a foundational definition of regimes. The author contends that "regimes are defined as principles, norms, rules, and decision making procedures around which actor expectations converge in a given issue-area" (Krasner 1). This definition provides a very loose notion of what is and is not a regime. Moreover, it seems that such a definition allows for a great deal of latitude when discussing the presence of a regime, for it would seem that the convergence of actor beliefs would not always tend to take the form of codified or institutionalized agreements. Rather, it 
seems that a regime may tend to exist if an actor or actors merely feel the presence of an arrangement. Moreover, the author provides the readers with a test that appears to further reinforce these notions, as he writes, "[i]f the observer finds a pattern of interrelated activity, and the connections in the pattern are understood, then there must be some form of norms and procedures" (Krasner 9).

Thomas (2000) further clarifies the notion of regimes through his discussion of the creation of norms. The author illustrates that norms exist as a system of values that transcend a given society, whether that be the society of a state or the society of the international system as a whole. Thomas contends that norms are formed at the intersection of two distinct sources. The first being that norms are grounded in moral principles that transcend a given group of people, thus such morals must be shared across a significant number of individuals. The second source of regimes arises from historical political and cultural moments that take on greater significance as time passes. The scholar uses these two sources of norms to describe how norms against assassination have taken shape over several centuries. (Thomas 115-121)

The work of Thomas delves deeper than the mere causes of norm creation, for the author explains why certain norms tend to take hold and other potential norms fail to gain strength within the system. The researcher illustrates that norms that take hold within a given international structure tend to be those norms which further perpetuate the hierarchy of powerful states over the less powerful. Thomas' case study of political assassinations explicates this idea, as it can be seen that assassinations have traditionally existed as a means for less powerful states to attack more powerful states, thus overcoming the problem of asymmetry. However, as Thomas illustrates norms against assassinations tend to be waning, as the problem of asymmetry has reversed itself in a world of international terrorism. Hence, the author contends that a 
weakening of such norms can be expected as great powers will need to utilize assassinations as a means of combating actors that cannot be combated with traditional military might. (Thomas 126-131)

Hass (1983) provides a study of regimes that leads the reader to see their existence in more of a perception, or socially constructed manner. Though, the author is careful to show that such constructions remain important in the international system. The work of Hass seems to echo the findings of Krasner, as Krasner's definition contends that the belief of the existence of a regime may be all that is needed for a regime to take hold. Moreover, the work of Hass is important as it attempts to isolate the costs and payoffs that regime members intend to gather as a result of their participation in such an institution. The author illustrates that hegemonic actors are seen as the main cost carriers in an international regime, yet the payoff structure of a regime can be viewed as a pyramid in nature. This relationship can be argued to exist as a the lesser partners in any regime may make short-term gains as a result of their participation, though in the long run the pay-offs are argued to be substantially higher for the hegemonic actor. Thus, this payoff structure exists as the reason as to why the larger actor would be willing to accept a higher degree of the cost burden. (Hass)

Puchala and Hopkins (1983) illustrate that regimes can exist in both "formal" and "informal" manners. The authors contend that such formalized regimes exist when international bodies are present to monitor and enforce regime norms and conditions, such as in regimes like the World Trade Organization that is based upon notions of free trade and economic integration. Additionally, the researchers argue that non-formal regimes are present when mutual self-interest guides the actions of regime actors. They show that these regimes find their enforcement powers in self-policing and surveillance mechanisms that exist between regime participants. Moreover, 
the authors illustrate that actors find themselves constrained by both forms of regimes, as regimes act as a means of normalizing actor behavior thus providing cues for appropriate and non-appropriate actions that tend to regulate the actions of actors. (Puchala and Hopkins)

Young (1983) provides a different look at the notion of regimes. He argues that regimes are not based upon a system of shared norms, which seems to be the prototypical notion of regimes, rather he argues that these international entities can best be viewed as social structures. The author argues that as social structures, regimes exist as artifacts of past human interaction that take on legitimacy as time passes. Moreover, the work of Young creates a three fold classification of regimes. He contends that regimes can originate in three fashions. First, it is argued that regimes can be spontaneous in nature, for this type of structure lacks conscience coordination and institutionalization among the actors involved. Young contends that most balance of power regimes can be classified into this group, as any number of balancing partners seeks to maintain the status quo, though they may not be working in concert. The author terms his second classification to be negotiated regimes. He illustrates that these regimes tend to have the highest amount of institutionalization, as there would tend to be constituted agreements and charter that lay out the ordering principles of this form of regime. Young's final type of regime is termed to be imposed regimes. In these social structures that author contends that hegemonic or dominant actors create this form of regime in order to further propel their domination of other states or groups. Young's work illustrates that regimes can change either slowly over time, due to changes in the power structure of the participants, or as a result of social forces that exist outside of the scope of the regime. (Young)

Young's work on the classification of regimes appears to strengthen the case that regimes have existed throughout multiple historical periods, and that simple balance of power 
relationships can exist as constraining structures without a great deal of institutionalization. Though, the author does not do a great deal to strengthen the work through the use of theory testing studies, yet this leaves room for this work to draw upon and improve the work. Furthermore, its is telling that Young considers structural power changes as a spur for regime change, which can in turn be used to explain regime transformation and termination across time periods.

Stein (1983) brings a game theoretic approach to the study of regimes. He uses such a framework to describe when and why regimes form in given situations as opposed to instances in which international regimes do not form. Stein illustrates that regimes form when the individual, best interest of states leads to an equilibrium point that either partner does not wish to achieve. Hence, because the equilibrium outcome is not perceived to be optimal in the eyes of the actors at hand the two partners would then seek to create norms or guidelines that will lead their behavior towards a mutually optimal conclusion. Furthermore, the author contends that regimes do not form in instances in which the equilibrium outcome is mutually beneficial or at least optimal for one of the actors involved. (Stein)

Stein's work would seem to describe why arms control regimes would tend to form. If an arms race was not in the best interest of at least one state in a relationship the equilibrium outcome, that being an arms race, would seem to be the outcome that would seek to be controlled. Thus, two states or a group of states would then be argued to seek to form some type of regime in order to protect themselves from the naturally occurring outcome. The work of Stein seems to become problematic when one considers regimes that provide unequal payouts, as it would seem that in such a circumstance it would not be in the best interest of at least one party 
to form a regime. However, it would seem that some coercive power could also be used to spur regime creation and commitment by larger states to induce such an arrangement.

Jervis (1983) provides a detailed comparison of traditional economic regimes and security regimes. He illustrates that security regimes exist on a different plane from more traditional regimes for several reasons. First, the author illustrates that these security regimes tend to be more competitive in nature than traditional regimes, as the potential costs of regime violations in a security situation can be seen as far more dangerous and destabilizing that in regimes that deal solely with economic considerations. Second, he contends that offensive and defensive state actions can trigger tension or conflict far more easily than in economic relations. Jervis argues that in trade relations a state may take defensive actions to protect against possible cheating by another state, yet in the case of security relations such defensive moves are perceived in a different light. He argues that such defensive moves can completely change security relationships, and hence even defensive moves can have destabilizing effects in a security regime. Third, the researcher argues that in security issues the consequences of actions are far greater, as security concerns deal with potentially life and death situations. Finally, Jervis demonstrates that identifying cheating and the security actions of other states are far more difficult in security regimes as opposed to similar concerns in economic regimes. The author's work illustrates that when a state adds tariffs to a good the price quickly reveals a violation in a trading regime, however weapons and troop movements are more easily hidden. (Jervis 1983)

Additionally, Jervis provides the criteria under which security regimes are formed in the international system. He argues that the great powers must want to establish such a regime; the actors must believe that other actors have the same values; the actors involved must agree to put aside dreams of expansion; and war and other means of changing power relationships must be 
viewed as highly cost prohibitive. The author concludes that the need for security regimes appears to be on the decline as the current system seems to have reached equilibrium in the area of strategic concerns. Thus, he argues that strategic parity brings increased international stability. (Jervis 1983)

However, the work of Jervis does not seem to differentiate between regime strengths, nor does the work provide any criteria for the elasticity or inelasticity of regimes. The author definitions of regime characteristics appear to lack the flexibility endorsed by the works of Krasner and others. It seems possible that security regimes would be more rigid than economic orders, yet the degree of rigidification that Jervis illustrates appears to be unlikely as the duration of security regimes would appear to be increasingly short, as the chances for cheating would tend to increase. Hence, it seems possible to argue that such regimes are more elastic than the author assumes, allowing for some degree of latitude in action without facing regime collapse and war. Jervis claims that the need for security regimes is in decline as the strategic environment appears to place too much emphasis upon the value of nuclear weapons. It seems to assume that nuclear weapons make great power wars a thing of the past, while other authors such as Mearsheimer have illustrated that conventional warfare remains a possibility even in the face of a nuclearized world.

Risse (2002) illustrates how such security regimes function within the international system. He contends that it is through the partnerships of these regimes that constraint is created in regime members, particularly in the dominant member in the relationship. The author argues that some verbal discord will normally be present between regime members, as it is the task of members to remind each other and the dominant state of norms that exist between them. Thus, if the dominant state were to take action or contemplate action that was deemed unnecessary or 
rash by the other regime members the institution exists as a means of conveying concern, hence causing the state in question to decide on the value of its foreign policy action as it relates to the value of the regime. Consequently, it would then be likely that in most instances the state in question would address the concerns of its regimes partners prior to action, and in turn allowing for constraint of its actions. (Risse 281-282)

A problem with Risse's work arises when one considers the motivations that the author assigns to states for the formation of security regimes. He assumes that the creation and adherence to such regimes is based in liberal notions of cooperation, thus he does not consider that such regimes and tolerated binding by the dominant state can be traced to realist notions as well. The theoretical grounding of this work contends that cooperation can occur in a self-help world, for cooperation and restraint can be in the best interests of the dominant state in most instances. This self-interested cooperation can be seen as the result of the need to weld power at the most efficient price. A hegemonic actor can take on a number of challengers at one time, however the more that this actor must undertake such costs the more the actor risks its position in the system. Therefore, constraining regimes exist as a means of preventing balancing if the state in question is willing to tolerate some impediments to policy.

Holsti (1998) provides readers with a different glimpse into the causes of conflict and peace. The author illustrates that a great many of the conflicts throughout history share certain key issues of contention between conflicting states. The researcher uses case studies of the major periods of peace and their demise into periods of war to uncover the underlying issues that led states to conflict. Holsti finds that these war driving issues fluctuate greatly over time, though across discrete time periods commonalties can be seen in issue types. The author illustrates that territorial issues are one such issue that has driven states to war in the past, yet he 
shows that issues such as this one may see declines in conflict origination as boarders become more static as development progresses. However, in certain areas of the globe one could expect territorial issues to remain at the forefront of conflict. The researcher shows that issues such as state generation have also seen their time in the spotlight, as moves for national selfdetermination have been seen in great numbers throughout history. Additionally, Holsti shows that ideology has played a large role as an issue base for more recent conflicts, which represents the ideological base of the Cold War period. (Holsti)

The author illustrates that in such an issue based system these issues often become institutionalized into treaties and international agreements that can be shown to actually prevent, in some instances, new escalations from existing issues. Holsti ultimately concludes that unless the international system is drastically altered to reflect a more universal international system of governance we can still expect to see a revolving door of peace agreements and new conflicts, as it seems that existing agreements are often unable to prevent new conflicts over traditional issues indefinitely. Additionally, the researcher's work point to various historical areas in which he concludes that force has ceased to be of great utility in solving various issue conflicts. This seems to suggest that issue or regime strength may be gaining momentum in certain issue areas as to further limit state actions. (Holsti)

The work of Holsti is very useful in providing origins and issues that form more historical regimes. Ultimately, it appears that Holsti would conclude that all treaties, no matter their time frame or degree of institutionalization, constitute regimes at some level. Moreover, the author's use of issue typologies may prove useful in any instances in which regime typologies could be utilized to provide additional explanatory force as a constraint for state action. Though, he seems to have undercut the strength of his findings, as it seems that drastic 
system level change may not be necessitated to see great reductions in conflict. It seems that certain issues are moving out of the class of conflict generators, though the potential for new classes of conflict generating issues remains possible, if not likely.

Lake (2001) adds greater depth to the study of internal regimes through his dichotomous classification of security regimes. The author classifies security institutions as either anarchic or hierarchic. He shows that anarchic regimes are far more plentiful throughout the history of the international system, and that such institutions exist when members are relatively free to exit the regime as they please and still maintain a great deal of sovereign autonomy when involved in the institution. Lake contends that it in these anarchic institutions a hierarchy of membership does not exist and anarchy in the system can still be pervasive from time to time. The researcher illustrates that institutions such as North Atlantic Treaty Organization (NATO) and the United Nations (UN) exist in an anarchic manner. (Lake 148-151)

The author depicts that hierarchic security institutions decrease anarchy among their members, as a dominant actor exists in the regime that has the ability to subvert the autonomy of the remaining institutional participants. Lake illustrates that it is these types of regimes that have the greatest effect on states in the aggregate, for hierarchic institutions can better regulate the behavior of states beneath the dominate actor in the group. He illustrates these forms of security institutions have largely been ignored in the literature on regimes, institutions, and international law, though they are fairly prevalent in such forms as: spheres of influence, protectorates, informal empires, and empires. Lake utilizes the Soviet satellite states and the Gulf War Coalition to illustrate the manner in which these hierarchies allow for the control of states lower in the institution. (Lake 132-136, 139-145, 152-154) 
The most important aspect of Lake's work for this research is his contention that both forms of security institutions can be used to bind dominate members into a set of normalized action. He argues that institutions can be used by a state to "limit its ability to exploit others" (Lake 159). Thus, this work strongly supports that main contention of this research, that being that hegemonic states operating within an unbalanced multipolar system can keep themselves free of balancing behavior through the utilization of binding regimes. Thus, such binding regimes can add stability to an unbalanced system, which is traditionally thought to be the most unstable international structures.

Jervis (1999) adds further weight to the theory at hand, as he shows that regimes can actually change the preferences of states and alter decision making behavior domestically. The author argues that regimes can change power conceptualizations and goals of domestic interests, thus exerting an internal effect on the actions of states. He shows that regimes change power calculations by increasing the costs for the breaking of international norms, and hence domestic actors as utility maximizers would tend to shy away from breaking with international regimes unless the benefits of norm breaking far exceed the costs. (Jervis 1999 57-62) This work provides a deeper impact to the effects of international regimes in effect creating a triangular relationship between regimes, the system, and domestic politics, hence, illustrating the interconnectivity of the variables within this work.

Finally, the work of Ikenberry (2002) clearly shows how regimes can be used to bind dominant states, thus preventing balancing from other great powers in the system. The author bases his work on a case study of the United States in the post - World War II era, however some of his notions can potentially be generalized to the larger population of hegemonic states across time. Ikenberry argues that institutions, and their underlying regimes, can constrain a 
dominant state, thus preventing these states from taking actions that would dominate other states in the system while also preventing such states from moving towards isolationism. (Ikenberry 213-214)

The author draws from several treads of theory to explain how such a binding system was created in the post Second World War era. First, he argues that the timing of the creation of these institutions was key, in that they took root after a great power conflict. Thus, the need to restore order and to create a more stable system despite power asymmetries made such regimes possible. (Ikenberry 214) This step can be easily generalized to a larger population, for hegemonic stability theory contends that transformations from one hegemonic order to the next are marked by conflict and thus the need to create a new order that is modeled after the new hegemon.

Secondly, Ikenberry contends that the order is based around a bargain between the dominant state and the other major players in the system. That bargain is that the dominant state gains assurances that the other system players will participate in the newly created order, and thus the hegemonic state pledges to restrain its power while not abandoning the system. (Ikenberry 215) This statement is at the heart of the theory of this work, though the specific motivation for the bargain is distinct from that of Ikenberry. This piece implies that such a bargain is the result of a cost analysis by the handcuffed hegemon, in that it is more cost effective to tolerate such constraints than to pay the high costs of warding off potential balancers. Whereas, Ikenberry assumes that liberal motivations of cooperation influence a decision to accept such a bargain.

Next, the author contends that over time the Western order has become more stabile, as the order has become institutionalized. Ikenberry traces this process through the notion of the 
institutionalization of the expected behavior of the member states, thus over time both the hegemonic state and the other states in the system learn what types of behavior are expected and the potential penalties for rule-breaking. (Ikenberry 215-216) While, it is possible that this high degree of institutionalization will be found in only these formalized regime structure, it is also likely that such imbedding of regimes will be found in earlier cases. Ikenberry's work has some theoretical problems, in that it attempts to exclude realism as a driving force behind such binding regimes, the work is key in that it helps the discipline come to grips with how international regimes can constrain actors, even the dominant actor in the system.

It is the contention of this work that international regimes can be likened to a traffic system. While it is anticipated that the case studies used in this research will illustrate that the traffic system analogy will become more evident as cases move closer to the present day, the comparison still has merit. Regimes can be seen as a system of traffic lights and highway signs, though the system of enforcement of these norms is self-policing. Regimes act as stop lights and yield signs that regulate state behavior. The signs may not always be followed, particularly when a road sign is new. Over time these systems of norms become normalized as states become aware of their placement and potential repercussions for breaking the rules. If a hegemonic state creates such a traffic system, it is often in its best interests to abide by the same norms as the other members of the community. This does not imply cooperation for cooperation's sake, rather it entails cooperation and binding for the stability of system positioning and to ensure that other states do not ally together to create a rival system of highway norms. Thus, cooperation and the following of norms can arise from self-interest, just as that same self-interest can lead a hegemonic state to violate those very rules. The deeper question is, what interests drive the 
dominant state to either restraint its actions, following the rules of the road, or create its own path?

\section{Domestic Politics}

Skocpol (1985) argues that the state as a level of analysis needs to be brought back into the realm of International Relations, specifically in the study the international political economy. This work appears to be a reaction to the proliferation of systemic levels of analysis that were popularized by authors such as Waltz, Gilpin, Keohane, and Wallerstein. Skocpol argues that states need to be viewed as the dynamic entities which they are in reality, thus this runs counter to the systemic belief that views states as static entities that merely react to the system. Skocpol illustrates the dynamic nature of states in her writing. She depicts how the autonomy of states can decrease over time only to see dramatic revivals in state power and autonomy. Her piece illustrates the importance of perception and misperception in the relations of states. States are not just "billiard balls" bouncing off one another following the laws of physics, but rather states are made up of individuals, power groups, and institutions that react to the various foreign policy moves of other countries and to the perceived goals of other states. The work shows that the institutions within a state matter, for not all states possess the same domestic institutions. Thus various states have institutional constraints where as other states lack such constraints and are freer to make unitary policy choices. (Skocpol)

Olson (1982) presents a theory of the rise and decline of state economies. He argues that increases in economic power and economic declines can be explained by the presence of special interest groups, such as labor unions and governmental lobby groups. Olson begins his work by discussing the difficulty in the birth of interest groups. The author explains that interest groups are hampered in their creation, for if individuals are rational actors they would not attempt to 
influence government, for each governmental influence that is obtained ultimately affects all of the citizens within a country. This is known as the "free rider" problem. Each law or state action that is taken ultimately affects all in a society. If a law is passed that mandates taxation or a social welfare policy all citizens reap the benefits or harms, thus why would one individual attempt to make such a move when if another group or individual takes the same action the affect will still be felt by all. (Olson)

The author proposes that interest group policies stagnate economies, for government actions that are taken to appease special interest may help the interest group's cause initially, theses special interest moves will eventually cause an economic decline. An interest group may push for protectionist trade policies to protect the jobs of indigenous workers, however, those protectionist policies led to economic inefficiency. Furthermore, interest group politics that seek the increase of wages or pensions can also cause economic inefficiency, and thus economic stagnation. (Olson)

Olson's work illustrates the difficulty and roadblocks, which are presented by the presence of special interest groups, yet he overstates his case regarding the impact of interest groups. It appears that interest groups may also spur economic development and international investment, for it would make little sense for all interest groups to push for policies that would only bring about the decline and eventual stagnation of their specific state. The utility of Olson's argument in this work is his illustration of the importance of special interest groups and their penetration of governments. Olson's work with interest groups is an excellent illustration of the amount of power wielded by special interests. His theory is useful in this pursuit for it illustrates the possibility of special interest constraint on hegemonic action. Gilpin assumes that the hegemonic actor can take whatever action it deems necessary in its pursuit to maintain its 
international position. Olson provides a counterpoint that depicts international actors as nonunitary actors with constraints on foreign policy action.

Snyder (1994) has more to offer to this argument, as he seeks to explain why great powers so typically overexpand. His work bridges the gap between the work of Skocpol and Olson. Throughout history industrialized states have seemed to enter into a downward spiral through overly aggressive foreign policies. This is a puzzle to Snyder, who questions why states would constantly seem to overstretch their resources and power. The work goes on to explain that it is domestic politics that drive such foreign policies. Snyder goes about his special form of foreign policy analysis with a decidedly realist thought process in mind. While he believes that the internal actions of states are key to their actions within the international system; he also agrees that the system is important and provides constraints and incentives for states. Jack Snyder appears to follow the school of defensive realism, in which anarchy exists in the international system, but that conflict arises from misinterpretations of state intentions and actions. It is with these premises in mind that the author builds his model. (Snyder)

The author argues that domestic action that causes the overexpansion of great power is derived from a series of myths, which seem pervasive in the international system. First, resources are seen in a zero-sum manner, in which those resources that are not controlled by a state will inevitably be taken by that state's competitors. This would create a strategic disadvantage, which cannot be tolerated. The second myth is one offensive advantage, the belief that gains will come from the aggressive action in a country's sphere. The third myth is entitled the myth of the paper tiger. The adversary of a state is seen as a terrible security risk, and at the same time as weaker than the state employing the myth. This myth aids in the use of the myth of offensive advantage, for ones adversary poses a threat, however, that threat can be taken out 
through an offensive attack. Imperialist groups that perpetrate these myths gain strength in the domestic political realm of a country by logrolling. Snyder terms this as when various coalitions trade favors and join forces so that each group gains what it desires most. By taking control of domestic politics these logrolled coalitions are able to take control of the states propaganda, and thus gain support of the public. It is these coalitions that drive public opinion that inevitability causes over expansion. This occurs through a situation that Snyder terms "blowback," this occurs when the coalition has saturated the public with so much propaganda and spread the myths so far that action begin to be demanded by the public. The action may not be the appropriate action the coalition desires, but the public's demands must be followed or the imperialistic coalition will lose complete control. This pattern is most prevalent in cartelized political systems, in which resources, organizational strength, and information are concentrated in the hands of an imperial coalition. However, Snyder explains that this turn of events can also happen in any other political system. (Snyder)

However, Snyder's argument is not without its flaws. Snyder does not come to grips with the possibility that certain special interest groups or coalitions may not move in manners that cause strategic overstretches. The author seems to argue that such extensions beyond the resource limits of great powers are self-fulfilling prophecies. Additionally, Snyder assumes that all imperial myths are in fact myths. It is possible that some of the constraints on the actions of great power are actually real, or at least perceived to be real by those in power. Kupchan (1994) argues that states must react to various threats or opportunities in the international system, however he argues that success or failure of such actions is determined by the actions that leaders choose. Kupchan argues that states can either over or under react to given situations. He believes that both under and over reaction can cause strategic overstretches, or conversely he 
argues that in certain instances under reaction by elites in power can cause strategic vulnerability. Kupchan's work goes far to illustrate that so called myths of empire may not be myths at all, but rather the actual worldviews of leaders that shape the foreign policy actions of specific states. (Kupchan 1994) Moreover, it seems that domestic politics, while acting as a spur of state action also have the ability to act as a constraint of state action, for these embedded interests may also move to keep foreign policy static in nature.

Schweller (1994) contends that those that focus solely upon balancing tendencies are ignoring a fact of the international system. He illustrates that not all states are status quo powers, that merely seek to maintain their power capabilities and station in the system, but rather the system also tend to contain revisionist states. These revisionist states seek to make power gains and redraw the power distribution of the international system, hence he contends that bandwagoning remains a viable alliance strategy for these states. Essentially, the author contends that some states may see it in their best interests to ally with a more powerful state, so as to reap the rewards of victory, and that such behavior can be the result of domestic perceptions of the international system or feelings of increased "greatness" that can arise from such revisions. Schweller illustrates that such states can choose to bandwagon for two different reasons. The first reason is the typical bandwagoning explanation, a State allies with a growing power in the hopes of appeasing the growing state and seeking to maintain its position in the system, this can be termed bandwagoning for the sake of fear. The researcher shows that another possible explanation exists for bandwagoning, a state hopes to make strategic gains through alliance formation. The author contends that balancing and bandwagoning behaviors stem from two drastically different motivations. Schweller argues that states seek to balance to decrease their chances of accruing a loss, while states seek to bandwagon with the desire to make gains. 
Thus, he argues that one can expect revisionist states to undertake bandwagoning, while status quo states are more likely to be those that make alliance decisions based upon the tenants of balancing. (Schweller 1994)

The work of Schweller provides this discussion a great deal to consider. It seems possible that some potential explanations and additional information will be uncovered throughout the course of this research. Moreover, the work provides the reader a glimpse into a potential state centric motivation for alliance behavior, in that domestic considerations seem to lye behind state motivations in choosing whether to undertake a path as revisionist state or as a status quo state. Hence, the work appears to make a crucial link between the systemic and state level of analysis, as it illustrates how political culture and elite notions translate into systemic action.

Schweller's (1992) work in the area of democratic constraints upon international powers may shed additional light. The author illustrates that the presence of democracy within powers tends to influence international action. He contends that when democratic power meets a rising democratic power that accommodation is seen as the typical action of the initially dominant state. Such an explanation may shed some explanatory light upon the reaction of the British to the rise of American power following the end of the Second World War. The author finds that preventative wars in the face of hegemonic decline are seen only in non-democracies, hence this supplants the work of Gilpin who argues that such wars of hegemonic decline are typical of all hegemonic actors. Rather, Schweller argues that defensive alliance formations may be the norm for declining democracies, as these alliances more easily fit into traditional democratic norms opposed to war to ensure continued dominance. (Schweller 1992) This work adds further 
credence to notions that traditional structural realism ignores the importance of domestic politics as constraints upon state action.

Kupchan (2002) adds increased depth to this class of variables in his more recent work. The author contends that a deeper domestic influence of behavior can exist in some hegemonic states, that being the willingness to lead. The researcher argues that merely possessing a preponderance of power in a given system does make a state a hegemon. Kupchan depicts that when such a level of power is obtained there must be the political will to utilize such power. The author "maintains[s] that internationalism among status quo powers is primarily a product of threat not opportunity" (Kupchan 2002 76). It is illustrated that states, including a dominant state, only seek to exercise their power when they feel that the system is threatened. This can be taken to argue that dominant states often do not posses the willingness to exercise power for actions that are not deemed vital to the national interest of the state. Thus, as threats to the system dissipate so to will the willingness to exercise power, as the domestic costs of international dominance are high. Hence, a question is raised, that being is a hegemon hegemonic if it has the power to act but lacks the will? It is possible for a detached, or absentee, hegemon to allow a shift in power from a system based on unbalanced multipolarity to one of balanced multipolarity, as its willingness to weld power decreases. The author traces the importance of will to the perceptions of leaders and to public opinion, and thus willingness can be a concern for both historical and more contemporary cases in this study. (Kupchan 2002)

Kupchan's work underscores the importance of domestic variables as the lynchpin of hegemonic constraint. Domestic politics can drive a dominant state to work within the bounds of its hegemony, and thus prevent counter-alliance balancing. However, these same forces can also cause a state to break its shackles of hegemony, thus moving towards more unilateral and 
unconstrained policies triggering balancing behavior. Finally, these very domestic forces can cause a hegemonic state to retreat from its position of power too soon, hence generating changes in the system that were ill-advised. Domestic politics influence how well a state will transfer latent power to realized power, and what types of constraints a dominant state will tolerate and at what costs. It is the dynamic nature of domestic political variables that allows for such variability in the other variable classes, consequently justifying the classification as the lynchpin class.

\section{Concentration of Hegemonic Power}

The degree to which hegemonic power is concentrated within one or more great powers is of great concern in this work. Image a system in which one great power possess a preponderance of military power, where as another great power has a dominance of economic power. Or, consider an international environment in which a state is hegemonic on the seas, but another state has hegemonic capabilities in the realm of land based forces. These hegemonic divides would lead to instances of dual hegemony, which in turn could drive system instability.

Wohlforth (2002) presents a counter argument to traditional neorealism that contends that asymmetries of power within a system will in turn produce balancing behavior by the remaining great powers in the system. The author contends that these imbalances of power can exist as durable power relationships provided that the dominant state in the system has a preponderance of power resources. Moreover, the work of Wohlforth runs counter to traditional theory, as he contends that once a dominant state reaches a threshold of power capabilities balancing is no longer an option for the other states in the system as it becomes counterproductive and inefficient. The author illustrates that once a dominant state gains sufficient resources and power capabilities the costs of balancing become unaffordable for the remaining great powers in the 
system, and that balancing will only take place if the dominant state in the system begins to decline, thus making balancing affordable for the other states in the system. However, if the largest state is able to keep its power and resources above the threshold the remaining states will choose other forms of engagement such as buck-passing and bandwagoning. (Wohlforth 98103)

While, Wohlforth does an excellent job of illustrating how a preponderance of power can prevent balancing he only considers systemic variables, such as military capabilities and economic power. The author fails to come to grips with other factors that can also lead to a lack of balancing by other states in a given system, such as varying forms of binding regimes and potential self-restraining dynamics that can exist within a dominant state. Additionally, Wohlforth fails to come to terms with notions of state motivation that can influence the perception of the power of the dominant state by those around it.

Walt (2002) highlights the importance of perception as it relates to dimensions of power. The scholar contends that it is not power that is of prime concern, but rather the perception of threat. Walt defines threat as "a function of power, proximity, offensive capabilities, and aggressive intentions" (Walt 2002 133). The author illustrates that power, both actual and latent is only one aspect that states take into consideration prior to deciding whether to engage in balancing behavior. Walt depicts that the proximity of states has a great deal of influence over potential foreign policy decisions, as he argues that the closeness of states determines how well a dominant state can project its power to influence the decisions of a lesser state, or take action to control a given state. Walt draws a distinction between offensive and defensive power, and illustrates that offensive power can be seen in military forces that are mobile and internal political considerations that illustrate the willingness of governments to take offensive actions. 
Finally, the author focuses on the importance of actual intentions, thus arguing that states will tend to balance dominant actors when they view them as having intentions to dominate territory or other less tangible concerns. It is with these factors in mind that Walt contends that states do not necessarily balance power, but rather threat. (Walt 2002 133-140)

Nevertheless, Walt's analysis dismisses the importance of international regimes as a tool that can prevent balancing of the dominant state. The author contends that regimes exist as a result of timing and the interests of states at a given moment in history, and thus as situational variables change a given regime will lose its purpose and eventually cease to exist. (Walt 2002 129-132) However, these reservations about the utility of such institutions fail to grasp the deeper importance of the norms created by international regimes, and in turn how they affect power relationships. This notion does not assume that regimes are used in the best interests of cooperation for the entire system, as neoliberalism would view regimes, but rather that individual states can utilize regimes as a means of binding themselves and allow other states to influence their behavior so as to avoid balancing. Walt's work assumes that a state that faces a dominant state in a given system have only two options, those being balancing or bandwagoning. The presence of international regimes exists as a third option for such states, as either binding or selfbinding regimes can exist as a check on the dominant power, while remaining more costeffective than balancing and allowing a higher degree of influence over the dominant state than a policy of bandwagoning. While the works of Wohlforth and Walt provide a deeper understanding of the importance of hegemonic power concentrations they are not perfect, and they do not provide a great deal of explanation as to how power can be measured and conceptualized. Thus, further works will need to be discussed to provide added depth on this group of variables. 
Ash (1951) presents a means of seeking a more objective measure of power. The author contends that past measurements of power have been too subjective in nature, thus decreasing the discipline's ability to compare across cases. Rather, he illustrates that power must be measured in an objective nature, and with this in mind he believes that more impartial variables must be used to add comparative value to the study of power. Ash states that armament levels can be utilized in this fashion, thus allowing comparison across cases and time. (Ash) However, this very approach limits discussions of international power to military power. The author assumes that military power drives state power and ignores other sources of power such as economic power, cultural power, and varying powers of influence that exist internationally. The dated nature of the research is an explanation for this line of reasoning, though it remains problematic on its face. Merely counting the number of armaments in a weapons class and comparing them between cases is useless if technological differences exist between two states that are not taken into account. Though, Ash's work can be used to allow for an easy power comparison of military power levels.

Hart (1976) is critical of measures of power that are based solely upon resources, as he contends that such resource counts ignores notions of interdependence, collective action, and alliances. The author illustrates that such resources measure are further complicated when one attempts to gain an exhaustive list of resources, for situational needs will necessitate the use of different resources. Hart shows the great difficulty that exists in measuring a will to use power, as a given state would certainly need a political will to take action. Hart's criticism can best be explained when unconventional weapons are considered. A state may possess a preponderance of power through its possession of such weapons, but this work would call their validity as a 
power source into question as a great deal of political will is necessitated to use such weapons, particularly in a first strike. (Hart)

It is with these criticisms that Hart leads the reader towards his measure of power. The researcher illustrates that power can best be measured by analyzing an actors ability to exert control over events and outcomes. He argues that this situational approach allows for an accurate measure of an actors power at a given point in time and in a specific situation. Hart draws his measure from the work of Dahl, who stated that power the ability of state " $\mathrm{A}$ " to move state "B" to take an action it would not normally undertake. The author shows that this conception of power is best as it can assume both coercive and persuasive forms of power. Hart takes Dahl's work farther by arguing that power need not be exerted by states alone, but by states in conjunction with other states, nongovernmental organization, and intergovernmental organizations. The author shows that in a given situation it is rarely seen that only one actor would have power, but rather all the actors involved would have some degree of power. Thus, Hart's view of power is more dynamic in nature as it attempts to look at power from multiple sources of power and varied vantage points in an event. (Hart)

The work of Hart is not without its faults, while the author takes a structured approach to the measurement of power the difficulty of the methodology can not be ignored. Hart's work focuses on the event level of analysis, and would allow for precise modeling of power relationships within a small number of events. Though, in the case of this research such an in depth approach to the measurement of power would certainly consume vast amounts of time. Moreover, Hart's event level focus does not create an ease of comparison across cases and time. However, the work is key in understanding that numerous actors can potentially exert power in a given situation or event. Thus, this piece provides a justification for the argument that a state can 
wield power over another state or group of states, while at the same time some form of international regime may be exerting a form of power over the dominant state.

Cline (1977) introduces a highly quantitative method for the study of power. The author uses a traditional definition of power that being a state's ability to get another state to take an action it would not typically undertake. The researcher's rigor in the measurement of power is of the most interest, as he surveys 40 states through the use of his perceived power formula. Cline's formula is as follows:

$$
\begin{gathered}
\mathrm{P}_{\mathrm{p}}=(\mathrm{C}+\mathrm{E}+\mathrm{M}) \times(\mathrm{S}+\mathrm{W}) \\
\mathrm{P}_{\mathrm{p}}=\text { perceived power } \\
\mathrm{C}=\text { population }+ \text { territory } \\
\mathrm{E}=\text { economic capability } \\
\mathrm{M}=\text { military capability } \\
\mathrm{S}=\text { strategic purpose } \\
\mathrm{W}=\text { will to use national strategy }
\end{gathered}
$$

While, the author's work has a traditional military focus that tends to measure more coercive power his use of variables is highly useful. Cline blends traditional power considerations, such as land, population, military strength, and economic capacity with the modifiers strategic purpose and national will. These two modifiers warrant the most attention as they delve deeper into the meaning of modern power. (Cline)

Cline conceptualizes strategic purpose as a means of operizationalizing the degree to which a state possesses a system of international goals either for the maintenance or expansion of its power base. Strategic purpose can also be seen as a measure of a comprehensive foreign policy agenda that can asses whether a state's policy is reactionary or purposeful in nature. The work's conceptualization of national will takes the conceptualization of power a step father, as the variable is used to determine the degree to which a state has the political will to implement its strategic plan. (Cline) 
Baldwin (1979) attempts to come to terms with what he terms the "paradox of unrealized power," through a review of the existing literature on the measurement of international power. The author is striving to understand why previous works that seek to measure power fail come to grips with questions of small state influence on great powers. Baldwin illustrates that the fault of previous studies in the realm of power analysis failed to realize that power is situational in nature, and thus a large degree of military or economic power cannot translate into vast power resources in all situations. The researcher articulates that constant assertions of the zero-sum nature of power have led to an inflation of the importance of military power as the predominant factor used to determine an actors degree of power. Baldwin shows that this focus has shifted the focus of power analysis away from other means of viewing power that better adjust for the situational nature of international power, as he asserts that in many arenas power is an interdependent commodity. Furthermore, he advocates a view of power that allows for the measurement of non-coercive power, such as incentives that can be used to persuade rather that force another state to take a specific policy action. (Baldwin)

Baldwin's discussions of power as an interdependent commodity are of great importance to the research at hand. The notion of traditional conceptualizations of power would then tend to allow power to be seen in a vertical relationship, with dichotomies created between those actors that have a great deal of power and those that do not posses such vast resources. However, an interdependent view of power allows for the realization that in certain purely non-military situations power can be wielded by both major and minor actors, as the tools of persuasive power are far more evenly distributed throughout the system. Moreover, this interdependent view of power relations allows for the conceptualization of an international system in which a hegemonic actor is both influencer and influenced by the states and regimes around it. 
Nye (2002) provides us with an alternate view of the world of hegemonic action in today's modern international system utilizing classifications of power. This hard/soft dichotomy of power is a main contention of the work of Nye. He argues that hard power is formed from traditional sources of power, such as military and economic sources of power, thus hard power can be viewed as power that can be utilized to coerce other actor to move their actions and views towards the coercing state's views. Nye articulates that soft power arises from his third level of state interaction, the transnational level. He contends that soft power largely arises from cultural power, thus soft power can be engaged as other states may tend to figuratively, "look-up," to a state with a preponderance of soft power, as other states seek to be more like the core state. The author illustrates that soft power can be utilized to gain a non-coercive means of persuading and ensuring needed action from states and actors in the international system. (Nye)

Nye's work is critical, in that he illustrates how the international system can be divided into multiple levels for consideration. Moreover, his work provides an excellent counter to the work of Mearsheimer in the realm of US hegemony, though the work is not without its potential drawbacks. Nye's division of cultural and economic systems appears to be a false construction, in that such realms appear to be largely interrelated. It seems difficult to compartmentalize an economic world from one of culture, as it can be argued that economics drives culture and that culture drives economics. The two issue areas appear to be very complex in nature, as well as intervening. This same problem permeates Nye's power dichotomy, as it seems hard to image that a target state can perceive a state's soft power, without realizing the notion that a great deal of hard power may also support such soft power. Hence, it seems difficult to assume that a careful use of soft power can truly ensure a non-balanced system for the United States, for any use of explicit soft power, persuasion, would seem to also have a great deal of implicit hard 
power, coercion, just beneath the surface. It seems that a more realistic dichotomy could be created in which hard power is seen as purely military power, and soft power is viewed as all non-military powers. Thus, coercion is present in varying levels in both power sources, yet the level of coercion would seem lessened in the cases of economic persuasion as opposed to gunship diplomacy.

Moreover, Nye's work dismisses the systemic impact of an international system in which two distinct powers have a preponderance of one of his two classifications of power. It is possible that one state has the highest level of economic and cultural power, while another state holds predominance in the arena of military power. Such a divide counters the basis of the work of Gilpin, as he assumes that such hegemonic powers are always present in the highest amount in only one state at a time. Such a division of power would then tend to lead towards increased instability within an unbalanced system, as both powers in question seek to augment the hegemonic power source in which they find themselves lacking.

The most holistic manner in which power can be discussed and operizationalized is to take a "shotgun" approach that takes into account many views of power and incorporates as many as possible into a given framework. Though, there are certain instances across time in which several forms of power may be of greater importance than others, and thus not all forms of power can be synthesized into a perfect measure. This would tend to be the circumstances in early cases in this work, such as the case of Spain as it relates to the importance of soft power. When considering the ability to influence others through the "power of attraction," as Nye (2004) contends in his most recent work, it is hard to imagine that Imperial Spain under Charles V and the Philip II would have such soft power resources. Although, one can envision that soft power resources would tend to become of exponentially greater importance as time progresses. 
However, from this review of the power literature a clear conception of how power should be defined for this work can be realized: that being that power is influence, whether it is influence through the use of a weapon, the threat of a weapon, economic incentives or penalties, or influence through attraction. It is this influence that is afforded to the dominant state in the system through its available resources, military size, projectable force, economic strength, soft power resources, and its political will. However, this work also highlights the influence that other states and institutions can weld over the dominant state, thus ensuring that more costeffective alternatives to balancing persist.

\section{Research Design}

In order to test notions of systemic constraint as posed by the shackles of domestic politics, the existence of international regimes, and the distribution of hegemonic power a case study approach remains the only logical approach to such an endeavor. Statistical analysis does not hold many possibilities in this research, as data is not present to adequately test theories and hypotheses. Moreover, in the hope of testing this theory and further building upon the utility of theory case studies appear to hold the key to doors of increased understanding. Statistical analysis seems prudent when one is attempting to find robust correlations across time and in cases where a researcher hopes to test the validity of a given theory in using new data or new time periods.

However, in the case of theory generation case studies serve as an excellent methodological tool. Van Evera (1997) illustrates that in cases of theory construction and theory testing case studies remain a viable method. He illustrates that through appropriate case studies researchers can delve deeper into causation and historical realties, as opposed to generalizations that may be created through the use of statistically driven research. Though, the author is careful 
to show that case study methods can lose ground in areas of generalizability and methodological rigor. (Van Evera 49-55)

Additionally, a comparative look into the questions at hand is necessary. It seems that to truly study and undercover the nature of the international system, the effects of regimes, and the impact of domestic politics among hegemonic or quasi-hegemonic actors one would need to compare these environments across time. Hence, the work of Peters (1998) will guide this portion of the research design. The author illustrates that when undertaking this form of comparative study the case selection criteria must be clearly constructed so as to ensure scientific rigor for the sake of validity and reliability. Peters contends that one of the best case selection processes is to engage in what is termed "most similar" comparison. In this approach a number of cases are selected that are selected on the basis of constructed criteria so as to control for great deviations among the cases, and thus limit the potential of differing variables throughout a sample population of cases. Thus, this work will lay out some case selection criteria that will allow the research to be conducted across time while still studying the most similar cases available, so as to introduce a level of variable control into the study. (Peters 36-40)

The first case selection criteria that seems important, is that the states in question must be seen as the preeminent military power either globally or regionally. This global and regional distinction appears to be important, for as these hegemonic states are considered throughout time it seems that a great deal of European powers, of the pre-industrial era will need to be studied. Thus, in this time period the notion of global military power seems to be out of reach. Moreover, it seems best to limit the concerns for this work to military powers for the sake of research completion. That is not to say that the theoretical base cannot be placed upon purely economic 
powers, nor powers that possess both forms of power, yet a large research burden would be created that would not facilitate a timely completion.

The second selection criteria is that for a state to be drawn into the study it would need to possess this preponderance of military power for a significant number of years, so as to facilitate the study of the state and the system during both times of peace and conflict. A state could achieve a preponderance of military power for a small time period, say one to five years, though the actions of the system may move too quickly to be valid to this study of unbalanced yet stable systems.

Thirdly, for a state to be included in the study there must be at least the possibility that an international regime existed to potentially constrain the state. Thus, other powers and formal states would need to be present to ensure that regimes as outlined by authors such as Krasner, Stein, and Jervis could potentially exist.

Fourthly, there must be a significant amount of historical knowledge present to undertake research on a state in question. For the purposes of this work a very limited amount of primary research can be undertaken, hence a good historical record must be present. ${ }^{1}$

Finally, there must be the ability to study the other states in each international system. This is essential for the ability to determine why, when, and how alliances formations were either undertaken or avoided.

An initial historical glance appears to suggest three cases to study to undertake the research at hand, those being: Spain under Philip II; France under the rule of Napoleon III; and

\footnotetext{
${ }^{1}$ The historical research will be undertaken with Kennedy's The Rise and Fall of Great Powers and Snyder's Myths of Empire: Domestic Politics and International Ambition as the primary models for source selection. That is to say that the research will be undertaken through the use of secondary sources that are of good standing for each case study or time period. These secondary sources will be well accepted authorities for each state and time period in question. The sources will then be combed for information pertaining to both the dependent variable and the independent variables. The information gathered will be presented in sections broken down by variable with little "story-telling" rather a just-the-facts approach will be used. Each case study will then be placed through the pregenerated structured focus questions.
} 
Germany under the leadership of Bismarck. Each of these powers seems to meet the standards set by the case selection criteria. Each state can be argued to have possessed a preponderance of military power for their individual time periods. All of the states exist in time periods that have had a great deal of historical research to illustrate both the realities of the individual states at hand and their system partners. Moreover, it seems possible to argue that regimes at some level, whether formal or informal, were present.

However, even with the grounded case selection criteria case study approaches are not without a great deal of criticism. While, it has often been argued that a case study approach to research often lacks the methodological rigor of other approaches such as statistical studies, it seems that the traditional case study method can be made more rigorous through the use of George and Smoke's (1974) focused comparison method. George and Smoke have created this method to introduce more structure into case research and hypothesis testing. The researchers illustrate that this design can be undertaken through the use of multiple cases and the utilization of a comparative methodology between the cases. Additional rigor is added to the process through the use of a system of hypothesis repeated across all the cases in the research. The focused comparison method is similar to traditional case study designs in that it still provides a great deal of research depth to the cases at hand, while using a structured approach in hypothesis testing. Essentially, a researcher using this method undertakes the case process in the same high information content approach present in standard approaches, though with the continued testing of the standardized hypotheses and structured focus questions.

George and Smoke show that the process is not without its shortcomings, for it cannot illustrate the frequency of dependent and independent variable occurrence. This fault is due to the fact that the method does not utilize statistical sampling processes. However, the authors 
contend that the focused comparison method can provide a high degree of theory verification, which is often not found in traditional case study research, while still presenting readers with a higher degree of historical context and information that is often not found in more statistical approaches to research. Moreover, the work of George and Smoke seems to provide a blueprint for those needing to employ case study research, while still attempting to bring a great deal of scientific rigor to their research. (George and Smoke 95-97)

Thus, following the lead of the work of George and Smoke a series of structured questions must be created to be asked in each case in question. The tenets of the structured comparison must be adhered to as each question will be asked of each case in the study. It seems that the questions would be best broken into the three variable labels, system, state, and regime.

\section{The Systemic Level (Dependent Variable)}

- Who are the primary actors in the international system, and what justifies such a classification?

This question is designed to unearth the major players in the system. The question also delves into the justifications for great power status. Such a consideration is important as these are the states that could potentially be seen as balancers or alliance partners for each specific case study period.

- What actually triggers alliance formation in a given historical situation?

This question would seem to go to the heart of the research, as it would seem to beg the question does the theory hold credence, are alliance structure sought to counter the failures of regime level constraints and the perception of the failure of domestic constraints. Moreover, it is possible that such formations could occur as a result of domestic politics within the dominant state that are perceived by opposing states to signal potential aggressive moves. 
- Is balancing or bandwagoning seen in alliance formations?

This question goes to the heart of the balancing verses bandwagoning debate. As it seems that balancing would be the typical structural result, as seen in the work of Waltz, in cases of increased power in one pole, while bandwagoning, as shown in the work of Schweller, would tend to illustrate that states are more likely to attempt to appease or make strategic gains as a result of the presence of a larger power in the system.

- Are cases of stability the result of a perception of non-threat by the larger pole? Is this stability the result of binding by the preponderant power in the system?

This question is grounded in the work of Walt, as he contends that states are more likely to balance threats as opposed to prototypical notions of balancing of power. Moreover, if threat balancing is seen this would appear to present a means of alternate causality in the face of unbalanced systems, for one could argue that the mere lack of a threat causes stability in an unbalanced system.

\section{The State Level}

- What is the institutional make-up of the state in question?

This question targets the actual governmental structure of a given state in the study, and attempts to isolate how various institutional designs may sway policy and action.

- Is the dominant state democratic in nature? And, are other system members also democratic?

The importance of this question would seem to increase as the study of cases moves towards more contemporary history, and the number of large democracies increases. Moreover, this work does not imply that democracies are on-face more pacific in their relations with each other, but rather that the presence of democracy in the dominant state and potentially in other great powers in the system will allow for increased influence in the governmental policies of states. Hence, this influence can be seen as a means of restraining the dominant power, thus creating 
increased stability in the system or increased instability if such forces were to lead to handcuff breaking.

- Does the state in question have a means for mass public opinion to influence state action?

The question at hand will be used to detect the amount of influence that public opinion has over the actions of the government. There is no expectation of mass public opinion activity in the earliest case of Spain under Philip II short of the potential for civil unrest. Nevertheless, there exists the possibility that mass public opinion may play a role in the governments of Napoleon III and Bismarck.

- What types of interest groups or elites are present in the state in question?

This question simply asks what types of interests are present within the state, so as to ascertain what issues may be of interest and what possible directions could such interests attempt to lead the state.

- In what directions are such interests moving the government?

Such a question is designed to delve into whether such groups are moving the state towards aggressive actions, or whether such moves are made to attempt to ensure a status quo policy within the international arena.

- Is the state in question a status quo power or could it be considered a revisionist power?

This question traces its origins to the work of Schweller, as the author shows how different state beliefs translate into international behavior. If a hegemonic state was status quo in nature one would expect to find a more governed foreign policy, whereas if a state were shown to be revisionist in nature such beliefs would seem to create instability in an unbalanced multipolar system. This question also delves into whether the state in question tended to follow the tenants 
of offensive realism, proposed by Mearsheimer, or the ideals of defensive realism, as described in the works of Waltz and his contemporaries.

\section{The International Regime Level}

- What types of regimes are present?

This is a very basic question, pertaining to whether the particular regimes present in a given case exist in a security framework, as described by Jervis, or whether the regimes are more economic in nature. Moreover, it is possible that regimes can exist outside of this dichotomy that can be found to have effects upon state action.

- Are these regimes formal or informal in nature?

The work of Puchala and Hopkins introduces the notions of formal and informal regimes. It seems possible to believe that formal regimes will be of more constraint than those of the informal variety. This seems possible as more formalized regimes would tend to be more institutionalized in nature, and thus would include international bodies that could act as road blocks to state actions that could stifle state actions that would otherwise trigger alliance formations that would then destabilize the system.

- Does the presence of regimes constrain state action?

Once again this question goes to the heart of the research at hand, as it is hypothesized that one of the explanations for the stability of what is typically seen to be unstable international systems may rest upon the constraints present in regimes.

- Who are the creators or architects of the regimes in question?

This question speaks to the work of Keohane (1984), for it would seem very telling in hegemonic states are responsible for their own shackling. Or, that such regime shackles could be 
the creation of a number of states with or without the intent to constrain the actions of their most dominant systemic member.

\section{The Power Concentration Level}

- Across potential competitors how is population divided?

This is most basic of power measures, as it relates not only to the amount of troops that a state could potentially mobilize but also to the number of hands working for economic development and growth. With the exception of the case of Spain under Philip II the Correlates of War Project National Capabilities data set will be of great assistance in normalizing measures and reducing bias. Historical data when available will also be used. The case of Spain will require total use of the historical record, because no data set is available with a high degree of reliability.

- How is economic power divided between the target state of each case study and the other great powers in the system?

This question can be answered through the use of both National Capabilities Data Set, with the exception of Spain, and the use of the historical record to assess the economic prowess of the states in question. For the purposes of this work economic power is seen as a means of supporting military power and providing additional coercive power reserves for foreign policy action.

- Across potential competitors how is military strength, as measured by either military personnel or military expenditures, divided? (In some cases both measures may be present)

This question will be answered through the simple use of military force numbers and reserve numbers available. The number of troops a country can utilize is shown in the literature to have a direct correlation to its overall power concentration level or at least the perception of power. 
- Are any technological or research and design issues present in a given system that could increase the power level of state in question that may not be detected by the previous questions?

Technological advances are considered in the operizationalization of hegemonic power concentration to redress the inherent bias present in using only troop and reserve levels. Advancements in technology and strategy can have a mitigating effect upon the importance of troop levels in some types of warfare. These advancements can also amplify the power of military force.

- If soft power is present in the system, how is such a resource divided between the primary actors?

This question is an acknowledgment of the rising importance of soft power as revealed by Nye. It is important to control for any effect that such alternate power considerations may have on the power distribution of a given international system.

- Does the dominant state have the political willingness to carry the burden of its position in the system?

The work of Kupchan highlights the importance of political will in a dominant state. A state that has the potential to be hegemonic may shirk its role and abilities as a result of a lack of willingness to undertake such a bourdon upon its power resources. This may either afford another state the ability to assume the position of hegemon, or it could mean that no hegemonic actor can be found to exist during a given period of time.

\section{Learning from the Past: Lesson Drawing for United States}

For the purposes of this work a lesson - drawing framework will also be used to draw strategic lessons from the three cases of handcuffed hegemony in order to provide information to show strategies that may aid the United States in its navigation of its period of dominance. ${ }^{2}$ Rose

\footnotetext{
${ }^{2}$ Initially the United States was considered as a fourth case study to be included in the actual research, however recent events such as the Afghan War and the Iraq War made this inclusion difficult. The difficulty arose not only
} 
(1993) illustrates the vast amount of knowledge that can be generated through drawing lessons from past events in the historical record. The researcher contends that those focused on public policy have little in the way of actual experimentation, and thus lessons must be drawn across space and time. The final chapter will focus on the use of "history - as - intelligence." This style of lesson - drawing sees historical events that can be seen as similar across states and time as a means of generating intelligence that can then be used by policy makers to better inform their decisions and ground future state actions. Such a methodology uses analogy from past cases that share similar traits to search for policies that have been both successful and unsuccessful. The research strategy can also be used to provide warnings to policy makers so that mistakes of past decision makers are not repeated. (Rose 78-81)

\section{Gazing into the Crystal Ball}

Prior to undertaking this research effort it would appear prudent to make a few slightly educated guesses as to what will be uncovered through the research process. First, in the case of finding support for the existence of unbalanced multipolar systems throughout time that are both stable and durable it seems that the outlook is bright. It seems likely that the durability and the stability of these systems will tend to increase as the cases in question move closer to the current time period. This appears to be likely as it seems that international regimes will be found to have gained strength over time. That is to say that in an earlier case such as Spain it would appear that regimes would be found in the informal vein, and that such informal regimes will tend not to foster the degree of durability and stability that will be found in more formalized regimes present in later cases. The case of France appears to sit on the proverbial fence, as it seems to exist in a

in an appropriate cut-off date for the case of the United States but also with the availability of comparable historical research. The problem of historical research is that it would be problematic to compare historical works dealing with the cases of Spain, France, and Germany to the contemporary works and news reports needed for the inclusion of the United States as a fourth case. Hence, it was decided that with the contemporary and evolving nature of the United States in the existing international system that a concluding chapter outlining strategies and lessons would be more methodologically sound and parsimonious. 
crossroads for the formation of regimes. It can be expected that higher levels of international regime formalization and norm generation will be seen in the final case of Germany under Bismarck.

In the case of the regime variables it seems likely to find a great deal of variability across time in the constraining power of regimes. Regimes appear to have evolved a great deal over the past centuries, thus it would appear logical that more informal regimes such as those found in treaties of the Sixteenth and Seventeenth centuries would be of less restraint upon states then the more formalized regimes that we see today. Furthermore, it seems likely that increased economic integration and the potential of hegemonic regimes based in public goods may further strengthen the impact of regimes as a state constraint in more recent times.

When considering the degree of hegemonic power concentration over time this group of variables will likely bring a great deal of explanatory light upon "problem" cases, those being the cases of Germany and its relationship with Britain in the 1800 s. Moreover, this notion of power concentrations illustrates a new variation in traditional hegemonic stability theory.

Domestic politics appear to be the cloudiest image in this view, as it seems that these variables will see the greatest amount of variability not only across cases and time but also within cases. The very nature of domestic politics appears to create this ever changing environment, as this group of independent variables appears to be the most dynamic. Though, it does seem likely, once again, that higher degrees of access to the government will be seen in latter cases. It also seems probable that more interests will find voice within their governments in latter cases.

Finally, in the realm of policy prescriptions that may come of this work, it seems probable to expect that these recommendations will guide hegemonic states to respect the 
constraints placed upon them. Moreover, such findings will seem to come at interesting time, as the United States currently appears to sit at the crossroads of hegemonic actions. One could only image how different these writings would be if they were undertaken some years latter. Yet, it is possible that they may be of greater importance and impact in today's geopolitical landscape. 


\section{Chapter Three The Accidental Hegemon: the Case of Spain}

Sixteenth Century Spain sits as the first case in the study of handcuffed hegemons. A brief survey of the historical record illustrates that Spanish hegemony came as a result of the dynastic creation of the Habsburg Empire under Charles V. The power of the empire was drawn from the vast resources of gold and other precious materials drawn from the empire itself as well as colonial activities. Moreover, these imperial holdings gave rise to the creation of mercenary armies, and thus for a time Spanish military hegemony appears to meet the first case selection criteria, that being a preponderance of military power. (Nye12-17)

Additionally, the case of Spain meets the second case selection criteria, in that its hegemony was not fleeting, but rather long lived. Kennedy (1987) utilizes the case of Spain to illustrate his theory. He contends that Spain gained and sought to maintain its dominance of Europe from 1519 to 1659 , thus providing a historical record of hegemony of 140 years. Kennedy also illustrates the ultimate decline of Spanish Hegemony as a result of the rising importance of naval power and the fact that Spain was ill prepared to follow this trend. (Kennedy 31-72) However, this analysis diverges from Kennedy, as he sought to explain the rise and fall of great states whereas this work seeks to explain stability of hegemonic reigns, for all states are not destined to overstretch.

The case of Spain also meets the third case selection criteria, in that throughout the 140year time period numerous treaties and instances of marriage diplomacy exist, hence satisfying the need for the potential existence of international regimes. (Kennedy 1987 and Grun 1991) While it cannot be argued that the regimes of the Sixteenth Century rival those of more modern eras in their institutionalization, this study accepts that these loose treaties and agreements of the time placed constraints upon Spanish dominance that kept the need for other types of balancing 
behavior by other great powers to a minimum. Finally, the case of Spain meets the final two case selection criteria in that there is an extensive historical record present that not only delves into Spain itself, but also the other rival powers of the era.

The case study of Spain under Philip II begins with a review of the international regimes actions and inactions of the state during this time period. The work begins with a discussion of the minimal amount of international regime activity undertaken by Spain. The historical record only indicates two real forms of international regimes that being the state's marriage diplomacy and its use of truces and treaties. At first glance marriages appear to be little in the form of international regimes, however if the concept is considered further marriages served the purpose of informal international regimes. These international arrangements had long been a Spanish tradition and Philip II and his predecessor Charles V utilized the concept to attempt to expand the power of the state. These marriages were not only used to formalize interstate relations, but could have also served as a means of creating channels of communication and lines of understanding. The case study will also show a number of international agreements undertaken by Spain, such as truces and treaties. However, what must be considered when reading the section detailing the international regime activities of the state is the motivation behind the Spanish polices. The study is looking for international regime actions that are undertaken to restrain or bind a dominant state either to the system or other great powers of the era. The case of Spain reveals another motivation, that being attempts by Spain to use international agreements as stop-gap measures to delay conflict for a more beneficial time point or to attempt to increase the power of the state through marriage alliances.

The domestic political variable class is particularly cumbersome, though rich with interactions and insight. The discussion begins with the supremacy of Castile within Spanish 
politics. This Spanish state plays a large role as the domestic economic engine of the Empire, and thus with this economic prowess comes a great deal of influence over the actions of the national government. What will be of key interest when considering the domestic power of Castile is the nationalism that was inherent within this region and its elites, and these tendencies will be important in how Spain comes to grips with what it should do with its new found international power. The study of domestic politics then focuses on the unique role that both domestic and foreign banking houses played in Spanish politics. This relationship is key in that the banking houses were both an instigator of expansion and a collector for the costs of expansion as the Spanish Empire should be seen as a state willing to mortgage future earnings from the Americas for cash on hand. The case also will consider the structure and weaknesses of the government of Philip II. This section should be seen as a means of tracing the increased number of entry points for influence over the government. The section also details the special relationship between the state and the Catholic Church, because Philip II saw himself as protector of the faith and at the same time this self-identity was a source of influence for the Catholic Church over the policies of the state. This complex domestic system should be seen in the context as the impetuses for the classic overstretch of power that occurred during the period of Spanish dominance, which can be seen in the conclusion of the section.

This chapter next moves to a discussion of the constraint of hegemonic power concentration upon Spain. The section focuses on both the economic and military power of the state. The section is denser than the remaining case studies in this regard, as there was no comparable dataset available for reliable and valid measures. However, the section is of great interest, as it illustrates Spain's inefficacy in transferring its latent power to actual power as well as the state's propensity to borrow heavily on its future earnings. The military power of Spain is 
also telling in that this section reveals the luck of Spain during its period of dominance, as the state was not well blessed with traditional stores of military power such as population and advanced military training and was thus forced to rely on mercenaries and outside arms dealers for much of its military power.

The case study concludes with a discussion of the balancing actions that the state faced during its period of dominance. The theme of luck will continue in this section, as France, Spain's natural rival, saw a period of internal turmoil during most of the period and was thus sidelined in many regards. Nevertheless, that is not to say that the Empire faced little balancing, which is to be expected given its expansionist tendencies and its lack of binding international regime use. The state faced balancing and power harassment attempts from England, the Netherlands, and Ottoman Empire, as well as English and Dutch joint balancing. What will appear most remarkable is how long Spain was able to carry on with rapid expansion, constant military engagement, and with little in the way of a domestic foundation for such actions.

\section{International Regimes - If Only Spain had Some Self-Restraint}

While the case of Spain does not yield a great number of instances of international regime creation, as it was assumed that the historical era would not be ripe with occurrences of international constraint in the form of binding regime creation. Some instances were found in the historical record. However, as was expected the international regimes in question were not very formalized and tended to be created in times of mutual need by the states involved. The majority of the regimes in question tended to take the form of marriage diplomacy, which can be considered a very weak form of regime, as the degree of norm creation would tend to be low. Rather, the success of marriage diplomacy often was dependent upon the length of life the partners in the union and whether the union produced heirs. Marriage diplomacy can be seen as 
a highly un-formalized instance of international regime creation, as the marriages across varying royal families not only attempted to further such royal blood-lines, but it also can be seen to have created linkages and lines of communication between potential challengers and combatants.

It must also be realized that marriage diplomacy existed as a cornerstone of Spanish diplomacy even as Spain began its rise to hegemony. In October of 1469 Spain took its first steps toward hegemony with an act of marriage diplomacy. Isabella, the heiress to the Crown of Castile, was married to Ferdinand, the heir to the Crown of Aragon. The marriage unified the two houses and created the foundation for a unified Spain. The alliance between the two houses was a threat to Louis XI of France, and was of such importance that it had to be done in secret, so as to prevent a potential assassination plot from the French. Moreover, the alliance and its codifying marriage created the hierarchy of Castile over Aragon in Spain, as Ferdinand was required by the marriage to live in Castile and work for the causes of Castile. The terms of the alliance were a result of strong Castilian nationalism and the strong need for Aragon to ensure its integrity was not threatened by France. The marriage alliance codified Castile's position of importance in Spain, while beginning the unification of Spain. (Elliott 17-22) This instance of marriage diplomacy not only unified Spain, but it also set an important foundation for the future of Spanish diplomacy. That foundation was that marriage diplomacy existed as a means of unification and as a means of gaining strength with the codification of unions by the church. While this was the first large case of marriage diplomacy in Spain's hegemonic history it would not be the last.

Ferdinand often attempted to utilize marriages as a means of increasing the territory controlled by Spain and as a means of pacifying potential balancers. This early form of diplomacy can be seen as a loose international regime, because marriage diplomacy created lines 
of communication between states and was a means of institutionalizing relations through the union of two royal families. The Treaty of Medina del Campo, in 1489 between Spain and England, was created with the marriage of Prince Arthur, son of Henry VII, to Catherine of Spain. Marriage diplomacy was also used to create the link between Spain and the Habsburg Empire, through the marriage of Juana to Philip of Burgundy, the son of Maximilian I. (Kamen 37) Additionally, Ferdinand was one of the first European monarch to use diplomats as a means of creating paths of communication and ties between states. These ties were initially created in the 1490s when he sent diplomats to posts in Brussels, London, the Holy Roman Empire, Rome, Venice, Milan, and Genoa. (Kamen 38)

It was also marriage diplomacy that was used to bring Spain into the fold of the Habsburg Empire, a move that would eventually give Spain its position of dominance in the European international system. Maximilian's move to arrange the marriage of his son Philip to Joan, the daughter of Ferdinand and Isabelle. This marriage joined the Habsburg Empire with Spain, and it was from this marriage that Charles V rose to become Holy Roman Emperor. (Kennedy 3233)

In 1526 Charles $\mathrm{V}$ arranged his marriage to his cousin Isabella, the daughter of Emmanuel of Portugal. This marriage diplomacy was undertaken in the hopes of drawing Spain and Portugal closer together, with the eventual hope that the Iberian Peninsula would be unified. The marriage resulted in the birth of Philip II, and thus Philip as an heir to both the crown of Spain and Portugal was eventually able to bring unification to the peninsula. (Elliott 162)

In 1554, Charles V attempted to expand his son's future inheritance and prevent English balancing during the reign of Philip II through an act of marriage diplomacy. Charles married his son, Philip II, to Mary Tudor. With this linkage between England and Spain Charles V was 
attempting to ensure that the Netherlands neighbored a friendly state, and ultimately that Philip II would rule England, the Netherlands, and Spain. As Charles now saw a world in which the threat of balancing was mitigated through wedlock he began to prepare for Philip to assume control. Charles V died in 1558, however in that same year so too did a childless Mary Tudor. (Elliott 207-208) Therefore, Philip II was left to face an international system in which Spain was dominant, but one in which the Netherlands remained a point of contention and England rejoined the ranks of the French and the Turks as power seeking to return the international system to state of power symmetry.

The earlier lessons of previous Spanish leaders were not lost on Philip II. Philip constantly sought to maintain good relations with the Habsburg Empire, particularly since a great deal of Spanish military power was based on the presence of German soldiers in the army of Spain and because of the close linkages that still existed as a result of his father's birth. Philip used marriage diplomacy to ensure positive relations with the Habsburgs, by successfully marring his sister Maria to Emperor Maximilian II in an attempt to ensure that amicable relations remained between the two powers. (Kamen 165)

The use of marriage diplomacy can be seen as an early instance of international regimes, as it bound ruling families together in the hopes of mitigating risk and creating similarities. Moreover, a great deal of transparency in diplomatic actions could not be expected at this early date in history, and these marriages represented a true means of fostering understanding and international friendship. However, the prospects of absolute success from such arrangements cannot be expected, as with more modern regimes such relations can be broken if they serve the best interests of a given state, even if such marriages cannot be so easily dissolved. It was the ease with which the linkages of most of these international marriages could be ignored that gave 
the states of the day a great deal of flexibility in their foreign policies. Instances of marriage diplomacy and their ensuing unions could then be touted in times of need and they could be ignored or downplayed if a given ruler determined that her or his state's interests diverged from the tenets of the marriage. The lack of formalized in these forms of international regimes meant that leaders were more apt to utilize this method of diplomacy.

In spite of its active pursuits of marriage diplomacy Spain often hesitated to enter into more formalized treaties with potential challengers. However, the state was willing to make exceptions when cases of need arose. One such case existed in 1559, when Spain and France entered into the Peace of Cateau-Cambresis. This peace treaty was signed between the two states, as France agreed to cease its hostilities against Spanish interests in Italy and the Low Countries. Spain, in return, agreed to halt its attempts to divide France. However, this treaty was not entered into by the two states in the hopes of promoting some degree of power stabilization, thus it was not Spain's hope that such a treaty could forestall balancing by France. Rather, the treaty was one of mutual need for both states, as both Spain and France had domestic problems which were distractions to their plans for each other. These domestic problems were those fostered by the Protestant Reformation, and the realization that Protestant revolts were taking on larger roles for both France and Spain. (Gilbert Et. al. 183-184) Additionally, this treaty exists as another example of marriage diplomacy, as the treaty was grounded in a marriage. In seeking peace with France and a commitment by France to agree to Spain's territorial rights in Europe, Philip sought to marry a French princess, and the marriage formalized the peace of Cateau-Cambresis. The peace also returned the Duke of Savoy to his lands, which was of great importance to Philip as the Duke was a key ally. (Parker 1998 85-86) 
However, the Peace of Cateau-Cambresis cannot be considered an international regime that was created to constrain Spain's power and thus prevent balancing by France, as the motivation behind this arrangement was domestic in origin. Essentially this peace can be seen as an attempt by both powers to call a timeout to their hostilities, as both states had more pressing areas of concern on the home front, in the form of the Protestant Reformation.

Later in Spain's course as a dominant actor in Europe it began to enter into what can be considered binding international regimes. However, the motivation behind such actions must be called into question. Prior to Philip II's death in 1598, he began to realize that Spain could not realize victory in Western Europe. He had attempted to bring great portions of Europe under the control of the crown, and under the banner of the Catholic Church. However, in his latter years he began to move towards a policy of coexistence with the other powers in Europe, and coexistence with the growing Protestant faiths. In 1598 a peace treaty with France was signed, thus ending the two states long history of conflict with each other. The peace was created because of Philip II's willingness to grant partial autonomy to the Southern Netherlands, though most political decisions and the military would still be controlled by Spain. In 1604, a similar peace was made with England, and in 1609 a twelve year truce was signed with the Dutch. This truce meant that military power would remain constant between the two states. Essentially the truce was meant to halt hostilities in the hope that time would allow for a political solution to the problems. The truce was moderated by diplomats from both France and England. (Kamen 310313) This truce was a binding of Spanish power in concert with the balancers of the era.

This binding of power was not the result of a hope by Spain for maintenance of power, but rather the truce came from the exhaustion of Spain and the hope that a regime could be created to maintain Spain's power for some period of time. The underlying motivation, that 
being the exhaustion of the Spanish military and the inefficient use of economic power, means that the motivations do not lend themselves towards an endorsement of the hypotheses in this work. Had Spain had a willingness to enter into such regimes prior to the realization of weakness then the state would have been taking actions in concert with the theory in question, however in this case the motivations illustrate that such actions were merely as a means of last resort rather than as a long-term strategy for the stabilization of an unbalanced international system.

Moreover, other instances of international regime creation as a last-ditch effort to stave off hegemonic exhaustion exist in the historical record. 1609 saw the creation of the Twelve Year Truce with United Provinces and diplomatic moves to decrease the balancer behavior of both France and England. The truce can be seen as a crushing blow to Spain as it recognized Dutch sovereignty, thus signaling a weakening of the state's power internationally. The move towards the creation of these of regimes can be seen as a move towards the maintenance of power asymmetry, while decreasing the costs of maintaining hegemony. However, it was the underlying costs of such power that led Spain to seek such stabilizing regimes, not an overarching sentiment to constrain its actions. These attempts at regime formation can be seen as cost cutting measures during times of decreased economic growth. (Lobell 124-126)

In 1621, Spain allowed the Twelve Year Truce with the Netherlands to lapse. The truce had been a key international regime for Spain, in that it prevented increased hostilities in the north from distracting the government and its finances from operations to protect the Americas and the more important home front. However, internal pressure forced Spain to increases it's balancing threats by allowing the truce to lapse. During the years of the truce the Dutch used the time of peace to gain ground commercially in the Spanish and Portuguese empires, thus decreasing the economic gains of the both the royal family and the nobility. Hence, such a truce 
became a liability in the eyes of the Spanish government. (Kaiser 40-41) In hindsight the Twelve Year Truce can be seen as a stabilizing regime that allowed Spain to regroup from its military losses from the English and the Dutch from the previous century, thus allowing Spain to conserve a portion of its power resources by limiting the number of potential balancers. It is possible that had the truce been resigned that Spain could have seen its military hegemony increase or at least maintain its power, while the Dutch only gained economic power. Thus, with a renewed truce the worst case scenario for Spain could have been a period of dual-hegemony rather than an ultimate decline with the reintroduction of a third balancer.

To add greater harm to their relations with the Dutch, Spain immediately began a policy following the conclusion of the truce that targeted the economic power of the Dutch. This policy was an attempt by Spain to gain back its economic supremacy. (Kaiser 41) However, it must have been certain that had this policy not been successful immediate balancing from the Netherlands would take place.

In December of 1646 Philip IV was finally forced to enter into a treaty with the Dutch in the hopes of creating an atmosphere in which Spain could maintain its grip on the empire. Mazarin was unwavering in his pledge to keep French pressure of the Habsburgs until such a time that they were willing to divorce themselves from Spain completely. The combined force of France and the Dutch was too much for Spain at this time, and thus a treaty with the Dutch was necessitated. The treaty provided that Spain would recognize the Dutch capture of territory from the Crown of Portugal in return for a Dutch pledge not to further impede Spain's ships and holdings in South America. (Parker 1997, 166-168)

This treaty should not be seen as a regime created to prevent balancing by the Dutch and the French, but rather as a treaty to "stop the bleeding" of the Spanish empire. Spain could no 
longer combat two balancers. However, one must question why Philip IV sought to find agreement with the Dutch as opposed to the French who had greater influence over the power relations on the continent. Thus, it seems that this treaty further illustrates the domestic political concerns driving the actions of the Spanish government.

\section{The Impact of Spain's International Regimes}

While a great deal of international regime activity was not expected to be found in the case of Spain under Philip II there still was found some degree of both formalized and unformalized international regimes. The problem with the state's use of international regimes laid in its motivations. The regimes in question were not used to constrain the states power, nor were they used to make the state's power more palatable to the other great powers of the time period. Rather, Spain utilized international regimes as stop-gap measures to secure peace for a set amount of time or during times of economic decline. The un-formalized regimes of marriage diplomacy were used to attempt to extend Spain's power to other areas of the globe. They were not used to build understanding and channels of negotiation between Spain and a potential rival. These acts of marriage were used by the Spanish Empire in a one direction path to extend the state's influence but not to allow a reciprocal influence that would flow towards Spain. Moreover, Spain's use of actual formalized treaties can be seen as last-ditch efforts to end conflicts that became un-winnable or inefficient. The treaties that were created to prevent warfare were used to hold off conflict until a time in which the Spanish state sat in a more advantageous position. The case study reveals more instances of international regime formation than was expected, but the motivations of these international institutions mitigate their value to the study. 


\section{The Handcuff of Domestic Politics (or the Key to Hegemonic Failure) The Supremacy of Castile}

A discussion of Spanish domestic politics and their impacts on foreign policy actions must begin with the two main houses of Spain, Castile and Aragon. An understanding of the distinctive nature of these two houses and the subsequent dominance of Castile over Spain's political frontiers will begin to illustrate the influence of Castilian elites and interests over the foreign policy of Spain.

The domestic politics of the houses of Castile and Aragon were shaped by each territory's distinctive political nature. Castile as a larger and more self-sufficient area, and thus was more inward looking in its policies and influences. However, Aragon a result of its commercial centers was far more outward looking, and thus more influenced by commercial interests that existed outside of the region. These distinctions may also help to explain the differences between the policy areas of Ferdinand and Isabella. Isabella was far more concerned with domestic political actions, than was her husband who concerned himself mainly with foreign policy. Moreover, these traditional distinctions help to explain differences between the populations and elites of each area. Castilians have been noted for the presence of a great deal of nationalism and a desire to leave lasting marks on the world through Spain's foreign policy, thus Castilian interests can be seen as more imperialistic in nature. Aragon and its commercial interests have largely been more concerned with profit than history, thus Aragon's interests can be seen as more liberal in nature. However, the union of these two houses must be seen in accordance with the hierarchy that was created by the merger, in that Castile was institutionalized as the dominant house. Thus, Aragon is responsible for fostering a more 
outward looking Spain, but for the goals that lay dormant in Castilian political culture. (Elliott $31-32,44-45)$

With the unification of the two main Spanish crowns through the marriage of Ferdinand and Isabella one would have expected centralization in the authority of the crown. Rather, what occurred was a continued division of the powers of the two houses. Often policy problems were dealt with in two different manners by the two houses, as a policy for Aragon and a policy for Castile were devised and implemented. This lack of centralization can be seen to lay the foundation for problems in the rules of Charles V and Philip II. Both monarchs had difficulty in administering the other regions of Spain, as Castile remained the sole house in which the ruler of Spain had almost total dominion. This problem can be traced to the marriage of Ferdinand and Isabella in that Castile was put in position of dominance in Spain, however the other regions appear to have been granted the ability to free ride on the power resources of Castile. This problem is best illustrated with the incorporation of Catalonia to Spain. Ferdinand, who formed and implemented the policy to draw in Catalonia, was fearful of increasing the power of Castile, and thus he allowed for the region to be constitutionally distinct. This meant that a policy of legal and cultural uniformity was not implemented, but that the divisions between Spain's various regions were perpetuated and would then become a source of domestic and economic weakness in the years to come. (Elliott 76-80)

During the rule of Ferdinand and Isabella rule was essentially divided as Isabella took the lead in most domestic matters and Ferdinand who came from the smaller of the two houses made foreign policy his realm. Philip II traced the origins of the Spanish Empire to the initial actions of Ferdinand, as he was credited with the expansion of the empire to Italy and the Americas (Kamen 9). However, it was the ten year war for Granada that helped to fortify the Spanish 
notion of empire. The war was fought against Muslims with both mercenary and Spanish troops. Moreover, Ferdinand was able to utilize the Crusade mentality and the support of the Catholic Church to increase the cohesiveness of the Spanish military and population. It was in the campaign for Granada that the tradition of papal legitimacy was created for Spain and its exploits, for with the support of the Church or the use of the Church's name as a cause for action large amounts of religious and national sentiment could be harvested for expansionistic polices. Additionally, it was Granada that brought Castilians, Spain's largest population center, into conflict, and created in the population a sense of virtue in military life. Moreover, it created sentiments of Castilian superiority over challengers, thus fostering notions of nationalism and imperialism. (Kamen 14-21) Ferdinand also established two long standing goals of Spanish foreign policy, those being the containment of France and the continued control of the western portion of the Mediterranean Sea (Kamen 36). While these two goals are both logical and attainable Ferdinand's lasting impact on the foreign policy of Spain is the creation of a foundation of militarism and nationalism.

The reign of Ferdinand and Isabella created the unification of the houses of Aragon and Castile. Moreover, it was during their rule that Spain was unified into the state that would become hegemonic in future decades. One such tactic for the unification of Spain was the creation of Hermandades, which were essentially urban law enforcement groups that doled out vigilante style punishment. Additionally, the rulers encouraged households to keep arms and to create local militia groups. This policy was initially out of fear of the rise of threats from Muslims and the Ottoman Empire, though it became a means of creating nationalism in the region, thus instilling pride and common purpose. However, this policy also introduced an element of militarism to the population, which can be argued to have created strong nationalist 
sentiments and a desire for expansion. Therefore, it is possible to trace Spain's expansionist tendencies to this early policy of militarization by Ferdinand and Isabella. (Kamen 7-8)

With the rise of Spain also came the rise of Castile as the dominant culture in Spain. Castilian nationalism soon arose as those in power sought to spread the culture of Castile throughout the Spanish empire. Castilian nationalism is illustrated through the rise of xenophobia, as movements were made to exclude other dominant cultures. The prime examples of these policies can be witnessed through the treatment of the Muslim and Jewish populations during this time. Jews were expelled from the region and were only allowed back if those individuals were willing to change their religion. Muslims saw similar treatment in the 1500s. (Kamen 342)

The rule of Charles V provided two vehicles for the fortification of Castilian nationalism. Charles saw two predominant goals for his foreign policy. The first was the defense of Christianity from the threats posed by the Islamic Turks. The second goal was the defense of the Catholic Church from the threats of the Protestant Reformation. Both of these policy goals were at the heart of the Castilian identity as strong Catholic population, thus building on the strong tradition of crusading in Castilian society. Strong religious beliefs fostered in the population of a Castile an understanding that allowed the transformation of traditional Castilian thought into a mindset that allowed for the creation of a hegemonic Spain. Previously Castile was a more inward looking region, whose thoughts for domination did not extend beyond the realm of the Iberian Peninsula. These dual goals fostered a shift in thinking that allowed Castile, a proud Catholic region, to extend its view to not only the peninsula but the Americas and beyond. (Elliott 159-160, 167) 
Castile was the largest, most populous, and most wealthy of the Spanish states. While Philip II was able to gain vast amounts of wealth from Americas, Castile represented the only real source of taxable income that could be gained from Spain itself. These taxes were not to come from the elites of territory, but from the peasants. Thus, the need for a reliable tax base increased to the power of the Castilian elites. Castilian nobility found themselves in a situation in which they were needed to ensure state revenue, and thus were able to gain top seats in the Spanish bureaucracy, and with these positions of power it is logical to assume that a great deal of influence could also be vested in the nobility of Castile. Furthermore, it was the Castilian elites that controlled the exploration and resource removal of the Americas, as they claimed that these resources were their discovery and hence their monopoly. The key position that Castile had in Spain's power resources further engrained this monopoly. (Gilbert et. al. 192-195)

The monarchy was greatly influenced by the power of the Castilian nobility. The crown essentially borrowed a great deal of its power from the Castilians, as they never challenged the actions of the nobility and the elites depended upon the crown for economic favors and patronage. The power of the Castilian elites was institutionalized in the council system of Spain. The councils were charged with the day to day ruling of the various provinces of the Empire, though the administration costs of the councils often meant that little tax revenue was generated. Essentially, the council system was a means for the crown to provide patronage to the elites of Castile, thus allowing the monarchy to free-ride on the power of the nobility. (Kaiser 25-28)

Charles V was constantly unable to gain large tax contributions from Aragon, thus he was forced to depend on the monetary resources of the Castilian tax base. However, this empowered the Castilian Cortes, which was the body from which increases in taxes had to be sought. The Cortes provided fifteen parliamentary grants from Castile. With this dependence on the Cortes 
of Castile one can easily see how the elites who made up this body were placed in a position to influence the policies of the Spanish monarchy. (Elliott 199-200) This meant that it Castilian interests and their inherent nationalism were most reflected in the policies of Charles V. Hence, as the dependence on Castile increased, so too did the power of its elites. While the power of Castilian elites, during the rule of Charles $\mathrm{V}$, was constrained in that their power was largely the power of purse, rather than power over actual policy this trend would change under the rule of Philip II.

Philip II created many councils during his rule over Spain, and thus as the number of councils proliferated so too did the power of the Castilian elites. The power of Castile was financial in nature, and thus one had to expect that after some time that financial interest would become a policy interests. Hence, with the proliferation of councils came the inevitable increase in the power of Castile. While the councils never had the power to take policy action they had considerable power to set the agenda and guide policy action. This power arose from three central tasks of all of the councils. The councils interacted directly with those individuals that came to Philip II's court with official business, thus the specific councils acted as gate keepers that had the ability to prevent some information from reaching the monarch, and they had the ability to influence the opinions of those seeking to meet Philip. Second, the councils were directed to refer all important issues directly to Philip, yet with this directive came enormous power. This directive meant that the council members could isolate in some instances what they deemed to be of importance and undercut issues that Philip himself may have wished to have had direct involvement. The councils also were charged with the summarization of royal correspondence, thus allowing them to influence the monarch's decisions based on their particular interests. (Parker 1998 22-23) Essentially, the councils functioned as a series of 
chiefs of staff depending on their specific issue areas, thus Philip had installed around himself a series of gate-keepers and filters for foreign, domestic, and economic policy. The influence of these councils is highlighted when one considers the degree to which patronage effected the decision making of the nobility of Spain.

The influence of the elites of the era and the power of the councils is further compounded when one considers the factionalization of the varying elites. Many of the interests of groups of Spain's era as a hegemonic state were not the groups we typically focus on in the discipline. Both Charles V and Philip II had to carefully divide political favors such as political positions to two competing families, those being the Alba and Eboli factions. The two factions were in constant competition for political favor. This fractionalization of elite interests is an illustration of the difficulties faced by the Spanish monarchy, as political positions and favors had to be divided in concert with the prevailing political tides of a given month or year. Moreover, vigilance in intelligence was of constant importance, for varying families often sought advantage, and these family troubles could easily become areas of concern for the monarchy. The potential for conspiracies against the monarchy or other leading families was a constant threat. It was the job of the monarch to protect power and ensure that it was utilized in the most efficient manner possible, something that would be difficult for the rulers of Spain. (Kaiser 1415)

Philip II was unable to deal with the factionalization of interest and disagreement between councils or advisors. Philip wrote, "[w]ith so many different opinions I have found myself in a quandary, and since I do not know the truth of what is happening there I do not know which remedy is appropriate or whom to believe; so it seems to me the safest to believe neither the one group nor the other, because I think they have [both] gone to extremes. I believe it 
would be best to take the middle ground, although complete dissimilation" (Parker 1998 141). This quotation illustrates the utter confusion in which Philip made some of his policy choices. This can be seen to have arisen from the council system with which Philip insulated himself.

Another domestic political problem existed in the realm of patronage. Nobles that were brought into places of political power often did not have the monarchy or Spain's best interests in mind when they made decisions. Frequently these individuals were beholden to other more powerful members of the nobility, and not merely the crown. A prime example was Perez, Philip II's Secretary of State, who was greatly influenced by the Ruy Gomez, prince of Eboli. Thus, when the interests of Philip and Gomez diverged Perez was likely to follow his financial needs over the need of the state. This lack of loyalty severally hampered the policies of the Spanish crown, and most importantly negatively affected the finances of the Spain as this led to an inefficient use of economic power. Adding to the difficulty, the upper nobility of Spain were often more interested in assuring the loyalty of their patrons than of carrying out the policies of the monarchy. (Kaiser 16-19) This problem was compounded when one considers that the nobility of the era typically considered conflict and war as a means of increasing their material wealth through conquest, rewards, and the raising and supplying of armies (Kaiser 22).

\section{Money and Influence}

A large role was played in Spanish politics by the banking interests, moreover these interests tended not to be domestic in origin. The global nature of the Spanish Empire meant that to secure financing for its actions Spain often had to seek loans from Italian and German banks. The origins of the influence of these foreign banking interests can be traced to the rule of Charles V. Charles sought to make money more internationally mobile through the use of foreign bankers. Ferdinand had used only local bankers in his financial matters, however Charles V 
sought to intertwine the government and financial centers of empire, and sought to increase the mobility of funds throughout Habsburg controlled territory. Thus, Charles V began to outsource his finances to banks in Germany and Italy. (Kamen 54) The impact of this policy will be seen in latter illustrations under the rule of Philip II, as he used the banking houses as a means of finance at the expense of discoveries in the Americas.

The importance of the banking interests in Spain is underscored by the lack of central control over military spending, and thus by the number of royal bankruptcies that were declared throughout Spain's time as a hegemonic actor. In the early years of the reign of Philip II bankruptcy was present as the new ruler was forced to suspend payments on the royal debt, as the vast resources of the Spanish empire were unable to meet the needs for capital for its vast holdings and interests. (Elliott 207-208) This scenario was again played out in 1575 when resources from the Americas and taxes at home were unable to cover the loans from banking houses throughout Europe (Elliott 260). Similar bankruptcies were also seen in 1596, 1607, 1627, and 1647 (Elliott 283, 287, 329, 352). The financial facts of Spanish hegemony exist in the reality that less than a quarter of the empire's revenues came from the resources of the Americas (Elliott 281-283). Rather, a majority of the wealth extracted from North and South America went to pay debts of the Crown, as Philip II's administration carried on a long standing policy of mortgaging future gold and silver shipments for money in hand at a given point in time. Thus, with the increases in resources mortgaged the Empire actually increased the number of interests that sought to gain from the actions of the state. (Kaiser 46-47) With each bankruptcy came increased demands by the banking houses for added return on their investments, and in turn increased revenues were expected to come from the Americas. 
An example of the influence that existed in the banking houses can be seen in their ability to force a policy change in the government of Charles V. Prior to 1524 the Spanish government was successfully able to prevent foreign commercial actors from engaging in trade with the Americas. This monopolization of the American trade routes and commerce was as a result of the influence of Spain's commercial interests who wished to maintain a stranglehold over the profits from the Americas. However, Charles V was pressured by the banking houses to allow such foreign interests to gain share of the market. The banking houses held large amounts of Spanish debts and were key in the securing of monetary liquidity for Charles' government, and their role and importance would increase under the reign of Philip II. (Elliott 179)

\section{Philip II and the Openness to Influence}

Philip II had many foreign policy tools at his disposal. First, despite a mismanaged economy Philip was blessed with the ability to raise funds from both taxation, as well as from mortgages from various lending houses on the riches of the Americas. This afforded Philip II the ability to field a very costly military force when times necessitated such expenditures. This also came from the size of the Spanish economy, which while not necessarily well managed was significantly large in comparison to the other economies of the day. The monarchy also utilized diplomacy as a means of extracting policy movements from other actors in the system, and as a means of propaganda to be used to the advantage of the state. Finally, Philip II's Spain was able to use both commercial and ethical pressure to gain advantage over other states in the system. This can be seen as an early form of soft power, as Spain possessed commercial power as a result of its discoveries in the Americas and its ability to use commerce as a carrot in foreign policy. Spain's ethical power came from Philip's standing as a leading Catholic monarch in the area, thus affording Spain some persuasive power with other Catholic's of the day, as well as other 
Catholic leaders. (Parker 1998 2) However, despite the potential sources of power that Philip II had at his disposal his rule of Spain was challenged by other factors, such as his on personal leadership weaknesses.

Philip II was drastically different than his father in one regard, the role of the Catholic Church. Charles V feared that the Pope and the Church could potentially gain enough power to rival the power of Spain. This fear of the power of faith was not present in Philip II. Philip was viewed as a champion of the Catholic Church, and a protector of the faith. While it can be seen that his views on faith were influenced by a desire for increased power and potential legitimation of his rule, they were not without actual deep held belief. Philip II was willing to risk some of his power and the reputation of Spain for his faith. (Gilbert et. al. 186-187)

Philip II's foreign policy strategy was based on traditional Spanish foreign policy goals. First, his policy was based on the belief that the national interest of Spain was to be the first aim of any policy undertaken by Spain. This policy goal reflects traditional realist thought, that being that self-interest should be the primary motivation behind the actions of states. Second, Philip believed that the Catholic faith was to be defended by Spanish power. This goal arose from the recommendations of Philip's father, Charles V, and from belief that Spain was a great Catholic state with enough power to defend the church. It also came from the realization that such a defense would grant Spanish policy with a certain air of legitimacy, and meant that Spain would have to stand strong against the rising tide of Protestantism and Islam. (Parker 1998 9193)

Philip's beliefs were grounded in what Parker calls "messianic imperialism." The author contends that Philip II felt that he, as the monarch of Spain, was charged with a directive from God to protect the Catholic Church. Thus, Philip is argued to have believed that his actions had 
the backing and blessing of a supreme being. Philip saw himself as both a monarch and a priest, thus in his dual role it was his belief that his actions were justified by the backing of a higher power. The monarch's deep felt religious beliefs led Spain towards unrealistic goals. Philip believed that it was his calling to do all that was possible in a given policy action and that divine intervention would ensure that the will of God was done. This strategic culture translated into a lack of caution, a lack of planning, and a lack of backup plans in the undertaking of foreign policy. These beliefs can be seen to underlie such policy failures as the 1588 Spanish Armada. (Parker 1998 93-105)

In addition to problems over amplified faith in the righteousness of his actions Philip II was plagued with a leadership problem, that being his inability to make timely decisions. The monarch was unable to make fast decisions, and instead choose to use long periods of deliberation to make formal decisions. This problem of over-contemplation meant that decisions were often weeks or month behind schedule. This meant that officials in the field often found themselves awaiting approval for a requested action, or awaiting directions. The problem of decision making was complicated by two factors. First, Philip II often used written orders and written reports, rather than oral directives or meetings to undertake the business of Spain. This appears to be the result of personal feelings towards human interaction. The monarch would prefer to receive a written report than to meet a military officer or banking official face to face. The written nature of his rule increased decision time, as increased time was needed for Philip to digest the large amount of reports and to draft responses. The second factor impacting decision making time was Philip's attempts to increase the centralization of Spanish governance, thus attempting to move away from the fragmentation of Charles V's rule. This meant that a great many decisions were left to Philip to deal with through his time consuming manner. (Parker 
1998 65-67) This problem is compounded when one remembers the council system of Spain that functioned as a gate-keeper for Philip, thus increasing the length of decision making.

Philip II came to power in Spain and yet always seemed to be measuring himself against the actions of his father. This led to a leadership problem for Philip, that being his indecisiveness. Philip constantly sought advice from his councils and his advisors, and yet he was typically concerned with the motives behind the words of these advisors. This skepticism and the need to rule up to the standards he perceived led to a slow decision making process, as Philip II was in fear of making incorrect decisions. However, it seems that often his worst decisions were merely slow ones, as the power of Spain was affected by his inability to make quick and calculated decisions. (Elliott 246)

Moreover, Philip's indecisiveness took form in matters of great importance to Spain, in the form of the royal finances. Philip lacked the ability to understand the vast finances of Spain. This meant that he often used his finance council to aid in his comprehension of economic issues. He was often puzzled by the reports sent to him by his council, and thus was forced to send out these reports for comment or to have officials interpret the findings. However, Philip did show some foresight in calling for projected budgets, though these advancements in financial planning in the era were of little real impact. The lack of impact was the result of Philip's inability to curtail his foreign spending despite slowing of returns from the Americas. (Parker 1998 40-41) Philip II's inability to comprehend financial matters meant that his financial council had vast influence over the economic policy of Spain. Moreover, his advisors could use his insecurities in these matters to gain more of a voice in the planning and execution of such policy, which would then increase the strength of the council system and the banking interests. 
Philip II's indecisive nature was brought into greater light through his need to centralize decision making power within the monarchy. Philip's centralization of power within the monarchy caused the problem of speed in decision making. This is seen through Philip's orders for foreign policy action in the Netherlands. In 1573 Spain was attempting to cool hostilities with the Dutch, however all decisions of this magnitude flowed through Philip. This meant that once Philip had given an order to adjust the level of hostilities or to take a new diplomatic route they would then be sent to officials in the theatre of action, though once directives arrived the were often outdated and the timing of such actions was damaged beyond redress. This was a result of Philip's inability to confer powers upon the diplomats and military commanders in a specific region. (Parker 1998 144)

\section{The Role of the Catholic Church}

At the onset of Spain's run as the dominant state in the world two key domestic political variables remained constant throughout most of Europe, the first being the increase in importance of religion. Religion came to the forefront of state conflict between the 1559 and 1639, as it played a large factor in both internal and external conflicts. This can be attributed to the rise of the Protestant faith, and thus the use of religious distinction by rulers of era to attempt to gain more power. This division of faith corresponded with the rise of absolutism in Europe, as more rulers sought increases in the centralization of state power. (Gilbert et. al. 179-181)

Philip II was fervent follower of the Catholic Church, as was illustrated by Parker in his assessment of Philip's messianic imperialism. Moreover, the beliefs of Philip II and their ability to allow an increase in the influence of the Church over the policies of Spain can be seen in Charles V's blueprint for the rule of his son, Philip. Philip II often consulted a document prepared for him by his father. Philip related to an advisor that he regularly reviewed his father's 
work, and stated that, his governance of Spain tended to operate more smoothly when he followed the words Charles $\mathrm{V}$ had written. In this guide for the monarch of Spain Charles charged his son with the defense of the Catholic faith. He contended that it was the protection of the faith that should be foremost in his decision making process. Moreover, Charles argued that peace was not always in the power of the monarchy, but rather he believed that peace was in the hands of neighboring states and other potential balancers. Charles V stated, "Avoiding war and keeping it at bay is not always in the power of those who want it... especially of those who rule realms as great and as numerous and as far-flung as God, in His goodness, has given me and which, if He pleases, I shall leave to you. Rather this depends on the good or ill will of neighbors and other states." (Parker 1998 77-78) These pieces of knowledge passed from father to son are of great importance in defining the origins of Philip II's strategic culture for Spain. The words illustrate that the Catholic faith can be used as a means for taking action and as a means of extending the glory of Spain. However, most importantly these words paint a strategic culture in which peace is not the burden of hegemon, but rather the burden of the other great powers. It seems that Charles was leading his son to believe that peace can be formed if others are willing to tolerate the power of Spain, rather than by Spain accepting limitations on its hegemonic power. Essentially, it seems that Charles argues that Spain need not to always seek peace, as it is the belief of Charles V that Spain can check its challengers. Philip appears to have taken two messages from the teachings of his father, that being that it was his duty to defend the Catholic faith and that it was the responsibility of the other European leaders to yield to the righteous path of a hegemonic Spain. Both of these lessons would prove to doom Spain's hegemony, for they do not lend themselves well to a handcuffed hegemon and they open Spain to great influence from the Catholic Church. 
Philip II, at the urging of Charles V, moved to create a strong relationship with Rome. This began when Philip created a policy in which large pensions were provided to cardinals in the Church. Monetary gifts were also provided to the pope as well. Spain also provided supplies to the Roman Catholic Church and military support to combat corsairs in the Mediterranean. In return the Pope provided positions within the Church for Spanish nobility and provided tax revenue from Spanish churches. Moreover, this relationship was made to provide legitimacy for the actions of Spain, as the state was then in a position to argue that its foreign policy was directed at the defense of the Catholic Faith. (Parker 1998 80-81)

The first great influence of the Catholic Church over the policies of Philip II arose from the missionary work of the Church in the Americas. The missionary practices of the Catholic Church took on a decidedly Castilian flavor, as the missionary groups attempted to introduce Castilian customs and social norms to the Native Americans they encountered (Kamen 278). This is an illustration of the pervasiveness of Castilian nationalism, as the social norms where not merely Catholic in origin but Spanish as well. Moreover, the presence of missionary groups in the Americas raises a question for the domestic politics of the state. It would seem that with the political power of the Catholic Church in Spain and the presence of such groups that there would then be an increase in church support for increased settlement in the area, as well as increased military support for missionaries and their travel to the Americas.

\section{The Armada Fails and the End is Near}

A clearer link between the policies of Spain and the influence of the Catholic Church can be seen in Spain's attempt to counter the balancing of England through the attack and invasion by the Spanish Armada. Both Pope Gregory XIII and Pope Sixtus V attempted to use their influence as leaders of the Catholic faith to persuade Philip II to undertake an invasion of 
England. They also pledged monetary support for such an enterprise. Philip initially rejected the notion of an invasion, though with each passing call for action by the Church Philip's resolve weakened. Philip originally felt that it would be unwise for Spain to attempt to topple the English government while it remained heavily involved in actions directed towards the Dutch. The king also felt that his policy towards the Dutch was worthy of praise, as Spain was combating a Protestant revolt with its war in the Netherlands. Though he relayed to the Pope that once his war with the Dutch had come to a victorious conclusion he was willing to entertain the Pope's plans. However, Philip's mind was swayed quickly by increased hostilities from the English, and the added impact of the endorsement of his Catholic faith. (Parker 1998 179-180)

In October of 1585 Philip sent word to the Pope that he was now willing to accept the Church's mission for an invasion of England. This change in policy by Spain, towards a policy of a two front war, was the result of new actions by England. First, Philip learned that Elizabeth I was funding a portion of the Dutch Protestant military. Thus, he felt that an attack against England could quicken the conclusion of the conflict in the Netherlands. Second, Philip's policy change was the result of a recent invasion of Galicia by Drake's forces. Hence, Philip intended to respond to increased hostilities toward Spain in the periphery with an attack against England on the continent. (Parker 1998 180)

The notion of a Spanish naval attack on England arose from several factors. First, the ease by which Spain was able to bring Portugal under the control of the crown created the sentiment inside the government that such an attack would also be an easy victory. Secondly, Spain saw its position as the dominant naval power slipping out of its grip, as the raids of Drake against Spain's Atlantic shipping were beginning to take a real toll. Thus, it seems that the decision to use the armada against England can be seen as a hegemon using preventative 
measures to try to stop its decline in naval power. Finally, Elizabeth I was aiding the Dutch in their conflict with Spain, and the thinking of the times was that if England was defeated the Dutch problem would be solved as well. (Kamen 306) Essentially, the Armada was thought to be a means of ending the Dutch problem by way of England, though it seems that Philip and his advisors failed to realize that Spain's great weakness was its weakness in the periphery, namely in shipping and the Americas. It was never realized that Spain's great power were not based on the continent but in the Americas. (Elliott 284-285) These factors in confluence with the pressures of the Pope were too much for Philip to discount. Thus, Spain acted in the core when its actions would have been better directed to defend the periphery.

The role of public opinion further locked Philip II into his decision to attempt an invasion of England. This potential "blowback" was made possible by the utter lack of secrecy that surrounded the armada plan. Spanish public opinion, as measured by historical references to public dialog and sentiment, was strongly behind the invasion of England. The strategic assessment of Spain's security began to pass through those on the streets in Spain. The public became concerned over the attacks of Drake against Spanish commerce and the Americas. Moreover, the public began to fear that England, as a Protestant state, may rise to invade Spain. (Parker 1998 189) This increase in public support for the invasion would also tie Philip's hands, for now not only could he not reverse his pledge to the Pope but his population began to demand action as well. Thus, it seems that Philip faced both his own psychological drive for action, as well as pressure from the Church, elites, and the public.

Commercial and banking interests were in support of the invasion. It did not require a great leap of faith to determine the views of both the commerce and banking houses on a potential invasion of England. Drake's actions were the primary actions that England had 
directed towards Spain. The English were attempting to use efficient balancing to ensure that Spain's powers did not rise from the riches discovered in the Americas. The interests of the commerce elites and the banking houses lay in the Americas. It was the commerce industry that stood to profit from the trade routes in the Americas, and it was the banking houses sought repayment and additional profit from Spain's successes in the Americas. Therefore, these two powerful interests had much to gain from the end of English harassment policies and from a removal of England as a threat to Spanish interests in the Americas. It can also be concluded that the monarchy informed these interests of its plans to calm their fears, thus decreasing the secrecy of the plan and increasing public talk of the invasion. (Parker 1998 218-219)

The intersection of interests that supported the invasion of England: the Church, the banking houses, commercial interests, and the public were not sufficient in their fervor to make up for the deficiencies in the plan. Three major problems existed in Spain's planned invasion of England. The first problem was a continual problem for Spain during the reign of Philip II, that being a problem of over centralization of policy power in the monarchy. As with the majority of policy decisions made during Philip's rule he did not permit the devolution of power to agents in the field. This is particularly troubling when one considers the fluid nature of a staged amphibious invasion, thus it would have be optimal for trusted battlefield leaders to have the ability to make alterations to the plan of attack as changes dictated. Second, the plan called for the merging of land forces from Flanders and the Armada itself while in open sea. This plan would need to run perfectly to achieve the meeting of forces at the optimal location, thus weather, sea conditions, and travel time would become primary concerns, not to mention communication between the two battle groups. The final problem was one of secrecy. The plan to invade England never was kept secret, as a result of the vast council nature of Spain and the 
need to send communications to and from forces stationed in Flanders, under the control of Parma. (Parker 1998 184-188) These three major problems with the undertaking of such a large military action would seem to have given pause to Philip, however the myriad of interests involved in the undertaking of the policy kept Spain locked on a collision course with failure and strategic overstretch.

The Spanish Armada can be seen as a absolute failure, in that not only did it fail in its attempt to defeat England it also triggered an increase in balancing and coordinated balancing by the other great powers. However, the failure of the Armada did not end in the English Channel, but rather continued as Philip sought to salvage some form of victory for the interests that drove Spanish foreign policy. With disgrace coming from the utter destruction of the Spanish Armada at the hands of the English Philip immediately turned his attention towards France and the fledgling French Catholic League uprising. Philip ordered Parma to invade France with 20,000 troops. However, though Parma quickly reached Paris Philip now faced aggression from France, England, and the Netherlands, instead of keeping France in turmoil and on the sidelines Philip decided to take the fight to France. It seems possible to conclude that Philip decided to use the military in such a way so as to attempt to gain some form of victory from the large amounts of planning and preparation for the invasion of England. Moreover, an invasion of France to support a Catholic uprising was also a means of attempting to please the Catholic Church, particularly since the failure in England had caused Philip to begin to move towards a peace with the Protestants in the Netherlands. (Parker 1998 274-276)

\section{The Impact of Spain's Domestic Politics}

The domestic politics of the Spanish Empire can be seen to have caused a classic overstretch of state power. The historical record indicates a lack of governmental institutional 
development as well as an over centralization of power within the monarchy of Philip II. This is overly problematic considering Philip II's lack of managerial qualifications; the council system established in the state that was able to both control and influence the flow of information to the decision maker; and the plethora of interests that gained access in the state. Each interest, both foreign and domestic, had reasons for continued expansion of the empire and for foreign military action. The high degree of influence from interests allowed the poorly organized institutions of the Spanish government to cause the squandering and continued mortgaging of Spain's power resources. This triggered a hegemonic decline that was unnecessary and arose too soon for a state with such a high degree of latent economic power.

\section{The Handcuff of Hegemonic Power Concentration (or Did Spain Really Borrow Power)}

In order to understand the power of Spain one must first realize the importance of inheritance to the Spanish Empire. Charles V gained the crowns of Castile, Aragon, Burgundy, and Austria. His family latter gained the crowns of Bohemia, Hungary, and Portugal. These vast claims from inheritance and not open conflict made Spain the premier power in Europe. However, with this vast amount of territory from which large amounts of latent power could be drawn one territory was of more importance to the Spanish Empire. Castile was the primary holding, for it was Castile that was directly controlled by the Empire. Thus, Castile was the province from which the largest amount of tax revenue could be gathered. The remaining lands were largely ruled indirectly by the Spanish crown, and thus such revenues were more difficult to gain. Moreover, it was in Castile that the royal seat existed, and hence with the presence of the monarchy came a greater fear of the populace.

The Italian states and the Low Countries were also of great importance, as it was these territories that led the way in wealth garnered through trade and banking. The presence of many 
of Europe's largest banking houses would be a great source of power for Spain, for the state could gain loans easily. However, the temptation of quick loans did eventually prove to be a major contributor to the downfall of the Empire. Additionally, it was in these areas that Spain was able to create its large trading and discovery routes. These routes placed Spain on the forefront of the Americas, which in turn allowed Spain to make unprecedented power gains from the wealth found in the New World.

The wealth from the Americas became a large source of Spanish power, as the gold and silver was apportioned so that the monarchy gained a fifth of all reported imports. Moreover, such imports also translated into wealth for the monarchy in the way of taxes, customs duties, and church levies. Additionally, those riches that made their way into private hands could then be taxed themselves. Thus, one can see that Spanish fortune was largely based upon the luck of inheritance and discovery. (Kennedy 43-44)

These vast amounts of economic power allowed Spain to recruit and pay a large mercenary army that was recruited from Italy, the Low Countries, Germany, and Spain. Spain was also able to draw its infantry leadership from Castile, as such military life in defense and for the glory of the Empire had become a popular notion among the lesser nobility of the area. Its was also the Spanish Army under de Cordoba that first integrated pikes men, swordsmen, and arqubusiers into one fighting force that was trained to support each other, rather than fighting in preordered waves. (Kennedy 44)

However, the naval forces of the Empire can be seen as a poor power transformation. The Spanish Navy, under Charles V, was largely based upon the conscription of merchant vessels and their sailors, as opposed to a standing navy. This largely untrained navy initially made up for its weakness with its size, though as naval strategies and vessels modernized the 
Spanish conscript fleet was fast becoming outmoded by its rivals. This forced Philip II to engage in a massive modernization of the Spanish fleet with the creation of approximately 150 naval galleys, as a result of the increased need in both the Atlantic and the Mediterranean. It is this naval problem that points to larger inefficiencies of Spain. (Kennedy 44-46)

\section{Economic Power}

The economic power of Spain was based on two distinct sources of financial power. First, domestically Spain was dependent upon the economy of Castile for the majority of its tax base. Castile was the sole Spanish kingdom from which tax revenues could be garnered with any degree of regularity. Spain's second source of economic power is typically considered to be the vast riches of the Americas that it was able to import, however this is only a portion of the truth. Rather, Spain was more dependent upon the wealth of the Americas as a source of credit for the various banking houses that it was dependent upon for loans to ensure marginal economic stability. Thus, the banking industry can be seen as Spain's true second source of economic power.

The reign of Charles $\mathrm{V}$ saw an increase in spending, as the monarchy attempted to fund its expensive foreign policy. As has been shown earlier this created a dependence on the resources of Castile to maintain economic power, though this dependence created was to the determent of the Castilian economy. Charles essentially began to mortgage the wealth of Castile as he sought additional financing from the banking houses of Italy and Germany. This meant that years of future tax revenue from Castile were expected to pay-off loans taken for policy action in a given year. Furthermore, the Castilian Cortes that permitted increases in taxation were not those individuals who would be paying the additional taxes, rather it was the small middle class and the peasantry. This taxation policy meant that with each passing year Castile 
was mortgaging economic growth and future tax revenues for influence in the policy actions of the monarchy for the present. (Elliott 204)

Spain's woes as a hegemonic state can be traced to its economic shortcomings and its inability to transfer latent power to realized power. The state's economic troubles were rooted in the unbalanced nature of its society. The majority of Spanish territories were owned by 300 families. This meant that while Spain had the potential for home grown wealth, 95 percent of the state's population were peasants. Moreover, Spain did not produce enough agriculturally to feed the majority of its population, and instead relied heavily on the importation of grain. The elites that held the majority of the land favored raising sheep, for the raw wool could be sold for finished imported goods. These economic realities meant that Spain lacked a great deal of manufacturing, and thus a middle class was slow to develop within the state. To add further difficulty to the Spanish economy and its translation of power resources was the fact that most of the nobility was exempt from taxation. These exemptions were a reality because the nobility was needed to ensure that the peasantry could be taxed. However, when attempting to find money to support a growing army and navy such an impoverished tax base was not large enough to meet the demands of the government. (Gilbert et al. 195-196) These economic problems meant that Spain would be forced to mortgage much of its interests in the discoveries of the Americas for cash in hand.

The second source of funding came from the Americas. As the chart bellow illustrates the Americas were a great source of funds for a hegemonic Spain. However, these vast riches do not illustrate on face the amount of wealth that was to be added to the royal coffers for the support of the monarchy and to be utilized in the policies of the Spain. The key portion of the wealth from the Americas is the percentage of the wealth that went to the royal house. In every 
year the vast majority of the imports from the Americas found its way into private hands. One could consider that a portion of the private revenues could be recouped through taxation, this was not the case, as the majority of Spain's tax revenues came from the peasantry of Castile and not from the nobility and commercial classes. Moreover, a great deal of the royal revenues from the Americas had to be used to pay-off debts from past foreign policy actions and to provide credit for future loans.

Table 3-1: Spanish Imports of Wealth from the Americas

\begin{tabular}{|l|r|r|r|r|}
\hline \multicolumn{7}{|l|}{ Total imports of Wealth from Americas (in Ducats) } & \\
\hline Period & \multicolumn{1}{|c|}{ Royal } & \multicolumn{1}{c|}{ Private } & Total & \%Royal \\
\hline $1503-1505$ & 116660 & 328607 & 445267 & 26.20 \\
\hline $1506-1510$ & 256325 & 722859 & 979184 & 26.18 \\
\hline $1511-1515$ & 375882 & 1058782 & 1434664 & 26.20 \\
\hline $1516-1520$ & 312261 & 879575 & 1191836 & 26.20 \\
\hline $1521-1525$ & 42183 & 118821 & 161004 & 26.20 \\
\hline $1526-1530$ & 326485 & 919640 & 1246125 & 26.20 \\
\hline $1531-1535$ & 518833 & 1461445 & 1980278 & 26.20 \\
\hline $1536-1540$ & 1621062 & 3104408 & 4725470 & 34.30 \\
\hline $1541-1545$ & 909346 & 5035460 & 5944806 & 15.30 \\
\hline $1546-1550$ & 911206 & 4699247 & 5610453 & 16.24 \\
\hline $1551-1555$ & 4354208 & 7484429 & 11838637 & 36.78 \\
\hline $1556-1560$ & 1882195 & 7716604 & 9598799 & 19.61 \\
\hline $1561-1565$ & 2183440 & 11265603 & 13449043 & 16.23 \\
\hline $1566-1570$ & 4541692 & 12427767 & 16969459 & 26.76 \\
\hline $1571-1575$ & 3958393 & 10329538 & 14287931 & 27.70 \\
\hline $1576-1580$ & 7979614 & 12722715 & 20702329 & 38.54 \\
\hline $1581-1585$ & 9060725 & 26188810 & 35249535 & 25.70 \\
\hline $1586-1590$ & 9651855 & 18947302 & 28599157 & 33.75 \\
\hline $1591-1595$ & 12028018 & 30193817 & 42221835 & 28.49 \\
\hline $1596-1600$ & 13169182 & 28145019 & 41314201 & 31.88 \\
\hline $1601-1605$ & 7823863 & 21460131 & 29283994 & 26.72 \\
\hline $1606-1610$ & 10259615 & 27426634 & 37686249 & 27.22 \\
\hline $1611-1615$ & 8655506 & 20778239 & 29433745 & 29.41 \\
\hline $1616-1620$ & 5217346 & 30917606 & 36134952 & 14.44 \\
\hline $1621-1625$ & 5869387 & 26543427 & 32412814 & 18.11 \\
\hline $1626-1630$ & 5542561 & 24402871 & 29945432 & 18.51 \\
\hline $1631-1635$ & 5680589 & 14852435 & 20533024 & 27.67 \\
\hline $1636-1640$ & 5629564 & 13947959 & 19577523 & 28.76 \\
\hline $1641-1645$ & 5723394 & 10944169 & 16667563 & 34.34 \\
\hline
\end{tabular}




\begin{tabular}{|r|r|r|r|r|}
\hline $1646-1650$ & 1998135 & 12126521 & 14124656 & 14.15 \\
\hline $1651-1655$ & 2686654 & 6065867 & 8752521 & 30.70 \\
\hline $1656-1660$ & 727829 & 3305510 & 4033339 & 18.05 \\
\hline
\end{tabular}

(From Elliott 181)

The Spanish economy was largely run on credit, despite the vast amounts of money that was brought to the continent from the Americas. The decisions of Charles $\mathrm{V}$ that sought outsourcing for finances to tie the empire together became a means for Philip II to have money in hand, as opposed to money on the way from the Americas. This credit climate spread to the remainder of Spain, to the extent that shopping in the major urban centers was largely done in credit as opposed to coinage. This created economic interdependence for Spain, in that economic actions in the Italy and the German territories then had a large effect upon the day-today economic actions in Spain. While interdependence can be seen as a stabilizing effect in today's market place, it can be seen in a different light during this era. Spain was not privy to the institutionalization of such a market, rather it was developed on the fly and thus the economic swings of the day can be seen to have had a more drastic effect. Moreover, it meant that Spain's economic health was now not solely in its own care, but in the care of foreign powers that may not seek the expansion of Spain's power base. (Kamen 293-298) This can be seen in calls for increased vigilance and action in the periphery by economic interests, while political elements in Spain sought to solidify Spain's interests in continental Europe.

These economic realities were further impacted through the Spain's growing dependence on Italy. Spain gained a great deal both economically and militarily from Italy, and thus it was very important for Philip to maintain strong ties to the government of Italy. Spain gained greatly from the latent power of Italy. Italian banking houses were key resources that enabled Spain to gain cash in hand, and to ensure that debt was managed to a degree. Moreover, Italy was a key strategic area, as it afforded Spain increased access to Lombardy, Germany, and the Netherlands. 
Italy was also a strong source of manpower for both the Spanish army and navy. Italy was also of importance because of the location of Rome, and the Catholic Church's importance as a source of Spanish power. Philip took a number of steps to ensure that Italy was keep within the Spanish fold. First, Philip created a large diplomatic system to keep Italy dominated by Spain. This system was forged with a marriage alliance between noble families in Spain and corresponding families in Italy. Moreover, Spain was able to maintain its domination over Italy as a result of the vast trade routes that Spain maintained, as the Italian financial system was dependent on these routes. Thus, since Spain controlled access to these routes, it too had a degree of influence over the actions of Italy. (Parker 1998 81-82) This can be seen as a quasi public good, in that Spain was able to provide access, as a hegemon, to such a good but Spain could also restrict access or threaten to restrict Italian access if the times called for such a policy.

Philip also appointed powerful, Italian nobles to posts within his government, thus giving prestige and increased economic health to interests that needed to be placated. Moreover, the size of the Spanish military and its presence in Italy meant that many portions of the Italian military could then be disbanded. This would prove an economic windfall for Italy, as it no longer had to pay for its defense. This also meant that the Spanish military could absorb a portion of Italy's forces into its mercenary army. (Parker 1998 82-85)

However, Philip may not have realized the nature of the relationship between Spain and Italy. Philip II sought to dominate Italy, and yet what seems to have been created was more of an interdependent relationship. While Spain had the ability to influence the actions of Italy, so too did Italy. It was the power of the Italian banking interests that would seem to have the most influence over the actions of Spain. One must remember that Philip mortgaged a great deal of the discoveries from the Americas to these banking houses, as well as future discoveries. 
Philip's government was dependent upon financial backing from Italy, and thus with dependence comes influence. It would then be in the banking houses best interests to push Spain to increase its actions in the periphery, as it was the Americas that were key to economic gains for the houses, both in security for existing routes and the creation of new sources of American income.

However, it is this very kind of relationship that this work hoped to find. This interdependent relationship meant peace between two neighboring states and influence for a lesser power over the actions of a hegemonic state. It seems that the relationship between these two states may have been more even handed than would typically be desired. Or, that Spain was unprepared to deal with the consequences and intricacies of such a relationship.

The 1560s saw Spain take in one million ducats of silver from the Americas, and by late in the reign of Philip II those revenues rose to two million ducats. However, this windfall of silver was not sufficient to finally balance the books of the Spanish Empire. With these new revenues Philip used them to guarantee increased loan amounts from the banking houses. This kind of fiscal policy saw the debt of the crown reach twenty million ducats by 1560 , fifty million ducats by the 1570 s, and eighty million ducats by the 1580 s. It was the constant need for military expenditures and the need to service existing debt that caused this economic problem. Furthermore, increases in revenues from the Americas almost certainly meant increases in the military planning. (Kaiser 33-34) While the monarchy of Philip II ran on a money in hand policy it seems that the money never lasted long enough to be efficiently used to stabilize the position of Spain in the international system.

Increases in silver extraction from the Americas in the late 1570s meant that Philip was able to take on a more aggressive foreign policy. These new discoveries and the use of mercury to refine silver corresponds with Philip II's plans for the invasion of England, attempted recovery 
of the northern Netherlands, and Spain's intervention in the France. Philip showed no concern with the worsening Spanish economy, rather deciding to use these funds in attempt to expand the reaches of the empire with ignoring the fact that the increased importation of silver could be used to place Spain on a better economic footing. (Elliott 265-266)

By 1590 it was realized that tax revenues of Castile were not sufficient to maintain Spain's economic strength. Less than one-third of Spain's revenues came from the Americas and the remainder of the financial resources were drawn from Castile or from loans from the banking industry. However, by this time the great exploits of Spain had already been undertaken and all that remained was the substantial mortgages from past actions. (Elliott 281-283)

Castile was one of the primary engines of the Spanish Empire, and yet was not immune to losing the desire to maintain Spain's power. Willingness to exercise power is defined as one of the key components of power. It is possible for a state to possess great power resources and still not have the will to utilize its power. The province of Castile was one of the driving forces behind Spain's hegemony. It was Castilian nationalism that pushed the Crown to attempt continued expansion in some instances, and Castile's latent economic power was what gave the region the ability to have such a voice in Spanish foreign policy. Castile's economic power arose not from its nobility, for they were largely exempt from taxation, but from its large peasant population that could be taxed for the Crown with the approval of the Castilian Cortes. The unwillingness of Castile to further endorse and underwrite Spanish military action came in 1592. It was in this year that the Castilian Cortes refused to allow increased taxation and flatly called for a reduction of foreign activity. (Kaiser 39)

The costs of attempting to maintain hegemony through a continued policy of conflicting relations with potential balancers fell on the population of Castile. This meant that the 
population of Castile, once one of the few tax rich areas of the empire was weakened to the point that Spain lost its large shares of its market to foreign goods, as large amounts of the peasants population was forced into subsistence farming. (Lobell 150-151) Spain's sustained military spending decreased spending on the domestic economy weaken the population to such a point that it was no longer able to field a military at the levels of the past (Lobell 162-163). Thus, overspending and an inability to cease aggressive actions meant that the costs of hegemony far exceeded the rewards.

The vast territories controlled by Spain and the prevalence of potential balancers meant that the state needed a large standing army, and thus finances were needed to ensure that such an army could be raised. Spain was blessed with the riches that could be imported from the Americas that wealth was neither constant nor continually present. Hence, there was the need for loans to create such large armies. Spain was both fortunate and cursed to have access to the largest banking house of Italy and Germany. However, to gain such large loans the monarchy was forced sign away both the revenues gained from the Americas and their administration. The problems of this military finance policy were two fold. First, such a policy enraged both the taxpayers and the nobility. The Spanish taxpayers were angered with the thought of the state mortgaging the riches of Spain for the profit of the banking houses, which were considered to be foreign in origin. The nobility was angered that the revenues from the Americas would not serve as monetary windfalls for their own houses. The second problem of this policy lay in the reality that such a policy opened the door of influence for the banking houses, for not only did they control the revenue streams and the administration of the endeavors, but the state's constant need for finances ensured that the banking houses would be in constant support of increased finds in the Americas and increased protection for their investment. Thus, the policy created a cycle of 
need for Spain, in that the state constantly needed additional loans and the banking houses needed new revenue sources. (Kaiser 20-21)

In times of economic difficulty Spain was forced to retrench from its foreign policy actions. This can be seen the numerous bankruptcies that the state endured, as a result of a lack of reinvestment and over-expenditures. The Bankruptcy of 1596 meant that Philip was faced with a great need to reduce the number of external commitments that Spain faced. This bankruptcy created a need for peace with Spain's challengers, for Spain was economically unable to continue to combat multiple challengers to its dominance. Thus, the ties between the Netherlands and Spain had to be loosened so that Spain could maintain some degree of international prestige. The control of the area was given to Albert and Isabella, who were tacitly controlled by Spain. However, this move began to place distance between the Netherlands and Spain. (Elliott 286)

\section{Military Power}

By 1580 Spain under Philip II took up position as the most dominant state in the world, as a result of its amount of power and resource potential. It was at this time that the Spanish empire gained the Crown of Portugal, and with that the Portugal's holdings in South America, Africa, and the East Indies. With this unification of Span and Portugal, Spanish power was then unchallenged based on control of trade routes, economic markets, and natural resources. This allowed Spain to become the continents leading holder of gold and silver, thus opening the financial doors for increased loans from the banking house of the era. The influx of precious metals into Spain and the added ability to secure loans on demand allowed the state to create a large standing army, as well as a sizeable navy capable of defense of both Spain's interests on the continent and overseas. As a hegemonic actor Spain was not without potential balancers. 
Other powers of the day included: England, France, the United Providences, and the Ottoman Empire, though the Ottoman Empire was only a challenger in the Mediterranean and Africa. (Lobell 123)

Spain's power inefficiencies were a result of underlying economic problems. First, a lack of governmental centralization meant that Spain was forced to use contractors to supply troops and ships, and thus Spain's military strength was not dependent upon the actions of the state but rather the actions of individuals and groups. Furthermore, these contractors can be seen as individuals attempting to profit from militarization, thus their council and military practices must be viewed in economic senses not as foreign policy and military decisions. This outsourcing of military decisions meant that Spaniards composed an estimated one-tenth of the Spanish military, in both the troops and the officer corps. Second, while the empire was large in size Castile was the sole territory from which tax revenue could be easily obtained, as the other territories and colonies were ruled by local interests. Thus, this localization of rule meant that the power of Castile was used to protect the territorial integrity and project the force for the entirety of the Spanish Empire. Third, Spain lacked a centralized banking system to deal with its finances and debt, hence economic interests were spread out throughout the banks of Empire. Fourth, the vast expanses of the empire far outstretched the means by which to fund their defenses. There was simply too much territory to defend and too many balancers to keep in check without a system of international regimes to ensure that balancers were kept a bay by other means. Moreover, information was slow to make its way to the seat of government, as a result of the lack of infrastructure in the era. Spain also lacked leadership in the lesser nobility, hence those officials that were placed in positions of importance throughout the empire could not be counted on to provide adequate council or decisive decision making. This is a result of both the 
system of patronage and lack of cohesion in the bureaucratic ranks. (Kamen 157-165) Spain was also dependent on the importation of military hardware, as the infrastructure and resources needed for the production of artillery, armor, gunpowder, and cannonballs was lacking in the state (Kamen 168). This meant the virtually none of the resources that the state expended for its military were returned to the population, thus Spain represented a the ultimate illustration of a guns-verses-butter tradeoff, as money spent for military matters whether it be spent on troops or supplies rarely returned to the domestic economy.

Italy and its population were essential to Spain's power. Italy not only provided financial services from its banking houses, but military support as well. The Italian population was used as a fertile source of infantry, as the population of Spain, proper, was not sufficiently large to provide even a minority of its needed troops. Italy was also key in that it provided military supplies that were produced within Italy. Spain's economy never fully adjusted to one of traditional hegemonic power, as the elites of the day wished to keep the Spanish economy centered on the wool trade. Additionally, Italy's nautical prowess was harnessed for the building of ships, which was not a traditional industry in Spain. (Kamen 381)

Spain was unique as a hegemonic state in that it did not possess overwhelming power on its own level of resources, but rather Spain created its power based on the resources of others. Spain was dependent upon other territories and other states for its military forces, as well as for its military hardware. Thus, Spain was able to rent a great deal of its military might. Moreover, while Spain was lucky to have been in the lead in discovery it mortgaged its new found resources. Thus, Spain became dependent upon the backing of the banking houses of the Italy and the German territories. (Kamen 488-489) 
Population exists a primary indicator of potential military power. ${ }^{3}$ However, Spain was unique in these terms as its power was not based largely on its population size. This also further highlights the importance of Spain's relationship to Italy and the Germanic territories, as these areas could be used as grounds to obtain increased numbers for the purposes of the military. The following chart illustrates the population breakdown of Spain at the end of the sixteenth century.

Table 3-2: Spanish Population

\begin{tabular}{|c|c|c|c|c|c|}
\hline \multicolumn{5}{|c|}{ Spain's Population (at the End of the 16th Century) } & \multirow[b]{2}{*}{$\mathrm{km}$} \\
\hline & Sq. km & $\%$ of land & Pop & $\%$ Pop & \\
\hline Castile & 378000 & 65.2 & 8304000 & 73.2 & 22 \\
\hline Aragon & 100000 & 17.2 & 1358000 & 12 & 13.6 \\
\hline Portugal & 90000 & 15.5 & 1500000 & 13.2 & 16.7 \\
\hline Navarre & 12000 & 2.1 & 185000 & 1.6 & 15.4 \\
\hline total & 580000 & & 11347000 & & \\
\hline & & & & & Elliott 25 \\
\hline
\end{tabular}

Castile, which was the dominant province in the Spain, was not a major population center in comparison to other leading territories in Europe. However, between 1530 and the 1580s Castile saw its population rise by 50 percent, and with this dramatic increase in population the economic production of Spain's largest European territory rose as well. These increases in population and production were the result of increases in wealth harvested from the Americas and from successes in the wool industry. (Kamen 154) The increases in both population and economic power levels corresponds with the rule of Philip II, however how well these increases in latent power can be translated to realized power will remain to be seen.

By 1584, Spain had reached the pinnacle of its military might. The state had 119,000 infantry at its disposal, and had the resources to raise that number to 200,000 if there was a need. The additional 81,000 troops could be raised from the empire in mercenary fashion. Spain also had some 28,000 cavalry troops. In addition to those land based troops the Spanish navy was 82

\footnotetext{
${ }^{3}$ See Chapter One for traditional measures of power, such as land mass, resources, and population.
} 
vessels strong in the Mediterranean and the Atlantic, with potential to increase those numbers through the use of merchant ships if the need arose. (Kamen 305) A comparison of increases in Spanish military power as compared to the other great powers of the era can be seen in the following graphic.

Table 3-3: European Increases in Military Manpower

\begin{tabular}{|l|r|l|r|r|r|l|}
\hline \multicolumn{2}{|l|}{ Increases in Military Manpower } & & & & \\
\hline Date & Spain & United P & France & England & Sweden & \\
\hline $1470 \mathrm{~s}$ & 20000 & & 40000 & 25000 & & \\
\hline $1550 \mathrm{~s}$ & 150000 & & 50000 & 20000 & & \\
\hline $1590 \mathrm{~s}$ & 20000 & 20000 & 80000 & 30000 & 15000 & \\
\hline $1630 \mathrm{~s}$ & 300000 & 50000 & 150000 & & 45000 & \\
\hline $1650 \mathrm{~s}$ & 100000 & & 100000 & 70000 & 70000 & \\
\hline & & & & & \multicolumn{3}{l|}{ From Kennedy Page 86 } \\
\hline
\end{tabular}

The graphic illustrates that Spain was able to keep abreast of its potential challengers, though the numbers indicate that the state may not have what can be termed a preponderance of military power. Spain would not seem too capable of countering a number of challengers at one time. A more thorough breakdown of the positioning of troops during the time of Spain's attempted armada invasion of England has the ability to shed more descriptive light upon the question at hand.

Table 3-4: Troop Levels 1587 to 1588

\begin{tabular}{|l|l|}
\hline \multirow{5}{*}{ Spain } & $\begin{array}{l}\text { Spain, North Africa, Portugal Troops } \\
\text { On the Armada: 19,000 } \\
\text { In Garrisons: 29,000 }\end{array}$ \\
\cline { 2 - 2 } & $\begin{array}{l}\text { Netherlands Troops } \\
\text { Invasion Force: 27,000 } \\
\text { In Garrisons: 40,000 }\end{array}$ \\
\cline { 2 - 2 } & $\begin{array}{l}\text { Overseas Troops } \\
\text { Asia: 5,000 } \\
\text { Americas: 8,000 }\end{array}$ \\
\cline { 2 - 2 } & Fleet \\
& Armada: 211 Ships; 194 Barges \\
& Mediterranean: 27 \\
\hline
\end{tabular}




\begin{tabular}{|l|l|}
\hline \multirow{2}{*}{ England } & $\begin{array}{l}\text { Troops: 45,000 } \\
\text { Troops with Royal Navy: 15,000 } \\
\text { In Dutch Republic: } 6,000 \\
\text { Fleet: 197 Ships }\end{array}$ \\
\hline Dutch Republic & $\begin{array}{l}\text { Troops: 17,500 } \\
\text { Fleet: 67 Ships }\end{array}$ \\
\hline & \\
\hline
\end{tabular}

These numbers illustrate that the troops positioned for an invasion of England were out numbered by the defending English troops and the troops of the Dutch Republic. The numbers also indicate that Spain outnumbered the English and the Dutch in terms of surface ships available for the invasion, however these numbers are artificially inflated as a result of the high number of barges used by Spain as troop transports rather than actual warships.

The numbers do not paint an accurate picture of the actual invasion force. A brief comparison of the English and Spanish fleets will provide a clearer picture, to better explain the ultimate failure of the Spanish Armada. While Spain enjoyed a slight advantage in the size of its fleet England held advantages in other areas. England's navy was commanded by a professional officer class, where as the majority of Spanish vessels were commanded by lesser nobility or hired mercenaries. England also held the advantage in guns per ship and the amount of cannon fire that each gun could maintain for a prolonged period of time. The English cannons were simply better forged. Moreover, England had the advantage of sailing in its own waters, and thus was more accustomed to the environment. Additionally, Spain was at a great disadvantage in ship construction, in that only the recently acquired Portuguese vessels were expressly created for battle, as opposed to being converted merchant galleys. Moreover, the Spanish fleet was really divided into three different nautical families, each with a distinct sailing purpose, and until the formation of the Armada they had not worked in unison, nor had their crews. Spain was also 
hampered by a lack of communication between the armada and Parma's troops on route from Flanders. (Parker 1998 253-258)

Spain's naval power was also distinct in that a large portion of its vessels were not created for military purposes, but private ships and that were called into service by the government. Often the Spanish government was unable to gain the funds necessary to build a modern navy with the ability to match those of the Dutch and the English. The government was forced to back private ships and their crews, hence licensing privateers in the hope of creating a navy sufficient to check aggressors. (Kamen 418)

The military might of the Spanish Empire was further limited in that the state was limited in its lack of well trained domestic military officers. Spain lacked trained officers to command the Spanish military. This problem is heightened when one considers the shear size of Spain's army. (Kamen 391) This is likely the result of a lack of mobilization in Castile. While it was Castilian nationalism that drove portions of Spain's foreign policy the nobility from which the officer corps would have been drawn lacked the drive to take such action. It seems that the nobility were in full support of the creation of a Spanish empire as long as others could be hired to do the majority of the fighting. (Kamen 490)

\section{Sources of Decline}

The problems of the Spanish navy point to deeper problems for the military of Spain as a whole. Spain was forced to rely on a mercenaries and conscripts for its fighting forces, as the population of Spain proper was not sufficient to supply such numbers. The presence of such large amounts of purchased fighting forces meant that Spain had to ensure that its armies were regularly paid, and to be mindful that the loyalties of these forces were not to Spain but to money in general. Such a discrepancy in forces meant that Spain was essentially outsourcing its 
defense, and that if financial problems arose the mercenaries could easily search for other employers.

Additionally, Kennedy illustrated that Spain was so vast, as territory was concerned, that it became difficult to find enough forces to defend the entire empire. Moreover, Spain was also unable to prevent balancing actions by its rivals. This meant that no matter how many forces Spain had at its disposal it would be forced to utilize them against numerous foes in concert. (Kennedy 46-50)

As Spain moved closer to its ultimate decline as a hegemonic state more and more resources were spent in the defense of the periphery as opposed to the utilization of those resources in a manner befitting a hegemonic state in defense of its hold on power. A vast amount of scarce resources was used to increases Spanish defenses in South America, as the Dutch had held a portion of Brazil since 1630. The diversion of resources to the periphery is further highlighted in October of 1639 when a convoy of ships carrying troops and supplies to the Netherlands was destroyed by the Dutch. Revolts in Catalonia and the Kingdom of Portugal finally drew Philip IV's attention back to the core of Spain's holdings. However, at this time chaos had ensued throughout Spain's holdings, as the government of Philip IV was forced to become a firefighter battling blazes with insufficient supplies and resources. (Parker 1997, 153154)

This need to defend the yard at the expense of the house could be linked to the domestic political considerations of Spain. As has been shown earlier Spanish nationalism grew from Castile, and their need to see a lasting historical impact for Castilian culture. Furthermore, the need to hold onto imperial lands can be traced to the banking interests from whom so much of Spain's future income was mortgaged. 
The decline of Spanish was power was not immediate or total, rather Spain could still effectively deal with a single balancer. However, Spain now faced balancing from a seemingly united front, that being France, England, and the United Provinces, which Spain was now ill equipped to deal with such challengers. It is at this point that Spain ceases to meet the criteria of a hegemonic actor, as its preponderance of power was not lost. (Lobell 130-134)

The sources of Spain's decline can also be traced to the strategic overstretch of the state's resources, as it was active not only in Europe, but in the Mediterranean and the Americas.

\section{Table 3-5: The Costs of Spanish Conflict}

\begin{tabular}{|r|r|r|r|}
\hline \multicolumn{4}{|c|}{ Costs of War on Two Fronts (Money From Castile in Ducats) } \\
\hline Year & Mediterranean Fleet & Army of Flanders & Yearly Totals \\
\hline 1571 & 793000 & 119000 & 912000 \\
\hline 1572 & 1463000 & 1776000 & 3239000 \\
\hline 1573 & 1102000 & 1813000 & 2915000 \\
\hline 1574 & 1252000 & 3737000 & 4989000 \\
\hline 1575 & 711000 & 2518000 & 3229000 \\
\hline 1576 & 1069000 & 872000 & 1941000 \\
\hline 1577 & 673000 & 857000 & 1530000 \\
\hline Total & 7063000 & 11692000 & 18755000 \\
\hline & & & From Parker 135 \\
\hline
\end{tabular}

"Philip's dominions spanned all twenty-four of the world's time-zones, making them, 'the greatest empire known since the creation of the world"' (Parker 1998 3). Despite the problems of Spain, Philip II came very close to achieving all of his objectives despite the state's numerous problems and inefficiencies. The success of Spain, in the face of such economic and governmental weaknesses is a testament to the vast amount of power that Spain possessed during its time as a hegemonic actor. The state's dominance can also be traced in large part to what can only be called luck. Spain was fortunate to witness turmoil in France. The French possessed a far more balanced economic system than did the Spanish, and French Culture was far more pervasive than that of Spain's, however France was far harder hit by religious turmoil than 
Spain. These religious uprising caused Henry II to sue for peace with Spain, thus forcing France to give up its aims in Italy. (Gilbert et al 201-203) The 1559 Peace of Cateau-Cambresis illustrates the degree of luck that was apparent in Spanish hegemony. As, a number one challenger was unable to maintain is position as a result of domestic problems on the home front. This was certainly a fortunate chain of events for Spain, as it effectively limited the balancing capabilities of France during Spain's period of heightened power.

\section{The Impact of Spain's Hegemonic Power}

Spanish hegemony is bizarre to say the least. The state of Spain was blessed with the discovery of its colonial wealth. Spain possessed vast amounts of latent economic power which it could have utilized to make up for its lack of a population base and a lack of true military might. However, the state was unable to truly capitalize on its riches. Some could argue that Spain was able to parlay its economic prowess into a considerable duration of hegemony, but these scholars ignore what could have been for Spain. Spain was cursed with a lack of population size and a lack of industrialization for its time period. It was able to compensate for these shortcomings through the use of other population centers throughout Europe for scores of mercenaries and used trade to bolster its lack of production. Still the state could have done much more with its power resources had it stayed clear of years of conflict and not decided to borrow so heavily on the promises of increased riches from the Americas. Spain instead chose to seek more cash-on-hand rather than settling for timely importations of wealth from its colonial holdings. This meant that Spain's time as a hegemonic actor was cut short through poor use of its latent power. 


\section{The Dependent Variable - The Balancing of Spain}

Spain's position as a hegemonic state was seemingly under constant challenge by the other great powers of the era. As was expected Spain was unable to prevent other states from taking action to check the asymmetrical power of this period. The Spanish rulers appear to have lacked the foresight to realize that Spain could have been better served with a more conservative foreign policy during most of its time as a hegemonic actor, as Spain constantly sought expansion, and appears to have come to the conclusion that a hegemonic state that was not constantly attempting to increase its power and holdings was one in decline. Spain was largely unaware on the power stakes involved in the majority of its foreign policy decisions, and thus continually triggered balancing by the other great powers of the time period.

The actions of Philip II can be seen as demonstrative of the foreign policy mindset of Imperial Spain. Philip II's economic problems were compounded by the number of military operations that his government undertook during his forty-two year rule. 1577 was the only year in which Philip's Spain enjoyed even six months of total peace. Philip faced war on at least two fronts during most of his rule: the Turks and Dutch (1572-1577); the English and Dutch (15851589); and the English, Dutch, and the French (1589-1598). (Parker 1998 87) However, while the actions of Philip II are telling, in that Philip sought constant expansion and only made moves to counter balancing in times of economic difficulty, Spain's problems with external balancers did not begin with Philip.

Rather, these troubles began much earlier, with the inheritance of Charles $\mathrm{V}$ which immediately alarmed France, as his possessions seemed to surround France. While Charles claimed to be in search of a lasting peace, the national interests of France quickly became antiSpanish. Additionally, Charles V's holdings also alarmed the German princes and the Catholic 
Church as well, for the Habsburg Empire was so vast that it was feared that such an imbalance of power would create a system in which the Empire had the capability to dominate all of Europe. (Kennedy 33-40) While the accumulation of power through inheritance can be argued to have been outside of the realm of Spanish foreign policy, as it can be argued that few leaders during this period would turn down such a birth-right, however measures could have been taken to lessen the glare of the French. While Charles V did make statements that attempted to lessen the security dilemma of France, he did not take the next step that being a binding treaty that could provide an alarmed France with more assurances.

It may be too much to ask for Spain under Charles V, with its vast holdings, to appear less threatening and adapt its foreign policy to one of a constrained hegemonic actor. This is the case because the power of Spain was increased quickly through an act of inheritance. This would be the modern equivalence of the present day United States being deeded Canada and the United Kingdom. Such a rapid rise in an already powerful state would certainly trigger security dilemmas throughout the globe, and thus in the 1500 s such dilemmas can certainly be expected in Europe. However, the rule of Philip II can be held to a higher standard, as this was a reduction in holdings for Philip from those of his father, Charles V.

Philip II was perpetually attempting to prevent balancing action by the other states in the international system. The monarch tried to assure the other leaders of the day the Spain had no desire to rule Europe. Philip stated, "I have no intention of breaking the general peace, which is the thing I myself wish to preserve, and I have urged all my ministers. But if ill-intentioned people should think of taking advantage of the troubles [in the Netherlands] in order to attack my estates and disturb the peace they will be restrained when they see that I am ready" (Parker 19985-6). This illustrates Philip's commitment to preserving the current asymmetry of power, 
while warning the other powers in the system that he was willing to use his hegemonic power if threatened. Thus, he invoked a claim that all of his actions would be camped in self-defense of Spain, rather than in the hope of imperialistic gains. However, these statements would not be enough to reassure the remaining powers in Europe of Philip's intention to maintain the status quo. Moreover, the statements leave open for interpretation what Philip can define as a threat against Spain, there is no codification or agreement as to how this period of power asymmetry is to be navigated. Additionally, the statements of Philip II must be seen in conjunction with his actions in the Americas and the Netherlands, as Spain sought increased expansion in those areas and acted to create trade monopolies that would not allow other European actors to make similar advancements.

By the 1560's England had realized that there was much to gain from the Americas, and that Spain could not be left alone to make such gains for herself. Thus, Elizabethan England came to openly challenge the hegemony of Spain. Elizabeth was able to utilize the growing religious distinctions between the two states to feed the fires of the conflict, and thus began a dual policy of financial support for the Dutch rebels against Spain's northern interests while beginning to raid Spanish shipping in the Americas. (Gilbert et al 221-222)

Elizabeth's policy toward Spain should be viewed as a means of balancing, for it seems that it was her intent to distract Spain with her actions in the north while moving to gain a foothold in the Americas. Thus, her policy was to initially ensure that Spain could gain no more of a power asymmetry from the riches of the Americas, while England continued to increase its power stakes. One need only remember that Spain made a choice to monopolize its interests in the Americas rather than to use the trade with the Americas as a public good. Moreover, Spain constantly used its resources to engage in power expansion activities. 
In 1570 England increased its modest attempts to balance the power of Spain. This was done through harassment strikes against Spanish shipping by Francis Drakes' forces in the Americas. At this pointing time England was unable to directly challenge Spain, however this policy of harassment decreased the amount of goods that could be shipped back to Spain, while diverting the attention of Spain towards the Americas. (Kamen 260-261)

Elizabeth I also attempted to use the Turks as a balancing partner against Spain, in that she hoped that she could bait the Turks into renewed conflict with Spain in the hopes of weakening Spanish power. England sought an understanding with the Sultan, thus it repatriated a hundred galley slaves Drake had freed during some of his raids in the West Indies. England was unable to persuade the Turks to begin a new war with Spain, though it was able to persuade them not to renew their truce with Spain. (Parker 1998 192) England was in search of any partners it could find to aid it in the balancing of Spanish power. While the harassment of Spanish commerce began earlier these new rounds of negotiations with the Dutch and the Turks did not begin until Spain's plans to invade England had essentially become public. Thus, this move towards the creation of more formalized balancing alliances by England was the result of the increased threats by Spain, in the form of a realization of Spanish plans to invade England.

In 1586, Drake called on the Dutch elites to provide cash and credit to aid in the maintenance of twenty-five warships to be used to further challenge Spain's power. This represents the formation of an alliance between interests in the Netherlands and England in the hope of balancing the power of Spain. England was a rising naval power, while the Dutch were a growing commercial power. This made the two states optimal allies with a mutual need to decrease the power asymmetry of Spain. (Parker 1998 193) 
Philip II's response to the attacks by Drake on Spanish shipping and colonies in the periphery was to increase hostilities with England in the core, by attempting to bring the conflict to England itself. This can be seen as an overreaction by Spain. The initial English balancing was more of a harassment than on the order of traditional balancing. Essentially, England's opening strategy was a balancing action taken by the most inexpensive route, for England only placed Drake's forces at risk and kept the balancing restricted to naval activities. Spain could have moved to counter this action in the periphery with acts against England in the same theatre, and by engaging a balancer in the core they increased their potential losses and increased the likelihood that England would begin a policy of balancing in Europe. (Parker 1998 177) Thus, the dual threat that Spain posed to both the Dutch and the English crystallized in the creation of an alliance between the two states. This threat was realized with the Spanish Armada attack of 1588 , and with that preemptive attack by Spain the alliance was not only utilized but justified in its creation.

Moreover, while Philip II prepared to attack England he also sought to ensure that France would be forced to stay outside of the fray. In 1588 Spain began to search for ways to counterbalance the actions of England, and for this aim Philip looked to an unlikely source, the French. Philip sought a rebellion from the French Catholic League to ensure that France did not become involved in the defense of England or the Netherlands. Philip's diplomats were able to pay 100,000 ducats to the Catholic League to persuade them to revolt at a given time, which corresponded with the armada's attack. (Parker 1998 199)

The failure of the Spanish Armada was followed by a further failing of Spanish foreign policy. The 1590's saw Philip II attempt to dethrone Henry of Navarre, thus triggering a formal balancing alliance. This act that violated the peace with France, and thus caused England, 
France, and the Dutch to join forces in against Spain. The three balancers were able to combat the forces of Philip II on both land and sea. They were able to create a draw between the army of Philip the II and to destroy the remains of his naval forces. Moreover, the aggression of Spain increased the nationalism of the French population thus taming the religious discontent in the country and in effect reuniting France against a common foe. The conflict between the four powers essentially ended without any real gains for either side. However, it must be viewed as win for France and a dramatic loss for Spain, as the vast resources of the Spanish Empire were unable to defeat its three challengers in unison. Spain was no longer hegemonic and was now officially in decline. (Gilbert et al 223-226)

\section{The Impact of Balancing on Spain}

As a hegemonic state Spain took virtually no action to prevent its balancing by the other great powers of the era. The state did not seek to create alliances that would prevent other actors from joining in encircling alliances. Spain only sought to limit potential balancers in times of economic decline, rather than attempting to make balancing inefficient for the other actors in the system. Moreover, the Spanish Empire used military action in the case of England and the Netherlands in a fool-hardy effort to prevent the formation of alliance between the two states. It seems that Spain sought absolute hegemony or nothing at all instead of seeking to limit its aspirations. This was to be expected from the case, as the knowledge of the difficulty of dealing with such alliances was virtually nonexistent. Thus, the case of Spain serves as a telling illustration of what can happen to even the most blessed state if such alliances are not halted and hegemonic dreams are not curbed. 


\section{Answering the Questions}

The Systemic Level (Dependent Variable)

- Who are the primary actors in the international system, and what justifies such a classification?

Table 3-6: The Great Powers in the Time of Philip II

\begin{tabular}{|c|c|}
\hline State & Great Power Justification \\
\hline Spain & $\begin{array}{l}\text { Dominant Power } \\
\text { Economic Wealth } \\
\text { Imperial Holdings } \\
\text { Military Strength }\end{array}$ \\
\hline England & $\begin{array}{l}\text { Potential Balancing Partner } \\
\text { Challenger in the Americas } \\
\text { Naval Power }\end{array}$ \\
\hline Netherlands & $\begin{array}{l}\text { Potential Balancing Partner } \\
\text { Source of Distraction } \\
\text { Rising Economic Power }\end{array}$ \\
\hline France & Potential Balancing Partner \\
\hline Ottoman Empire & $\begin{array}{l}\text { Challenger in the Mediterranean } \\
\text { Potential Balancing Partner }\end{array}$ \\
\hline
\end{tabular}

- What actually triggers alliance formation in a given historical situation?

Spain as a dominant state in Europe was under almost constant threats of balancing and actual balancing warfare. In fact the government of Philip II only saw six months of absolute peace during the King's entire reign. The constant balancing that Spain faced was a result of Spain's imperial policies not only in on the continent but in the Americas as well. While Philip openly stated that his government sought to maintain the balance of power within Europe and only sought to take military action when the interests of Spain were threatened, the actions of Spain suggest otherwise. Philip not only sought to maintain Spain's dominance in the Low Countries, but it also sought to undermine the government of France and eventually to topple the government of England. These continental policies do not represent the policies of state content 
with the status quo, rather they depict a state with a desire to expand its holdings within Europe and drastically redraw the power relationships of the international system. In addition, Spain also sought an imperialist foreign policy in the Americas, as it attempted to create a monopoly in the Western Hemisphere for its commercial interests and those interests allied with it. This appears to have been the largest trigger of initial balancing by the English.

The 1560 s can be seen as a watershed decade for the balancing policies of England, as this time period sees a dramatic increase in English balancing of Spain in the Americas. Their policies began in what can be seen as a form of indirect balancing through the harassment of Spanish shipping and ports, though over time their policies became more brazen. Elizabeth appears to have realized that if Spain were to continue to maintain a monopoly in the Americas its position on the continent could eventually become unchallengeable. The balancing policies of England were only increased as the government of Philip II sought to end such indirect balancing in the periphery and perceived English support of the Dutch through an invasion attempt of England. Thus, Spain sought to meet the periphery challenge of England with action in the core, rather than meeting the threat in theatre of operation.

- Is balancing or bandwagoning seen in alliance formations?

Little bandwagoning is seen in the historical record, as Spain appeared to be too threatening as a potential ally to attract bandwagoners. Italy could be considered by some to be bandwagoners, however the area had little choice in that Spain had placed large amounts of troops within the region to ensure stability. Additionally, the dependency that Spain had on the Italian banking houses and the influence of the Catholic Church took the relationship away from a bandwagoning framework. 
Large amounts of balancing can be seen by the other great powers of the day in an attempt to check the power and policies of Spain. England must be seen as primary balancers, as Elizabeth took numerous steps to attempt to challenge the dominance of Spain. First, England pursued a policy of irritation and distraction in the Americas which was led by the naval power under the command of Drake. This can be seen as a policy to increases Spain's use of power in the Americas, thereby distracting it from the continent and increasing England's wealth through interdiction and capture of Spanish assets. Secondly, England moved at one time or another to seeking balancing alliances with the Dutch, the French, and the Turks as the state sought to counter the rising power of Spain and its expansionist foreign policy. England appears to have been the instigator of the majority of the balancing of Spain, as the other powers were either still growing in power or distracted by internal challenges.

The dominance of Spain coincided with internal difficulties for its geographically closest rival, that being France. This can only lead one to surmise that a great deal of luck existed in Spain's rise to power, as a traditionally strong France would have been very determined to ensure that such a power did not grow on its southern boarders. France was distracted at many times by the growing forces of the Reformation, which impacted the state at high levels. This decreased the power of France from what could have been a potential challenger to a balancing ally for anther state that had the power and political willingness to take on the increasing dominance of Spain.

The Ottoman Empire existed as purely a regional power during the height of Spanish power, and thus could only challenge and distract Spain in the Mediterranean Sea. This was of interest to Aragon and to Italy as they were more concerned with commercial interest in the Mediterranean that was interrupted by the Turks. England did attempt to form a balancing 
alliance with the Empire, yet it seems that cultural differences may have limited the role that European would allow the Ottomans to play.

The Dutch existed as a very dependable balancing partner for the English, as it was in the Netherlands that Spain sought to expand its continental power. However, the Netherlands can be seen as more of a commercial and economic power, rather than a military power which limited the role that they could play in any alliance. Yet, they could ensure that Spain was forced to expend valuable resources in through rebellions and irritation of the dominant state. Thus, it seems that Spanish power was challenged both in the periphery by England and in the core by the Dutch which allowed for the exposure of Spain's economic and military inefficiencies.

- Are cases of stability the result of a perception of non-threat by the larger pole? Is this stability the result of binding by the preponderant power in the system?

Binding and restraint are not policies that were implemented by the Spanish until the waning days of the Empire. Spain was also seen in a threatening light for the majority of its time of dominance, whether because of its holdings in the North; its merger with Portugal; or its attempt to monopolize its control over the new discoveries of the Americans. Spain did not seek any international agreements on its level of power, nor did it attempt to create norms that would regulate the behavior of states in the system. It sought only the extension of its power and the creation of Empire, based on its increase in nationalism. The case of Spain exists as a representation of a dominant state that did little to assure the other members of the system of their security or position. Thus, the case can be said to exist as the perfect comparison case that illustrates what can happen to a hegemonic state that attempts to function without restraint or constraint. 


\section{The State Level}

- What is the institutional make-up of the state in question?

At a first glance Spain appears to have been a mere monarchy, though this does not uncover the actual depth of the institutional make-up of the Spanish government. Sitting at the top of any organizational chart of the Spanish government during the time in question was the monarch, however one cannot assume that it was the monarch who made all or even a majority of the decisions for the state. Additionally, by viewing Spain's government as solely a monarchy undercuts the levels of influence and decision making that took place outside of the throne.

The first clue to the actual make-up of the Spain's government is the high degree of decentralization that was present in the system. The level of decentralization has its roots in two problems that faced Spain. First, there was the immense size of the Spanish Empire, which created governance problems as a result of problem of distance. This meant that even during the era of Philip II, a ruler who sought increased centralization of decision making as apposed to that of his father, Charles V, had to realize that not all decisions could be funneled through the throne. The second problem for Spanish government arose from the federalized system that was institutionalized through the union of the distinct houses of Spain. The importance and size of Castile afforded the province a great deal of self-control. However, this relationship is made all the more interesting when one sees that Castile was the only house that could really be counted on for tax revenue, as the system of government allowed the other territories to ignore any tax liabilities. At the same time Castile's position as the sole responsible house gave it added power and empowered the Castilian Cortes, which was a council of Castilian elites that was charged with the ratification of tax increases and other regional issues. 
The importance of the Castilian Cortes is further highlighted by Philip II's creation of numerous councils throughout his rule. These councils were created to provide both a measure of gate-keeping for the reclusive monarch and to provide council to a king who appears to have constantly doubted his own decisions as he sought to compare himself to his father. The councils were created along issue areas, such as: war, finance, and trade. The councils were comprised of government officials and other elites. There primary roles were three-fold. First, they were charged with a gate-keeping capacity, as they were the first to interact with individuals who sought a meeting with Philip, and thus with this responsibility they had the power to exclude certain opinions or facts from Philip's decision making process. Their second role of the councils was to refer important issues to the king and to advise the monarchy. This afforded the councils enormous power as they had the ability to influence a great deal of the agenda of the government and to advise an overwhelmed monarch on issues in their arena of interest and knowledge. Finally, the councils were charged with the summarization of royal correspondence, which created yet another avenue for influence over the decision making process as such powers allowed members to highlight certain aspects of correspondence and downplay or omit other passages.

The influence of the Cortes and councils over the decisions of the monarch is further called into question when one considers the vast system of patronage that existed in Spain during its height of power. The elites and council members were not merely acting in their own interests, but also there was the possibility that in some instances they were acting under the direction and influence of more powerful elites. One such instance can be illustrated by the political influence held by the powerful Eboli and Alba families. 
Additionally, the importance of the council system during the rule of Philip II is further seen through the monarch's inability to comprehend matters of financial importance or to sort through disagreements between council members or distinct councils. Thus, the councils could be both a source of influence, as Philip was dependent upon their guidance in certain issue areas, and a source of governmental paralysis through disagreement. The structure of the Spanish government illustrates the various avenues of access present for interest groups and elites to seek influence over the policies of Spain.

- Is the dominant state democratic in nature? And, are other system members also democratic?

Obviously, this is not an applicable question to the case in question, as Spain during its time as a dominant state was not democratic in nature, nor were any other states during the time in question functioning democracies.

- Does the state in question have a means for mass public opinion to influence state action?

The historical record reveals little in the way of avenues for public opinion influence over the policies of state. There are two points of potential interest in the arena of public opinion. First, there is the threat of revolution and civil unrest that faced the government of Philip II. This is a phenomenon that represents the basic beliefs of the masses, and also allows for a means of public influence over state policy action. The fear of open revolt or mass uprising can be seen as a source of governmental influence. This fear was particularly important when one considers the primacy of the region of Castile, as this region was the primary source of tax revenues for the state. However, the historical record shows few instances of revolt during this time period, nevertheless the possible revolts and their subsequent interruption of tax revenues cannot be discounted as possible sources of influence. The historical sources reveal little in the way of illustrations of public sentiment or opinions that could be connected with times of unrest other 
than the individual pressures of taxation and questions about the legitimacy of Philip II as a Spanish ruler. It also must be remembered that these tensions could typically be put down and covered through the use of passive legitimacy, as the state possessed the might to put down most uprisings and limit their spread throughout the entirety of Spain.

The final consideration that must be taken into account during the time of a dominant Spain is the importance of the Reformation as a social and religious issue. While Spain during this time existed as a largely Catholic state the pressures of the Reformation may have instilled in the population a belief that Spain, as a dominant Catholic power, should have been a champion of Catholicism in the world. This possibly illustrates yet another link to policies that were proCatholic in nature and thus more confrontational with territories that were more Protestant, such as the Netherlands and certain German territories. The economic ties present between Italy and Spain must also be considered, as Italy is the home to the Rome and the Pope. The importance of Spain's relationship to Italy can be highlighted by the fact that Italy was not only a source of military personnel for Spain but also a source of a great deal of financing for the foreign policies of Spain as a result of the presence of large banking houses within Italy. These considerations do not present clear causal ties to the importance of public opinion, but represent potential sources of influence that may have lie under the surface of Spanish politics.

- What types of interest groups or elites are present in the state in question?

The historical record reveals five primary interests functioning within or influencing the Spanish government. The first, to be considered should be the Castilian elites. These elites gained their voice both out of numbers and out of the importance of the area to the Spanish Empire. Castile was the largest and most populace region of Spain at the time of its dominance, which lends itself well to the strength of the voice of its elites. However, the economic and 
political realities of the Spanish Empire further increase the importance of this group of elites. Castile was the only house from which the Spain could reliably tax, though a check in this power of taxation existed in the Castilian Cortes, which further increased the power and influence of the elites of the area. Castile also represented the largest source of state revenue outside of the funds drawn from the Americas, which often say great fluctuations across time. These political and economic realities ensured that the voice of Castile was heard loudly at the seat of Spanish power.

The elites of Aragon also represented another interest within the Spanish government, though their power cannot be seen in the same light as that of Castile. Aragon existed as a less populated region of Spain and it was essentially protected from taxation through the unification of Spain. The Aragonites wanted to ensure that they were not dominated by the larger Castile, yet the lack of revenue generated for the state meant that the interests of the Aragon were not equally represented. The area was the primary driving force behind Spain's commercial and trade related interests, thus the power and interest of this region cannot be ignored.

The high degree of state financed debt made the banking industry of Europe a powerful interest in the government of Spain. The government of Philip II was not content to utilize merely tax revenues and the vast sums of money arriving from the Americas, instead his government chose to mortgage and sell interests in the Americas in exchange for loans that would provide cash on hand for the state. The banking houses of Italy and the German states were initially happy to provide such assistance to the state. Nevertheless, the creation of such a dependent relationship between a state and foreign banking houses also carried with it influence and considerations increasing the political power of the banks. 
Italy existed as another foreign interest with potential influence over the actions of the Spanish Empire. Italy's unique relationship with Spain was two-fold. First, it was Italy that housed a great deal of the banks from which Spain was able to secure loans to supplement its foreign policy expenditures. Italy saw increased value in the eyes of the Spanish government, as it was a source of military might in the form of troops and a foundation for naval and commercial power.

The Catholic Church also existed as an interest with influential power over the government of Spain, particularly during the rule of Philip II. First, Philip considered himself to be a protector of the Catholic Church, and he seems to have realized that camping policy action as a defense of the Catholic Church would grant it increased legitimacy. Additionally, the Catholic Church possessed an indirect influence over the policies of the Spain, as Castile the largest of the Spanish interests saw their Catholicism as a source of national pride and identity, thus providing another input circuit to the government of Spain. It must also be remembered that the Reformation movement coincided with Spain's era of dominance, hence the voices of the Catholic Church would tend to gain easy access as the church faced a religious crisis.

- In what directions are such interests moving the government?

This question attempts to determine the typical policy direction that the interests of Spain would typically try to persuade the government to undertake. These policy directions are determined by the primary goals of each group, and whether those goals involve Spanish action in the periphery, such as the Americas, or the core, that being Europe. 


\section{Table 3-7: Spanish Interest Group Activity}

\begin{tabular}{|l|l|}
\hline \multicolumn{1}{|c|}{ Interest } & \multicolumn{1}{c|}{ Policy Direction } \\
\hline Castilian Elites & $\begin{array}{l}\text { Desire for Empire (Periphery) } \\
\text { Defense of Catholicism (Core) }\end{array}$ \\
\hline Aragon Elites & Liberal Expansion (Commercial Interest) \\
\hline Banking Interests & Continued Return on Investment (Periphery) \\
\hline Italy & $\begin{array}{l}\text { Defense of Catholicism (Core) } \\
\text { Continued Return on Investment (Periphery) }\end{array}$ \\
\hline Catholic Church & $\begin{array}{l}\text { Defense of Catholicism (Core) } \\
\text { Catholic Expansion (Periphery) }\end{array}$ \\
\hline
\end{tabular}

The elites of Castile can be seen as having both core and periphery interests, as they sought not only a nationalist desire for empire building. Which, appears to have risen not only from their desire to leave a lasting impression upon the world around them as a result of the newfound wealth of the Americas, but also from the policy of militarization that took place under both Ferdinand and Isabella and Charles V. These discoveries and militarization of the Castilian society can be said to have transformed their once inward looking world view into on that was more nationalistic and in search of leaving a mark upon its surrounding world. Nevertheless, Castilian elites can also be argued to have sought foreign policy action on the continent of Europe as well, for their identity was also strongly tied to the regions high level of Catholicism and devotion. This meant that the elites would also look to aid in the defense of their church. This can also be seen as potentially motivated by the desire to leave a Castilian mark upon the continent as well.

- Is the state in question a status quo power or could it be considered a revisionist power?

Despite the sentiments expressed by both Charles V and Philip II in regards to the peace that Spain sought in Europe, and Philip's expression of a need for stability in Europe these statements are only lip service to a need to maintain a balance of power. Rather, the historical record reveals that Spain only sought to maintain the status quo during times of economic crisis, 
or during the years of decline that Spain faced in the twilight years of its dominance. Spain must be considered a revisionist power as the confluence of interests and the beliefs of the majority of those in power sought an almost constant expansion of Spanish power. The policies of Spain can be seen to have sought expansion of power not only in the periphery, the Americas, but also in the core, that being Portugal and the Netherlands. Ultimately it can be said that Spain's desire for a total hegemony prevented it from an efficient use of resources that could have allowed for an extended continuation of its era of dominance. The revisionist nature of Spanish foreign policy is also reflected in the balancing alliances that its policies created.

\section{The International Regime Level}

- What types of regimes are present?

The case of Spain presented two distinct forms of international regimes. The first and most pervasive were regimes arising from marriage diplomacy. The existence of marriage diplomacy was a cornerstone of Spanish diplomacy as far back as the rule of Ferdinand and Isabella, and was thus present through all of Spain's time as the a dominant state in Europe. This form of diplomacy was used in two manners. It was often used in an attempt to create additional territorial holdings, as was the case of the marriage of Ferdinand and Isabella which unified the two most powerful Spanish houses: Castile and Aragon. Marriage diplomacy was also used to attempt to regulate state interaction through the creation of similarities and lines of communication. This is best seen in 1554 when Charles V attempted to prevent English balancing and normalize relationships through a marriage of Philip II to Mary Tudor, though the early and childless death of Mary Tudor doomed this act of diplomacy.

The second form of intentional regime present in the case is varieties of treaties and truces. These international regimes must be called into question as Spain really only sought to 
create such regimes when Spain was in need to lessening its international commitments, either as a result of economic shortfalls or times of domestic political tension. A classic illustration of such a treaty was the 1559 Peace of Cateau-Cambresis. This treaty was signed between France and Spain, though it was signed during time at which the forces of the reformation were of heavy concern to both states. A treaty such as this one is not what this research hoped to find, for these treaties of necessity do not represent meaningful instances of constraint or restraint. Rather, these types of agreements represent agreements of necessity not agreements by which the dominant state hopes to instill a level of understanding and restraint that would lesson fears of expansion or revision in the capitals of the other regional powers.

- Are these regimes formal or informal in nature?

Most of the instances of marriage diplomacy cannot be seen as formalized in nature, unless marriage was used as a means of further guaranteeing a treaty or truce which can be seen in some portions of the historical record. When we consider a formalized international regime we would expect to see the creation of norms through either codified articles or the creation of international institutions. Now, the creation of international institutions was not expected in the case of Spain, though a higher degree of treaty and truce creation was expected. However, the historical record indicates that during the time of Spanish supremacy Spain did not appear to hold strong to the agreements of its early treaties, and was willing to violate such agreements if the wealth or timing of potential policy moves were right. This indicates a low degree of regime formalization, as they tended to violate them regularly and did not tend to create lasting regimes or even talking points for diplomats concerning international interaction. 
- Does the presence of regimes constrain state action?

The only true constraints of state action that can be found in the case of Spain are not found during Spain's time at the height of its power. Rather, such constraining regimes tended to come into existence as Spain's power was waning in order to preserve some degree of power a normalization of relations with traditional Spanish balancers was sought. These types of international regimes can be seen in the 1598 treaty with France, which ended years of hostilities between the two states, though the agreement also forced Spain to recognize a degree of autonomy in the Netherlands. A similar treaty was signed with England in 1604, and an agreement was brokered with mediation aid from France and England with the Dutch in 1609. Once again this types of constraining regimes were not expected from a case as early as Spain, particularly since Spain seams to a have lacked a unified grand strategy.

- Who are the creators or architects of the regimes in question?

In the majority of instances Spain was the originator of its international regimes. The only case in which there was considerable outside assistance in the creation of an international regime was during the creation of 1609 Twelve Year Truce that was created between the Dutch and Spain with mediation assistance from France and England. Thus, the historical record does not indicate much in the way of external sources of binding or constraint.

\section{The Power Concentration Level}

- Across potential competitors how is population divided?

In the case of Spain this is a difficult question to answer on two fronts. First, there is a lack of a universal data set that would provide population numbers across the great powers of the era, as the National Capabilities data set from the Correlates of War project does not include the time period of Spain's dominance. Secondly, the historical record indicates that Spain was 
unique in its dominance, in that it did not posses the largest population in Europe. The state was able to compensate for its demographic short-comings through the use of mercenaries and nonresident labor. This too adds difficulty for the assessment of the state's population strength or weakness. Elliott provides some population numbers for Spain.

\section{Table 3-8: Spanish Population and Distribution}

\begin{tabular}{|c|c|c|c|c|c|}
\hline \multicolumn{5}{|c|}{ Spain's Population (at the End of the 16th Century) } & \multirow[b]{2}{*}{ Pop/sq. km } \\
\hline & Sq. km & $\%$ of land & Pop & \% Pop & \\
\hline Castile & 378000 & 65.2 & 8304000 & 73.2 & 22 \\
\hline Aragon & 100000 & 17.2 & 1358000 & 12 & 13.6 \\
\hline Portugal & 90000 & 15.5 & 1500000 & 13.2 & 16.7 \\
\hline Navarre & 12000 & 2.1 & 185000 & 1.6 & 15.4 \\
\hline total & 580000 & & 11347000 & & \\
\hline & & & & & Elliott 25 \\
\hline
\end{tabular}

Such numbers are telling to illustrate the compact land mass of Spain, as well as its lack of true population strength and urbanization. However, one must remember that the dominance of Spain came at the dawn of the urbanization movement; was pre-industrialized; and prior to any revolution of military affairs. Thus, we can only take the population numbers to show that Spain was not beyond challenge in population numbers and that the need to compensate for such shortcomings may have led to a less efficient use of resources than could have been implemented had the state possessed a larger population.

- How is economic power divided between the target state of each case study and the other great powers in the system?

Once again the economic power of Spain, during its dominance, is hard to judge due to the time period and the data available. However, if one were to look purely at the vast amounts of resources that the state was able to generate from its holdings in the Americas it would be easy to conclude that Spain was an economic heavyweight of its era. 
These numbers do not tell the whole story in terms of economic power for the state. Spain did not rely solely on its riches from the Americas for its wealth, rather it also used tax revenues generated largely from Castile. Moreover, the state was largely dependent on credit to maintain its foreign policy activity, and despite the vast resources available to it still managed to declare bankruptcy several times throughout the period. Its seems that Spain was an economic juggernaut on paper, nevertheless the constant expenditures and a policy of using credit to gain cash on hand as opposed to utilizing its massive intakes on a more efficient basis robbed the state of latent power that could have been called upon in times of true need. Spain's vast economic power was wasted through both an inefficient use of credit and overexpansion by the government.

- Across potential competitors how is military strength, as measured by either military personnel or military expenditures, divided? (In some cases both measures may be present)

With the data available Spain can be seen as possessing the dominant military of the era, through an evaluation of raw numbers and the recruitment rates.

Table 3-9: Military Recruitment 1470 to 1650

\begin{tabular}{|c|r|r|r|r|r|l|}
\hline \multicolumn{3}{|l|}{ Increases in Military Manpower } & & & & \\
\hline Date & \multicolumn{1}{|c|}{ Spain } & United P & France & England & Sweden & \\
\hline $1470 \mathrm{~s}$ & 20000 & & 40000 & 25000 & & \\
\hline $1550 \mathrm{~s}$ & 150000 & & 50000 & 20000 & & \\
\hline $1590 \mathrm{~s}$ & 20000 & 20000 & 80000 & 30000 & 15000 & \\
\hline $1630 \mathrm{~s}$ & 300000 & 50000 & 150000 & & 45000 & \\
\hline $1650 \mathrm{~s}$ & 100000 & & 100000 & 70000 & 70000 & \\
\hline & & & & & \multicolumn{2}{|l|}{ From Kennedy Page 86 } \\
\hline
\end{tabular}

Nonetheless, these numbers do not tell the entire story when in comes to a comparison of military might across the great powers of the day. Spain faced several shortcomings in its military. First, the Spanish military was based largely on mercenaries recruited from outside of the kingdom, such as Italians and Germans. This can be seen as weakening factor, for these 
soldiers did not have a true allegiance to Spain. Such a purchased military also meant that morale was based upon regular pay, which was something that the government of Spain could not always provide. Next, the officer corps was also largely from areas outside of Spain, and those that were native Spaniards were not necessarily well trained. The naval forces of Spain must also be seen in this light. Such limitations in quality must certainly be seen to decrease the value of the quality of forces.

Additionally, the expansive nature of the Spanish empire must also be taken into consideration. The size of the Spanish forces while large in numbers was stationed throughout the empire, which included: Spain, Italy, Portugal, the Low Countries, and the Americas. This means that any comparison with purely regional powers would need to discount the raw numbers of the Spain's armed forces. Thus, with a need to match forces with two regional powers simultaneously Spain would either have to make use its forces on the continent or reposition its forces which would take time and weaken the state in the periphery.

- Are any technological or research and design issues present in a given system that could increase the power level of state in question that may not be detected by the previous questions?

Technological differences can be seen the distinctions between the Spanish and English fleets. Spain's naval vessels were typically created for civilian use and converted to military use. While on the other hand the navy of England was based on warships created with the express purpose of naval combat, such differences allowed England to defeat the numerically superior Spanish Armada.

Yet, another strategic fault of the Spain's military existed in the manner in which it formed its armies. Spain, as a dominant state, was not typical in that its population size could not support a vast army. Rather, Spain was dependent on mercenaries for both the bulk of its enlisted men and its officer corps. This meant that the Spanish forces were loyal to monetary 
payments, which were often delayed as a result of financial shortfalls, instead of a national loyalty. The impact on this strategic difference cannot be perfectly operizationalized, and still it seems to be a potential secondary explanation for the shortcomings of the Spanish army.

- If soft power is present in the system, how is such a resource divided between the primary actors?

The only potential source of soft power present in Spain is the state's role as a dominant Catholic state at the time of the Protestant Reformation. Philip II saw himself and his empire as defenders of the Catholic state. It seems that this religious leadership did not add much in the way of persuasive power to Spain. The only potential illustration of any persuasive power may have existed in the Spain/Italy dyad, nevertheless this is difficult to assess as Spain also had large amounts of troops stationed in portions of Italy and a strong economic relationship that could also indicate a more coercive relationship. Furthermore, if anything it appears that such Catholic leanings may have increased the soft power of the Catholic Church over the policies of Spain, thus persuading Spain to take actions it might have deemed untenable in order to preserve its moniker as the protector of the Catholic faith.

- Does the dominant state have the political willingness to carry the burden of its position in the system?

Determining the political willingness of the government of Philip II is a difficult proposition, as the monarch existed as a complex individual and decision making had numerous levels of influence. The very nature of the question must also be raised as political willingness implies that the public had a large stake in the approval of actions of government, and yet the only check that the masses had over the government was their ability to revolt. However, for this case the definition of the term can be expanded to include influence and desires of interests and elites. It is fair to say that the government of Spain, during its time as a dominant state, was fairly slow to act. This can be seen in the through the presence of a large bureaucracy, for the 
day, that consisted of various issue specialized councils and regional governing bodies. Additionally, it was the hope of Philip II to undertake some role in most decisions of importance. The government of Philip II was slow to act it can also be characterized as stubborn to a fault, this can be seen to have arisen from Philip's "messianic imperialism" that the work of Parker details.

His particular form of imperialism can be seen as a belief that his government was undertaking the will of a higher being, and hence it would be successful in its policies and if success was not found that too was the will of God. This can be seen to have increased the political willingness of the state to a level that would not allow policy changes once undertaken. This can be seen in the planning for the invasion of England, which became largely public knowledge yet the government continued with the policy.

\section{When Hegemony Goes Wrong}

The years of Spanish dominance were marred by a great deal of balancing behavior and conflict between the great powers of the era. The utter lack of international regime constraint exists as a confounding explanation for this behavior in the dependent variable, though the remaining independent variables can be seen to add more explanatory weight. First, the great degree of interests can be argued to have led to an overextension of Spain's hegemonic power resources. It seems that periods of peace for Spain can be traced to times of severe economic need. Furthermore, the competing interests present in Spain pushed the state towards expansion into several areas, and thus such state expansions would certainly trigger balancing behavior and strike fear into the other great powers of the day. Moreover, the rulers of Spain during its period of hegemony led the state towards both loose federalism and over centralization. Additionally, Spain's inability to efficiently transfer its vast amounts of latent power to realized hegemonic 
power can be seen as a large factor underlying its inability to avoid balancing by other great power in the system. The case of Spain does not exist as "neat" case in the study of hegemonic constraint, although it exists as a necessary case to provide historical comparisons to latter cases and to study more in depth the presence of the chosen independent variables.

At first glance one may wonder why the case of Spanish hegemony was included in this study, particularly when one comes to see that no binding or self-binding regimes were present during the state's era of dominance. However, it is this lack of constraint that makes the case an excellent control case study, as the utter lack of formalized and developed international regimes appears to lead a state to expand and overstretch its power base. Future cases in the study of hegemonic constraint will hopefully illustrate more restraint on the part of the hegemonic actor, and thus illustrate the importance of regimes in unbalanced multipolar systems. Thus, the case of Spain raises another question, will more stable unbalanced systems be seen as a result of increased economic, institutional, and regime level development over time?

The case of Spain under Philip II is a classic example of a strategic overstretch of hegemonic power. First, in the government displays little in the way international restraint, which is not to say that there were no instances of international regime activity, as was previously feared. However, in the case of Spain the state's international regime activity did not take place with the most noble of intentions. The marriage diplomacy used by the government was used solely in attempts to extend Spanish power, and the few international agreements that the state was willing to enter were not motivated by an innate desire for restraint but out of economic or military need so as to delay conflict until a time more suitable for Spain. The misuse of the state's hegemonic power resources is also striking. Spain was fortunate in its discoveries, but it was not as fortunate in its domestic resources, and still the government 
squandered its power and luck in exchange for constant military action and attempts at expansion. In the area of Spanish domestic politics we see a number of interests each pushing for continued expansion coupled with a weak leader biased by his council system. The case does not reveal a satisfied status quo power, but rather a revisionist power willing to mortgage its future earnings for cash and power gains. In short, Spain's period of dominance should be seen as a case of when hegemony goes wrong, as it saw little in the way of peace during its hegemonic moment. 


\section{Chapter Four France under Napoleon III - Hoping to be Handcuffed}

In this case the work studies the theory of handcuffed hegemony through the use of the case of France under Napoleon III. ${ }^{4}$ The case covers the French politics from 1848 to 1873. This case is interesting in that it diverges greatly from the case of Spanish hegemony. The case of France will allow the research to witness a state and government that actually sought to restrain itself and work within the constraints of the international political environment. In this era there was a pre-existing international system of norms conveyed through an international regime, that being the Concert of Europe system. What makes the case of French dominance and its attempts to navigate constraint and restrain interesting is that the state played a role in the demise of the Concert of Europe system through the outcome of the Crimean War. However, France under Napoleon III not only attempted to rebuild the concert system but to deepen the underlying international regimes. ${ }^{5}$ Napoleon III's France was also able to avoid a great deal of international balancing through the evasion of encircling alliances.

Alas the case is not as perfect as it would seem, after all French dominance under Louis Napoleon only lasted some twenty-five years. France during this time period can be seen as less powerful, and thus lacking in terms of hegemonic power concentration. This makes the selection

\footnotetext{
${ }^{4}$ The following are sources that provide a well rounded description of France under Napoleon III as it related to the other powers in the European system: Craig, Gordon Alexander. Europe Since 1815. New York: Holt, Rinehart, and Winston, 1961. Gilbert, Felix et al. The Norton History of Modern Europe. New York: W. W. Norton \& Company, 1971. Gildea, Robert. Barricades and Borders: Europe, 1800-1914. New York: Oxford, 1996. Bartlett, C. J. Peace, War, and the European Powers, 1814-1914. New York: St. Martin's, 1996. Bridge F. and Bullen. The Great Powers and European States System, 1815-1914. New York, Longman, 1980. Rich, Norman. Great Power Diplomacy, 1814-1914. New York: McGraw-Hill, 1992. Taylor, A. J. P. The Struggle for the Mastery of Europe, 1848-1918. New York: Oxford UP, 1954. Kupchan, Charles A. The Vulnerability of Empire. Ithaca: Cornell UP, 1994 Snyder, Jack. Myths of Empire: Domestic Politics and International Ambition. Ithaca: Cornell UP, 1994. Peterson, Susan. Crisis Bargaining and the State. Ann Arbor: Michigan UP, 1996. Richardson, James. Crisis Diplomacy: The Great Powers since Mid-19th Century. London: Cambridge UP, 1994.

${ }^{5}$ Conventional views of Louis Napoleon's foreign policy contend that it was his aim to disrupt and destroy the Concert of Europe, as he saw the concert system as a means of degrading French power. This work acknowledges these views, but also recognizes that Napoleon III also tried to work within the concert system in some instances, but his attempts to create a new European system with Paris as the center the of Europe must also be remembered.
} 
of this case unique in that it depicts the interchanges of the independent variables so well, by showing the impacts of power concentration and domestic politics upon a government that sought to use international regimes in manner consistent with the theory underpinning thus work. We can see through the case of France a state that tried to bind itself to other great powers and attempted to foster a system based on international regimes, but at the same time this was a state that was hampered by its recent past and disadvantaged by a lack of hegemonic power.

Nevertheless the case does meet the case selection criteria. First, France under Napoleon III was seen at the time to have had the most dominant military in Europe This is the case despite the power of Britain, as British power was largely based on naval power and the British desired to remain on the outside of European foreign affairs. Thus, one can see that France in this case was given its dominance by Britain's lack of willingness to shoulder the burden and by Britain's lack of power projection upon the continent. The case also meets the time duration selection criteria in that France's dominance extended some twenty-five years, from the rise of Napoleon III and the corresponding economic boom to the conclusion of the Franco-Prussian War. France under Napoleon III is also an excellent early example of a state utilizing restraint and international regimes as a large portion of its foreign policy, and finally the case allows the use of many excellent secondary sources that build upon a large historical record covering not only France during this time period but the other great powers as well. Essentially, the case allows us to see when a state has the best intentions for its period of dominance but no partners or friends to help.

The case of France under Napoleon III begins with a review of the historical works surrounding the state's international regime activity. Louis Napoleon's France is traditionally considered to be an aggressive and revisionist state, however a look at the state through the lens 
of international regimes compels otherwise. Readers should pay attention to Napoleon III's visions for French foreign policy as well as his thoughts for the future of Europe. This will reveal that France during this time period was a state seeking some restraint, and furthermore in instances in which the state sought to wield power the government sought to camp its actions within multilateral actions or concert diplomacy. The international regime section will also address the special relationship that Napoleon III's France attempted to cultivate with Britain, as well the steadfast British policy of remaining outside of the typical power interactions of continental Europe. The international regime section of this case study should challenge us to readdress the manner in which we view the government and polices of Napoleon III's France.

The case study then turns to the review of the domestic politics of France during this time period. The work pays close attention to the ordering of the government and Napoleon III's rise to power. The historical record indicates a strange outcome that arose form Louis Napoleon's 1852 Coup and subsequent plebiscite. These actions while returning the state to monarchy actually set the French Parliament as an institution of power, because following the coup only the parliament could actually see increases in power and influence as Napoleon III then had to walk a precarious line between his authoritarian rule and the powers of liberal change. Additionally, the case will also pay close attention to the influence of public opinion over the actions of the French government. The case exists as one of the first in which we can see public opinion actively shaping governmental decisions, as well as governmental policies to guide and direct mass beliefs. Readers should also be attentive to the variations in opinion along both rural/urban and mass/elite lines.

The final independent variable class discussed in the chapter is the hegemonic power concentration of France. The work will base its measure off of the Correlates of War National 
Capabilities Data Set, but the historical record for this time period will also be important. The case study will focus on the impact of the Crimean War as it related to the power of France in relations to the other great powers of the era. This conflict is traditionally seen as the point in which Napoleon III's France destroyed the Concert of Europe, however the historical record also shows that this was an attempt by the French government to regain some degree of international trust by acting in concert with Great Britain but also by taking a balancing action against a threatening Russia. The value of the Russian threat during this time period cannot be ignored, as it will be seen that it was this perceived threat that allowed France to reassert its dominance in the region without a direct challenge. A central question that exists within the section is whether France possessed sufficient power resources to attract binding partners, and of additional importance is the question that can be raised in regards to the political will of the state during this time period and how that impacted the power and policies of Napoleon III's France.

When the dependent variable of balancing actions is discussed two considerations must remain on the forefront of the work. First, the case of French dominance reveals very little in the way of direct balancing. This supports the notion that Napoleon III's France was not as revisionist and threatening in nature as some traditional works believe. It also underscores the manner in which the government of France implemented and attempted to restrain its foreign policy. Finally, the forms of balancing that are seen in the case are divergent. Prussia/Germany balances France directly which ultimately brings about the decline of French power. However, what is of great interest is the lack of bandwagoning undertaken by Great Britain that could have deterred or stabilized Franco-Prussian relations. 


\section{International Regimes and France - The Hope for a Restraining Hand}

The Treaty of Vienna created a more formalized international regime system. The Treaty of Vienna which created the Concert of Europe along with the other treaties that ended the troubles of the Napoleonic period and created a foundation of five norms for powers of Europe. First, only the five great powers of Europe should have the ability to decide great power problems for the continent. Second, war should not be undertaken on the continent for territorial gain, nor should a great power promote or fund revolutionary forces inside of another European power or within its sphere of influence. Next, another power could not raise an international question of great importance to another power without the consent of the state in which the question. Fourth, if a great problem arose of concern for the continent no great power could refuse invitation to a congress, and no great power could be excluded from such a congress. Finally, confrontation between the great powers had to be avoided at any cost. (Echard 7) Yet, the environment that Napoleon III would face as he sought to bind and restraint France through the use of alliance systems and congress policy was also influenced by the hopes of the other great powers in the ultimate endgame of the Vienna framework and for the future of international regimes in a Europe not challenged by Napoleon I.

At the time of the Congress of Vienna, Austria found itself as a weakening power. It feared Russia to the east and France to the west. With these security considerations in mind Austria sought a return to a balance of power that would allow the state to maintain its power for as long as possible. The Austrian delegation was also concerned with the potential spread of constitutions across the continent, as it was the thinking of Metternich that such political developments could potentially spread revolution and threaten the power of Francis I. These realities and thoughts meant that Austria's aims were more to prevent the implementation of 
other state's policies than advancing their own goals. (Chapman 22-23) The desires of the French were quite simple. France sought to limit the degree to which the Treaty of Vienna would punish the state, thus decreasing its power and hindering its development (Chapman 25). Prussia too sought expansion at the Congress as a means of gathering both territory and resources to better ensure its protection from Austria and France (Chapman 24). It was Russia's hopes that the Congress could bring increased expansion and security for the state. The Russian contingent sought the annexation of Poland, as a protective buffer for Russia, and the expansion of territory to Constantinople so as to allow access to a warm water port, for both increases in trade and for additional power projection capabilities. (Chapman 23-24)

The views of these powers are important, however the foreign policy hopes of Britain are of great importance. This is the case because Britain existed as a potential off-shore balancer for the European system. It is telling that Britain's hopes for the post-Napoleonic War era can be seen in a light that completely diverges from the beliefs that France would have hoped for them to hold. ${ }^{6}$ As the Congress of Vienna came into fruition Britain came to the conference with a distinct goal in mind. It was the aim of the British to create an international regime that would ensure that the state could implement a policy of isolationism in regards to the continent of Europe. (Chapman 16-17) This would allow Britain to expand its colonial activities and become a balancer of last resort for Europe. Castlereagh saw the politics of the continent as a potential quagmire that could decrease the state's growing power. Thus, it was Britain's aim that the Congress would allow the British to feel safe from attack and unneeded as a day-to-day balancer. It was their hope that the other powers Europe could be counted on to maintain the status quo distribution of power, hence France was not to be weakened to the point that it could not function

\footnotetext{
${ }^{6}$ For a more detailed accounting of Britain's hopes to avoid a deeper congressional commitment see Echard, William E. Napoleon III and the Concert of Europe. Baton Rouge: Louisiana State UP, 1983: 137 - 140.
} 
in a balancing capacity. This would allow Britain to focus its resources on the development of its colonial holdings (Chapman 20).

This policy is better seen in light of the Syria Crisis, as France sought the inclusion of Britain in its intervention and a deeper congressional solution to the conflict. 1860 saw a crisis arise in Syria, as elements of the population sought to genocide of the Christian population. France immediately sought to take action, though France stipulated that it would only take action if it was as an actor for Europe. The state's need to take action arose from three goals of French foreign policy. First, the state had a desire to be seen not only as a regional power, but also as a state that could project its power globally. Second, it sought to protect the Christian population, as Christianity formed a large portion of the state's cultural make-up. And finally, taking action in Syria for such a cause may have been able to serve as a distraction for the French population from the difficulties that arose from France's policies in Italy. However, despite these three strong foundations for French action, the government of Napoleon III refused to take action without the expressed consent of the other European great powers. (Echard 129-131) Thus, this episode depicts a state that sought and recognized international constraint. The causes of action in response to the events taking place in Syria were also demonstrative of another ongoing event that being the tension in purpose that existed between the French and the British on the purposes of the European concert system. France can be seen to have constantly sought to expand the scope of the concert system, while Britain was constant in policy of opposing such expansions. This can be seen despite France's willingness to compromise on almost any policy, in the hopes of gaining British support and agreement. Britain was driven by its traditional policy of attempting to stay outside of the day-to-day politics of the continent, and thus using its resources to expand its foreign holdings. (Echard 132-133) This disagreement between the two powers is 
very telling of the system in which France under Napoleon III found itself. France sought international regimes that would constrain it from action and de-alert the balancers of Europe, yet Britain the most suitable binder of Napoleon III's France wanted no part of that portion of European power politics hoping instead to remain in splendid isolation.

\section{Louis Napoleon's Dreams of Restraint}

"But Louis had always maintained a visionary belief that major questions of dispute between nations should be settled by discussion rather than war. He favored an International Council of national representatives, meeting at regular intervals, that would secure the peace of Europe by endeavoring to talk through problems before they could ignite into armed conflict." (Bresler 374) There were some hopes that the Congress of Vienna could serve as a foundation for a deeper entrenchment of norms across the great powers of Europe, with the hope that this treaty could exist as a building block for future negotiations as additional conflicts and disagreements arose. However, it was the belief of Castlereagh that without a unifying French threat such agreements and exchanges would be unlikely to occur. (Chapman 81) Napoleon III's foreign policy attempted to rejuvenate the desires for a deeper congress system for Europe. ${ }^{7}$ Ultimately Louis dreamt of a unified or confederated Europe. "A nationality for him was a family within the European Community; he was first of all a good European. His economic conceptions went beyond the frontiers of the country he ruled. Instead of the snarling autarkies which were to torment Europe between the two World Wars; he was looking forward to freer trade; and he had to impose his liberalism upon the French business world." (Echard 130) ${ }^{8}$

\footnotetext{
${ }^{7}$ Napoleon III used virtually every diplomatic meeting to convey his hopes that European foreign policies could eventually be organized and managed through the use of a highly formalized congress system. Echard, William E. Napoleon III and the Concert of Europe. Baton Rouge: Louisiana State UP, 1983: 21.

${ }^{8}$ Napoleon III also envisioned a permanent legislative body for all of Europe. Echard, William E. Napoleon III and the Concert of Europe. Baton Rouge: Louisiana State UP, 1983: 1 and 293.
} 
Beyond Napoleon III's desires for an ever deepening congress system he was aware of the importance of Britain. "The most astute feature of the emperor's foreign policy was his effort to improve relations with Great Britain. Having brooded long over the history of the First Empire, Napoleon III had concluded that Britain had been the greatest obstacle to his uncle's success and that the hindrance exerted on France's freedom of action on the Continent by this state should be removed by winning its friendship. Accordingly, he sought to break down tariff barriers and establish closer relations with Britain. He backed British policy in the Near East, and during the Crimean War, French troops fought alongside instead of against British troops in a European campaign for the first time since the days of Cromwell." (Gilbert et al 1083-1084) The British and the French also cooperated in their policy to open trade with China and in the early phases of the failed Mexican policy (Gilbert et al 1084). Essentially, France sought a permanent alliance with Britain that would allow Britain to monitor and influence the policies of France. ${ }^{9}$ Napoleon III had hoped that such a relationship could outlive the issues that he based his British policy around, however as we have seen Britain sought to remain largely outside of the day-to-day actions on the Continent.

\section{Attempts to Implement Restraint}

As the Crimean Crisis began in 1853 France sought a European solution to the problem. Napoleon III once again looked to the Concert of Europe as a means of preventing conflict between the great powers of Europe. His government made it clear that France did not wish to act alone in any conflict with Russia or any stabilizing actions taken in the Ottoman Empire. France ultimately was looking for a unified and binding enforcement of international norms created in the Treaty of 1841, which called for the independence of Turkey. (Echard 32-33)

\footnotetext{
${ }^{9}$ For more information about the importance of a permanent British alliance and Louis Napoleon's desires for a binding regime with the state see Echard, William E. Napoleon III and the Concert of Europe. Baton Rouge: Louisiana State UP, 1983: 34.
} 
France also sought an increasingly formalized binding regime, " $[\mathrm{t}]$ his might consist of a treaty by which the Five Powers would bind themselves to respect and maintain the integrity of the Ottoman Empire and the independence of its Government, to refer all points of difference which may arise between them and Turkey to the arbitration of a conference, and in the event of a dissolution of the Turkish empire from internal causes, to abjure all schemes of individual benefit" (Echard 33). This illustrates both the French hopes for binding regimes and the state's calls for increased regime building and cooperation among the great powers of Europe.

The failure of this attempt at congress policy can be seen as beneficial to French foreign policy, in that the ensuing conflict allowed France to work in concert with Britain and regain some level of international credibility by acting as a balancers in the conflict. "The Turks, he told Crowley, were to understand 'that France and England were not protecting her, as Turkey, but as a parcel of territory the integrity of which was necessary to the balance of power in Europe"” (Echard 167). This meant that France saw a transition from a balancing target to a balancing partner. $^{10}$

More important for France, than the actual war, was the actual Congress and Treaty of Paris, as these entities granted France renewed power, credibility, and allowed Napoleon III to make attempts to create international regimes that could regulate state behavior in Europe. Napoleon III stated, "[w]hen the war with Russia had resulted satisfactorily, a European Congress would be absolutely necessary, to solve all the questions that had not been completely decided at the Congress of Vienna, and to give the nations a permanent peace at last" (Echard 46). Furthermore, he also stated prior to the completion of the war, "Europe would soon see the monarchs united in congress, fixing the bases of the peace and forming among themselves an

\footnotetext{
${ }^{10}$ France's involvement in the Crimean War also represents the defense of the regimes created by the Treaty of Vienna, thus moving France to the "just" side of international norms. Echard, William E. Napoleon III and the Concert of Europe. Baton Rouge: Louisiana State UP, 1983: 35.
} 
unbreakable bond" (Echard 46). The Congress of Paris, which ended the Crimean War, effectively codified six international norms and can be seen as a major advancement in the formulation of international regimes for Europe. Additionally, the Congress can be seen to have been both formalized and binding in nature, as the agreements called for additional supervision of the conflict points and any new conflicts by the great powers of the day. ${ }^{11}$ The first action of the Congress was to admit the Ottoman Empire to the Concert of Europe, which effectively gave the waning power a higher degree of legitimacy as a great power. This also can be seen as an institutionalization of the balance of power, for it represents the reforming of traditional power arrangements for the purposes of future balancing needs. The second action of the regime provided for the collective mediation of any potential conflicts between a signatory of the treaty and the Ottoman Empire. The treaty also placed the Ionian Islands, the Danubian Principalities, and Serbia under the protection of the great powers. The Congress also called for the principles of self-determination and a future conference to permanently solve the problems of the disputed territories. The regime internationalized all of the great rivers of Europe, thus establishing the rivers as a public good for the entirety of Europe. Finally, the Congress also included the Declaration of Paris, which formalized the rules of naval warfare; this was a provision of the Congress that was added on by France. (Echard 70) This is a crucial portion of the Congress, since it was an addition created and lobbied for by the French. It represents France attempting to limit the power of a challenger, namely the British, whose naval power far outstripped the naval power of France. The declaration can also be seen as a binding regime targeted at a state that could come to balance the power of the dominant state. Moreover, it seems possible to argue that France was calling in a favor in response to its alliance with Britain.

\footnotetext{
${ }^{11}$ For more information on the actual congress policy of France see Echard, William E. Napoleon III and the Concert of Europe. Baton Rouge: Louisiana State UP, 1983: 29-31.
} 
Furthermore, the Congress of Paris and the subsequent Conference of Paris created a European Commission that was to carry out continued negotiations and programs that were set by the Congress. This commission formalized lines of communication between the great powers of the Era, and centralized European power politics within Paris. It was the goal of the commission to ensure that desires or wishes of a single power did not disrupt or challenge the existing European power structure. (Echard 73) This can be seen as an attempt by the European powers to return to the long peace of the Concert of Europe and to deepen the international norms that underpinned the relationships of states. Napoleon III entered the discussions of the Congress of Paris with the intent to create norms that would foster discussion and mediation prior to the outbreak of future conflicts in Europe. It was his hope that the Congress would foster the formulation of an interactive arena to prevent conflict without the outside infringement on state sovereignty. (Echard 71) This can be seen as a true advancement in the creation of international regimes, as a leader of a dominant state sought to create norms that would further stabilize the system as well as potentially restrain the rising dominant state in the system. ${ }^{12}$

It was France's hope that the alliance formed with Great Britain to balance the rising power of Russia would outlast the conflict. Ultimately, Napoleon III believed that the norms and regimes codified in the settlements following the Crimean War could be used not only to bind French power, but also to tie Britain to the continent. Alas these attempts to persuade Britain to formalize its relationship with France could not be achieved, as the barrier of splendid isolation and the draw of colonialism were to too great. It is important to realize the importance that the French government placed on its relationship with the British, even if those sentiments were not

\footnotetext{
${ }^{12}$ Still, Napoleon III left the Congress of Paris feeling that a deeper set of regimes was still possible. It was his hope that the congress could be built upon in a functionalist manner so as to further bind the powers of Europe together, and most importantly bind France so as to make its power more palatable. Thompson, J. M. Louis Napoleon and the Second Empire. Oxford: Basil Blackwell Publishing, 1965: 103.
} 
reciprocated. (Echard 55) One must also wonder whether such ploys to involve the isolationist power would have been more successful if France had possessed more power, thus making a binding alliance look more desirable. ${ }^{13}$

On October 31, 1861, France, Britain, and Spain signed the Tripartite Convention. ${ }^{14}$ The aim of this multilateral agreement was to attempt to force Mexico to pay off its foreign debts and by doing so to recognize the European norm of property rights. The three states undertook a joint naval mission to capture the Mexican port city of Vera Cruz, and to take over the Vera Cruz customs house and use costumes collections to pay of the Mexican debt owed to these states. However, the mission was impractical and short-sighted in that there were insufficient forces deployed to the area, thus shortly the Spanish and the British withdrew from Mexico. ${ }^{15}$ Though, this was not the policy of Napoleon III, as he sought to gain a foreign policy victory in Mexico to avenge the losses that the three states were dealt by the Mexican army and most importantly to salvage French pride and increase French holdings. Louis Napoleon sought to install Maximilian as Emperor of Mexico, while the United States was distracted by its own Civil War and perceived to be unable to enforce its own regional regime, that being the Monroe Doctrine. Still, several problems existed within this policy. First, the US Civil War would come to end before Maximilian's rule could be firmly established, and secondly France failed to commit sufficient

\footnotetext{
${ }^{13}$ The prize of an Anglo - Franco alliance was so alluring that Napoleon III even attempted to use marriage diplomacy to build such a relationship. . Thompson, J. M. Louis Napoleon and the Second Empire. Oxford: Basil Blackwell Publishing, 1965: 141.

${ }^{14}$ It is shown that France considered Britain and its hopes of a lasting relationship to be a key potential gains from its Mexico policy. Thompson, J. M. Louis Napoleon and the Second Empire. Oxford: Basil Blackwell Publishing, 1965: 214-215.

${ }^{15}$ The defection of Spain and Britain is significant in that France only agreed to undertake the action if it were to work in concert with the other European powers, yet the historical record indicates that it is at this time that domestic political needs began to outweigh France's desire for concert action, in this case. Gilbert, Felix et al. The Norton History of Modern Europe. New York: W. W. Norton \& Company, 1971: 1085.
} 
forces to pacify the Mexican population. Hence, as Napoleon III sought to increase domestic approval through a foreign policy victory he was handed a stunning loss. (Bresler 310-313)

Nevertheless, what is truly telling about the origins of this policy is that it began as a French led attempt to instill European norms upon a colonial state. ${ }^{16}$ This is an illustration of an actual hegemonic attempt to extend international regimes globally. While, this foreign policy mistake is also an depiction of the influence of domestic political concerns on the foreign policy of the Second Empire, as a victory was still needed to save face and further increase the dwindling approval ratings of the government. What is more significant is that France was essentially defeated by a developing state at what can be considered the height of its power, thus foreshadowing the events that would unfold in the decade to come.

One of Louis' first actions as to create policies that would allow France to realize a degree of economic growth. The primary focus of his policies was the expansion of credit in France, thus allowing for easier access to entrepreneurial loans and small business loans. These of course would also curry him favor with the business class. He also extended credit to farmers and merchants to further deepen the economic expansion of France. (Gilbert et al 1079) "The economic policies of the Second Empire prompted the greatest building boom up to that time in French history" (Gilbert et al 1080). Napoleon also sought to lower import tariffs to provide French business with less expensive raw goods and to provide the masses with cheaper food costs. Such reforms were not popular with certain elements of the French business community, as they felt that this would weaken the position of French industry in the face of increased global competition. Though, Napoleon further sought to institutionalize such trade relationships with other European powers, which would then bind the economic fortunes of the European states to a

\footnotetext{
${ }^{16}$ For a detailed account of France's initial attempts to create norm building policy in Mexico see Gilbert, Felix et al. The Norton History of Modern Europe. New York: W. W. Norton \& Company, 1971: 1085.
} 
degree. "In 1860, the Cobden-Chevalier trade treaty with Britain significantly reduced French tariffs on British goods and opened British markets to French products. In the next six years France concluded similar reciprocal-trade agreements with Belgium, the German customs union, Italy, Austria, Sweden, Switzerland, the Netherlands, Spain, and Turkey." (Gilbert et al 1081) These treaties also served as a signal to the other powers of Europe that France was willing to work in concert with the other powers, and these treaties can be seen as an extension of a public good from France to the remainder of Europe. ${ }^{17}$

When Napoleon III sought to create economic regimes with many European states there was much public outcry from both the agricultural and business sectors, as these regimes were designed to be reciprocal reductions in tariffs of the states in question. The interests were concerned that such tariff reduction would serve to hinder the economic growth of France through increases in international competition. Nevertheless, the government of Napoleon III was willing to tolerate a decrease in the economic increases of France in exchange for the creation of ties between the states of Europe. (Wright 160) This shows Louis' willingness to provide a public good that being a higher degree of openness of the markets of France, additionally the tariff reduction treaties also created a network of states in which France played a significant role as the originator of the policy. It also must be remembered that France possessed the largest domestic market.

A predominant foundation of Napoleon III's foreign policy was the creation and maintenance of a durable and long-lasting Anglo-Franco alliance. ${ }^{18}$ Though, it seems that economic competition likely doomed any lasting understanding between the two states. This

\footnotetext{
${ }^{17}$ A more detailed discussion of France's tariff reduction policy can be found in Wright, Gordon. France in Modern Times: From Enlightenment to the Present. New York: W. W. Norton and Company, 1987: 143.

${ }^{18}$ During the 1857 Crisis France's first policy action was actually to consult Britain, in the hopes that this crisis could be utilized to deepen the two states' relationship. Echard, William E. Napoleon III and the Concert of Europe. Baton Rouge: Louisiana State UP, 1983: 82.
} 
was the case despite France's reduction in tariffs and the signing of a reciprocal tariff reduction treaty. (Wright 192) One must also not forget the British aims in the post-Congress of Vienna era to remain as isolated as possible from the day-to-day actions of the continent in the hope of dedicating more resources to their colonial expansion. Thus, it seems that no matter the French attempts economics and isolationism meant that the state would be denied its optimal partner for both alliance efforts and binding.

\section{Conference Calling - Why Won't London Answer}

France under Napoleon III saw each foreign policy problem that arose within the scope of European affairs as another avenue to attempt to deepen and broaden its congress style of foreign policy, in the hopes of attracting binding partners. ${ }^{19}$ In January of 1858 a group of Italian nationalists attempted to kill the emperor. Napoleon III took this opportunity to seek to redress what he perceived as Austrian domination of Italy. Though, rather than merely taking a unilateral action Louis sought to act in concert with other European powers to remove the influence of Austria. Following the success of Congress of Paris, he was of the opinion that such an action would not only be able to diminish the power of Austria, and thus increase the power of France, but it could also be done in a multilateral process that would allow a power expansion of France without potential balancing actions undertaken by the remaining European powers. The Congress was proposed by Russia at the behest of France, Napoleon III was also able to gain a pledge of neutrality from Russia if a Franco-Austrian war was instigated. (Echard 92-97) This represents Napoleon's goals of expanding the zero-sum power of France without triggering

\footnotetext{
${ }^{19}$ France proposed a general congress in the hopes of using the problems of Poland as a jumping-off point for deeper discussions about the nature of the European system. Britain, Russia, and Austria do not agree to an openended congress, as they each feared meetings that were not fixed in scope. The other great powers of Europe also balked at Napoleon's notions that the congress be open to all the states of Europe, as opposed to being restricted to the great powers. Echard, William E. Napoleon III and the Concert of Europe. Baton Rouge: Louisiana State UP, 1983: 51, 156-158.
} 
balancing behavior by the other states in the system, thus acting with the legitimacy of a congress and with multilateral backing.

France also used the Congress to create an explanation for conflict with Austria. ${ }^{20}$ By calling for a congress to deal with this Italian question Austria was placed in a position with only two potential outcomes. Austria could reject the congress and continue its status quo policy, yet such an action would place Austria on the wrong side of the remainder of Europe. Austria, could also accept a congress and be forced to compromise. Ultimately Austria decided to forgo a congress, thus allowing France the international cover to deal a blow to Austria. (Echard 98101)

During the height of unrest within Rome and portions of Italy France was called upon to aid the Italian states, particularly since Napoleon III was seen as someone sympathetic to Italian nationalism as a result of his support for national self-determination and his developmental experiences in Italy. Though, even as the French contemplated action in Italy the government of Louis Napoleon sought to involve the states and apparatuses of the Concert of Europe. These moves were made not only to legitimize French policy and action, but also in the hopes of drawing support from the other major European powers. Moreover, this can be seen as an attempt by France to allow some constraint of its foreign policy, so that the other powers of the era did not perceive French action in Italy to be expansionist in nature. (Echard 17-18) This seems to illustrate a desire of Napoleon III to expand and further entrench the norms and institutions of the concert system, as he attempted to move Europe towards a more unified system of relations.

\footnotetext{
${ }^{20}$ This can also be traced to the influence of public opinion, which was war adverse at least in urban areas, and the rise of New Internationalism in some elite circles. Echard, William E. Napoleon III and the Concert of Europe. Baton Rouge: Louisiana State UP, 1983: 223.
} 
Once France called for a great power congress to settle the Italian questions, it called for the congress on the basis of the British plan, as envisioned by Cowley (Echard 121). This once again illustrates that France sought to maintain close ties with Britain, even in the face of international conflict. This is particularly the case when one realizes that the British plan was not a pro-French plan, but rather the plan called for both Austria and France to remain outside of Italian politics unless the great powers of Europe authorized any further action. Napoleon further echoed his hopes that a binding regime could be created to deal with the Italian question through a pledge not to take any further action without the consent of Europe. (Echard 121-122) This piece of the historical record indicates that France sought binding regimes that could constrain its actions. $^{21}$

By the time of the 1866 Rome Crisis, Europe had tired of France's congress proposals. Only Austria, a weakened power, truly hoped for a congress solution to the problem. The remainder of the European great powers did not wish to find themselves any more constrained in policy options, and desired that the guidelines of the congress be strictly written prior to any diplomatic meetings. (Echard 264) The weakening of French recommendations for multilateral responses to European problems can be traced to two potential explanations. First, there could certainly be an exhaustion created by the use of congressional diplomacy. Nevertheless, the second explanation may add more depth, for France may not have been perceived to be the dominant state on the continent by this time. This could have meant that the other great powers may not have seen such a need to indulge France in its desires for mutual binding, as France was being eclipsed by a growing Prussia/Germany.

\footnotetext{
${ }^{21}$ The later Rome Question also drew a French call for a congress to draft a reasonable settlement. Echard, William E. Napoleon III and the Concert of Europe. Baton Rouge: Louisiana State UP, 1983: 259-260.
} 
A primary goal and hope of the Emperor was to create strong European alliance system with France at the center of the system. Napoleon III was not guided by a massive plan of territorial expansion, though the need for grand victories and success for domestic consumption did push the state in those directions sporadically. It was Louis' ultimate goal to extend the congress system and deepen the norms of alternate conflict resolution. This it what appears to have been Napoleon III's hope for a lasting legacy, a strong France with an intertwined European balance of power structure. (Wright 196-197) This depicts a state that recognized the need to bind itself to prevent the problems of the past, thus attempting to ensure that France could increase in strength without triggering the massive balancing actions that destroyed its past attempts to gain hegemony.

France also attempted to use a series of bilateral alliances to further perpetuate trust. Such trust throughout the international community was thought to be a currency that the state could use to increase support for a deeper congress system in Europe. The government of Napoleon III sought to form bilateral alliances with Britain and Russia, the two other large powers present in the European system. Though, Britain as a result of its ingrained distrust of France was unwilling to alter their informal entente to a more formalized bilateral alliance. Britain's reluctance to formalize an alliance with France also affected Russian perceptions, particularly since Russia too held memories of France's aggressions. (Echard 192) The failures of the French attempts to create formalized alliances shows the state's benign intentions, but that an underlying distrust and a potential perception of unorganized power made such regime formations unlikely.

Even as France began to realize the coming storm from the east congress style foreign policy was still a consideration. As the negotiations moved on within the French government an 
idea was floated to call for a congress to convene of the great powers of Europe to end the disagreements between France and the growing Prussian state without the use of war. It was the hope of some within the government of France that a norm could be created that would prevent the thrones of the continent from being occupied by members of other ruling families. (Wetzel 168) This illustrates the strength that congress diplomacy was gaining within France at the time and the hopes of Napoleon III's government that such diplomacy and the expansion of norms of alternate conflict resolution. This is particularly the case when one considers the gravity of the situation in the eyes of France.

Though, this congress proposal is quickly put down, as those in government soon began to fear a public backlash would follow such a proposal in the face of what was perceived as a large threat to France and to the state's reputation and standing in the European community (Wetzel 170).

More importantly France was aware that it had to attempt protect its credibility and image with Great Britain. Napoleon III alerted Britain to its situation with the new German territories stating, "I can only guarantee the peace of Europe so long as Bismarck respects the present state of affairs. If he draws the South German states into the North German Confederation, our guns will go off of themselves." (Wawro 20) This can be seen both as a French attempt to make Britain aware of the potential danger that a unified Germany in the heart of Europe posses to stability, and as a means of attempting to convey to the British that it was not the French who sought to revise the balance of power of Europe. This is particularly telling when one considers the British hopes of remaining a balancer of last resort for the continent. ${ }^{22}$

\footnotetext{
${ }^{22}$ Restraint was a key aspect of France's foreign policy under Napoleon III, however fear of French power remained ingrained in the capitals of Europe. Wright, Gordon. France in Modern Times: From Enlightenment to the Present. New York: W. W. Norton and Company, 1987: 188-189.
} 


\section{The Impact of International Regimes}

When considering the impact of international regimes upon France during this time period one can only see how far international politics had come since the era of Spanish dominance. The case shows a state that truly understood the impact of encircling alliances, and a state that worked to avoid such pitfalls as it increased in power. Napoleon III's France can be seen as a state that worked within its given restraints, both the Concert of Europe and Britain's special role as an off-shore balancer. Moreover, the case also shows France as a state that challenged to increase and deepen the international regimes of Europe. Nevertheless what makes this case most interesting is what lays ahead in the case study, that being what went wrong for a state that appears to have acted with such stabilizing intentions.

\section{Domestic Politics - A More Complex State}

Hazareesingh (1998) isolates three major problems of the domestic politics of France under Napoleon III. ${ }^{23}$ The author illustrates that the dramatic change from an authoritarian style of governance toward a more democratic form of government caused a great deal of uncertainty for the government of Napoleon III. It is also shown that this period in France represents a change in the place of religion in French society, and that issues of citizenship were changing within France as a whole. This can be seen in the rise of some degree of popular sovereignty and changing notions about the importance of religion in politics. (Hazareesingh 306) These evolutions in French politics point towards an unsettled domestic political landscape as new

\footnotetext{
${ }^{23}$ The following sources are excellent resources for information on the landscape of French domestic politics during the Second Empire: Wright, Gordon. France in Modern Times: From Enlightenment to the Present. New York: W. W. Norton and Company, 1987. Tombs, Robert. France 1814-1914. New York: Longman, 1996. Magraw, Roger. France, 1815-1914. New York: Oxford University Press, 1983. Bury, J. P. T. France 1814-1940. London: Methuen \& Co. Ltd, 1956. Zeldin, Theodore. The Political System of Napoleon III. New York: St. Martin's Press, 1958. Agulhon, Maurice. The French Republic, 1879-1992. Oxford: Blackwell, 1990. Plessis, A. The Rise and Fall of the Second Empire. New York: Cambridge University Press, 1998.
} 
political forces were on the rise to challenge the existing power structure of political life in France.

The introduction of universal suffrage was a distinct change in the politics of France. This meant that the traditional strategies of governance were in need of change, and thus political leaders had to pay closer attention to the movements of public opinion. ${ }^{24}$ This shift in politics also appears to have begun a liberalization of a significant portion of the French public, as parties of the left began to increase in size and importance. (Hazareesingh 312) The Second Empire was key in the transition from elite controlled politics to politics more influenced by the masses (Hazareesingh 313).

When Napoleon III became President of France he spent his time away from Paris traveling throughout the state to new areas of development, not merely to gain an understanding of his native country but also to be seen in his position of power. This would aid him in gaining further legitimacy with the population of France, as he would begin to put a face with his historical family name. Hence, Louis Napoleon began the process of reuniting France around another Bonaparte. (Bresler 229) This unification project was complicated by the lack of personal resources that Napoleon III possessed at the beginning of his political life in France. "Louis 'did not know one man of importance who could serve him and had not one friend whom he could suitably make a minister'. He was virtually a foreigner, or at least a stranger, in his native land. But, astute as ever, he asked Odilon Barrot, who had been the last leader of the parliamentary opposition under Louis-Philippe, to be his Prime Minister.” (Bresler 227) This illustrate the newness that Napoleon III must have felt upon being elected President of France in 1848, and his lack of advisors at the onset of his rule. Thus, this increased his need for allies

\footnotetext{
${ }^{24}$ Napoleon III came to power in a unique time in French political history, as the period represents the confluence of urbanization, industrialization, and universal suffrage. Wright, Gordon. France in Modern Times: From

Enlightenment to the Present. New York: W. W. Norton and Company, 1987: 129.
} 
domestically, and his need to insulate himself with powerful individuals to ensure legitimacy for his government. The government of Napoleon III was not solely encapsulated within himself, rather he needed the cooperation of his ministers to govern effectively. These individuals were not mere implementation tools for the Emperor to use at his discretion. These ministers possessed their own agendas and influences and left their marks upon the policies of the government. (Zeldin 2)

Following his 1848 election, Louis Napoleon began a program to enhance his personal following. ${ }^{25}$ He moved to create ties to the masses, the elites of the day and the military. First, he sought through regional visits to instill the belief in the masses that he was their best block to the disrupting forces of revolution, this was a particularly astute political message as the stories of the difficulties of the previous revolutions were still fresh in the minds of many. He also sought to create an air of a better and brighter future for France. He used political appointments to create a stable cabinet and to extend his reach through the other branches of government, such as the army, the police, and regional governmental positions. Additionally, he utilized political favors to gain favor with the existing political powers of the day. Finally, he used promotion as a tool to advance already loyal members of the military to positions of increased power, and further promotions to win the support of existing elements of the military. (Gilbert et. al 1067)

The 1852 coup that made Louis Napoleon the Emperor of France arose from a constitutional issue, for under the existing French Constitution he was unable to seek another term as President of France. ${ }^{26}$ His initial predilection was to seek an amendment to the

\footnotetext{
25 "Louis Napoleon polled 5,500,000 cotes compared to 1,500,000 for Cavaignac, 370,000 for Ledru-Rollins, 37,000 for the radical Raspail, and almost insulting 17,000 for Lamartine. A further shock followed when the new unicameral Legislative Assembly was elected in May, 1849. The moderate republicans who had shaped the new regime were almost wiped out; the big winners were the monarchist right with some 400 seats and the resurgent radical left with almost 200." Wright, Gordon. France in Modern Times: From Enlightenment to the Present. New York: W. W. Norton and Company, 1987: 136.
} 
document that would allow additional terms. However, it was his advisors with the support of elements of military that desired not only to keep their station in life but to see France restored to its imperial grandeur that persuaded Napoleon to orchestrate a coup. ${ }^{27}$ (Bresler 232-233)

Following Louis Napoleon's coup and the subsequent plebiscite the legitimized his ascension to the throne the need for domestic political allies increased. The Emperor not only needed strong friends to back his policies, he also needed to create a new ruling class. This was done through the creation of a new legislature of 261 members. (Zeldin 10) Furthermore, following the 1852 coup and the subsequent plebiscite it is difficult to imagine that Napoleon's powers could see any more of an increase. Rather, institutionally the only body that was able to realize a significant increase in powers was the legislature. This body saw such an increase in powers as it realized an institutionalization and legitimation of its powers overtime. The body gradually increased in its oversight capabilities and more importantly became a true force in the finances of the state. These devolutions of power can be seen as a result of the political realities faced by the government of Napoleon III. After consolidating power through a coup and legitimizing this power through a plebiscite and parliamentary elections the power of the parliament would need to increase over time so that Napoleon could ensure the domestic stability

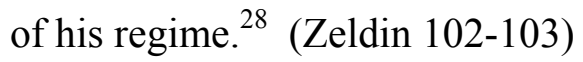

The members of the French Parliament did not serve as a means of "rubber stamping" the policies of Napoleon III, but were people of standing in their own right. They had free thoughts

\footnotetext{
${ }^{26}$ Additional information on 1852 Coup can be found in Gilbert, Felix et al. The Norton History of Modern Europe. New York: W. W. Norton \& Company, 1971: 1068-1069.

${ }^{27}$ More information about the supporters of the coup can be found in Wright, Gordon. France in Modern Times: From Enlightenment to the Present. New York: W. W. Norton and Company, 1987: 139-140.

${ }^{28}$ The historical record indicates that Napoleon III faced little in the way of actual political opposition. What is most interesting is his perception of domestic political constraint. He appears to have been very sensitive to his perception of potential opposition and thus attempted to pacify and in some instances meet the expectations of others within and outside of the French government.
} 
and often disagreed with their emperor. ${ }^{29}$ Moreover, the French Parliament of Napoleon III was not a place for its members to gather wealth, as most members had careers of their own and standing outside of their parliamentary titles. (Zeldin 60-61)

\section{The Constraint of Public Opinion}

The public opinion of France during this time period was largely guided by an aversion to war, with the exception of the Franco-Prussian War (Case 116-117). This is likely the result of the previous years of war under Napoleon Bonaparte and the fact that it was the masses who did the bulk of the fighting and dying in French conflicts. Constant moves for congress style diplomacy and norm formation are seen as a cornerstone of Napoleon III's foreign policy. Public opinion can be seen as a source of this over arching policy, as through most of the years of Louis' reign the mood of the public was terribly war and risk adverse. This left the government with little room to maneuver in some instances and this can be viewed a contributing impetus for the new breed of foreign policy formulated by France during this time period. (Echard 208-209) This should be seen as a direct link to the hopes of this work that domestic constraint could be found in the policies of Napoleon III. ${ }^{30}$

The opinion of the bourgeoisie tended to be more of a belief in peace "at any price, whereas the peasants could be more greatly influenced by calls for empire and grand foreign strategies. ${ }^{31}$ However, these pacifist sentiments were not the result of moral beliefs about the

\footnotetext{
${ }^{29}$ A breakdown of the background of French MPs can be found in Zeldin, Theodore. The Political System of Napoleon III. New York: St. Martin's Press, 1958: 62-63.

${ }^{30}$ For more information on the role of public opinion as a constraint see Echard, William E. Napoleon III and the Concert of Europe. Baton Rouge: Louisiana State UP, 1983: 37.

${ }^{31}$ The rule of Napoleon III corresponded with Urbanization, Industrialization, and the rise of the middle class Wright, Gordon. France in Modern Times: From Enlightenment to the Present. New York: W. W. Norton and Company, 1987: 164-165
} 
cause of war, but the belief that war disrupted the typical pursuit of wealth and progress. (Case

117-118) This belief that war disrupted growth and business affairs can be seen as a true domestic political constraint upon the government of France, which would thus illustrate the hopes of the theory in question, that being the public opinion and sentiment could act as a restraint upon a government and its foreign policy. Now, earlier evidence has illustrated that the government did not always follow the opinions of the masses, though this is a large advancement in that there does appear to be an avenue for public influence.

Public opinion was an important factor in the foundation of French foreign policy in the middle of the nineteenth century. Even considering from the point of the shackled press, one is nonetheless convinced of the influence opinion played. The very circumstances which show that the press was censored, bribed, bludgeoned, and inundated with syndicated articles all bespeak of the concern over opinion and its expression. But on the positive side, the systematic efforts made by the government to ascertain genuine opinion beneath the sham of press opinion by ordering the continuous sounding of opinion by the procurers general, prefects, and the prefects of police are convincing proof that there was not only a voice but also loud-speakers by which voice could be heard in accents clear. Case 113

This seems to indicate the consideration that public opinion was given by the government of Napoleon III, in that great lengths were taken not only to gauge public opinion but also to attempt to guide it in the direction that the government hoped to move. The measure of public opinion were not necessarily used to understand the policy beliefs and ideals of the public, rather they were used to come to grips with the manner in which the government would need to try to push opinion (Case 114). However, this is not meant to say that opinion that could not be influenced would be the champion of the day in regards to French foreign policy. The government undertook an unpopular war with Austria despite the wishes of the population for peace, and the government sought to create a satellite state in Mexico also against the public wishes. (Case 115-116) It seems that the French government sought to influence opinion at the onset or to follow public opinion if such influences were unsuccessful, but lastly to cast the will 
of the public aside if other interests deemed it needed. Napoleon III seemed uniquely sensitive to the perception of real political opposition, despite the fact that little existed. This may have been the result of his fears of revolution following his 1852 Coup.

The Crimean War serves as an excellent example of the power that public opinion welded over the policies of Louis Napoleon. ${ }^{32}$ Louis felt a great deal of public pressure to secure an early peace for the Crimean War. This raised some concern with the British who felt that Napoleon was not to be trusted when it came to peace negotiations, as he showed interest in the signing of preliminary agreements that could then be finalized and changed during future meetings. (Echard 61) This illustrates the considerable pressure that the government of Napoleon III was under in terms of the French public's demands for a peace agreement. This is particularly telling when one remembers the hopes that Napoleon had for the peace to follow the Crimean War, as he hoped to extend the alliance with Britain past such troubles; he hoped to extend the concert apparatus and expand its scope following the conclusion of the war; and he desired a honorable victory to increase the perception of power of the French military.

However, not all public opinion was so war-averse. The existed a division between the beliefs of the rural and more educated urban populations. This same divide can also be seen in the division between rural opinion and elite opinion. Napoleon III faced a great deal of tension in the domestic politics of France. The business interests were largely concerned with the maintenance of the status quo, as a means of ensuring the continued economic growth of France. Whereas, the new rising force of rural mass public opinion in France still tended towards the hope that France would one day be able to regain a degree of its imperial glory. (Renouvin 94) ${ }^{33}$

\footnotetext{
${ }^{32}$ A larger discussion of the impact of urban public opinion can be found in Echard, William E. Napoleon III and the Concert of Europe. Baton Rouge: Louisiana State UP, 1983: 34.
} 


\section{Government and Influence}

The initial government of Napoleon III found supporters from four distinct sources. First, a great deal of support was given from business elites, for they found Louis' original economic policies to be of great importance, though their support waned once Napoleon began to move towards more liberal trade and tariff policies in regards to the other powers of Europe. ${ }^{34}$ The president also found support in the church hierarchy, as a result of his support for Italy, the Pope, and his support for Christians in their clashes with Muslims in the Ottoman Empire. He also found a large bulk of support from the peasantry of France, as they favored a return to prouder days for France. Finally, Napoleon III also had the support of the growing urban populations as he sought the presidency of France. ${ }^{35}$ (Wright 144)

Napoleon III's personality also opened the leader to influence, not merely from his supporters but from the political environment in which he found himself. "He could be diverted from a straight course of principle by the need to conciliate a political party, or the fear of international complications" (Thompson 103-104). Napoleon III possessed two great forms of influence. He was able to trade on his family name to influence the masses, as this name drew upon memories of a stronger more respected France. His main means of influence over other politicians of the day appears to have been his personality and his means of persuasion. (Zeldin 68) Even as emperor Napoleon III stilled remained a politician, and was thus always willing to

\footnotetext{
${ }^{33}$ This division in public opinion opened the possibility that the government could use foreign policy, specifically the search for empire, as a means of diverting the public's attention from domestic problems. These domestic problems included: domestic fallout from Louis's reductions in tariffs; opposition to his coup; and calls for additional liberties and representation. For a larger discussion see Thomson, J. M. Louis Napoleon and the Second Empire. Oxford: Basil Blackwell Publishing, 1965: 134-135.

34 Though the support of business interests tended to wane after the tariff agreements Napoleon still found support from more enlightened elements of this elite group. For more information see Wright, Gordon. France in Modern Times: From Enlightenment to the Present. New York: W. W. Norton and Company, 1987: 169.

${ }^{35}$ Napoleon III also found support out of both the officers and enlisted men within the French military. Wright, Gordon. France in Modern Times: From Enlightenment to the Present. New York: W. W. Norton and Company, 1987: 141.
} 
compromise. This allowed for devolution of power away from the throne, which seems to run counter to what would traditionally be considered the role of a monarch. Though, it must be remembered that Napoleon was a new kind of monarch and he was forging a new form of government. (Zeldin 17) The elections of 1852 that followed the plebiscite illustrate the creation of a different form of empire. "I6 "It did not represent a mere dictatorship of the masses, but sought to combine aristocracy with democracy and to build a society in the shape of a pyramid, with the people as its base and a hierarchy of merit at its top" (Zeldin 44). The elections also show how the foundation of Napoleon III's liberal empire was formed (Zeldin 45). Interestingly, Louis Napoleon sought to maintain complete control over the foreign policy of France, as he saw this as his duty and his means of leaving a lasting legacy (Renouvin 96). It was his belief that leadership should not be influenced in a reactionary manner, but rather that foreign policy should be guided by ideals (Renouvin 95). Louis Napoleon also sought after 1860 to further institutionalize position as an emperor so that it could be left within his family upon his death (Zeldin 107).

The Italian Crisis can be used to illustrate the importance of the beliefs of Napoleon III in shaping the foreign policy of France, as well as Louis Napoleon's diplomatic and political skill. The Italian crisis found itself at the cross roads of two of Napoleon III's primary foreign policy goals. First, it was his aim to always attempt to move within the bounds of the concert system in Europe, so as to allow for growth and expansion of France without invoking the suspicions and fears of the remainder of Europe. Second, Louis found himself to be an ardent supporter of selfdetermination. Thus, Italy, which was seen in France as an area that was dominated by Austria,

\footnotetext{
${ }^{36}$ The 1852 Coup also meant that Louis Napoleon perceived that he was then in need of a strong domestic base more than ever, as he had seized power from an elected body. Gilbert, Felix et al. The Norton History of Modern Europe. New York: W. W. Norton \& Company, 1971: 1082.
} 
would test the limits of these two policy goals. France under Napoleon III found itself in a position to aid Italy by war if needed, and yet such a conflict would need to be undertaken with at least the tacit blessing of the remainder of Europe, so that France could avoid the label of an aggressor state. Luckily for France, Austria failed to respond meaningfully to calls for a congress to attempt to remedy the crisis, which allowed for Austria to be viewed as the state that sought to live outside of the norms of the concert system. This allowed Louis to engage in a war with Austria with minimal fears of triggering external balancing. (Echard 104-105)

However, this same conflict also demonstrates the domestic political restraints that the emperor faced. The outbreak of the Franco-Austrian War did not end the constraints that Napoleon III felt domestically in regard to his foreign policy. Louis was under great pressure from public opinion and commercial interest to make every attempt to find a diplomatic solution to the conflict. And still, after the outbreak of hostilities his government felt such pressure from the masses, which were very war adverse at the time, to sue for an early armistice in the war. Once the armistice was complete the warring parties convened a congress so that the other great powers of Europe could have input and help guide the eventual treaty. (Echard 108-109) This not only depicts a French foreign policy that was constrained domestically, but also a France that was wise to remain within the bounds of the norms and regimes that had been formed through the Congress of Vienna and subsequent diplomatic exchanges. ${ }^{37}$

Essentially Napoleon III was able to piece together three distinct groups or dimensions upon assuming the title Emperor. He was able to foster relationships with both the traditional landed elites as well as the growing population of industrialized elites. Louis was also able to

\footnotetext{
${ }^{37}$ More information on the Italian Crisis can be found in Thomson, J. M. Louis Napoleon and the Second Empire. Oxford: Basil Blackwell Publishing, 1965: 107-108. Additional information on the degree to which Napoleon III was influenced by his respect for Italian nationalism can be found in Thomson, J. M. Louis Napoleon and the Second Empire. Oxford: Basil Blackwell Publishing, 1965: 138.
} 
walk a fine line that allowed him to appeal to both the rural and urban masses on distinct levels, as rural mass opinion tended to support a return to empire and glory and the urban population tended to be more pacific and liberal in their aggregated opinions. Finally, the social developments of the era also meant that Napoleon III was one of the first rulers that needed to use both popular and elite politics simultaneously. (Wright 145-146)

The state's policy during the Crimean Crisis illustrates the role of influence played within the government. Napoleon's decision to take a more proactive foreign policy when dealing with Russia in the Crimea can be traced to two main influences. First, there was the need to galvanize public support behind his government and certain elements of the population could easily be swayed through military and diplomatic successes. Second, there was the need to gain further support from the military, and thus by engaging in and winning a conflict the military could then achieve some much needed recognition and a partial return to the pride of past decades. ${ }^{38}$ (Thompson 145) Moreover, the Catholic Church was also calling for French action in the Crimea as there area was seen as an Islamic threat (Thompson 147-148).

Upon entering the Crimean War the government of Napoleon III had two primary goals. First, it France needed to end the conflict as a quickly as possible, as a means of attempting to appease the anti-war tendencies of French public opinion. Though, France too had a second goal that being the maintenance of its alliance with Britain, as Napoleon isolated the British alliance as a key to his foreign policy and the continued growth of France. France also had to ensure that any settlement with Russia was acceptable to both its masses and to the British. (Echard 39) This depicts the severity of the two-level game that France was forced to play during the

\footnotetext{
${ }^{38}$ The Crimean War and other conflicts entered into by the government of Napoleon III were also seen as means of ensuring the preservation of French honor. Echard, William E. Napoleon III and the Concert of Europe. Baton Rouge: Louisiana State UP, 1983: 5.
} 
Crimean conflict, as it sought to take action to continue and strengthen its relationship with Britain, all the while negotiating the constraints of public that was war averse at the time.

"By 1866, the Second Empire had come to depend almost entirely on diplomatic and military victories - 'national dignity' - for its popularity” (Wawro 21). This illustrates the fact that the government of Napoleon III had moved out of its "honeymoon period" with the French public and was in need of diversionary tactics in the form of foreign policies successes to maintain its legitimacy as a government. It also highlights the growing importance of public opinion as opposed to elite beliefs in the maintenance of governmental stability. ${ }^{39}$

The foreign policy of Napoleon III was represented by a great deal of ideological tension. It seems that Louis Napoleon faced this tension of ideas within his own mind, which was no doubt influenced by the domestic and international political realities that he and his government faced. On one side of Napoleon's mind he found himself in complete support of the ideals of nationalism, as he argued that it was national self-determination that could bring about some degree of stability to Europe. However, this ideal was not popular in many of the powerful circles of Europe. Though, these ideals stood in conflict with his government's almost constant search for international respect, which could then be translated to domestic political capital. (Wright 143) It appears that Napoleon III sought to follow his national sentiments in times in which glory could not be found, and thus followed a more imperial foreign policy when instances presented themselves. However, these constant transactions from Liberal policies to policies of empire appear to depict a troubled an unpredictable decision making process.

The government of Napoleon III found its end from failures in foreign policy more so than from its domestic political policies. The first and primary failure of Louis' government was

\footnotetext{
${ }^{39}$ France's policy during its Syrian involvement can also be seen as rooted in domestic politics, as Napoleon III sought additional glory for the military as well as a source of distraction for the masses. Echard, William E. Napoleon III and the Concert of Europe. Baton Rouge: Louisiana State UP, 1983: 135.
} 
its inability to correctly deal with the rising power of Prussia/Germany. The government appears to have ignored the geopolitical realities that a united Germany would create. Bismarck's united Germany meant that France then had a direct challenger on the continent, and yet Napoleon's government failed to gain the requisite territorial gains that would have provided France with a larger buffer to the rising German power. Moreover, France allowed itself to be boxed into a corner by Bismarck, thus granting Bismarck his final needed action to create a unified state. Second, Napoleon undertook a failed and draining policy in his attempt to create a Catholic satellite state in Mexico. This policy was not only a stunning failure in both military and prestige concerns, but it also served a significant drain on the resources of France in the periphery in a time that France would have been better served by the additional use of resources in the core. Finally, the French government failed to create needed alliances with both Italy and AustriaHungary. (Wright 148-149) These security regimes would have provided a stronger deterrent to Germany and could have signaled to the rest of Europe France's willingness to bind itself to others in the region.

Moreover, the conflict between France and Prussia had taken on the meaning of French national pride and dignity. This was the case as it was seen that the government of Bismarck had repeatedly challenged the power of France and that the government of France had repeatedly backed down from such challenges. (Wetzel 180) This signifies how little room for negotiation and exchange existed within France in the months and days leading up to the onset of conflict, as French public opinion appears to have been virtually locked into a war and honor mentality. ${ }^{40}$ At the onset of hostilities between France and Prussia Napoleon III faced a growing domestic

\footnotetext{
40 "On July 14, 1870, Louis Napoleon ordered the mobilization of the French army and its reserves. This call to arms was met with crowds and cheers, as the masses shouted, "On to Berlin! Down with Wilhelm! Down with Bismarck!" The war was successful in that it distracted the masses from their dismay over the state of their government. Now, France just had to win the war. Wawro, Geoffrey. The Franco-Prussian War: the German Conquest of France in 1870-1871. Cambridge: Cambridge UP, 2003: 38.
} 
reform movement. The state had become weary of his 1852 constitution that gathered the majority of state power within the institution of the emperor and his cabinet. The Emperor also faced declining health and a lack of a transition plan for the era that would face France after his death. (Wawro 25) This growing liberalization of the parliament and the masses further placed the Louis Napoleon in a constrained policy arena, as diversionary foreign policies appeared to have been the sole tool remaining for the state in the wake of the unpopularity of the government. By 1870, Napoleon III had come to the conclusion that the Franco-Prussian War could be used as a diversionary war to aid him in dealing with domestic political realities of France $^{41}$ (Wawro 29).

\section{The Impact of French Domestic Politics}

The case of France shows a great deal of variation and intrigue when domestic politics are considered. The government was forced to begin to deal with the growing impact of public opinion, as the 1852 Coup made the government of Napoleon III tenuous at best, at least in the perception of Napoleon III. Moreover, despite Napoleon III's position as Emperor of France the legislature still saw increases in power. These realities meant that the government was forced to deal with these growing influences all the while attempting to reshape the international regime system and remain viable as a dominant power. France can be seen at times to have followed the war adverse nature of urban opinion to a fault, which can be seen in outcomes of the Crimean War and the Franco-Austrian War. In these instances it has been argued that France moved too

\footnotetext{
41 "At any rate, it does seem certain that after 1859 Napoleon was moving in the right direction so far as the bulk of French opinion was concerned. The most persuasive evidence for this view was given by the voters in May 1870, when they were summoned by plebiscite to approve or reject the new Olliver constitution. The pro-regime share of the vote, which had been only 55 per cent in the 1869 elections, rocketed to 83 per cent; the opposition total fell by more than half. No greater victory had been won by the regime since the days of the authoritarian empire." (Wright Wright, Gordon. France in Modern Times: From Enlightenment to the Present. New York: W. W. Norton and Company, 1987: 147. This is a key illustration of public support, as 1870 represented the beginning of the FrancoPrussian War, thus depicting the amount of support that Napoleon's government could garner through the use of a unifying foreign event.
} 
quickly towards peace at the risk of being seen as politically weak-willed. Still instances such as Napoleon III implementation of tariff reduction treaties went completely counter to elite beliefs, thus showing the governments willingness to act in accordance with its strategic goals, deepening the integration of France into the system and increasing international credibility, despite domestic political pressures.

The days leading up to the Franco-Prussian War are even more interesting in that public opinion was very pro-war and yet the government still sought to avoid war. This may be the result of a state once again following corporate interests that hoped for peace and stability and thus continued economic growth, or it can be seen as a form of blowback in reverse. The domestic political influences of the France during this time paint a picture of a state attempting to deal with new political forces in a time of uncertainty. Moreover, it seems to indicate a fractured decision making process in which various influences and the overriding strategic plan battled from day to day and policy to policy. Domestic politics cannot be seen to have pushed the state towards an overstretch of power, but rather towards a chaotic decision making process that did not allow the state to react quickly enough to the changing international system.

The Handcuff of Hegemonic Power Concentration (Being in the Right Place at the Right Time)

“When Louis' 'Golden Year' of 1860 ended, the Second Empire had seemed more secure that ever before and Louis' own position as 'the arbiter of Europe' accepted without question" (Bresler 323). While it seemed unlikely after the Congress of Vienna, Napoleon III was able to increase the power of France to the point that it could once again be considered the dominant power in Europe. One must only consider the hegemonic power concentration to see whether the Second Empire had achieved the state power necessary to become a handcuffed hegemon. As a dominant power the government of Napoleon III's foreign policy goals can be seen in the 
following quotation. "[H]is foreign policy consisted of the reorganization of Europe roughly in accord to the principles of nationalities, a reorganization for which the Ottoman Empire would largely foot the bill, and which would be arranged and thereafter supervised by a new concert of Europe. He conceived of this concert as a congress system, dominated by but not restricted to the great powers, brought about by a system of alliances, and willingness not only to accept necessary change but, in fact, to supervise its development." (Echard 161-162) This passage suggests that Louis Napoleon sought constraint not only for the other powers of Europe but for France as well. This illustrates the hope of the emperor that his France would be capable of using its power more wisely and with more restraint in comparison to his uncle, and the hope that France's term as a dominant power could be more lasting and more stable.

Ultimately France was blessed as the approximate strengths of the other great powers of system following the Napoleonic Wars tend to show France not as potential dominant power. However, the realities of the international system, with Britain seeking to remain aloof in European politics meant that the France of Napoleon III could rise from the aftermath of the errors of Napoleon I's reign. ${ }^{42}$

Table 4-1: Great Power Strengths following the Napoleonic Wars

\begin{tabular}{|l|c|r|c|r|r|r|l|}
\hline \multicolumn{2}{|l|}{ Summary of Approximate Strengths of Great Powers 1815 } & & & \\
\hline Country & Pop & Land (Sq km & Army & Ships & $\begin{array}{c}\text { Coal } \\
\text { (tons) }\end{array}$ & $\begin{array}{c}\text { Iron } \\
\text { (tons) }\end{array}$ & \\
\hline Britain & 18000000 & 315000 & 100000 & 235 & 15000000 & 400000 & \\
\hline France & 29000000 & 550000 & 250000 & 71 & 1000000 & 250000 & \\
\hline
\end{tabular}

\footnotetext{
${ }^{42}$ A look into the National Capabilities dataset as collected by the Correlates of War Project further supports this conclusion. An aggregate adjustment of Cline's power measure was utilized to check the historical record against the compiled data for the years of 1848-1873. The equation that used is a follows: Perceived Power $=($ Population + Iron and Steel Production + Energy Use + Military Expenditures + Military Personnel)/1000. An average score was created for each great power. France scored 80,684.85; Britain scored 139,074.85; Russia scored 98,942.38; Prussia/Germany scored 49,403.73; Austria - Hungary scored 51,392.15. These numbers illustrate that Britain's desire to remain an off - shore balancer and lack of ground based military effectively lent the title of dominant state to France. Moreover, the numbers point to the great deal of latent power present in Russia which was not properly translated into actualized power. The numbers do seem to under - account for the rising power of Germany as they do not capture the importance played by the German reserve system.
} 


\begin{tabular}{|l|l|l|l|l|l|l|l|}
\hline Austria & & & & & & & \\
\hline Russia & 43000000 & 22000000 & 1000000 & & & & \\
\hline Prussia & 10000000 & & 200000 & & 1000000 & 400000 & \\
\hline & & & & & & \multicolumn{3}{|c|}{ Chapman 19 } \\
\hline
\end{tabular}

Ultimately it would be the Crimean War that would raise Napoleon III's France to a position of dominance.

\section{The Impact of the Crimean War}

The Crimean War began for France not only as a means of building international credibility as a responsible member of the international system, through balancing of Russia, but also as means of increasing the prestige both internationally and domestically of the French military (Echard 45). The onset and conclusion of the Crimean War can be seen as watershed events in the reign of Napoleon III. "Nevertheless 1856 remained the climax of Louis' career. He had succeeded, where Napoleon himself had failed, in winning the alliance with England and in reversing the verdict of 1812. By re-establishing an Imperial dynasty and inspiring an international treaty he had made himself the supplanter of Nicholas, and France was once more the predominant power on the continent - a power which might challenge the settlement of 1815." (Thompson 166)

The Crimean War not only saw the defeat of Russia at the hands of the French and the British, but it also made clear the dominance and superiority of the French military in comparison to army of Britain. The French army was significantly better prepared for the Crimean War than was the British military. This was the result of the foundations of both militaries and distinctions in experience. The British Army was based on an officer system in which all officers arose from upper social classes, thus morale was not high among the enlisted men as there was little room for advancement. Additionally, the French Army's combat experience dwarfed that of the British, as the majority of the French troops deployed to the 
region had previously served in Algeria. (Thompson 153) These differences in military capabilities may have also served to further prop up the myth of superiority of the Armies of France, not to mention the success against what was perceived to be a rising Russia.

The most important outcome the Crimean War did not take place on the battlefield, but rather in Paris. The conclusion of the Crimean War, which effectively left the Congress of Europe in shambles, was ended with the Congress of Paris. This new congress effectively recognized Napoleon III's France as the dominant state and arbiter of Europe. The Treaty of Paris also superseded the Treaty of Vienna, which was seen by the French to be a horrible document that robbed their state of its rightful place among the great powers Europe. This new agreement not only gave France its new membership card, but it also allowed France to retake a position of power on the continent. (Echard 71-72)

\section{New Powers - New Hopes}

The reign of Napoleon III also saw a dramatic increase in the economic power of the state, to the point that France during his rule was able to outstrip the other great powers of the day in terms of economic growth. "Industrial production doubled between 1852 and 1870; foreign trade tripled, outstripping the growth of any other European nation; the use of steam power rose fivefold; railway mileage was increased six fold" (Wright 158). Additionally, in the years preceding Napoleon III France also saw striking increases in population. "France's population in 1824 - twenty-nine million - exceeded that of any other European nation save Russia. The figure increased by more than 30 percent since 1750; it was destined to grow another 33 percent by 1870" (Wright 175). 
The differential growth rates that are seen in the international system that tended to favor France also meant that the state could hope to expand its power resources in new directions. ${ }^{43}$ Louis hoped that these increase in power resources could be translated into soft power reserves. "Might it not be the destiny of France to exercise a moral hegemony, achieved, as the work of European regeneration would have to be achieved, not on the battlefield but at the conference table, where Europe would unite to ban the specter of war from the Continent?" (Echard 6) This illustrates Napoleon's hopes that France could take the lead in European politics and steer the landmass towards an alliance system that decreased the potential for conflict. It is also explicit in his words that he desired the creation of norms of alternate conflict resolution. Furthermore, Napoleon III realized how France's large standing army could be perceived by other European power, particularly in the face of the actions of his uncle. Louis hoped for a day that he could reduce his state's troop levels. He believed that such reductions could take place if France was allowed to feel safe within its borders and able to exist in an international environment of mutual constraint of the great powers. (Echard 165) This desire for a reduction in military force depicts the wishes of Louis Napoleon for a restrained international system. ${ }^{44}$

It was the belief within France that these power resources could be translated into a specific foreign policy. "[F]rance within its present boundaries was already large and powerful enough and that France had the will and strength to promote a foreign policy the essence of which was the reconciliation and the harmony of three goals-promotion of a sort of French

\footnotetext{
${ }^{43}$ For more information on the importance of differential growth rates see Gilpin, Robert. War and Change in World Politics. Cambridge, UK: Cambridge UP, 1981.

${ }^{44}$ This restraint by France on the continent did not necessarily transfer to restraint in the periphery. France's Mexico policy, that began in concert with Britain and Spain, to extend the regime of property rights. However, this policy soon became one of colonial expansion that forced France to utilize 27,000 troops in an attempt to salvage a victory. For more information see Thomson, J. M. Louis Napoleon and the Second Empire. Oxford: Basil Blackwell Publishing, 1965: page 218.
} 
moral hegemony in Europe, satisfaction of nationalities, and encouragement of European concert" (Echard 303). ${ }^{45}$

\section{The Franco - Prussian War and France's Fall From Dominance}

Bismarck's policy to draw France into a conflict would unearth the reality of French power that being the state's inefficient transformation of latent power to realized power. Specifically France's power base had become suspect in terms of its military might, yet that reality was not seen in the capitals of Europe until the fallout of the war. Prior to the onset of hostilities it was largely assumed not only in France but in the majority of Europe that the French army was had the world's superior fighting force. It was so widely held that the states such as Austria, Italy, and Denmark were hoping to bandwagon with France to attempt to make gains from the predicted military successes. (Wetzel 179-180) Still, "Bismarck got his war because of the French people, half-led by and half leading their Emperor, blundered into a senseless conflict for which they were totally unprepared" (Bresler 353).

As the Franco-Prussian war approached the Prussian army had over one million troops available for the conflict, however the French army would only be able to produce some 400,000 troops. These differences arose from the fact that the Prussian military was based on universal conscription. $^{46}$ Every twenty year old man capable of service was called upon for an initial deployment of three years, which was to be followed by four more years of service in the reserves, and five more years of service in the National Guard. The French army was based on a volunteer system with seven year enlistments and bonuses to be paid on reenlistment. This also

\footnotetext{
45 This sentiment was reaffirmed through Louis Napoleon's pledge, “The Empire means peace." Wright, Gordon. France in Modern Times: From Enlightenment to the Present. New York: W. W. Norton and Company, 1987: page 195

${ }^{46}$ For more of a comparison of Franco-Prussian military realities and strategies see Thompson, J. M. Louis Napoleon and the Second Empire. Oxford: Basil Blackwell Publishing, 1965: page 290-292.
} 
meant that the Prussian army was considerably younger than the army of France. It was seen that while the French Army may have been better trained that the shear numbers of the Prussian army would be able to make up for any qualitative differences. (Wawro 41-42) Additionally, the command and control structure of the Prussian Army can be seen as superior, in that Prussian officers underwent more advanced and constant training and were considerably younger than their French counterparts (Wawro 48-49). The mindset of French military strategy can also be seen as lagging. "France had plunged into a conflict unprepared, with a brave army, but grievously disorganized and with hopelessly outdated equipment and generals whose mind-frame was still set in the Crimean War" (Bresler 365). It can be seen that France appears to have rested on its Crimean victory and did not find a spark to innovate in its actions in Syria and Mexico.

\section{Deeper into the Decline}

"[T]he foreign policy of the Second Empire did not fail. Napoleon III destroyed the Metternichian concert but he could not reshape it as he had wished. And when Prussian nationalism, flowing the example already given by Cavour in Italy, shook loose from the control of Europe and became, at least in the minds of Frenchmen, a menace to France, the emperor could not reconstruct against Germany the conservative pre-1856 concert that the conquerors of his imperial predecessor had erected against France." (Echard 304-305) The rise of Germany was certainly the final straw for French dominance, yet several death rattles could be heard long before this final blow. Napoleon III faced an uphill battle in international community from his rise to power. His family name was of great importance to him in his domestic political life, yet asking the powers of Europe to trust another Napoleon was a difficult proposition that handicapped his foreign policy from the beginning. There was also a persevering desire in the 
other capitals of Europe to maintain the status quo. (Echard 305) Louis Napoleon was not a revisionist in the true sense of the dichotomy, still he was not seeking in his grand strategy to maintain the status quo. It was his hope that a more peaceful Europe could be created through the formation of formalized norms conveyed through a deep and lasting congress system. This was something that the other great powers feared, as the motivations of France were not seen as a pure, and the need for such a system of binding relationships was questioned in the face of weakened France.

The threat perception of France by the other great powers, particularly Britain, can be seen as a vehicle for the retrenchment of realist views of foreign policy (Echard 306). This is telling in that in order for Napoleon to realize his grand strategy of a norm-bound Europe he would have needed an expansion of the liberal polices that arose from the original concert system that he was partially responsible for destroying. Still, that was not the political force that met his overtures. France's policies were met with a mixture of fear and un-interest. The uninterest that met the policies of Napoleon III are telling in that the other great powers were both fearful of the legacy and intentions of another Napoleonic France, while seemingly unimpressed with the power and willingness of his France. The other great powers saw the lack of efficient uses of resources and they questioned the political willingness of the government, as it was seen as too heavily influenced by mass public opinion (Echard 307). In the conduct of the Crimean War and the Franco-Austrian War public opinion forced France to sue for peace before all the stated goals could be achieved. This depicted a weak-willed state in the eyes of the other powers. The perception of a willingness problem and the resource/military power differentials can be seen as a creating a picture of a great power unworthy of undertaking a new course of binding despite Europe's views of its emperor. 
The power of France must be seen in conjunction with the state's ability to convert resources into military power. Louis Napoleon's government did not efficiently transfer latent power into realized military might, as the power of the military lagged behind the resources available to the state. (Echard 275) This portion of the historical record must be seen in two distinct lights. First, was this inefficient power transformation the result of a perceived lack of need for such might in light of the state's congress policies? Or, was the lack of transformation out of a policy of attempting to ensure that balancing was not necessary for the other great powers of the day? If the latter was the case, one could then argue that such a policy actually failed to work to the advantage of the France, since France's lack of military efficiency can be seen as a cause of the failure of the congress policy. A state with a highly useful and robust military that seeks binding partners would tend to find more willing participants, as the other members of the system could see binding as a desirable policy in comparison to policies of balancing or bandwagoning, as binding could have then be seen as a more efficient and less costly option.

\section{The Impact of France's Hegemonic Power Concentration}

France's weakness can be found in its lack of true hegemonic power. While, the state can be seen to be lacking in power resources in comparison to Britain in economic regards and in comparison to Russia in terms of population size it still possessed the largest and most funded land based military of the era. France was also seen as the preponderant military by the other states in the system, but this perception was based upon France's actions in relatively small scale conflicts. Moreover, France was weakened by the perception that it lacked a great deal of political willingness to back up its power resources. These historical facts placed the French state in a telling position as a state that was seen as potentially threatening because of its recent 
past and military numbers but still lacking in political willingness. Thus, France was unable to attract the kind of binding partners that it truly sought. But, still in its time of most need during the Franco-Prussian War Britain, a potential and logical balancing partner, stayed on the sidelines seeing France as both able to fend for itself and in need of a decrease in power. France under Napoleon III was both too powerful and too weak to induce other states to joint it in alliances or increased binding regimes.

\section{The Dependent Variable - The Balancing of France}

The rise to power in France of another member of the Bonaparte family was enough to increase the fears of the other great powers of Europe. Nevertheless, Napoleon III attempted to ensure that his France would not face the same balancing challenges that met the France of his uncle. Louis Napoleon's policies were not sufficient to prevent the creation of any fears as the following quote reveals. "But when a year later the anonymous President proclaimed himself Emperor under the name of Napoleon III, Europe was suddenly alarmed. Had not the Powers assembled at the Congress of Vienna solemnly sworn that no Bonaparte should again sit upon the French throne." (Thompson 137) Napoleon III did have one advantage to his uncle, that being the geopolitical realities of the international system at his point of ascension to power in France. "The Concert of Europe had originally been formed to safeguard the states of Europe from French domination, and the rise of a new Napoleon, like the revolutions themselves, might have been expected to encourage the other monarchs to close ranks. That this did not happen was due above all to the fear of the growing power of Russia, which obscured the emergence in France of a renewed threat to the old order." (Gilbert et. al 1065) This was a great benefit to the Second Empire, as France was not perceived to be in need of balancing in the same manner as 
the growing Russian threat. Napoleon III's France was also placed in a position to build credibility and good will through its balancing of Russia.

The government of Napoleon III was aware of the potential risks posed to the state through international balancing, a fact learned by members of the government through the actions of Napoleon I. This realization meant that Napoleon III's advisors and ministers would attempt to move Louis away from ideologically based foreign policies. (Wright 133) However, this would ultimately prove to be a difficult proposition for those around Napoleon, as his thoughts in the foreign policy arena tended to lean towards the ideological. This is seen in his favoritism for national self-determination and his beliefs about the state of Europe. This does illustrate that members of government were concerned over potential balancing actions, and desired to remain unbalanced through the execution of France's foreign policy. This will be seen as a both blessing to France as well as a curse. Yet it is key to this work that the government of France realized that its power utility could be maximized through policies that prevented balancing and favored binding of French power. ${ }^{47}$ Another reality of the international power landscape that can be seen as both a blessing and a curse for a dominant France was the foreign policy and perceptions of Britain.

As the Congress of Vienna came into fruition Britain came to the conference with a distinct goal in mind. It was the aim of the British to create an international regime that would ensure that the state could implement a policy of isolationism in regards to the continent of Europe. (Chapman 16-17) This would allow Britain to expand its colonial activities and become a balancer of last resort for Europe. Castlereagh saw the politics of the continent as a potential quagmire that could decrease the state's growing power. Thus, it was Britain's aim that the

\footnotetext{
${ }^{47}$ The Government of Napoleon III also sought to avoid any policies that could be interpreted as a land grab by the other great powers of the day. More detail can be found in Echard, William E. Napoleon III and the Concert of Europe. Baton Rouge: Louisiana State UP, 1983: page 303.
} 
Congress would allow the British to feel safe from attack and unneeded as a day-to-day balancer. It was their hope that the other powers Europe could be counted on to maintain the status quo distribution of power, hence France was not to be weakened to the point that it could not function in a balancing capacity. This would allow Britain to focus its resources on the development of its colonial holdings (Chapman 20). This can be seen as blessing for the government of Napoleon III, in that Britain desired to remain aloof of the majority of continental politics, and thus France could expect to remain unbalanced by Britain unless its actions became so egregious as to call Britain onto the continent as an off-shore balancer. ${ }^{48}$ The preferences of Britain were also an irritation to Louis' polices since he hoped to create a binding alliance with Britain. Such an alliance was expected to make the dominance of French power more palatable to the remainder of Europe; to keep Britain engaged in European affairs; and to provide an ally for France if such a need were to arise. (Echard 34)

The Crimean War represented France's first avenue to increase its international credibility and build good will with the other powers of Europe. The conflict was also a means of taking action on the opposite side of a balancing arrangement as opposed to the state's more recent balancing experiences. "The Turks, he told Crowley, were to understand 'that France and England were not protecting her, as Turkey, but as a parcel of territory the integrity of which was necessary to the balance of power in Europe"' (Echard 167). The war was undertaken by France and Britain, working in concert, to balance the rising power of Russia and to prevent the Russian state from gaining strategic areas in the Ottoman Empire that would have afforded it a warm water port. The war with Russia also served the secondary purpose of increasing domestic and international prestige for the French military.

\footnotetext{
${ }^{48}$ For more information on the concept of off shore balancing see Mearsheimer, John J. The Tragedy of Great Power Politics. New York: W. W. Norton \& Company, 2001.
} 
Louis Napoleon was aware of the need for foreign policy victories that re-instill French pride, and invigorate his leadership. Russia presented such a potential victory. Russia existed as such a target, for it was Russia rising power that largely supported the treaties of 1815 which were perceived to be restraining France. (Gilbert et. al 1069) However, Louis was aware that such a unilateral war against Russia would only strengthen the cause for renewed balancing of France. Napoleon was able to gain British support for a balancing war against Russia in the Crimea, thus providing France with a key ally and a military relationship to aid in the fight against Russia. (Gilbert et. al 1071) Britain was so ready to join France in this cause, not out a perceived need to increase French power, but out a need to check the rising Russian threat. However, it was the Crimean War the effectively destroyed the Concert of Europe and weakened Russia, thus allowing France to regain its position as the dominant continental power. (Gilbert et al 1070) Napoleon also gained a diplomatic victory as Paris was the site of the treaty negotiations that followed the war, moreover the Treaty of Paris was created in a manner so as to bind the Russian state and relieve so constraints upon France (Gilbert et al 1077). Though, Louis still sought a degree of restraint for France so as to prevent the beginning of balancing activities.

The Congress of Paris that followed the Crimean war could have also served France as it hoped to ingrain its ties to Britain as Louis desired to ensure that the British alliance outlasted the war with Russia. Still the British feared that the Congress and the peace settlement could be created in such a way so as to entangle it in future continental matters. This was the goal of Napoleon III but the goals of the two balancers could not be combined, as France was unable to guarantee future British involvement. (Echard 64)

Nonetheless the government of Napoleon III, through its congress policy and multilateral actions, was able to prevent a majority of balancing. The case of Napoleon III's France in 
regards to balancing is really a case of the failure of other powers to come to aid of France when it needed balancing partners in its relations with Prussia/Germany. It can be seen that no matter how good a citizen the state of France attempted to be it still could not earn back the trust of the remainder of the great powers of Europe and this is telling when one realizes that the other European powers failed to come to the aid of a state that had sought to create a more unified and pacific Europe during its time as a dominant actor in the international system.

The Austro-Prussian War and the subsequent annexation of increased territory quickly brought Germany to a power level that would rival France. The new territories increased the German population to 30 million, which then rivaled France's population of 38 million. The German use of universal conscription also meant that the German army was now one-third larger than that of France. France's neighbor who was once easily dismissed had just taken a position of military dominance situated on the French boarder. (Wawro 19) The policies of Bismarck were undertaken in such a way that he was able to gain nominal British support for his unification policy as well as French neutrality. By 1862, Bismarck had informed the British of his plans to unify Germany through a consolidation of the German territories and a war with Austria (Bresler 336). It can be seen that the British approved of such a plan, for they wished to remain outside of the day-to-day balance of power politics of the continent and that a unified Germany would make an impressive counterweight to the power of France. Moreover, Bismarck had also gained Napoleon's neutrality in a war with Austria. The French granted such neutrality without even a request of territory from the war or a pledge of Franco-German peace. (Bresler 337) This can be argued to have arisen from either of three of Napoleon III's ideals. First, it could have been the result of his support for national self-determination, as he had long championed this cause. Second, it could have arisen out of the French population's desire for 
peace. Or finally, it could have come from Napoleon's hope that a consolidated Germany would decrease continental fears of French power, thus allowing Louis to better guide a less asymmetrical Europe. However, Napoleon must not have counted on the reaches of the German successes, or the fact that such unification would cede the predominance of power to a new, united German state.

Still the unification of Germany under the policies of Bismarck can also be seen as an utter surprise to France. Napoleon III's cabinet immediately called for war, as did the increasing liberal parliament. Yet, France did not move quickly towards war, though the Prussian army was stilled engaged with Austria. Rather, Napoleon called for German support of the pre-Congress of Vienna boarders, a call that was decidedly rejected by the German government. (Wawro 17) The failure of the French government to quickly realize the power stakes of German unification were complicated by the pragmatic manner in which Bismarck prepared the diplomatic ground for the Franco-Prussian War. Bismarck was well aware of the of the need to make the France of Napoleon III resemble the France of his uncle, in that France must had to made to look as the aggressor. Thus, the Prussian leader played on the French need for territorial stability and its long term aims to regain the boarders of the 1814. Furthermore, he placed Napoleon III on the wrong side of an ideal for which he had long been a champion, that being national selfdetermination. Bismarck was also aware that only a great foreign policy struggle could provide the optimal environment for the unification of Germany. (Wawro 22)

Finally, the foreshadowing of the end of France's position as a dominant power and Germany's rise was written in Napoleon III's constant, futile attempts to create a more formalized European system. "War was destined to erupt over precisely the sort of question of 'law' and European order that the concert might have been expected resolve" (Echard 297). The 
passage indicates that the Franco-Prussian War arose from the very tensions and fears that a successful congress system, as lobbied for by Napoleon III, would have been able to prevent. It is telling that the war that would officially end France's time as a dominant state in the international system could have been prevented had the policies of the dominant state been better able to shape the international environment. France's inability to shape the international system can be traced to two competing difficulties for the state. France was seen at times as both too threatening, as a result of its recent history, and too weak to fear, as a result of its problems transferring resources into efficient military power. These conflicting perceptions of Louis' France meant that the other great powers of the era were either too skeptical to follow the state's lead or uninterested in the potential power of France.

\section{The Impact of Balancing on France}

The historical record shows that throughout most of Napoleon III's reign France was able to avoid major balancing, particularly the encircling alliances that troubled the state's recent history. This indicates that the government of the day was able to successfully navigate the preexisting constraints placed upon the state by the concert of Europe and to some extend Louis Napoleon was able to extend and deepen international regimes. The conclusion of France's period of dominance came from the state's inability to detect and respond to the growing threat of Prussia/Germany and the inaction of Britain. The lack of bandwagoning by Britain that could have prevented the rise of German power on the continent should be seen as a form of balancing.

It can be seen that Britain sought to balance French power by not bandwagoning with it, thus it was a balancing action that contributed to the demise of French dominance. 


\section{Answering the Questions}

The Systemic Level (Dependent Variable)

- Who are the primary actors in the international system, and what justifies such a classification?

Table 4-2: The Great Powers in the Time of Napoleon III

\begin{tabular}{|c|l|}
\hline State & \multicolumn{1}{c|}{ Great Power Justification } \\
\hline France & $\begin{array}{l}\text { Economic Power and Hub } \\
\text { Perception of Predominate Military } \\
\text { Arbiter of Europe following Crimean War }\end{array}$ \\
\hline Britain & $\begin{array}{l}\text { Global Economic Power } \\
\text { Naval Power } \\
\text { Off - Shore Balancer } \\
\text { Potential Balancer }\end{array}$ \\
\hline Russia & $\begin{array}{l}\text { Population Advantage } \\
\text { Latent Power } \\
\text { Potential Balancer }\end{array}$ \\
\hline Prussia/Germany & $\begin{array}{l}\text { Rising Power } \\
\text { Growing Economic Power } \\
\text { Potential Balancer }\end{array}$ \\
\hline Austria - Hungary & $\begin{array}{l}\text { Declining Power } \\
\text { Potential Balancer }\end{array}$ \\
\hline
\end{tabular}

- What actually triggers alliance formation in a given historical situation?

The major alliance created during this time period was the alliance formed between France and Britain in order to balance the growth of Russian power and thus win the Crimean War. The Franco - Anglo Alliance was not a permanent alliance, though France did hope that the alliance could be formalized and extended beyond the war with Russia. This alliance was triggered as a result of the fear of Russian power. It gave the French state the ability to act as a balancer an enabled the state to attempt to regain some degree of its credibility that was 
diminished by the Napoleonic Wars. The alliance was not a defense of Turkey per say, rather it is merely a balancing alliance targeted towards Russia.

Another minor alliance that occurred during this time period was another temporary alliance between France, Spain, and Britain. The alliance was created with colonial and international norm considerations in mind, as the three states attempted to force Mexico to adapt European style property rights that would then favor the three states. This alliance was also one that was not permanent in nature, but merely an attempt to take common action. The same can be seen in Franco - English cooperation during the Syrian Crisis. These alliances while not permanent in nature can be seen to have increased channels of dialog and influence. They also depict French efforts to create a system of alliances that would have bound the power of the state to other great powers of the era. It was a long term goal of the government of Napoleon III to create a European system of alliances with France as the hub and Britain and Russia as the cornerstones of the alliance, but the realities of France's recent history and the states lack of real coercive power likely made the alliances seem inefficient and unneeded to the other two states.

- Is balancing or bandwagoning seen in alliance formations?

Other than the balancing of Russia, as discussed above, this era saw very little in the way of traditional balancing and bandwagoning in response to the dominant power of France. Napoleon III's government was well aware of the impact that balancing alliances had on the previous Napoleonic government, and was thus vigilant in his attempts to not only attract binding partners for France but also to self-restraint the power of French state. Louis Napoleon's foreign policy was conducted with concert style diplomacy whenever possible. Moreover, the historical record indicates that the Emperor did not undertake military action without the blessing or alliance with other great powers. The Franco-Austrian Conflict is a prime illustration of 
Napoleon III navigating the constraints of the existing treaties to ensure that the conflict appeared to be one of last resort for the French state. The prevention of balancing alliances can be seen as basis of the state's foreign affairs during this time period.

While France was able to prevent a great deal of balancing one such instance is seen in the historical record, however this form of balancing does not occur in a traditional manner. The Franco-Prussian War which ultimately signaled the decline of French dominance. Bismarck planned to lure France into the war that would eventually unite Germany sought British neutrality. One would consider that Britain would have had a vested interest in insuring that France remained a viable balancing partner and that it would not have desired the rise of another great power in Central Europe. However, the British despite the attempts of Napoleon III to convince them still feared the power of France. It was the belief of the government in London that Germany would serve as a good counterweight to French power, as they believed that Prussia could only marginally decrease French power. This seems to be case of what can be termed balancing by not bandwagoning. It would have been logical for Britain to have bandwagoned with France against Prussia/Germany as it sought to ensure the preservation of the status quo power distribution in the system. But instead of taking this traditional action it choose to remain on the sidelines, and thus balanced French power by not bandwagoning with it. ${ }^{49}$

- Are cases of stability the result of a perception of non-threat by the larger pole? Is this stability the result of binding by the preponderant power in the system?

France despite its best efforts was never really able to attract any serious binding partners, though the state was able to prevent a great deal of balancing through the use of a procongress foreign policy and the avoidance of unilateral action. The state worked through the

\footnotetext{
${ }^{49}$ This should prove to be a valuable post-dissertation research area, as this balancing by not bandwagoning action differs from Mearsheimer's notions of bloodletting and baiting and bleeding since Britain took no active actions to encourage or prolong the conflict but rather hoped that the conflict would only decrease the power of France even marginally.
} 
existing Concert of Europe international regime system and attempted to expand the system were possible as through the Congress of Paris and the state's bilateral tariff reduction treaties.

These regimes which were formalized in nature were able to create lines of dialog and influence to some extent, and thus some degree of minimal binding. But, what appears to have decreased the balancing activity of the other great powers in the region was France's careful navigation of the existing restraints placed upon the state and its ability to moderately deepen the existing restraints. One can only think of how the system would have been different had France had a greater preponderance of power that would have encouraged the states in the system to take more seriously the French overtures for binding and a system of alliances. Still one would never know if France would have taken the same course with such a higher degree of hegemonic power concentration.

\section{The State Level}

- What is the institutional make-up of the state in question?

In 1848, Napoleon III was elected president of the France and he sat atop the French political system that included a prime minister, ministers, and a parliament elected by universal suffrage. 1852 saw a coup in which Louis Napoleon took the title of Emperor. The coup arose from the French constitutional realities that did not allow Napoleon III to seek another term as president. He initially attempted to seek a constitutional amendment that would allow additional presidential terms, however this route became untenable and a coup became the only path that could reasonably to be taken. The coup was legitimized through the use of a plebiscite that allowed citizens to either support or reject Napoleon III's title as emperor with the condition that the legislature and ministers would remain focal points of the new French government. Napoleon III's motivations for his domestic political concerns is truly interesting. During the 
majority of his rule he lacked any real domestic political opposition, however Louis Napoleon remained sensitive to domestic politics out of a perception of its importance.

This blended style of government was unique in the case of Napoleon III's France as a needed to maintain the credibility of the legislature to maintain control of the state. The population of France had had a taste of democracy and was seen as a population that would tolerate the removal of all their new rights, and thus such a political reality meant that the legislature was the only body that could conceivably increase in power during the emperor's reign or the state could face yet another revolution. The power of the legislature existed in two forms. First, the body had oversight capabilities, and thus the ability to voice their concerns or objections to the population which was growing in power in the new French government. The legislature also had a great deal of power in terms of its powers of finance, and with control over tax and spending issues the legislature held some true power over the Emperor Napoleon III. Moreover, the manner in which Napoleon III came to power meant that the French Parliament could not be easily dismissed as this would quickly draw the attention and wrath of the masses.

The French political environment was further shaped by Napoleon III lack of political experience within the state. Louis Napoleon came to power in France as a virtual outsider, as he was raised and educated outside of the state. This meant that he lacked any strong personal connections within the society or the government, and thus upon gaining power he needed to act quickly to create a system of domestic allies. The perceived need for political partners further entrenched the power of those in the legislature and the ministers that Napoleon III choose, as it was known that these individuals were as a needed by Louis Napoleon as they needed him. Furthermore, the Emperor never lost his title as a politician and was thus never afraid to compromise or change policy directions if the political environment changed. Louis' lack of 
political experience within France and his perception of need for domestic political allies opened his government up to influence from a host of interests.

- Is the dominant state democratic in nature? And, are other system members also democratic?

Napoleon III was certainly the most powerful actor within the French government, but the power of the legislature and the masses could not be discounted in the government. The nature of the French government created a great deal of uncertainty in the government as these new paths of power were being created and newly navigated. Napoleon saw the majority of his state power arise from his family name as well as from the support he was able to gain from not only commercial interests but also the military which hoped for a return the halcyon days of Napoleon I. The legislature gained its legitimacy as a perceived democratic check on the power of the emperor. The government of Napoleon III was crossing new ground as tensions existed between the powers of liberalism and imperialism all the while the government fluctuated throughout the political spectrum.

The other government in the system that can be seen as potentially democratic in nature is the government of Britain. However, these commonalties between the two states did not bring them closer, despite the hopes of the France. Britain watched with concern as Napoleon III achieved more power through the 1852 Coup d'état and even with the presence of a legislature the state still feared France. More importantly Britain desired to stay outside of the foreign affairs of the continent unless its balancing powers were needed. Britain's hopes to remain aloof from European affairs and the increased fear of Russian power meant Napoleon III government drew less attention from the British than it may have in other conditions. 
- Does the state in question have a means for mass public opinion to influence state action?

The government of Napoleon III was influenced by the forces of public opinion. In France at this time the government was not necessarily purely driven by public opinion, but it was certainly influenced by public opinion. The government took measures through its local offices and officials to assess the state of public opinion and often sought to lead public opinion through these local officials or through the press. However, if the government was unable to successfully influence public opinion the state did respond to the opinions of the masses. Such an instance can be best seen in the cases of the both the Crimean War and the Franco-Austrian War, in both instances that government moved early to settle the conflict and bring about armistices.

There existed a division in public opinion along urban-rural distinctions. Rural opinion tended to be more easily swayed by recalling the past and calls for a return to the glory of recent French history, and thus rural opinion more tolerated military action. Urban opinion which was more war adverse in nature, and desired peace at almost any cost with the notable exception of the Franco-Prussian War. This forced the government to walk a fine line between the two groups, and thus Napoleon III's government attempted to use short military engagements that added honor to the French military to distract public opinion. The existence and influence of the masses at this time cannot be seen to be as powerful as future governments, but public opinion remained important and influential.

- What types of interest groups or elites are present in the state in question?

Other than the divided nature of French public opinion during this era that is discussed above there are also three other primary interests in the state that must be considered. First, commercial elites played a substantial role in French politics, particularly during Napoleon III's 
election and subsequent ascension to the seat of Emperor through the 1852 Coup. These commercial interests drew their power in French politics from two distinct areas. Louis Napoleon came to power in France without a great deal of knowledge of the domestic political environment and lacked a great deal of political allies. This meant that he was forced to seek out allies on the fly and these commercial interests which were also growing in power at the time as new centers of commercial and industrial power were created were perfect sources of support. Moreover, Napoleon III though eventually taking the position of Emperor of France still remained a politician and was thus willing to comprise and make deals for political purposes.

The strange relationship between the government and these commercial interests can be seen in both the tariff reduction treaties and the failed French policy in Mexico. The majority of French commercial business feared the free trade policies that the state began to implement as Napoleon III sought to increase the influence and status of France through the landmark reciprocal tariff reduction treaties. However, Louis was willing to run against these interests in this regard and attempted to regain their support through the state's policies in Mexico. The failed Mexican venture began as a multilateral effort of France, Spain, and Britain, and soon proved draining on the state. France decided to continue on in Mexico alone evening hoping to install a friendly government in part to appease commercial interests seeking such a mercantilist victory.

The French military's existence as an interest can also be traced back to Louis Napoleon's rise to power. As President of France he gained the support of the military through the promotion of supportive members of the military. In order to ensure that the 1852 Coup and plebiscite were to run smoothly Napoleon III would also need the support of the military. Thus, the French Army became a large and powerful interest within the government. The army sought 
a return to glory not only for France but more importantly for the French military which was embarrassed by its failings in its recent past. This need for glory and increased honor can be seen to have created a policy of the use of small military engagements that were approved by other powers in the system in order to feed to the desire for victory in the French military. However, in cases in which the military action were not necessarily quick or decisive the government would take actions to try to gain an armistice in order to appease the war adverse masses in urban areas as well as commercial interests that sought a continuation of the status quo, as was the case in the Crimean and Franco-Austrian wars.

The final interest that should be considered is the Catholic Church. The Church was able to gain its position of power within the government of Napoleon III by playing upon the Catholic leanings of the population as well as by using Louis' proclivities toward self-determination to gain his support for Italian questions. The Catholic Church sought both support for Christians and support for Italian questions. The Church's influence can be seen in France's actions in Syria to protect Christian populations and in the Franco-Austrian War which had its roots in questions of Italy and Rome.

- In what directions are such interests moving the government?

Table 4-3: French Interest Group Activity

\begin{tabular}{|l|l|}
\hline Interest & \multicolumn{1}{c|}{ Policy Direction } \\
\hline Urban Public & $\begin{array}{l}\text { War Averse } \\
\text { Liberalization of Government }\end{array}$ \\
\hline Rural Public & Return to Glory of Empire \\
\hline Commercial Elites & $\begin{array}{l}\text { War Adverse } \\
\text { Protectionism }\end{array}$ \\
\hline Military & Return to Glory of Empire \\
\hline
\end{tabular}




\begin{tabular}{|l|l|}
\hline Catholic Church & $\begin{array}{l}\text { Protection of Italian Interests } \\
\text { Protection of Christians }\end{array}$ \\
\hline
\end{tabular}

- Is the state in question a status quo power or could it be considered a revisionist power?

This is an interesting question when one considers the case of France. In most instances the dichotomy between status quo and revisionist states is determined by whether a state actively seeks of gain additional power within a system through the use of force. France under Napoleon III is unique in that the state desired to change the distribution of power in the system but not through the use of military force. Louis Napoleon hoped to return to the distribution of land in Europe as it was prior to the Congress of Vienna. Moreover, the French emperor desired a confederation of Europe or at least a system of alliances in Europe with Paris as the hub of power. However, France during this period of time did not seek to redraw the system or gain more power through the use of military force. The state was well aware of the constraints that existed throughout the system and sought to further restraint itself.

The government of Napoleon III was well aware of the potential dangers that existed in triggering countering alliances. France sought to build its power based on its existing stores of power as well as through the use of power generated through economic development and the use of diplomacy. The actor can then be seen as a revisionist state in some regards, but it did not operate with the tools and methods that a traditional state of this ilk would utilize.

\section{The International Regime Level}

- What types of regimes are present?

The case of France under Napoleon III reveals a great deal of activity within the international regime variable class, as it was Louis Napoleon's goal to make the rejuvenation of French power more palatable to the other great powers of Europe. The first international regime 
that must be considered is the Treaty of Vienna and the ensuing Congress of Europe, as it is this grouping of norms that set the table for the future international regime actions that were to take place during the rule of Napoleon III. The treaty set five primary conditions for state interaction within the European international system. These norms were designed to maintain the status quo distribution of power and to ensure stability between the great powers of the era:

1. Only the five great powers would have the ability to decide great power problems.

2. War was not to be undertaken for territorial gain, nor were great powers to aid in revolutionary causes within other states.

3. One power could not raise a question of importance to another state without its consent.

4. If a crisis or question arose any great power could call for a congress to mediate the problem, and no great power could be excluded.

5. Confrontation between the great powers was to be avoided at all cost.

These five primary norms as set by the Congress of Vienna were the guiding framework for the foreign policy of Napoleon III. He was aware of the precarious position that his France found itself in, as the power that caused the need for such a congress and created encircling alliances that fostered great warfare on the continent. Thus, he sought to abide by these restrictions and restraints while attempting to deepen the European congress system. It was his ultimate goal to create a confederated Europe with Paris as the hub of inter-continental activity.

The Syrian Crisis of the 1860s illustrates the importance with which France placed upon congressional style action. The government of Napoleon III was able to find both domestic and international grounds for French intervention in Syria to protect the regions Christian population, and still the state would not take this international action without the consent of the other European great powers, particularly Britain. Napoleon III recognized the importance of friendly and stable relations with Britain and ultimately hoped for a lasting alliance between the two 
states, as he saw the isolationist state as the perfect binding partner for France. The French state's unwillingness to act in Syria without the approval of the other great powers illustrates the states willingness to be constrained and to prevent the potential formation of resentment and fear within the seats of European power.

The failed Mexico policy of France also began as a joint effort of France, Britain, and Spain to place European style norms of property rights upon Mexico. While France essentially decided to finally attempt to take latter actions alone the policy only began with the consent and blessing of the other European great powers. It was after all a policy that Napoleon III hoped would gain France both international credibility as an enforcer of norms but also pay dividends domestically as a means of diverting public attention from the decline in democracy within the state.

Most importantly for the consideration of international regimes in the case of France is the Congress and Treaty of Paris that followed the completion of the Crimean War. The war afforded France the ability to act as a balancer and to regain some degree of international credibility. The conflict was also a means by which France could act in alliance with Britain, and its was the goal of Napoleon III to use this war time relationship with the British to parlay it into a lasting alliance that could coax Britain into taking a more active role in continental affairs and produce an optimal binding partner for the French state. The goal of an Anglo-Franco alliance was never realized but the congress and ensuing treaty did provide a forum for Napoleon III to attempt to deepen the existing congressional relationship between the great powers of Europe. Louis Napoleon was a primary architect of the Treaty of Paris and the conditions of the treaty can be traced to his ideas about the relations of states within Europe. The Paris treaty codified seven basic norms. 
1. The Treaty of Paris admitted the Ottoman Empire to the Concert of Europe.

2. The treaty provided for collective mediation of any disagreements between the Ottoman Empire and the signatory states of the treaty.

3. The congress placed the Ionian Islands, the Danubian Principalities, and Serbia under the protection of the great powers.

4. The agreement called for further congress action and the principles of selfdetermination to resolve the disputes surrounding the territories.

5. The regime internationalized all the great rivers of Europe.

6. The congress also included the Declaration of Paris which formalized rules of naval warfare.

7. The congress also created a European Commission that was to carry out continued negotiations and programs as set by the Treaty of Paris.

The importance of the Congress of Paris lies in its deepening of channels of negotiations and lines of communication as well in its expansion of the norms of the Congress of Vienna. The creation of a standing European Commission can be seen as watershed moment for European affairs, as this formalized lines of negotiation and channels of communication between the great powers of the day. It can also be seen as a means of conveying both restraint and influence between the seats of power in Europe. The incorporation of the Ottoman Empire into the Concert of Europe can be seen as a de facto grant of great power status to a weakening state in the hopes of preventing an outright decline of the power. The Declaration of Paris and the internationalization of major European rivers can be seen as major events as well. These norms were created by Napoleon III and can be seen as the use of international regimes to limit the impact of naval power, thus they are a direct action by France to limit the power advantage of the British posed by that states naval superiority.

A final and key aspect of Napoleon III's international regime policies was his insistence on the creation of reciprocal bilateral tariff reduction treaties. First, it is important to note that 
these trade agreements ran in the face of the prevailing economic interests within France who desired the continuation of France's protectionist policies and yet Louis saw these tariff reduction treaties as a means of expanding France's economic influence and as a means of garnering international support and goodwill. Moreover, the tariff reduction treaties created a system of trade in which Paris was the hub as the originator of all of the treaties, and thus these reductions in import taxation by the economically robust French state can be seen as a public good extended to the European international system. These systems of treaties began in 1860 with the Cobden-Chevalier Trade Treaty with Britain, and were soon duplicated by the government in Paris to include similar agreements with Belgium, the German Customs Union, Italy, Austria, Sweden, Switzerland, the Netherlands, Spain, and Turkey. The tariff reduction treaties essentially made France the hub of freer trade throughout Europe, and they also showed France's willingness to take losses to foster better relations and stability throughout the international system.

- Are these regimes formal or informal in nature?

The treaties, congresses, and agreements of Napoleon III's France illustrate the growth of codified and formalized agreements throughout the European system. These international regimes can be seen to depict a rise in the formalization of such regimes. The constant congresses called by Louis' government and the state's willingness to enter into formalized agreements show positive motion and progress in international regime legitimation. The importance of the increase in regime formalization exists in the growing regulation of state behavior. That is not to say that these international regimes could not be bent or broken if the environment was right, but it does mean that these international norms fostered an international system in which actors were aware of the types of behaviors that were and were not acceptable. 
The proliferation of more formalized international regimes during this time period meant that states were then aware of the actions that would draw reprisal. These known boundaries meant increased stability for the system.

- Does the presence of regimes constrain state action?

France under Napoleon III can be seen as constrained by international regimes, both those that his government was key in creating and regimes that predated his ascension to power. Louis Napoleon's France showed a dedication to taking foreign action only with the consent of the other great powers, thus showing a true dedication to the ideals of a congressional style of diplomacy and foreign affairs. The government of France went so far as to consider the calling of a great power congress in the hopes of dealing with the rising threat of Prussia to the east. This is demonstrative of a state that feared encircling alliances and particularly the balancing of Britain, as it learned its lessons well from the failures of Napoleon I's France. The dedication of the French to policies of restraint are further illustrated in the state's Syrian, Italian, Mexican, and Polish policies, all of which were centered around unified great power action or at minimum approval from another great power.

However, the Franco-Austrian War does show that the state was willing to use the international regimes and channels as a means of conflict legitimation. The government of Napoleon III was able to use calls for congresses and Austrian responses to show the Austrian state in such a light that France could undertake a conflict without fear of direct balancing by other great powers. This portion of the historical record illustrates both a respect for the importance of restraint and the governmental ability to navigate restraints without triggering the traps of balancing alliances. 
The respect that France had for its restraints during this time period are better seen in the long term goals that Louis Napoleon held for the European system. It was his goal not only to help foster a confederated Europe but more realizable he had hoped to create a European alliance system that would have been defensive in nature and ensured mutual protection and restraint through the capitals of the great powers. The downfall of this alliance plan lay in France's inability to regain the level of international credibility with states such as Britain and Russia. The Emperor's France did not have the bargaining power and leverage to make binding bilateral or multilateral alliances appealing to these two primary powers.

- Who are the creators or architects of the regimes in question?

Napoleon III used the Concert of Europe as the foundation and backdrop to his foreign policy. This represents an external constraint upon France, as France played the role of the foil in the Congress of Vienna. However, Louis Napoleon was able to deepen and expand the original concert through his international regime undertakings. The case of France represents the existence of both internal and external sources of restraint and a deeper understanding of the need for power constraint than was expected from this case and this time period.

\section{The Power Concentration Level}

- Across potential competitors how is population divided?

The graphic bellow provides an illustration of the population break downs of France and the other major players of the era. ${ }^{50}$

\footnotetext{
${ }^{50}$ The numbers in the graph are taken from the Correlates of War Project's National Capabilities Data Set. The numbers are the mean population of each state from 1848-1873.
} 


\section{Table 4-4: Great Power Population Size during the Rule of Napoleon III}

\begin{tabular}{|l|r|}
\hline \multicolumn{1}{|c|}{ State } & Population \\
\hline France & $36,819,615$ \\
\hline Britain & $29,202,500$ \\
\hline Russia & $75,223,077$ \\
\hline Prussia/Germany & $22,709,192$ \\
\hline Austria - Hungary & $36,256,385$ \\
\hline
\end{tabular}

The numbers illustrate that France held an advantage over all great powers in the system, save Russia. The Russian state is unique in its population numbers, as it was a state of vast territory on the outskirts of the European system. The historical record indicates that Russia during this time had difficulty transferring its substantial population advantage into a projectable military force. The Napoleonic Wars illustrate that these population advantages were useful as a defensive measure, however the Crimean War shows that these numbers did not equal military superiority on foreign soil. Austria - Hungary is also a point of interest as their population numbers were close to those of France, yet once again the Austrian state must be seen as a declining power as seen through its hopes for the Concert of Europe and its failings in conflicts of the era.

- How is economic power divided between the target state of each case study and the other great powers in the system?

The numbers bellow depicts the iron and steel production as well as the energy consumption of each state. $^{51}$

\footnotetext{
${ }^{51}$ The numbers are created using the same method undertaken to illustrate the raw population numbers in the previous section.
} 
Table 4-5: Great Power Economic Indicators in the Case of France

\begin{tabular}{|l|r|r|}
\hline \multicolumn{1}{|c|}{ State } & Iron and Steel Production & Energy Consumption \\
\hline France & 941,000 & $14,860,192$ \\
\hline Britain & $4,151,923$ & $82,774,654$ \\
\hline Russia & 281,192 & 633,538 \\
\hline Prussia/Germany & 756,692 & $17,631,192$ \\
\hline Austria - Hungary & 313,423 & $2,970,962$ \\
\hline
\end{tabular}

Iron and steel production and energy consumption are used as reliable variables to aid in the uncovering of economic prowess for this time period. The numbers show that in the realm of iron and steel production France was only surpassed by one challenger that being the British state. Britain must be seen as a unique case in this time period of the study, as it was a state of enormous global power. Yet, the British hoped to remain outside of continental power politics as they hoped to further expand and extract wealth from their colonial holdings and remain in isolation in Europe. This is echoed in their lack of action within the Europe, with the exception of the Crimean War in which they acted as a balancer of Russia in an area of strategic importance, as the state did not wish for Russia to gain a potential warm water port nor the ability to interrupt trade. Britain's beliefs during the creation of the Treaty of Vienna are also telling in this regard. The state sought to aid in the creation of a system that would need little attention from the island country. Thus, it can be seen that France was granted its European dominance by the British who did not desire the drain in resources and time.

The numbers along with the historical record do indicate that many in Europe appear to have ignored the rising power that was Prussia/Germany. The areas energy consumption as well as its iron and steel production must be seen as significant. It seems that those in power in the capitals of Europe were either under prepared for the unification of the German state or did not believe that Bismarck would have the ability to unify the region. Still, during most of France's time of dominance the Germanic region must be seen as a mere gathering storm for these 
considerations. These economic also aid in a more complete telling of the stories of Russia and Austria-Hungary, as the numbers show that both states were lacking in economic development and growth.

France's economic growth during the rule of Napoleon III is further supported by the historical record. France during this time period not only saw a dramatic increase in its population, but the state also witnessed an economic windfall. The state during this time saw a doubling of its industrial production; a tripling of its trade; as well as an increase in its railways. These developments outstripped the growth rates of all of the other great powers in the system, and also leant to the perception of France's return to dominance.

- Across potential competitors how is military strength, as measured by either military personnel or military expenditures, divided? (In some cases both measures may be present)

This work holds military might to be the supreme determinant of hegemonic power concentration, as both population and economic power can be seen to feed military might. The graphic bellow illustrates the mean military personnel numbers and expenditures during the rule of Napoleon III.

Table 4-6: Great Power Military Comparisons for the Case of France

\begin{tabular}{|l|r|r|}
\hline \multicolumn{1}{|c|}{ State } & Military Personnel & \multicolumn{1}{c|}{ Military Expenditures } \\
\hline France & 504,769 & $27,559,269$ \\
\hline Britain & 270,615 & $22,675,154$ \\
\hline Russia & 865,500 & $21,939,077$ \\
\hline Prussia/Germany & 237,692 & $8,068,962$ \\
\hline Austria - Hungary & 350,077 & $11,501,308$ \\
\hline
\end{tabular}

It is here that we can see a more compelling illustration of French dominance. France outspent all of its potential competitors in terms of military funding. The numbers are more telling if one considers the bias in British funding that must exist when the size of the British 
Navy is taken into account. The Russian spending is also spread out over a greater number of troops, but the historical record of the era shows the dominance of the French Army over the larger Russian Army. France's actual military force numbers are only surpassed by the Russian Army, an army with vast territories to protect and little in the way of power projection.

The joint actions of the British and French armies illustrated the superiority of the France. This is also supported through the belief in the testing and training of the French military. France was also blessed with the perception of military strength by the other great powers, with the exception of Bismarck's state prior to the Franco-Prussian War. The historical record shows the importance with which the notion of perception of military strength must be considered. It seems that the other powers of the era remembered the power of the French Army from the days of the first Napoleon and assumed that that the army still possessed such levels of training and power.

- Are any technological or research and design issues present in a given system that could increase the power level of state in question that may not be detected by the previous questions?

Technological and strategic advances of other states in the system, particularly the rising German state were largely undetected by the previous questions. The military power of France was largely assumed by the other states in the system in the save Prussia/Germany as a result of superiority of the French military in the Crimean War in relation to both British and Russian forces, however the French Army was not on the cutting edge of technology or strategy but merely seemed superior in comparison to the other forces. The German forces possessed an advantage that came from both technology and strategy that were seen in the Franco-Prussian War. Germany had rapidly used the new power of railways to increase the mobility of its forces and supplanted this advantage with a new reserve system that allowed the state to mobilize large forces of well trained and exercised troops. This must be compared to the general malaise of the 
French forces that were wrought with alcoholism and were under prepared. The officer corps of the two states were also diverging as the German forces had an officer corps that was younger and more trained, thus providing an increase in morale for their forces.

- If soft power is present in the system, how is such a resource divided between the primary actors?

Within the government there was the desire for the cultivation and use of soft power by the state. This does not mean that a large degree of soft power was necessarily realized by France. Napoleon III sought to create a type of "moral hegemony" within France based on his strong desire to see the implementation of self-determination and the creation of a confederation of European states. However, this desire for soft power and the realization of soft power resources are two distinct things. France was challenged in its power to attract other states through its recent history and the name of it emperor. Louis Napoleon attempted to create good will and trust through the use of tariff reduction treaties, calls for congress, and joint action, but these attempts seem to have been too little to overcome the stigma created by his uncle's actions. The government of France at this time appears to have grasped the importance of the power of attraction and soft influence, though it never was able to realize its goals.

- Does the dominant state have the political willingness to carry the burden of its position in the system?

The political willingness of the government of Napoleon III must be approached from two distinct angles. The first being a willingness to undertake new forms of foreign affairs, principally the willingness to undertake a congressional style of foreign policy, in this regard the willingness of the government must be seen as high. Louis Napoleon and his government were unafraid to make unified European action a rallying cry for their policies. The state did not shy away from calls for conferences and the like when problems arose in the system. This distinct approach to policy must be taken into account and in some ways praised as it diverged from the 
standard practice of power politics of the era. However, underlying this particular brand of political willingness was an utter lack of willingness to undertake large scale military actions over a prolonged period of time.

France under the government of Napoleon III was faced with two influences that detracted from its willingness for military action. First, the government was well aware of the problems of military action and their impacts upon domestic affairs as the memories of France's previous brush with greatness had not been erased or moderated. The next influence was the urban population and elites which were extremely war adverse. This war adverseness arose from the memories of the past and the bright economic future that was blossoming in the state. The government of Napoleon III was attuned to the voices of the masses, and thus this area of political will was made lacking. The government was able to use small scale engagements to distract the population such as was the case in both Syria and Mexico, but larger scale conflicts were not desired or supported by large elements of the population. The rural masses were more attracted to notions of past glories, but this was not the population that was closest to the seats of power in Paris.

The Crimean War exists as a primary example of this lack of willingness, because France made overtures for peace and settlement before their British allies deemed necessary due to the lack of support for the war within public opinion. The time leading up to the Franco-Prussian War is also demonstrative in that the population had eventually come to realize the threat posed by the growing power to the east, and still the government delayed and considered calls for 
congress. Thus, France under Napoleon III must be seen in the unique time period in which it existed, as the state regained power following the folly of its past greatness. ${ }^{52}$

\section{France - Trying to Make Amends}

With the case of France we are able to see a state that truly desired to achieve restraint, however those hopes for restraint could not attract binding partners. The foreign policy of Napoleon III was grounded in concert politics and multilateral action. Louis Napoleon was aware of the perils of balancing, as France under Napoleon I provided a clear illustration of the problems of balancing and equally important the role of Great Britain as an off-shore balancer. With these realities in mind the government of Napoleon III made numerous attempts to induce Britain into a lasting binding relationship, through its Crimean War policies, its Mexico policy, as well as its economic policies. Still, France was not able to draw the British out of their island and empire cocoon, and France's attempts to deepen existing relations with other European powers were hampered by memories of past French aggression and the lack of French power sufficient to induce other great powers to bind with the state. The study of French power reveals that the state was essentially granted dominance over Europe by the British policy of splendid isolation and that the state was perceived to be much more advanced militarily than the outcome of the Franco-Prussian War revealed. Moreover, the state's difficulties in projecting power to Mexico and its lack of political willingness in the Crimean War must also be considered. This leads to two conclusions. First, France under Napoleon III was motivated by military needs to pursue a multilateral foreign policy, and secondly that the state's inability to draw out binding partners may have also been effected by its lack of real military dominance. The domestic politics of the state prove ever the more complex as an interesting mix of authoritarian and

\footnotetext{
${ }^{52}$ Future research may consider the question of how the two types of political willingness are intertwined. It is possible to consider that the state's willingness to find international concurrence and to expand international norms may have arisen out of its extreme aversion to war.
} 
liberal policies can be seen in the state, as Napoleon III attempted to maintain central control over a population moving towards democratization. Still, the overall balancing behavior of the other great powers illustrates that France under Louis Napoleon was successful in most instances in preventing outright balancing until its ultimate downfall in the Franco-Prussian War and the subsequent British policy of balancing by not bandwagoning. 


\section{Chapter Five Germany under Bismarck - Binding Itself While Trying to Defuse a Bomb}

The case of Germany under Bismarck exists as an optimal case in the study of hegemonic constraint. ${ }^{53}$ Germany during this time period sat at a crossroads in its existence, as there were numerous potential challengers present as well as many paths to war. However, Bismarck for some twenty-five years was able to steer the state around most of the potential roadblocks, all while attempting to defuse the powers of nationalism that were growing in the state. The case of Germany is remarkable in the manner in which the state was able to restrain other actors in the international system and itself. Germany also presents a high degree of domestic political variability along with the needed presence of international regimes for inclusion in this study. ${ }^{54}$

This case allows us to witness a state that possessed the requisite amount of power and willingness to carry the burden of its dominance. We are also able to see a state that truly had the ability to maintain the status quo power distribution and prevent the formation of countering alliances through the use of international regimes. However, what is most telling in the case is the role that domestic politics played as an eventual hindrance to the successful implementation

\footnotetext{
${ }^{53}$ These sources illustrate the relation and actions of Germany under the rule of Bismarck in relation to the other great powers of the era: Craig, Gordon Alexander. Europe Since 1815. New York: Holt, Rinehart, and Winston, 1961. Gilbert, Felix et al. The Norton History of Modern Europe. New York: W. W. Norton \& Company, 1971. Gildea, Robert. Barricades and Borders: Europe, 1800-1914. New York: Oxford, 1996. Bartlett, C. J. Peace, War, and the European Powers, 1814-1914. New York: St. Martin's, 1996. Bridge F. and Bullen. The Great Powers and European States System, 1815-1914. New York, Longman, 1980. Rich, Norman. Great Power Diplomacy, 18141914. New York: McGraw-Hill, 1992. Taylor, A. J. P. The Struggle for the Mastery of Europe, 1848-1918. New York: Oxford UP, 1954. Kupchan, Charles A. The Vulnerability of Empire. Ithaca: Cornell UP, 1994 Snyder, Jack. Myths of Empire: Domestic Politics and International Ambition. Ithaca: Cornell UP, 1994. Peterson, Susan. Crisis Bargaining and the State. Ann Arbor: Michigan UP, 1996. Richardson, James. Crisis Diplomacy: The Great Powers since Mid-19 ${ }^{\text {th }}$ Century. London: Cambridge UP, 1994.

${ }^{54}$ Germany under the rule of Otto von Bismarck meets all of the case selection criteria to allow inclusion in this research. First, the state can be seen as the dominant military power in the European system during this time period. This is seen in both COW National Capabilities Data Set as well as in the historical record. The state's victory over the previously preceived dominant power of France further illustrates the states military prowess. The case also meets the selection criteria in duration of time, because German dominance in the system can be see to have existed from its victory over France until the eventual creation of Franco-Russian balancing alliance. This allows twentyfive years to study the influence of the variables in the study. Germany under Bismarck also provides the study with several instances of international regime formation, mainly through the state's defensive alliance system. Finally, there exists a large resource of secondary source material on this time period and its international interaction.
} 
of the state's foreign policy. Bismarck's Germany exists as the final case in the study because of its ability to show us this interaction in variables.

The chapter will follow the general outline of the three independent variable classes, that being international regimes, domestic politics, and hegemonic power concentration, followed by an exploration of the dependent variable, systemic balancing. As readers approach the chapter it will probably help to have some idea of what can be found within each sub-section. In the case of Germany's international regimes the case study will focus heavily on Bismarck's alliance system. It is not just the number of international regimes in which the German state participated in during this time period that is key, but more importantly is the motivation that led Bismarck's Germany towards such a policy of international regime formation. It will also be important to underscore whether the German alliance system could be considered to be binding in nature, that is did Bismarck's government undertake this alliance policy to restrain the German state by binding the fate of the state to other actors as well as the international system as a whole? The end of Bismarck's period of rule will also be of great interest in the case study, as this time period will illustrate how quickly a move away from defensive, binding international relations can trigger systemic patterns of balancing.

As the case study turns to the domestic politics of Germany under Bismarck a key portion of the work is the power of Bismarck as Chancellor of Germany, however upon undertaking the beginnings of the research for this case study it was my initial impression that this case would show little in the way of domestic political variability. This could not be further from the truth, but domestic political interactions do not flow through the study in the same manner. The case will show the gradual reduction in the absolute powers of the Chancellor as the influence of mass public opinion increases through the use of mass politics by both agrarian and industrial 
interests. The trend of nationalism is also present through much of the study. Bismarck reluctantly used the forces of nationalism to unify the German state, but rather than relenting to the call of the masses Bismarck attempted in most cases to place the monster back in the box. What will be interesting to uncover are the means by which Bismarck attempted to cast out or restrain the forces of nationalism.

The final independent variable class that will be covered in this chapter is that of Germany's hegemonic power concentration. What will be important in this portion of the work is not only the amount of power that the state possessed in relation to the other great powers of the system, but also other factors that could have impacted the distribution and utilization of the power during the period of German dominance. Great Britain's role in the international system will be of great importance, as it will be shown that the British sought to remain aloof from the majority of power politics on the European continent. What we must consider is whether Germany possessed enough power to be considered dominant, but also whether the state had sufficient power to trigger other great powers to bind with it.

Finally, the case will turn to the dependent variable of balancing behavior. What will be of most interest is the number of years that the German state was able to prevent direct balancing by the other great powers of the era, as well as the manner in which balancing of Germany was ultimately triggered. This will be important if we can see a period longer than the traditional five to seven year period without balancing, as this will show the viability of an unbalanced multipolar system. Additionally, Bismarck's strategy of status quo preservation and balancing prevention will be key, in that this will provide the work with potential lessons that can be drawn and applied to future states wishing to become handcuffed. 


\section{German International Regimes - The Ties that Bind}

The Bismarckian alliance system did not divide the great powers of Europe into polarized factions, but rather created a system of defensive alliances that bound alliance partners into arrangements that fostered the preservation of the status quo power distribution. ${ }^{55}$ If a state in the system were to act aggressively it would have been met with an overwhelming coalition of states that sought to maintain the existing power relationship. Bismarck also built a great deal of flexibility into his alliance system, as each treaty was only set for a number of years. The fixed duration of each treaty allowed Bismarck to adjust the system as systemic changes in power or perception occurred. The limited time for each regime also allowed for renegotiation of each agreement after or prior to its lapsing if the geopolitical environment called for such action, and through renegotiation Bismarck was able to seek new aims or open new avenues of exchange. Each alliance also ran through Berlin, which institutionalized Germany as the hub of the international regime system and added power to the German state in relation to its alliance partners. (Gilbert 1226-1227) The alliance system can also be seen as a means of making German dominance more palatable to the international system, as Germany found itself bound to the principles of negotiation and the maintenance of the status quo power distribution. ${ }^{56}$ These regimes also fostered lines of communication and influence between the alliance system partners, and thus can be seen as an international system check upon the dominance of German power. The problem with such a complex system of alliances and agreements was their dependence upon the mind and skill of Bismarck.

\footnotetext{
${ }^{55}$ More information on the German alliance system can be found in Fulbrook, Mary. A Concise History of Germany. Cambridge: Cambridge UP, 1990: 134-138.

${ }^{56}$ A discussion of Germany's policies of restraint can be found in Schulze, Hagen. Germany: A New History. Cambridge: Harvard UP, 1998: 165-167.
} 
Bismarck's alliance system can be seen as a true system of binding alliances that tied states together in a system of influence for the ultimate goal of war prevention and stability of the international distribution of power. "Now it was necessary to bind together the peoples of Germany and Austria-Hungary; this could be done only by formal agreement. Treaties bound governments to their own people as well as to each other. Alliances were engines of publicity even when their terms were secret. Bismarck himself publicized the fact of the Austro-German alliance and would have liked to publish its terms. He made out that it revived 'the organic link' between Austria and the rest of Germany which he himself had destroyed in 1866.” (Taylor 264)

Germany under Bismarck also sought to ensure that it could ally with any number of states to maintain a stable distribution of power, and to prevent any erosion of the new German power. $^{57}$ "Bismarck's Realism conceived of politics as an exercise in building temporary coalitions, based on power and interests of the participants, which included both states and social groups within states... Bismarck always sought to retain the option of allying with any number of actors while trying to restrict his opponents' alliance possibilities. Inevitably this had a moderating effect on Bismarck's tactic, since the pivot could normally be occupied only by accomplishing the interests of a majority of the players and refraining from threatening their security." (Snyder 82-83)

The Chancellor's policy was one of stability and tension. Germany during this time period was unafraid of using brinksmanship to coerce other great powers to ally with it, thus educating the other powers of the system to the desirability of German restraint and international stability. "Does it make sense to call the latter Bismarck a man of peace simply because he was satisfied with the Germany he had made and found the best way to buttress and sustain it was to

\footnotetext{
${ }^{57}$ Otto von Bismarck's foreign actions showed a willingness to cooperate, so as to achieve the efficient use of power and to keep channels of discussion and negotiation open throughout the capitals of Europe. Snyder, Jack. Myths of Empire: Domestic Politics and International Ambition. Ithaca: Cornell UP, 1994: 70-71.
} 
keep all of Europe desperately guessing, and fearing, so that when he had gone there was nobody capable of keeping within the bounds the tensions he had created?" (Crankshaw 303) Bismarck used a policy of Brinksmanship to ensure that the other great powers of the day had an interest in German alliances and relations with the dominant state in Europe. The policy of brinksmanship utilized by the Chancellor was to use the already conflicting France as an anvil for potential German aggression. This ensured that the other great powers had a vested interest in the status quo. (Dill 179) Essentially Germany often made threat gestures towards France that would then draw the attention of states such as Britain and France. Bismarck could then back away from such threatening actions and continue Germany's relationships with the other powers of the day. France was a excellent target for such threats as the state could not be expected to be counted on as a German alliance partner. The threats increased the need for the other powers to bind themselves to Germany in the hopes of pacifying the state's policies. What these threat gestures truly did was make binding relationships appear more efficient than isolation followed by last second balancing.

Bismarck's Germany acted to gain international credibility as a supporter of the existing balance of power. ${ }^{58}$ The German state used the trilateral regime between Austria, Russia, and itself to impress upon Russia and Austria the need for stability between the two traditional foes. The Balkans had traditionally been a point of contention between the two great powers. Bismarck was clear in assuring the two states that if such a conflict arose Germany would balance with either power to ensure that neither state could gain victory. (Gilbert 1208) The balancing strategy of Bismarck conveyed not only to the two states directly addressed but to all

\footnotetext{
${ }^{58}$ A key facet of Bismarck's foreign policy was his use of timing and patience in his dealings with other great powers. He essentially was willing to allow the path towards resolution to darken so as to induce states to take action. These qualities also lent themselves to his pragmatism, since he was willing to make any possible agreement to preserve the status quo in power distribution as long as such agreements did not mortgage Germany's position in the system. Gilbert, Felix et al. The Norton History of Modern Europe. New York: W. W. Norton \& Company, 1971: 1112-1113.
} 
of Europe that it was Germany's intent to maintain the existing distribution of power and maintain a general peace between the great powers.

A large fear for the dominant German state was the outbreak of war between any of the great powers of the era. A primary concern was that a war could arise out of the relations between Russia and Britain, as their interests were often in conflict in the Mediterranean area. Thus, Germany was called upon to the play the role of a pacifier. Britain was comforted by that fact that Germany was willing to use its alliances and relationships with Russia to influence the states foreign policy. (Dill 178) Germany under Bismarck also saw war as a last resort in its foreign affairs. ${ }^{59}$ Bismarck realized that any conflict, particularly one in which Germany was a primary actor would likely trigger encircling alliances. It was these encircling alliances that Bismarck most feared. He saw balancing as a path to a decrease in German power, and as the architect of German unification he sought to protect Germany's new found power and dominance. (Gilbert 1113)

\section{The German Alliance System}

The German system of alliances can be seen to have begun following the Franco-Prussian War and the ensuing congress. ${ }^{60}$ "The Congress of Berlin made a watershed in the history of Europe. It had been preceded by thirty years of conflict and upheaval; it was followed by thirty-

\footnotetext{
${ }^{59}$ Bismarck's war averseness can also be traced to his moral and personal feelings about combat. He felt a strong moral obligation to prevent warfare. The Chancellor also feared his responsibility to send troops to their deaths, moreover Bismarck's fear of war and placing the German military in harms way has been traced to the fact that he had two sons serving in the army as officers. The Chancellor feared that his sons could perish in a war that he created. This paternal fear seems to have shaped Otto's aversion to war, as well as his belief that stability for the German state meant that wars involving the German state needed to be prevented More information on these personal sentiments and influences can be found in Crankshaw, Edward. Bismarck. New York: Viking Press, 1981: 133-134 and 270-271.

${ }^{60}$ More information on the Congress of Berlin and its impact on the balance of power can be found in Kagan, Donald. On the Origins of War and the Preservation of Peace. New York: Double Day, 1995: 106-108.
} 
four years of peace. No European frontier was changed until 1913; not a shot was fired in Europe until 1912, except in two trivial wars that miscarried.” (Taylor 255)

"The Congress of Berlin demonstrated that a new balance of power, centered on Germany, had come into existence" (Kagan 107). Bismarck was willing to limit the goals and desires of Germany, as he realized that any further conflict in Europe would likely draw Germany into a war, thus risking a loss of German power or a rearrangement of power within the system. Thus, the state sought stability in the system and looked for means to bind German power in order to both restrain itself and the other great powers of the system. Germany under Bismarck also sought to create peacetime alliances. A key alliance being the Dual Alliance with Austria that was formed in 1879 this alliance was created on the foundation of a fear of Russian attack. It provided for mutual defense in the case of a Russian attack, and it also ensured neutrality if an attack was undertaken by another power. This can be seen as a new alliance system, as it was only specific in nature in one instance, but general in nature in all other instances. The Dual Alliance was also a means by which Germany could check the power and policies of Austria, hence ensuring that Austria did not take actions that could trigger a Russia attack. Such a policy was undertaken both to keep Germany out of conflict and to protect against a potential system changing conflict between Austria and Russia. (Kagan 107-108)

The Dual Alliance also provided Germany with leverage to reopen the Three Emperor's League with Russia, as Russia now saw that Germany sought to limit the actions of Austria and thus acting to stabilize the European environment. The recreation of this trilateral alliance further prevented the formation of an opposing Franco - Russian alliance, thus keeping France isolated in European affairs. Moreover, functionalism can be seen to be taking hold as this 
alliance system expanded with Germany as the hub with the creation of alliance extensions with Italy and Rumania. (Kagan 109-110)

1873 saw the creation of an international regime between Germany, Austria - Hungary, and Russia. This League of Three Emperors was an international agreement that required the three states to consult each other to aid in the maintenance of stability in Europe. The League also provided for a defense pact, while not a military alliance that could have been engaged if say Germany decided to attack France preemptively. The regime was built around the shared political styles of the three states, and was clearly centralized within Berlin, as Bismarck sought to create a spooks model of diplomacy in which exchange and agreement ran through the German state. (Kagan 102) Austria, Russia, and Germany found more in common than their mere hopes to maintain the status quo. They also shared a fundamental reasoning for the maintenance of the European power arrangement, that being domestic political similarities. The three emperors realized that any system changing events could also come with state changing events, such as liberal revolutions that could sweep out their conservative based governments. (Gilbert 1207)

Bismarck's bilateral alliance with Austria - Hungary had a side benefit for the relations between Russia and Germany. On face one may believe that such a treaty would have caused total Russian alarm and the reopening of a Franco - Russo relationship, as Russia would have feared an alliance between its primary threat, Austria, and a large power such as Germany. However, the bilateral alliance between Austria and Germany actually caused Russian fears of isolation and thus made Russia eager to readdress the continuation of its relationship with Germany. (Dill 183) The treaty represents yet another attempt by Bismarck to use a policy of 
brinksmanship to make binding relationships appear more desirable for alliance partners. The fear of isolation or aggression was able to induce the deepening of relations.

Bismarck was in constant fear of Russian-French counter balancing. Because of this fear in 1879 he sought an additional treaty with Austria. The purpose of this treaty was threefold. First, the treaty served as a means of providing additional support to Germany if any aggression were to arise from the east. The treaty also served to ensure that if a Franco - Russian alliance was formed it would not include a revisionist Austria searching to regain power in Eastern Europe. The regime also sought to increase the German ability to act as an outside check, or influence, over the foreign policy of Austria, as Germany did fear that Austria may have taken hostile actions that would have had a system changing effect or at the least draw Germany into a war that could squander its power. (Gilbert 1213)

Germany was also able to use the formation of the bilateral Austrian Alliance to spur change in the policies of Russia. The bilateral alliance increased fear within Moscow to the level that the state was now willing to reopen the Three Emperor's League. Bismarck sold the bilateral Austrian alliance as a means of Germany codifying its influence over the more aggressive and revisionist Austria. This sentiment found an open ear in Moscow, as Austria was a primary Russian rival particularly in the Balkans. Thus, through such a threat gesture Germany was able to further bind itself to Russia and prevent the formation of a counter alliance from both the east and the west. (Gilbert 1213-1214)

In Bismarck's eyes the Austrian alliance was needed for one primary reason. Britain, while a world power, was not a continental power and thus an alliance with Great Britain really did nothing to ensure stability in Europe. Bismarck saw that the British navy was overrated in terms of its ability to project power onto the continent, furthermore the British Army left much to 
be desired, and close relations with Britain could have certainly triggered Franco-Russian balancing as a result of Anglo-Russian relations. (Taylor 265)

“He set out to detach Austria-Hungary from 'the Crimean coalition' by offering her the security of an alliance with Germany; once she was caught, he made it a condition of this alliance that she be reconciled to Russia. His real fear was Austro-Hungarian restlessness, not of Russian aggression; but he could not avow this until the Austro-German alliance was made." (Taylor 259) Bismarck was also able to convince the French that this alliance was targeted towards Russia and not France. This had the dual advantage of keeping France on the sideline and making Russia look less appealing to France as an alliance partner. The Chancellor was also aware at the time of the Austro-German alliance that there was little chance of an alliance between France and Russia at the time of alliance formation. (Taylor 260-261)

Russia was a key actor in the international system at the time of Germany's dominance, though Germany's goal was to prevent not only a war between Russia and Austria but it also had to ensure that conflict did not arise between Russia and Britain. ${ }^{61}$ Just as with Napoleon III's France, Germany too saw Britain as a lynchpin ally. Bismarck understood that the policies of Germany had to be kept in synch with those of Great Britain, as the state existed as an aloof, off - shore balancer. The state was seen as a power that could potentially tip the balance of power scales in any direction if conflict or tensions were to arise on the continent, yet the realities of Anglo-Russian relations meant no formal binding was possible for the Germany and Britain. (Kagan 117) The Congress of Berlin which was headed by Bismarck represents a true aspect of regime building to ensure that Russia and Britain's relationship did not deteriorate to the point of

\footnotetext{
${ }^{61}$ The importance of the Russian alliance in regards to Franco-Russo, Austro-Russo, and Anglo-Russo relations is discussed in depth in Mann, Golo, The History of Germany since 1789. New York: Praeger Publishing, 1970: 227228.
} 
warfare. The integrity of Turkey was ensured as was the division of influence within the Balkans. Germany also placed itself as a balancer of last resort in the region. (Dill 180-181)

\section{Additional Regimes - More Rope to Tie the System Together}

Bismarck was not content to allow the Three Emperor's League and the Congress of Berlin to be the only international regimes acting within Europe. He needed flexibility and redundancy for the alliance system. In 1882, Germany completed yet another alliance to add to its alliance system. The Triple Alliance was formed with Italy and Austria. ${ }^{62}$ This alliance provided for Italian and Austrian neutrality in any attack against Germany by Britain, France, or Russia. The treaty also allowed for German influence over yet another state's foreign policy as Italy was then tied to the German state. The regime was based upon the principles of shared government type across the three participation countries. (Gilbert 1218)

The relationship between Italy and Germany had two main effects. First, their relationship elevated Italy to the league of great powers, though Italy did not have the requisite power level. However, the second effect of the relationship was more important to Germany. The German state's relations with Italy provided an indirect link between Germany and Great Britain, as Italy and Britain had direct relations and agreements based on their shared desires for stability in the Mediterranean. Germany was unable to have direct relations with Britain due to its need to maintain strong ties to Russia, a challenger of British power in the Mediterranean and Asia. However, these indirect channels allowed for influence to flow between the two powers. The indirect relationship allowed for Britain and Germany to work together for stability in the system while ensuring that Bismarck's systems of alliances remained largely stable. (Croce 328329)

\footnotetext{
${ }^{62}$ More information on the intricacies of the Triple Alliance can be found in Taylor, A. J. P. The Struggle for Mastery in Europe: 1848-1918. London: Oxford UP, 1954: 275.
} 
In 1887, Germany sought to further expand its alliance system and to increase its credibility as a supporter of international stability through the creation of the Mediterranean Agreements. These agreements created channels of discussion and exchange between Germany, Britain, and Italy. The agreements codified the desire of each state to maintain the status quo in the Near East, and the agreements sought to ensure that Turkey was kept free from outside control. $^{63}$ The states agreed to occupy Turkish territory if any state sought to control the strategic area. Essentially, the agreements were targeted at the potential for Russian expansion, and thus firmly placed Germany on the side of Great Britain in any conflict with Russia in a quest for a warm - water port. ${ }^{64}$ (Gilbert 1225-1226)

Germany could not renew Three Emperor's League due to Austro - Russian hostilities, thus the Reassurance Treaty was used to create a secret non - aggression bond between Germany and Russia to ensure that the isolation of France would continue and that Germany would remain unbalanced. (Gilbert 1224-1226) In 1887 Russia and Germany concluded the secret Reassurance Treaty. The three year agreement pledged neutrality in any conflict either state was to engage in, other than a German attack on France or a Russian attack on Austria. The treaty also provided for consultation between the two states prior to any changes in power in the Balkans. This agreement can be seen as a German move to further comfort and control Russian policy, thus decreasing the need for a Franco - Russian alliance. It also signals Russia's fear of isolation from the German alliance system, as it shows that Russia considered Germany to be the major power broker of Europe. (Kagan 113) The Reassurance Treaty also illustrates the

\footnotetext{
${ }^{63}$ The Mediterranean Agreements further underscored the role that a dominant Germany played as a creator and enforcer of international norms. Mann, Golo, The History of Germany since 1789. New York: Praeger Publishing, 1970: 231.

${ }^{64}$ The Mediterranean Agreements essentially aligned the interests of Germany and Britain and created as much of an alliance as could be tolerated by Russia between the two states. Dill, Marshall Jr. Germany: A Modern History. Ann Arbor: University of Michigan Press, 1961: 185-186.
} 
moderator role that Bismarck and his policies played throughout Europe, as Russia tolerated the German relationship with Austria-Hungary as it was known that Bismarck was able to moderate Austrian policies and further assuage Russian fears (Kagan 105-106).

Ultimately Bismarck's system of alliances bound various great powers together had a restraining effect upon the German state, which is exactly what the Chancellor hoped to create, as he feared a blowback of the nationalism that he used to create a united Germany. It was his fear that German nationalism would create domestic pressure for preventative wars and for imperial actions, both of which would certainly trigger encircling alliances and spell the end of German dominance. ${ }^{65}$ Bismarck was aware that war had to be the last course of action that the German state could consider. He knew that in order to restraint Germany's domestic political tendencies international constraints would be needed to increase the costs of conflict. ${ }^{66}$

\section{The Falls Going to Hurt}

Even prior to Bismarck's retirement/dismissal the glory days of the German system of international regimes began to crack, for Bismarck over-played his brinksmanship style of international politics. In 1887, Bismarck embarked on a new policy with Russia, that being of policy of brinksmanship to reeducate the Russian state of the importance of its relationship with Germany. Russia had long depended on Germany for loans, and yet the state still remained troublesome with its expansionist tendencies and its policies towards Austria. Bismarck had Russia cut off from the German capital market knowing that France would quickly move to fill

\footnotetext{
${ }^{65}$ By 1875 , Germany began to consider a preventative war against France, as France could be seen as a humiliated and isolated great power that could soon rise to challenge the dominance of Germany. However, both Germany's alliance commitments through the Three Emperors' League and its relationship with London created restraint within the German government. This can be seen as a requirement of the other great powers of the era for Germany to remain dominant in the system. The open diplomatic channels created lines of communications that conveyed the hopes and expectations of the other powers for the German state. Kennedy, Paul. The Rise and Fall of Great Powers. New York: Random House, 1987: 189.

${ }^{66}$ For more on the goals of German foreign policy, namely peace and stability see Gilbert, Felix et al. The Norton History of Modern Europe. New York: W. W. Norton \& Company, 1971: 1211.
} 
the vacuum and that these economic ties could quickly be translated into an alliance relationship that would target Germany. Yet Bismarck hoped to make a lasting and quick impression on Russia and restart their economic relationship. (Stern 442-443) It seems that Bismarck overestimated the quickness with which he could secure a rapprochement with Russia, or that he underestimated the quickness with which France would move in attempting to fill the vacuum created by the German action. Either way this appears to be one of the few major mistakes made by the Bismarck government in the arena of alliance maintenance.

The fall was worse once Bismarck's rule ultimately ended in 1890. The new government of Kaiser Wilhelm II did not renew the Reassurance Treaty with Russia. This triggered an almost immediate relationship between France and Russia, the very alliance that Bismarck had labored to prevent throughout his time as chancellor. Hence, with the formation of the FrancoRusso alliance a balancing coalition was now formed to counter German power. (Croce 335) The end of Germany's relationship with Russia ultimately came from too sources. First, it was believed that the British would serve as a better alliance partner than the Russians by the new government, as Wilhelm considered himself to be pro-British though this would be the very state his naval plans would directly challenge. The new government also failed to heed Bismarck's warnings about the lack of continental power held by Great Britain as well as the long held policy of isolation put forth by the island state. (Snyder 84-85) The second reason behind the failure to renew the Reassurance Treaty lay within domestic politics. Few within the German government and within the elites of the state understood the complexities and necessities of Bismarck's Russian policy. It was not truly understood that a friendly Russia meant an isolated France. (Stern 440) At the conclusion of Germany's regime relationship with Russia Britain as a result of its isolation and it fear of the new German government and its plans for the future 
failed to accept the German invitation. Additionally, balancing had now begun in earnest between the great powers and Germany's time as a dominant power would soon end. The end of Bismarck's rule also signaled a shift from the defensive alliances that had maintained system stability to a system of alliances that would eventually lead to the World Wars. ${ }^{67}$

\section{The Impact of German International Regimes}

The case of Germany provides the study with a real look at binding international regimes in action. Bismarck was able to use his alliance system to restraint the German state for a time. He also realized the importance of restraining other powers in the system, as the German position of dominance during this time period was dependent upon a lack of system changing events. What is particularly telling is the manner in which Germany conducted its international regime policy during this time period. Bismarck ensured flexibility and adaptability in his international agreements through the use of set time limits on all treaties. This allowed Germany the ability to deepen future agreements; cast aside the agreement completely if the international environment changed in such a way; or merely renew the agreement if no changes were needed. Flexibly in international relations also meant that Germany could stay abreast of the constantly changing international system and orchestrate alliances to best maintain the status quo power distribution.

\section{The Domestic Politics of Germany - Trying to Keep the Monster Tucked Away}

German history, with the exception of the latter portion of the Bismarck era, illustrates tendencies towards the use of military shows of force, the use of ultimatums, and an inability to accept compromises (Snyder 68). ${ }^{68}$ This indicates the underlying strategic culture of the German

\footnotetext{
${ }^{67}$ More information of the impact of the end of the Bismarckian system can be found in Gilbert, Felix et al. The Norton History of Modern Europe. New York: W. W. Norton \& Company, 1971: 1227-1228.

${ }^{68}$ The following sources provide a good overview of the German domestic political environment during Bismarck's era: Ramm, Agatha. Germany, 1789-1919: A Political History. London: Methuen, 1967. Holborn, Hajo. A History of Modern Germany, 1840-1945. Princeton: Princeton University Press, 1969. Carr, William. A History of Germany, 1815-1990. London: Arnold, 1991. Craig, Gordon A. Germany: 1866-1945. New York: Oxford
} 
state. Bismarck's fears of democracy illustrate his desire to undercut the natural tendencies of the German state to move the state towards more of status quo actor in the international system. Bismarck realized that the preservation of the status quo power distribution was in the best interests of Germany. ${ }^{69}$ He saw the need for Germany to take up the position as an honest broker in European affairs. The Chancellor was also aware that even the smallest of problems or conflicts within the European system could become system changing events, and thus he preached patience and restraint in his diplomatic exchanges. (Kennedy 190)

The constitution of the Second Empire was created to bolster the power of Bismarck as Chancellor and Prussia. ${ }^{70}$ It created a federal empire that allowed the states to remain autonomous in many domestic issues. The two main areas of national interest and dominance were the realms of foreign policy and warfare. The parliament, Reichstag, sat at the bottom of the national government and was elected by universal manhood suffrage. The parliament was designed to appear democratic in nature, yet it had little real power other than the power to voice opinion. The upper house of the German government was the Federal Council, or Bundesrat, which initiated legislation while the parliament really only had moderate veto - power. The national government was designed to be dominated by the Emperor, or as in the case of Bismarck and the presence of a weak and trusting Emperor, Germany was really meant to be dominated by Bismarck. (Fulbrook 129-131)

University Press, 1978. Blackbourn, David. History of Germany, 1780-1918: The Long Nineteenth Century. New York: Oxford UP, 1998. Feutchtwanger, Edgar. Imperial Germany: 1850-1914. New York: Routledge, 2001. Wehler, Hans-Ulrich The German Empire, 1871-1918. New York: Berg Publishers, 1985. Berghahn, Volker R. Imperial Germany, 1871-1914: Economy, Soviety, Culture and Politics. Providence: Berghahn Books, 1994.

${ }^{69}$ Following the Franco-Prussian War and the unification of Germany Bismarck attempted to the best of his ability to place the cover back on the Pandora's Box that was German nationalism and to guide the state as a status quo power. The historical record indicates for those that follow the line of state strategic culture that the Bismarckian era marked a divergence from the norm of the state's strategic behavior. Croce, Benedetto. History of Europe in the Nineteenth Century. New York: Harcourt, Brace and Company, 1933: 328-329.

${ }^{70}$ Information in regards to the structure of the German government can be found in Gilbert, Felix et al. The Norton History of Modern Europe. New York: W. W. Norton \& Company, 1971: 1195-1196. 
The German government, through its federal form lacked a large and developed bureaucracy. It was forced to rely upon the bureaucratic agents of the German states to enforce federal mandates. This further decentralized the German government, as agents were then beholden to two distinct principals. Moreover, the ministers and secretaries of the state were not responsible to the parliament or to public opinion, but only to the Kaiser and more importantly to Bismarck as Chancellor. This further centralized power into the hands of Bismarck, yet on domestic matters one must question the degree to which Bismarck's power was total as a result of the lack of centralization in the German government. (Gilbert 1197) The lack of a truly federal government also meant that the state lacked a large degree of governmental centralization, and without such centralization domestic politics tended to take place on a state level with the exception of high level finance questions and foreign policy (Gilbert 1195).

\section{The Power of the Chancellor}

The rise of German power followed the rise of Otto von Bismarck as Chancellor of the German state. During the majority of his rule it was his power that was absolute and not the power of the Kaiser, though he served at the pleasure of the Kaiser. Bismarck ensured through his foreign policy that he remained needed within the German state until his retirement/dismissal by Wilhelm II, a Kaiser that sought more power to be housed within the monarchy of Germany. "His ability to solidify the place of the new and threatening entity in a European system shattered by its emergence and to create a new international order in which Germany could live and prosper may have been even more remarkable... Bismarck's second great achievement rested, in part, on Germany's strong military and industrial power, which gave his policies weight and respect.” (Kagan 100) 
Otto von Bismarck's power within German politics was as authoritarian as possible for a chancellor in a governmental system that included both a monarchy and two elected parliamentary bodies. $^{71}$ Bismarck's power arose from the fact that it was he who created a vast majority of the state's constitution, which instilled a majority of power within his position. The Chancellor did not serve at the pleasure of the legislature; rather he served at the pleasure of the Kaiser. Hence, so long as the Kaiser sought to give Bismarck virtually complete control and as long as he could successfully navigate the constitutional system the Chancellor enjoyed a great deal of power. ${ }^{72}$ Still, Bismarck feared challenges to his power and failed to groom or create a position or individual that could be his successor. Bismarck was reclusive by nature and trusted few individuals and thus the decentralization of Germany domestic politics and the centralization of foreign politics within his position suited his personality and governing system well. Ultimately the Chancellor most feared democratic rule, as he did not trust the will of the masses or the influence of special interests particularly since Germany was in its infancy as a unified state. Therefore, Bismarck played the state's political parties off of each other to ensure that none garnered too much power, yet these power plays also hindered the development of responsible parties within the state. It also meant that if problems arose within the domestic political environment a new coalition of parties would need to be created to pass legislation or the legislature would have to be dismissed which further hindered the development of Germany’s party system. (Mann 219-221)

As Chancellor one could imagine that Bismarck would have had a great dislike of democracy, though this fear was real it was not solely for selfish reasons. Bismarck's fear of

\footnotetext{
${ }^{71}$ More information about the distribution of power within the German government can be found in Sturmer, Michael. The German Empire: 1870-1918. New York: Modern Library, 2000: 31-34.

${ }^{72}$ Bismarck could only last as long weak Kaiser was in power, which was something that he was fortunately blessed with throughout much of his rule. Kagan, Donald. On the Origins of War and the Preservation of Peace. New York: Double Day, 1995: 115.
} 
democratic rule arose from the powers of nationalism that he knew all too well from his successful use of the force to unify the German state. It was his fear that democratic Germany would follow a path of imperialism and pan-Germanic policies that would weaken or cause the end of German power in the international system. He realized that a democratic state would be held captive by the will of the masses, and thus politicians would have the ability to use foreign policy actions and nationalism to attempt to maintain domestic political power. Essentially, Bismarck contended that a powerful but new Germany would move towards revisionist tendencies if the masses were both in control and influenced at the same time. (Mann 227) Bismarck must be seen as a powerful force within German domestic politics, but his power was unable to quell the powers of nationalism that he had released in his unification efforts. Nationalism was constantly beneath the surface of German politics. (Crankshaw 315)

One of Bismarck's largest opponents was the Catholic Church. ${ }^{73}$ This arose out of the Chancellor's fears that the Church would pose a transnational challenge for the alliance of German citizens. The Catholic Church had recently published its doctrine of papal infallibility, which Bismarck saw as a direct challenge to the power of states, and most importantly the German state. However, his policies to counter the power of the Church won him few domestic allies, as his nationalization policies in this area actually stiffen the backs of the central and liberal party members that feared such national policies and strengthen their own domestic support. (Gilbert 1198-1199)

The successes that Bismarck was able to realize in the foreign policy arena were not seen in domestic politics within Germany, as the Chancellor used the same tactics in both realms. Bismarck created few lasting domestic alliances or partnerships. He choose to create temporary

\footnotetext{
${ }^{73}$ Additional information in regards to Bismarck's anti-Catholic policies can be found in Stern, Fritz. Gold and Iron: Bismarck, Bleichroder, and the Building of the German Empire. New York: Alfred A. Knopf, 1977: 394-397.
} 
alliances and friendships to gain the passage of key pieces of legislation of budgetary motions. This meant that Otto von Bismarck would quickly turn against a domestic ally if the political climate change, thus with such political moves the party system of Germany was hindered in its development and little of the government gained any real sense of legitimacy other than the Chancellor's office. (Stern 177)

Bismarck's lack of domestic political tact and foresight did not undercut his degree of power within the German government. Throughout Bismarck's rule as Chancellor he had many conflicts with the German parliament. Each time that a conflict arose he followed a set strategy. Bismarck would first attempt to forge a compromise solution with the parliamentary leaders, or he may have chosen to make some conciliatory offer. However, if these measures failed to produce results Bismarck was often willing to play out the conflict within the population. He often chose to illustrate the obstructive nature of the parliament to the German population, as he would highlight their violations of the constitution. This was particularly powerful coming from Bismarck as he was a primary author of the document. The majority of Bismarck's clashes with the legislative body arose around issues of finance and taxation. Between 1863 and 1866 the Chancellor simply ignored the rulings of the parliament and sought only to enforce through his tax collector the taxes allotted from past years. Bismarck was able to use such a tactic as the majority of the taxes were designated for military expenditures, thus ensuring that the military backed him in the conflict. The parliament could only call for an open revolt against the Chancellor, a path they were unwilling to take as such a path could not guarantee an increase in power for the body. (Gilbert 1114-1115)

In 1874, Bismarck and the legislature came to a compromise agreement over the funding of the national army. The agreement called for military finances to be passed every seven years. 
The agreement did allow for Bismarck to once again circumvent the power of the purse that was held by the parliament, as he could show an outside threat existed and necessitated the continued funding of the army. ${ }^{74}$ In 1887 there were once again difficulties in reaching an agreement, and thus Bismarck dissolved the legislature and opposed new elections citing the threat of a war with France. Under threat of an external enemy Bismarck was able to use popular and nationalist sentiments to ensure the continued funding of the army. (Mann 226)

Despite Bismarck's immense personal power within the German state and the relative weakness of the parliamentary bodies the Chancellor did find that the German Reichstag provided political cover for his domestic political actions. The legislature could be used to either defuse blame for policies that went awry or could be used to show to the population that such a policies had the backing of its elected officials. This dual-use of the legislature as both a tool for placing political blame or for gaining public support did create negative consequences for the development of a stable and responsible democracy, as Bismarck's actions painted the democratic body as both useful and worthless depending on the political climate of the day. This may have been Bismarck's intent all along, as he was fearful of a democratic Germany. (Stern

\section{The Power of Interests}

Germany was challenged by its lack of institutional development, for the state had yet to evolve towards a true representative democracy. Thus, the special interests within the state had little encouragement to moderate their polices or seek compromise. This meant that the government was then forced to either choose between competing interests or implement competing policies. (Kaiser 298) This does not mean that Germany lacked interests that were

\footnotetext{
${ }^{74}$ Bismarck also used similar tactics to push alliance related measures through the parliament. Kagan, Donald. On the Origins of War and the Preservation of Peace. New York: Double Day, 1995: 112-113.
} 
capable of welding power in state. Snyder provides a detailed explanation of the German international experience as he contends that the state over expanded as a result of its domestic political influences. He argues that his was a result of the pattern of late industrialization that allowed for the centralization of influence within a limited number of elite interest groups. However, the author does show that German foreign policy was most moderate during the time of Bismarck, as he was able to better navigate the perils of such interest groups through both his personal political powers and the more closed political system in which he operated. (Snyder 6667)

The Prussian state dominated the domestic political landscape of Germany. ${ }^{75}$ Not only was Bismarck Prussian himself, but the majority of the bureaucratic system for the German state came from Prussia as well. Bismarck even realized the need to better integrate Prussia into the Germany, but this was largely impossible as the vast amount of Germany's power came from this one state. Additionally, it was Prussia and its conservatism that dominated the German political scene, as the majority of the other German states were more liberal in nature. (Croce 271-272)

Bismarck looked outside of the German government for his primary advisor. The Chancellor's primary advisor and main influence is seen by many to have been the banker, Bleichroder, whose primary areas of expertise were finance and industry. Moreover, Bleichroder had numerous contacts and relationships throughout Europe, and was thus able to carry messages and assess sentiment and beliefs for Bismarck. He also was seen throughout the capitals of Europe as one of the few individuals from whom Bismarck solicited true advice and council which further increased his bargaining abilities and political clout. (Stern 178-179) Bleichroder

\footnotetext{
${ }^{75}$ Another resource for the discussion of the power of the Prussian state is Sturmer, Michael. The German Empire: 1870-1918. New York: Modern Library, 2000: 33.
} 
also acted as the main liaison between Bismarck and Association of German Industrialist, which was the primary interest group for German industry (Stern 193-194).

Bleichroder also acted as a agent for Bismarck abroad. The Chancellor felt that the most important aspects of German diplomatic action could not be trusted to the state's diplomats. Essentially it seems that Bleichroder was seen as a proxy for Bismarck himself. This also had the added advantage of not attracting a significant amount of attention, for Bleichroder would conduct Bismarck's work as he conducted his own banking work or after a business meeting. Bleichroder was also not seen as a individual with an independent political agenda by Bismarck, as Bleichroder had no political aspirations of his own. (Stern 311)

Bleichroder lack of a formal position within the German government and his position of power within the banking industry also meant that his exchanges with foreign government officials and non-governmental officials can be seen as a means of keeping back - channel sources open between Bismarck and other individuals of international and economic importance. (Stern 339-340)

Bismarck's primary advisor also illustrates the importance of the banking industry as an interest within the German government. The industrialization and commercialization of Germany required the development of a banking industry as well. However, the number of banking houses in the state remained small as the tendency was for the creation of a limited number of large banks. This meant that a small number of individuals and corporations controlled the banking and industrial sectors of the German economy, and thus there were a limited number of commercial interests in the state at the time of its dominance. (Dill 159-160) The influence of the banking interests can also be seen in Bismarck's moderate and pragmatic foreign policy. Bleichroder as Bismarck's closest political advisor was also deeply committed to 
the preservation of peace and stability. This arose from his profession and livelihood in the banking industry. It was his belief that peace and international stability better insured profitability and reduced economic risk. (Stern 308)

The power of banking houses in German politics must be seen in concert with the power of industrial interest groups, as the financial and industrial interests were essentially the same Germany as its was the banking houses that drove and controlled the state's industry. The power of the banking houses arose from Germany's late development and rapid industrialization that occurred as the state was unified. The banking houses themselves also gained additional power by the fact that these banks employed such a large number of the new middle class of Germany. (Mann 200-201)

But perhaps the strongest interest seen within the German state is the dual interest of industry and agricultural, which has come to be know as the coalition of iron and rye. ${ }^{76}$ By 1879 domestic forces encouraged Bismarck to abandon his policy of free trade in favor of a new policy of protectionism. German industry faced strong competition from British manufactures, and Germany's agricultural sector faced similar competition from the United States and Russia. Bismarck had initially supported free trade as an imperial policy to avoid confrontation and competition with Britain, and as a means of potentially drawing the island state closer to Germany. However, as the German economy continued to slump beginning in 1873 domestic interests continued to push for change illustrating the power that the iron and rye coalition had even in Bismarck's most powerful days. The tariff policy was successful in rebounding the German economy, as it quickly began to outpace both Great Britain and France. (Gilbert 1202)

\footnotetext{
${ }^{76}$ More information on the influence of iron and rye can be found in Mann, Golo, The History of Germany since 1789. New York: Praeger Publishing, 1970: 225-226.
} 


\section{The Role of Public Opinion}

Bismarck's government, no matter the power of the Chancellor, was not immune to the growing power of public opinion in European politics. By 1884, Germany was forced to incorporate imperialism into its foreign policy, though this was seen as a potential drain on the state's resources, as a result of the growing lure of Weltpolitik on the German public. Germany's colonial policy was driven by two forces. First, was the growing desire for increased lebensraum (Living space) for the German population, this can be seen as an instance of blowback from the large amounts of nationalism that Bismarck prescribed to unify the state. The second factor influencing Germany's policy was its commercial interests that saw imperialism as both a source of raw materials and needed explanation for continued naval growth. Bismarck also used the state's colonial policy to divide the National Liberal Party that sought to challenge his rule, as the desire for a common German vision of unity and expansion was a goal of the party and thus the creation of a large imperial navy and holdings built on these desires. (Kaiser 295-296)

While public opinion cannot be seen as significantly important to Bismarck's government he did desire some public approval or at least public acquiescence to his policies. The Chancellor was able to use the newspapers to generate movement in public opinion. Bismarck's rule coincided with an increase in literacy and a decrease in printing costs, and thus the news media became a more viable means of influencing the beliefs of the public. However, as Bismarck power began to wane the role of public opinion increased in German political life, as those seeking to lesson his power began once again to play upon the nationalism of the German people and Bismarck's harsh domestic political style. Bismarck's government increasingly faced 
a division in public preferences the population became divided between those that desired a policy based on Lebensraum and those that supported the tenets of Weltpolitik. (Kaiser 298)

The rise of Wilhelm II and his sentiments towards Britain brought about a rise in anti British public opinion within Germany. Such a phenomenon arose from the use of Social Darwinism as a foundational belief system for increases in German power. Nationalism and the belief in German superiority was on the rise and Britain was cast as the barrier that stood between Germany and greatness. This also played into the hands of both industrial and steel interests as the cause for increased shipbuilding lent itself to their economic gain. The domestic stage was no set for domestic causes to loosen the handcuffs that Bismarck had tried so hard to fix to the German state. (Kagan 132-133) The creation of a strong navy can also be seen as a nationalist tool to prevent domestic upheaval. The domestic environment in Germany was in such a way that genuine calls for parliamentary reform or all out revolution were actual possibilities. Hence, nationalism and the use of Britain as a paper tiger were two means by which the Kaiser could keep a hold on the growing social changes within the German state. (Kagan 137)

German domestic politics can be seen as a hindrance to Bismarck's goal of building a lasting relationship with Britain through the formation of international regimes. The domestic influences that drove the state to create a large naval force and seek imperial holdings placed Germany in competition with Britain, and thus limited the expansion of their strategic relationship. It also placed the two states on a potential collision course, as Germany had now entered the realm dominated by Great Britain. (Kaiser 297)

It was also the power of German nationalism that Bismarck himself could not re-close that increased unwanted tensions between Germany and France. The tensions between France 
and Germany arose out of their 1870 war, however those problems could have conceivably been repaired had Germany not annexed Alsace - Lorraine. It was the annexation of territory that enflamed the division between the two states beyond any real chance of repair. The reason behind the taking of this area of land lay in German domestic politics. Bismarck utilized nationalism as a means of unifying the state in the face of what he termed a French threat. He also used this much disputed piece of territory as a means of galvanizing public support. If following the conflict Bismarck had returned Alsace - Lorraine to France the conflict could have been seen to have occurred in vein, yet by keeping possession of the land Bismarck seems to have given the forces of German nationalism a victory in the hopes that it would be sufficient for the state. The annexation while potentially domestically necessary created a foreign policy problem that ensured that Bismarck's Germany would need to remain ever vigilant in its attempts to keep France isolated. (Mann 228-229)

The 1880s saw Germany make a radical change in its foreign policy. Bismarck had long believed that imperial gains for Germany would do nothing to add to the power or security of the state, moreover he also felt that any movement on colonial expansion could weaken Germany's relationship with Britain. However, domestic political realities caused a change in the mentality and opinion of Bismarck. The Chancellor faced a potential challenge to his authority from the Crown Prince. Thus, by moving towards a colonial policy Bismarck was able to strengthen his position within the government by attracting the support of imperialist within the government and within the interest groups that surrounded the government. (Gilbert 1220)

Otto von Bismarck did not take this action in a geopolitical vacuum. He, the consummate pragmatist, realized that such actions could damage Germany's relationship with Britain and possibility trigger increased competition between the two states or at worst outright 
balancing. However, the Chancellor was aware that his continental alliance system was in such a position to make the British virtually powerless to balance with another great power against Germany. The only real potential ally available to Great Britain was France, and with this in mind Bismarck worked diligently to keep France on the sidelines or at minimum on the wrong side of the issue to allow Britain to easily create an alliance of necessity. Bismarck increased his calls for French colonial expansion and used his loose relationship with France to further weaken Britain's position. ${ }^{77}$ Though, he was aware that any such relationship with France could only be temporary for France and thus was unwilling to destroy his connection to England. (Gilbert 1220-1221)

Bismarck is quoted as stating, "[a]11 of this colonial business is a sham, but we need it for the election" (Kagan 111). The Chancellor realized that Germany needed to ensure its influence in Europe before any mercantilistic dreams could really be fulfilled through a major colonial policy. Yet, he was also aware of the fine line that needed to be traversed as a result of the domestic political realities that his government faced. Public opinion and elite perceptions had taken hold of the opium - the desires that colonial glory held. (Kagan 111-112)

Bismarck had long held to the principles of free trade as he believed that the state's economic policies should be subservient to the German state's diplomatic and foreign policies. The Chancellor felt that tariffs and protectionist policies were unnecessary in German industry and agriculture were willing to make efficiency adjustments to allow them to compete in the international system. He was long able to cast a deaf ear upon the calls from German industry for the creation of protectionist polices, however in 1878 Germany's agricultural sector also

\footnotetext{
77 The Boer War can also be seen to illustrate the growing anti-British sentiment among the German masses. German nationalism could not be covered-up completely and thus the public sought to lash out against the global power that it perceived to be blocking Germany from its preordained greatness. Kagan, Donald. On the Origins of War and the Preservation of Peace. New York: Double Day, 1995: 142.
} 
began to call for similar tariffs to protect them from both Russian and American grain importation. These calls coincided with Bismarck's need for a strengthened domestic coalition and presented the possibility of providing a policy in which Bismarck could unite both conservative political parties and conservative interests into a coalition that would then enable him to deal a blow to the liberal parties that he most feared. The confluence of the demands of interests and the domestic political landscape that Bismarck faced caused a change in his underlying belief system and a movement towards a more protectionist Germany. Germany's protectionist policies also had the added advantage of support in the majority of German public opinion, as German heavy industry had already waged a long campaign to increase awareness of the need for tariffs in the public consciousness. (Stern 201-202) This move also signaled to the international system a move away from a public good of open markets and the rise of a more competitive German economic system

\section{Bismarck's loss of Control}

1888 was the year in which Bismarck lost his absolute grip on power within Germany as Wilhelm II rose to power following the deaths of two kaisers. ${ }^{78}$ The new German leader saw his role in policymaker mindset, and thus resented the power that Bismarck had gathered unto himself. The new Kaiser also had a strong desire to increase German power, as he believed that the power resources of the German state had not been used sufficiently under Bismarck. ${ }^{79} \mathrm{He}$ did not realize the importance of the precarious balance that the Chancellor had forged and navigated and still sought additional power for Germany, actions that would eventually trigger balancing by the other great powers of the day. (Kagan 119)

\footnotetext{
${ }^{78}$ A detailed accounting of Bismarck's dismissal can be found in Fulbrook, Mary. A Concise History of Germany. Cambridge: Cambridge UP, 1990: 137-138.

${ }^{79}$ Wilhelm II sought increased power within the German government and the international system. He also saw a great divide in the world views of himself and the Chancellor. Kagan, Donald. On the Origins of War and the Preservation of Peace. New York: Double Day, 1995: 115.
} 
Kaiser Wilhelm II also had what can be seen as a love/hate view of Britain, as he admired British power and society while enviously hoping that Germany could also follow such a path. ${ }^{80}$ He did not see the pitfalls that would follow any engagement of Britain, nor did he realize the importance of alliance system that had been created to foster stability in the system. Ultimately Germany would come to attempt to challenge Britain on the seas, an area that Great Britain had isolated as strategic realm of importance. ${ }^{81}$ Bismarck had realized that Britain did not desire to wield power on the continent, but that global power was a different matter for the island state. However, this was a battle with the new Kaiser that Bismarck could not win. (Kagan 120-121)

Towards the end of Bismarck posting as Chancellor he had lost the support of the military as a backing interest. ${ }^{82}$ The military openly called for his dismissal. This can be seen as the result of his desire for Germany to remain a status quo power, thus not allowing the military to gain the prestige and honor that it sought. (Fulbrook 137) The successors of Bismarck quickly took the bait that domestic politics offered them, that being the political rewards of increased economic expansion through the creation of large German fleet. This represented both a nationalistic action that cold benefit the government in terms of public opinion and such actions were also pleasing to industrial interests. (Snyder 87-88)

\section{The Impact of Domestic Politics on German Dominance}

The domestic politics of Germany during this time period can be seen to have been the lynchpin to German binding in the international arena, as was hypothesized at the beginning of

\footnotetext{
${ }^{80}$ Snyder contends that Germany created a myth of Britain as a paper tiger, as Britain was seen as an aggressive competitor yet unlikely to fight German efforts to correct power imbalance globally.

${ }^{81}$ Snyder points to the use of risk theory by Wilhelm II in his attempts to challenge Great Britain with the creation of an inferior fleet. Snyder, Jack. Myths of Empire: Domestic Politics and International Ambition. Ithaca: Cornell UP, 1994: 140-141.

${ }^{82}$ More information on Bismarck's fears of the Military General Staff can be found in Kagan, Donald. On the Origins of War and the Preservation of Peace. New York: Double Day, 1995: 114.
} 
the study. Bismarck knowingly released the power of German nationalism in order to unify the state in the years leading up to Germany ascension to the position of arbiter of Europe. However, the German Chancellor made many attempts to lock German nationalism back in the box from which it came. He utilized both internal and external measures to restraint German politics, but eventually these forces became too much to be controlled. Bismarck saw his international regimes not only as a means of conveying understanding between the states in question but also the respective populations, thus attempting to tie the hands of the collective German psyche. He also attempted to discourage the growing force of political parties and public opinion within his country through the use of destructive temporary domestic political alliances and a strong centralized government. These ties worked for a period of time, but the agrarian and industrial interests of the era soon began to mobilize the public. This would prove to be too powerful a force even for Bismarck, and thus once Kaiser Wilhelm II took his position of power German domestic politics had reached such a point that restrain was no longer possible. This time in domestic politics marked the point at which the Bismarckian alliance system began to crumble, not from external pressure or balancing but from within as the state began to break the ties that had stabilized the state and the status quo international system.

\section{German Hegemonic Power - Powerful at the Right Time}

Germany's rise to power coincided nicely with other systemic changes. ${ }^{83}$ Austria Hungary found itself in a period of decline and isolation, as did France following the Franco -

\footnotetext{
${ }^{83}$ A look into the National Capabilities dataset as collected by the Correlates of War Project further supports this conclusion. An aggregate adjustment of Cline's power measure was utilized to check the historical record against the compiled data for the years of 1870-1894. The equation that used is a follows: Perceived Power $=$ (Population + Iron and Steel Production + Energy Use + Military Expenditures + Military Personnel)/1000. An average score was created for each great power. Germany scored 132,161.76; France scored 107,710.76; Britain scored 211,624.8; Russia scored 143,480.44; Austria - Hungary scored 63,883.52; and Italy scored 45,019.04. These numbers illustrate that Britain's desire to remain an off - shore balancer and lack of a ground based military effectively lent the title of dominant state to Germany. The numbers point to the great deal of latent power present in Russia which
} 
Prussian War. Britain still remained distracted from the continent by its imperial ambitions.

Truly, the only potential challenger that faced Bismarck's Germany was Russia, and yet

Germany was able to ensure relatively good relations with the Russian state as a result of ideological similarities and mutual need. (Kennedy 189)

'Under Bismarck's astonishingly adroit handling, the Great Power system was going to be dominated by Germany for two whole decades after 1870; all roads, diplomats remarked, now led to Berlin. Yet as most people could see, it was not merely the cleverness and ruthlessness of the imperial chancellor which made Germany the most important power on the European continent. It was also German industry and technology, which boomed still faster once national unification had been accomplished; it was German science and education and local administration; and it was the impressive Prussian army." (Kennedy 187)

The end of the Franco - Prussian War and the subsequent unification of Germany created a new center of power on the European Continent. ${ }^{84}$ The German army was then seen as the class of Europe and Bismarck's power as an arbiter of Europe was then without question. Germany had defeated the power that was perceived to be the class of Europe, and had done so convincingly and quickly. Bismarck was aware of the apprehension with which the other great powers viewed the German rise to power, and he wanted to ensure that balancing coalitions did not weaken Germany's new found power. Hence, he committed the new power to the maintenance of the status quo, after all Germany had just placed itself on the top of the proverbial mountain and the status quo distribution of power had to be more than acceptable in face of potential system changing balancing. (Gilbert 1206-1207) The Chancellor was well aware of the power stakes that could be gained through the possession of state prestige, still he was opposed to policies that were driven by the need for both international and domestic

was not properly translated into actualized power. The numbers show support the conclusion that with the geopolitical realities of the day Germany can be considered a dominant actor in the international system.

${ }^{84}$ More information on the unification of the Germany through the Austro-Prussian War and the Franco-Prussian War can be found in Gilbert, Felix et al. The Norton History of Modern Europe. New York: W. W. Norton \& Company, 1971: 1117-1128. 
prestige. He felt that such gains often came at too high a price for a power increase that could be fleeting overtime. (Stern 317-318)

The rise of German power was fortunate to come at a time of relative British decline. The 1870s saw the beginning of an overstretch of power as a result of colonial expansion and domestic economic instability, which also meant that Great Britain would tend to focus on its economic problems and its empire. The island state also faced a domestic political conflict between Disraeli and Gladstone and the beginnings of unrest in Ireland. (Stern 336)

The rule of Bismarck coincided with a vast economic boom within Germany. ${ }^{85}$ The 1870s saw an increase in German industrial production to the point that it was only rivaled by the isolationist United States. Between 1871 and 1910 the population of Germany from forty million to sixty - five million, and these population numbers can be compared to France who only saw its population increase to thirty-nine million. Additionally, Germany saw massive increases in its urban population as the population shifted from agrarian production to more industrialized production. These demographic forces were built upon with the massive increase in railway transportation. (Dill 156-158)

Germany was also able to parlay its new economic power into international influence. Bismarck saw economic policy and specifically tariff policy as tools to be used in the service of diplomacy. The Chancellor envisioned state power as the primary goal and all other sources of power were to be used to ensure its maintenance. (Mann 162) This conceptualization illustrates that even a leader as powerful domestically as Bismarck can also be influenced by domestic politics, for he believed that tariff and economic policy should be used to support diplomatic aims. Yet, he too found himself forced to sacrifice diplomatic goals, namely a stronger

\footnotetext{
${ }^{85}$ A detailed explanation of German economic expansion can be found in Kennedy, Paul. The Rise and Fall of Great Powers. New York: Random House, 1987: 199-203 and 210-212
} 
relationship with Britain, for agrarian and industrial interests though increased tariffs would certainly weaken Germany's diplomatic relationship with England and cause a line of competition. Germany realized the importance that its foreign capital market, as the giving of loans to states to ensure their economic stability afforded the German state power in other areas. Through the use of its banking industry Germany was able to gain influence in other states, as these countries were then dependent upon German banks for liquidity and credit. These loans could be used to increase German prestige in the international system as well as serving the ultimate interest of international stability, as Germany's two largest clients were Austria Hungary and Russia. Bismarck was well aware of that economic declines could trigger warfare as states seek to make gains through warfare, or the option for states to engage in warfare to distract their populations from the hardships faced on the home front. (Stern 309-310)

Beyond economic power the German military can also be seen as a vast source of international power. The Franco-Prussian War illustrated the dominance of the state's army, as it defeated what was considered the class of the European military forces. The historical record also indicates the superiority of the German military in comparison to other military powers of the era: such as Austria-Hungary, Russia, and Britain. The Austrian and Russian militaries were out-matched by their lack of technological development, while Britain lacked a large land based military and its navy lacked the ability to be a power projection force when faced with a developed state as the target. The German military gained its superiority in several manners. First, the German reserve system that included three classifications of soldiers allowed for a vast number of mobilized troops. The state's reserve system also allowed for continuous training for even the older reserves. The organization and leadership of the German military also added to its strength, as the German Army was organized into outfits that trained together either in the 
reserve system or in front line regiments. The professionalism of the German officer corps also added strength, as German officers tended to train more and train with their actual enlisted troops. The age of the German officer corps also meant that morale and health were not an issue within the German Army. Finally, the transportation system within Germany meant that the German Army was the most mobile of any of the great power militaries of the day, as a result of the vast number of rail lines present in the state. (Gilbert 1126-1127)

\section{The Impact of German Hegemonic Power Concentration}

Germany made the most of its rise to dominance through unification and rapid economic development. The state saw a dramatic rise in economic power during this period and was able to couple it with its impressive military abilities, as shown in the Franco-Prussian War. The state was able to create a vast military force, for a state of its size, through the use of a two tiered reserve system. However, what was most impressive about Germany's hegemonic power concentration was its willingness to use its power to restraint itself and others in the international system. Germany showed a desire to protect the status quo and the power to make the diplomatic moves necessary to prevent the eruption of war on the European continent. The state also benefited during this time from the policies of the Great Britain, which entrapped the island state in the periphery. Germany for a time certainly made the best of its dominance and the period of stability in Europe during this time period illustrates the power of the state and its ability to wield it wisely.

\section{The Dependent Variable - No War, No Balancing}

The government of Bismarck chose to restrain its foreign policy rather than seek expansion, as he realized that the system was indeed in a precarious balance in which Germany would be allowed to be dominant provided that it did not seek expansions in physical size or 
power. ${ }^{86}$ Rather, the Chancellor was aware that France sat to its west ready to balance any form of German expansion as a means of regaining the prestige and territory that it lost during the Franco - Prussian War. Thus, Otto encouraged France to expend its energy for imperial gains, which could then distract the embarrassed state from its history. The need for restraint also meant that Germany would need partners to aid it. Bismarck looked to Russia as a means of preventing an encircling alliance between France and Russia. He also sought a partnership with Austria - Hungary to ensure that traditional German allies did not entangle Germany in any system changing actions. (Kagan 101-102) "The distinctive quality of Bismarck's realism resulted from his ability to recognize the limitations of his own powers and those of the state he governed" (Gilbert 1112).

"Bismarck assiduously sought to remain in the good graces of at least two others within the balancing system of five great powers. In particular, he tried to ensure that the alliance with Austria remained defensive only, so that the onus of aggression would always lie with other parties. In this way aggressive Russian behavior would always stimulate British resistance, and aggressive French behavior would not be assisted by Russia, while Germany would make sure that Austria would not engage in the reckless activities that might unify Russia, France, and Britain against the Germanic powers. Even before 1870, when Bismarck's strategy was not the maintenance of the status quo, he always tried to place the onus of aggression of his opponents, while reassuring third parties that his limited aims did not extend to overturning the European balance of power." (Snyder 69)

Germany at the height of its power had to remain aware of all of the potential balancing alliances that it could face in the coming years. Bismarck had to maintain an alliance system that ensured that several system changing alignments were not created. The first alignment of concern was the creation of an alliance between France and Russia created with Germany as the target. Essentially any alliance that was formed with France would most certainly have been

\footnotetext{
${ }^{86}$ For more information on Germany's fears of balancing collations see Gilbert, Felix et al. The Norton History of Modern Europe. New York: W. W. Norton \& Company, 1971: 1204.
} 
targeted towards Germany, as the French state was in almost constant search of alliance partners to seek revenge against Bismarck's state. Germany also had to be wary of a trilateral alliance of France, Russia, and Austria with Germany as the targeted state. In addition to alliances that targeted the German state there was also concern over the creation of alliances that could force Germany to act as a balancer to attempt to maintain the status quo distribution of power in the system. Such a conflict or alliance system that pitted Austria and any combination of allies verses Russia and a system of alliances also had to be avoided, as Austria and Russia had clashed in the past over the Balkans and could conceivably renew tensions without the moderation of German policy. There also existed the threat of a Anglo-Russian conflict that may have required German intervention or caused a redistribution of power. (Mann 229-230)

Bismarck was aware that Germany possessed too much power to seek expansion or a greater expansion of influence. The other great powers of Europe would not tolerate any German attempts to further weaken France. Traditional German allies would also seek to balance the state had Bismarck sought a more aggressive or assertive foreign policy. Restraint and binding remained the most pragmatic approach for Bismarck's Germany. (Kagan 103) “[Bismarck] wanted peace and ever increasing power-because international affairs was not a static system and because he knew that after centuries of defeats and disunity, his own people would forgive internal disappointments for external glory. To Bismarck, then, diplomacy was the essence of survival." (Stern 307) Bismarck realized the importance of interdependent issues such as economics and national security. He saw the importance of staying ahead of international system changes and the preservation of stability within the system. (Stern 307)

One of Bismarck's most unsuccessful policies was his Kulturkampf that sought to eliminate that power of the Catholic Church within Germany. This policy created a large amount 
of domestic political backlash, however the policy was not created to limit domestic challenges to Bismarck's power but rather to further enforce Bismarck's foreign policy. The Chancellor saw Germany's challengers as predominantly Catholic and thus through his cultural policy domestically he sought to decrease the power of his state's foreign challengers such as: French Monarchists; Habsburg Austrians; and various Polish factions. Ultimately Bismarck ended his cultural homogenization programs not out of fear of domestic political backlash, but as a result of the treaties he was able to create with Austria and Russia that increased the German state's level of security. (Mann 223-224) Bismarck's anti-Catholic policies can be seen as an illustration of the Chancellor placing foreign policy ahead of domestic politics. The sources of these policies were more foreign in nature, as he feared the growing strength of transnationalism within Germany. It was his concern that Catholicism would unite states such as Austria and France against a united Germany and that such ties would create revolutionary sentiment within the Catholic population of Germany. (Dill 151)

France was a state of primary concern for the government of Bismarck, as France had lost territory and prestige to Germany in the Franco-Prussian War. Germany realized that the nightmare of balancing would likely begin with France as the state sought to return to its past glories. ${ }^{87}$ The German Chancellor also realized that there was only one real pathway for France to exact its revenge upon the German state. "Bismarck's system looked east: French revenge was not a serious danger unless there was an Austro-Russian war. Waterloo came after twentyfive years of French victory; Sedan confirmed half a century of decline, which many men realized after 1871, as they had not realized after 1815, that the greatness of France lay in the past—a greatness to be preserved, not to be advanced." (Taylor 281) This illustrates the

\footnotetext{
${ }^{87}$ More information about the fear of a scorned France can be found in Stern, Fritz. Gold and Iron: Bismarck, Bleichroder, and the Building of the German Empire. New York: Alfred A. Knopf, 1977: 319-320.
} 
importance with which Germany viewed its role as a pacifier of Austro-Russian tensions and the crucial nature of German influence over both states. $^{88}$

Germany had made two main attempts to divert French attention from its war losses. Following the Berlin Conference Bismarck was aware of the resentment towards the German state that was growing within France. The French felt embarrassed after their loss to the new German state and had lost land as well, in Alsace - Lorraine. The Chancellor was aware that this was the recipe that could cause France to become a revisionist state. Thus, he embarked on a path of reassurance and diversion with both the government and people of France. He sought to encourage French colonial interests as a means of diverting the attention of the wounded state towards the periphery. He also sought to assure the population that Germany meant no additional harm to the state, while never offering to cede the concurred territory. (Gilbert 1217) The German state also sought to influence French domestic politics so as to further hinder the creation of balancing coalitions. The German government was well aware of the threat posed to it by France and any state that the French government could find as a balancing partner. Thus, Germany found itself in support of the republican movement within France, which can be seen to run counter to the traditional beliefs of the German state at this time. Their support of republicanism within France arose from Bismarck's belief that such a government in France would discourage monarchial governments such as Russia and Austria - Hungary from allying with the French state. (Crankshaw 313)

On face Great Britain would have seemed to have been a primary balancing concern for Germany, however Britain was more concerned with its domestic economy and its imperial territories. During the period of German dominance Britain remained largely entrenched in its

\footnotetext{
${ }^{88}$ A detailed discussion of Franco-Russian relations can be found in Kagan, Donald. On the Origins of War and the Preservation of Peace. New York: Double Day, 1995: 126-127.
} 
policy of splendid isolation. ${ }^{89}$ The isolationist policies of Britain did not mean that Germany was completely trusted. Following the Franco - Prussian War Disraeli stated: "[ $[$ ] his war represents a German revolution, a greater political event that the French Revolution of the last century.... Not a single principle in the management of our foreign affairs, accepted by statesmen for guidance up to six months ago, any longer exists. There is not a diplomatic tradition which has not been swept away. You have a new world, new influences at work, new and unknown objects and dangers with which to cope.... The balance of power has been entirely destroyed, and the country which suffers most, feels the effects of change the most, is England." The formation of the Three Emperor's League was also of some concern to Great Britain not only because of its potential system changing effects but also as a result of the governmental makeup of its members, that being three dynastic governments. However, the formation of the loose alliance system was not sufficient to cause Britain to depart from its continental strategy of isolation. Rather the British state was pleased that such a relationship would allow Germany to influence the actions of both Russia and Austria and in so doing containing Russian desires in the Balkans and the Mediterranean Sea. (Crankshaw 314-315)

The closet that Bismarck's Germany came to outright competition with Britain was during the German movements towards a colonial empire. Inefficiency of German industry in competition with other great powers meant that these economic interests would benefit greatly from German colonial holdings, as it would then open market space for Germany's industries. (Stern 415-416) The need for colonial expansion can essentially be traced to a collective action problem within German industry, as German capitalists had failed to undertake the economic

\footnotetext{
${ }^{89}$ As Germany rose to dominance on the European Continent Britain maintained its use of Cobden's Doctrine which stated that the continent was of no concern to the British so long as the general peace was maintained. This allowed the island state to use its resources more globally and remain and off-shore balancer. The doctrine also meant that Britain had a vested interest in German power, so long as Bismarck was able to weave a web of alliances to maintain stability of the international system. More information about the British policy can be found in Taylor, A. J. P. The Struggle for Mastery in Europe: 1848-1918. London: Oxford UP, 1954: 283-284.
} 
hardships needed for competition and expansion of trade. The government remained the only remedy for such limitations. (Stern 434) Prior to the colonial policies of the German state its trade was largely located in states that had undertaken protectionist policies, which meant that colonial expansion was one of the few remaining outlets for burgeoning German economy. Still Germany's late entrance into the colonial realm meant that there was limited territory for expansion without direct conflict. These areas included the Near East, Middle East, Equatorial Africa, South America, and China. (Stern 426)

\section{The End of an Era - Bismarck's End and the Beginning of Balancing}

By 1894, Germany's Triple Alliance of Germany, Austria - Hungary, and Italy was now balanced by a Franco - Russian alliance. This beginning of earnest balancing arose both out of the forced retirement of Bismarck and the transition towards a more hostile and less restrained diplomacy by his successors. This marked the end of Bismarck's long strategy of driving a division between Russia and France. (Kennedy 250)

In the post - Bismarck era balancing soon followed, as his replacements did not take long in attempting to revamp his alliance system. Germany quickly broke off its relations with Russia, which had been a cornerstone of Bismarckian policy as it served to keep Russia out of the welcoming arms of France. It was the thought of the new German government that Britain, the same state that Germany would soon seek to challenge, was a more suitable alliance partner. Wilhelm II saw Bismarck's alliance system of checks and balances as too complex and felt that he could lure Britain out of its splendid isolation. Were Napoleon III had failed the new Kaiser saw opportunity, yet his attempts were ultimately in vain. And without fail Russia was not alone long as France soon came calling for a balancing partner, the downfall of Germany was now only years and moves away. (Kagan 121-123) 
The removal of Russia as a key partner for Germany only decreased the power of the German state, as Britain wanted no part of a binding alliance with the German state particularly in light of new found aggressive tendencies. This only increased the influence that Italy and Austria held over Germany as its two remaining alliance partners. Otto's alliance system had been turned on its head; the master state was now no longer the head of its own table. (Kagan 125)

The end of Bismarck's rule over the foreign affairs of Europe was truly signaled by the failure of Germany to renew its Reassurance Treaty with Russia, which allowed the Russian state to move into the waiting arms of the French. ${ }^{90}$ The beginning of the new German policy was also signaled by Wilhelm II move to challenge the dominance of the British Navy, which triggered an all out arms race between the two states. ${ }^{91}$ This arms race and the alignment of France of Russia against Germany effectively signaled the end of the period of stability in European affairs and the beginning of the march towards war. ${ }^{92}$

\section{The Impact of Balancing on Bismarck's Germany}

Bismarck was able to prevent balancing throughout his term as Chancellor of Germany, and this should be seen as a large task as the international system during his rule was populated with potential balancers and ripe with the possibility of a system changing war. Bismarckian Germany was able to bind itself to both Austria-Hungary and Russia which not only pacified both states but restrained Germany. These alliances also had the added benefit of keeping a

\footnotetext{
${ }^{90}$ More information on the end of the Reassurance Treaty can be found in Croce, Benedetto. History of Europe in the Nineteenth Century. New York: Harcourt, Brace and Company, 1933: 335.

${ }^{91}$ Detailed accounts of the Anglo-German Arms race can be found in the following sources: Kagan, Donald. On the Origins of War and the Preservation of Peace. New York: Double Day, 1995: 137 and Snyder, Jack. Myths of Empire: Domestic Politics and International Ambition. Ithaca: Cornell UP, 1994: 68 and 86-87.

${ }^{92}$ It was not Bismarck's alliance system that ultimately led to the World Wars, but rather the utter divergence from his system that allowed for encircling and non-defensive alliances to be created. Kagan, Donald. On the Origins of War and the Preservation of Peace. New York: Double Day, 1995: 108.
} 
revisionist France isolated. Germany was also able to prevent large scale conflict from erupting between Great Britain and Russia through its influence over the Russian state. Thus, during this time period Germany was able to prevent both an Austro-Russian and Anglo-Russian conflict through the use of its flexible alliance system. Germany was able to prevent these conflicts while maintaining its position of dominance in Europe and without the use of military force. This lack of great power conflict meant that Germany was able to stave off a system changing war and prevent balancing actions targeted towards it. The eventual balancing acts that ended Germany's dominance did not occur because of external actions, but rather this balancing was triggered from within Germany. As Bismarck's power waned within Germany and his retirement was eventually forced the powers of nationalism where in full effect inside the state. Germany moved towards policies of imperialism and protectionism which began to send warning signals throughout Europe, and the state failed to renew its Reassurance Treaty with Russia. The failure to renew the treaty pushed Russia into the waiting arms of a scorned France, and thus the beginning of encircling alliances was born. The delicate system of defensive alliances was soon turned into one that would lay the tracks for systemic warfare.

\section{Answering the Questions}

The Systemic Level (Dependent Variable)

- Who are the primary actors in the international system, and what justifies such a classification? 
Table 5-1: The Great Powers in the time of Bismarck

\begin{tabular}{|l|l|}
\hline \multicolumn{1}{|c|}{ State } & \multicolumn{1}{|c|}{ Great Power Justification } \\
\hline Germany & $\begin{array}{l}\text { Military Strength } \\
\text { Rapid Economic Development }\end{array}$ \\
\hline Great Britain & $\begin{array}{l}\text { Global Influence } \\
\text { Naval Power } \\
\text { Economic Power } \\
\text { Potential Balancer }\end{array}$ \\
\hline Russia & $\begin{array}{l}\text { Population Size } \\
\text { Potential Balancer }\end{array}$ \\
\hline France & $\begin{array}{l}\text { Declining Power } \\
\text { Isolated Power } \\
\text { Potential Balancer }\end{array}$ \\
\hline Austria - Hungary & $\begin{array}{l}\text { Declining Power } \\
\text { Potential Balancer }\end{array}$ \\
\hline
\end{tabular}

- What actually triggers alliance formation in a given historical situation?

Germany was the instigator of alliance formations during the Bismarck era. That is not to say that Bismarck's Germany triggered countering alliance, but rather that Germany during this time period fostered an alliance system in order to preserve the status quo distribution of power. The German state was able to generate numerous defensive alliances in order to create a system that restrained not only Germany's alliance partners but Germany itself. It is during this time period that we are able to see some of the only truly successful binding relationships created in this study. Germany was able to use its system of alliance to restraint both Austria - Hungary and Russia in order to prevent a war between the two states that would have required Germany to act as a balancer on either side of the conflict dyad.

Additionally, Germany was also able to provide influence over Russian policies that were able to minimize the degree of contention between Great Britain and the Russian state. This further prevented a major clash of great powers in Europe that could have drastically redrawn the power relationships of the international system. Germany saw war as a last resort at during this 
time period and was willing to restraint itself and the nationalistic forces that were present in Germany during this period. The German alliance system was also able to keep France, a potentially revisionist state, isolated during most of Bismarck's rule, as the state was able to keep some form of alliance relationship with Russia present until the last portion of the Bismarck era.

- Is balancing or bandwagoning seen in alliance formations?

Balancing and bandwagoning with Germany as the target are not seen during the Bismarckian period. Conversely following the removal of Otto von Bismarck from power we are able to see the almost immediate balancing of German power in Europe. The reign of Wilhelm II and the end of Bismarck's leadership of Germany began with the non-renewal of the Reassurance Treaty with Russia, which left the Russian state without a partner in the system thus pushing Russia into the anxious and open arms of France. This non-renewal of a key Bismarckian relationship triggered the kind of balancing that the former chancellor feared most.

It was the belief of the German government at the time that Great Britain could be used as a substitute for Russia, though Great Britain was the same power that was attempting to remain isolated from European politics; that Germany had recently moved to challenge in the realm of colonialism; and that Germany was then moving into competition with through its increased development of a navy. This alliance gamble ultimately failed as Germany was left with only Italy and Austria - Hungary through the Triple Alliance as partners. Kaiser Wilhelm II's foreign policy misperception illustrates a lack of understanding of the importance of RussoGerman relations, as well as a lack of understanding of the British relationship with Europe during this time period.

- Are cases of stability the result of a perception of non-threat by the larger pole? Is this stability the result of binding by the preponderant power in the system? 
During the Congress of Berlin Germany made great strides to reassure Europe of its desires to maintain the status quo power distribution and assure the other great powers in the system that it had no aspiration to seek additional territory. However, while these pleas were compelling they did not completely instill confidence in the other European capitals. Britain to an extent still feared a powerful state in the center of Europe, as did France which had recently seen the force that Germany was able to apply. Great Britain was pleased with Germany since the state was willing to take up the call to restrain both Russia and Austria. This does not mean that the other great powers of the era completely saw Germany as a status quo power.

Germany under Bismarck was able to make up in some regards for the perception of the German threat and even use the perception of threat to bind itself to other states in the system so as to retrain both Germany and its alliance partners. Germany utilized binding relationships with both Austria-Hungary and Russia to restrain itself and the other states. Bismarck saw alliances not only as agreements between states but also as a means of conveying understanding between populations. It was the population of Germany that Bismarck feared most in some regards. The Chancellor was fearful of democratization in the German state, as he was well aware of the nationalistic forces that he had unleashed through his German unification plan. He was aware that this newfound German nationalism, if not restrained, could have caused the state to overstretch its power resources and act in such a way that would certainly triggered encircling alliances. He saw these alliances as a means of tempering German desires, and as a means of preventing other states such as Russia and Austria from taking actions that could have led to a system changing war.

Bismarck's defensive alliance system was created in such a manner so as to reassure states that if conflict were to arise the aggressor would be met with an overwhelming coalition of 
balancers. This deterred states within the alliance system and on the outside of the system from taking overly aggressive policy actions. Through each alliance Bismarck was able to weave a channel of influence that would create dialog in times of disagreement and foster consultation between the great powers. Germany's alliance system at this time was at its heart a binding system that mutually constrained the actors involved. Bismarck's Germany was also able to use the inherent fear of German power that existed in the other great powers through a policy of brinksmanship to induce state into binding with Germany. The German state was perceived as threatening enough to persuade states to create alliance relationships with the state in the hopes of restraining it. This perception of fear was useful in making states such as Russia see alliances as more efficient uses of resources as opposed to potentially needing to balance the German power. Germany was also able to use France, a state that it had little hope of inducing into an alliance relationship, as an anvil. Germany could make threat gestures towards France that it could latter back away from to coerce Russia to renew alliance relations.

\section{The State Level}

- What is the institutional make-up of the state in question?

On its face Germany during this time period resembled an anocracy. The German Constitution, which was largely written by Bismarck, was created in such a manner so as to give the majority of the power to the Kaiser. This meant in that during the rule of Bismarck that the majority of the power in the German state was held by Bismarck himself as Chancellor of Germany, because the Kaiser at the time of inception of the unified German state was weak and desired Bismarck to take the lead in most matters. There did exist at this time both an upper and lower house in the German Parliament. The lower house was elected by universal manhood suffrage, however this should not convey the title of democracy upon the German state. Power 
was centralized above the elected parliament and into the hands of the Chancellor. Bismarck distrusted democracy not only due to his power but out of a general fear of what the German people would do if they were given true political power. Thus, Bismarck took measures to stunt the growth of political party power in the state and took action to undercut the legitimacy of the parliament.

One of the few initial powers of the German parliament was the power of the purse. But, Bismarck ensured that there were means to circumvent this power. The Chancellor was able to dismiss the body or disregard the body if he felt there were substantial external threats to warrant such an action. This essentially meant that Bismarck could either relieve that members of parliament of there titles if they became too troublesome or inflexible, which was a tactic he was more than willing to use if necessary. Until the waning years of Bismarck's rule he was able to implement almost any policy that he deemed fit within the realm of the national government. However, the lack of centralization of the new German state meant that the national government's powers were lacking in some regards.

The constitution of Germany was created in such a manner so as to leave a great deal of power within the local states. The national government also lacked a sizable bureaucracy by which to govern the state. This meant that the powers of the national government were mainly limited to foreign policy, military affairs, and the powers of finance. These were the powers that Bismarck wished to keep centralized, while the remaining governing areas were mainly left to the states of Germany.

- Is the dominant state democratic in nature? And, are other system members also democratic?

Germany during the rule of Bismarck cannot be considered a democratic state, at best the state was anocratic in nature. Germany's lack of democracy during the era in question did not 
negatively affect its ability to attract allies, furthermore Germany's conservative leanings seem to have provided additional grounds for one of its most important alliances. The alliance that was influenced by the state's form of government was the Three Emperor's League of Germany, Austria-Hungary, and Russia. A foundation of the League was the desire of the three states to avoid potential revolutions that could have ushered in more liberal forms of government and disrupted the system's distribution of power. Thus, in the case of Bismarckian Germany we can see that non-democracies were attracted to other non-democracies in the hopes of preserving their governmental systems.

- Does the state in question have a means for mass public opinion to influence state action?

During the 1870s the role of public opinion in the German state can be seen as lacking, but as the state continued to evolve there was an increase in the impact of public opinion upon state action. In the early years of the unified Germany Bismarck possessed a strangle hold upon most high level governmental actions. It was his desire to mitigate the importance of public opinion simply because he did not trust the beliefs of the German public. But, as political parties grew in strength and Bismarck began to see the potential for domestic political challenges the power of public opinion increased. The 1880 s saw a dramatic increase in the power of the public as long running nationalistic desires began to percolate to the surface of the German political scene. Interests such as agrarian and industrial interests had been priming the public for some time to encourage a more protectionist and imperial foreign polices.

Bismarck had long held that economic policy should be determined by foreign policy, and thus he had grounded Germany in a policy of free trade as this was seen to have increased the state's flexibility in regards to foreign policy and kept the state away from directly challenging states such as Great Britain. The late 1870s saw the beginning of a large 
protectionist movement within the German population, which was begun by industrial interests and eventually logrolled by agricultural interests. These interests gained power by using the inherent nationalism of German public opinion to support their goals. This resulted in Germany's introduction of new protectionist tariffs.

The use of public opinion by these interest groups did not end with protectionism, but were also used to bring about another large change in German policy, as Bismarck a long time detractor of colonialism soon found himself moving towards an imperial policy. This colonial policy soon placed Germany at the center of the Britain's radar, as the state was then moving into geopolitical arenas that would conflict with British interests. Bismarck had long tried to avoid such policies and the influence of interests and public opinion, but he could not permanently halt the evolution of the German political system, nor could he extinguish the fires of nationalism within the German public.

- What types of interest groups or elites are present in the state in question?

A primary interest early in Bismarck's rule was the banking houses of Germany. This interest group was formed from the relatively small number of German banking houses. Their initial influence can be seen in Bismarck's primary and most trusted advisor, Bleichroder. However, this interest was one that moved more within the circles of Germany's existing foreign policy. The banking interests had similar goals as those of the Bismarck government, that being the preservation of the status quo and thus the reduction of uncertainty in their financial decisions. These sentiments can be seen to have supported Bismarck's pre-existing ideals about the maintenance of the European power distribution. The banking houses gained their influence not only from their place of privilege in having a representative as Bismarck's primary advisor, 
but also through the fact that a great deal of the new German middle class had come to be employed by the relatively small number of banks.

The other two primary interest groups within the German state at this time should be seen in Snyder's framework as a cartelized interest, for they did not gain their true power until their ideals began to follow similar patterns. These interests were the German agricultural industry as well as the state's industrial sector. This group has become known as the Iron and Rye Coalition. The German agricultural interest was by far the older group as the area had previously found its economic sources of power from the land. The group gained its power from the Prussian state, as this was a primary agricultural sector of Germany. Prussia during the rule of Bismarck held a special position of power within the new united Germany, as it was from this state that Germany drew the majority of its military might. Prussia was also the state from which the Junker elites drew their power, and it was also the state from which Bismarck had risen to power. It was also in this German state that the seeds of German nationalism were planted.

The industrial sector was the newer economic resource of Germany, as Germany had recently seen rapid economic development. The industrial sector originally saw its domestic power rise from the banking sector, but as more and more of the Germany's growing urban population came to work within German industry the group saw an independent power resource. But, it was not until these two domestic interests groups saw a convergence of views that they realized their true power, as the two groups were able to merge the political force of older landed Junkers and the rising urban elites along with the power of the their respective workforces. It was the confluence of elite power and mass nationalism that was able to divert the German government from a policy of status quo preservation to one of power revision. 
- In what directions are such interests moving the government?

Table 5-2: Interest Group Activity in the time of Bismarck

\begin{tabular}{|l|l|}
\hline \multicolumn{1}{|c|}{ Interest } & \multicolumn{1}{c|}{ Policy Direction } \\
\hline Agrarian Interests & Protectionism \\
\hline Industrial Interests & $\begin{array}{l}\text { Protectionism } \\
\text { Imperialism }\end{array}$ \\
\hline Banking Houses & Status Quo/Stability \\
\hline \multirow{3}{*}{ Public Opinion } & $\begin{array}{l}\text { Nationalism } \\
\text { Lebensraum } \\
\text { World Politics }\end{array}$ \\
\hline
\end{tabular}

- Is the state in question a status quo power or could it be considered a revisionist power?

Germany under Bismarck was most certainly a status quo power, following the unification of Germany. This was not out of lack of traditional realist though, but rather out of pragmatism. Bismarck was aware of the dangers of countering alliances and was also aware of Germany's precarious position as the dominant state in the European system. He knew that if Germany did not restraint its policies that it would have quickly found itself balanced by other states in the system. Additionally, the German state during this time period sought to ensure the preservation of the general status quo throughout all of the European system. The Chancellor knew that any war could be a system changing war. Germany during this time period showed a willingness to cast aside territorial expansion and additional glory for the state in return for the preservation of the status quo, though just beneath the surface of German politics laid sentiments of nationalism that would soon destroy the status quo once Bismarck began to loss political power. 


\section{The International Regime Level}

- What types of regimes are present?

Germany under the leadership of Otto von Bismarck was able to create a system of alliances grounded in three basic principles. First, each of the German alliances was created with a time limit, a set number of years for which the alliance would last with the provision that the agreement could be renegotiated by the parties if desired. This left the Bismarck government room to maneuver as power relationship and the demands of the international system changed. These time limitations also meant that Germany could better monitor the actions of its alliance partners to determine if a continuation of relations was in Germany's best interests. Next, each alliance was defensive in nature. That is to say that each alliance was created to defend the states in question from a specific aggressor, for example the Dual Alliance created with Austria was based on mutual defense in the case of a Russian attack and mutual neutrality if the attack came from another state. However, the alliance did not call for support if either state was the aggressor in a conflict. These defensive alliances allowed for the reassurance of the state or states in question along with the ability for Germany and the other state to have some degree of influence upon the each others actions. In the case of Austria this allowed Germany some control over the state in its relations with Russia, as Germany could then remind Austria of their commitments and reassure the Austrian state that if Russia was to become aggressive Germany would support the state. The final principle upon which Germany's alliance system was based was the defense of the status quo power distribution. Germany saw war as a last resort policy action. The state was also aware that any war within the European system would have likely resulted in German involvement, and thus increased the chances of a power redistribution in the 
system and a potential loss of German dominance. This meant the alliance system had to be created in such a manner so as to deter conflict and increase stability.

The period of German dominance began with the Congress of Berlin that concluded the Franco-Prussian War. The congress was founded on Germany's willingness to forego further expansion and its willingness to limit its aims. The Congress solidified Germany as the dominant state in Europe and gave the state a jumping off point for further agreements that would allow the creation of the German alliance system.

A primary alliance relationship for the German state was its relationship with AustriaHungary, as Germany was the pacifier of the state as well as its security blanket. 1873 marked Germany's first foray into the creation of its alliance system. It was during this time that Germany, Russia, and Austria - Hungary created the Three Emperor's League. The League required that the three states consult each other and aid each other so as to maintain the stability of the European system. The League also functioned as a defensive pact between the three states. This relationship was based upon the shared governing styles of the three states and their joint fear of liberal forms of government and the potential for the spread of revolution. But, this relationship was difficult for Germany to maintain due to the tensions present in Austro-Russian relations. As the League lapsed Germany entered into the Dual Alliance with Austria, as a means of continuing its influence with the state, and as a means of inducing Russia to rejoin the alliance. This ploy did allow for an eventual renewal of the Three Emperor's League. However, eventually the League could not be renewed for a third time.

This non-renewal left Germany with the possibility that Russia could ally with France, and thus Germany had to ensure that this balancing action did not occur. Bismarck used the secret Reassurance Treaty to prevent such balancing of German power. The agreement pledged 
consultation and neutrality if either state became engaged in conflict. The non-renewal of the Three Emperor's League allowed Germany to expand its alliance system elsewhere through the creation of the Triple Alliance between Austria, Italy, and Germany and the formation of the Mediterranean Agreements with Italy. In both of these agreements Germany used Italy as a conduit to form informal relations with Great Britain, thus increasing the branches of the German defensive alliance system. The System can be simplified in the following graphic:

Table 5-3: Bismarck’s International Regimes

\begin{tabular}{|l|l|l|}
\hline \multicolumn{1}{|c|}{ International Regimes } & \multicolumn{1}{|c|}{ States } & \multicolumn{1}{c|}{ Functions } \\
\hline Three Emperor's League & $\begin{array}{l}\text { Germany } \\
\text { Austria- } \\
\text { Hungary } \\
\text { Russia }\end{array}$ & $\begin{array}{l}\text { Consultation } \\
\text { Defensive Alliance } \\
\text { Restraint }\end{array}$ \\
\hline Dual Alliance & $\begin{array}{l}\text { Germany } \\
\text { Austria- } \\
\text { Hungary }\end{array}$ & $\begin{array}{l}\text { Defensive Alliance } \\
\text { Restraint }\end{array}$ \\
\hline Reassurance Treaty & $\begin{array}{l}\text { Germany } \\
\text { Russia }\end{array}$ & $\begin{array}{l}\text { Neutrality } \\
\text { Restraint } \\
\text { Maintain Communication } \\
\text { Avoid Franco-Russian Alliance }\end{array}$ \\
\hline Triple Alliance & $\begin{array}{l}\text { Germany } \\
\text { Italy } \\
\text { Austria- } \\
\text { Hungary }\end{array}$ & $\begin{array}{l}\text { Neutrality } \\
\text { Restraint }\end{array}$ \\
\hline Mediterranean Agreement & $\begin{array}{l}\text { Germany } \\
\text { Italy } \\
\text { (Great Britain) }\end{array}$ & $\begin{array}{l}\text { Maintain Status Quo in Near-East } \\
\text { Keep Turkey Independent } \\
\text { Consultation }\end{array}$ \\
\hline
\end{tabular}

- Are these regimes formal or informal in nature?

Bismarck utilized both formal and informal international regimes in his foreign policy. The treaties and alliances that his government was able to create can be seen as formal in nature, such as: the Triple Alliance, the Three Emperor's League, and the Reassurance Treaty. These international regimes can be seen as a formalized since they were actually codified in writing and 
used as building blocks for future relations. However, these more formal regimes did tend to have time limits contained within them, which better allowed Bismarck to maintain a more flexible foreign policy. These time limits for agreements allowed for Germany to decide prior to the agreements expiration date as to whether the regime should be renewed, voided, or built upon. Time and environment dependent international agreements were not considered by Puchala and Hopkins, but these agreements do meet the codification requirement. Moreover, Bismarck's time limits for his agreements seem to allow for more organic and adjustable international policies.

Despite Germany's use of formalized international regimes the geopolitical environment also made the use of informal regimes necessary. This was the case in relations between Germany and Britain, as Britain's relations with Russia during the time period meant that Germany could not use treaties and agreements with the Russian state as a means of restraining Russia while having openly close relations with Great Britain. If Germany and Britain were to have become formally aligned Bismarck knew that this would have placed Russia on the defensive and thus pushed Russia into the open arms of France, which was a worse case scenario for the German state. Bismarck was also aware that Britain was not a suitable binding partner since its continental powers were limited. The international environment made it vital that Germany and Britain not be formally aligned. Bismarck's Germany did maintain close symmetry of foreign policies with Britain and agreements such as the Mediterranean Agreement brought the two states closer through the use of connecting states, in this case the connecting state was Italy.

The ouster of Bismarck illustrates the reality of this environment as Germany began to look to towards Britain as a partner only to lose Russia and thus trigger a balancing alliance 
created between France and Russia. The collapse of Bismarck's alliance system can be seen to have arisen not only from his ouster as chancellor, but more importantly from his inability to educate the elites of the German government on the nuances of his system. Bismarck, a man who feared political challengers, also failed to create and train an individual who could have assumed his duties with equal skill.

- Does the presence of regimes constrain state action?

The presence of international regimes can be seen to have both constrained Germany as well as Germany's balancing partners. Bismarck was aware of and feared the powers of nationalism that he used to forge a unified German state, and thus he knew that international restraints were needed to coerce the German state to behave within the bounds of the European system. He was aware that under the surface of German domestic politics were sentiments that could have led the state towards imperialism and overexpansion, and was thus proven correct in the years following his removal from power.

Bismarck saw international agreements not only as understandings between states, but also as means of creating understanding between state populations. He knew that such regime foundations forged the creation of norms of expected state behavior. More than any other leader in this study Bismarck sought to restraint the potential actions of his state, albeit for limited durations of time.

Germany also sought to restrain the actions of the other states in within the European system. First, the state used its international agreements to limit potential balancing possibilities that could have been targeted towards Germany. This was the case in Germany's relations with Russia, as it was known that if Germany allowed Russian relations to deteriorate it would have meant a certain alliance between Russia and France, a state with revenge and revision on the 
mind. Additionally, Germany had a vested interest in ensuring that war was prevented between any European powers, as such a war would have certainly necessitated German action as a balancer and thus opened the possibility for a redistribution of power in the system and a potential loss of German power. Bismarck identified two main conflicts that had to be avoided. The first such conflict was a war between Russia and Austria.

A Russo-Austrian conflict would have created the need for Germany to act as a balancer on either side of the affair and thus could have redrawn power relationships within the system. Bismarck used his alliance system to restrain both actors. Bismarck's primary restraint target in this dyad was Austria, and thus he had to guarantee a channel of German influence remained open with the Austrian state. Germany also had to be concerned to a degree that Austria, as it declined, could become more revisionist in nature and potentially ally with a revisionist France. The Three Emperor's League was the initial, easy means of creating Russo-Austrian peace, however as the relations of the two states continued to decline over the Balkan region separate bilateral agreements were used to achieve the same goal. Germany during this time period can be seen as the pacifier of this potential conflict dyad.

The second potential cataclysmic war dyad at this time existed between Russia and Great Britain. Conflict between these two states was possible during this time over clashes in the Mediterranean region, as Britain sought to maintain its global dominance and Russia sought the foundation of increased great power status and a key warm water port. It was Bismarck's aim to keep Russia locked in the box marked status quo power, thus preventing a total clash between the two states. In order to play the role of peacemaker and arbiter Germany grounded its international regimes on the foundation of defensive alliances, and made even more limitations of the agreements defensive natures by limiting the scope of the which states Germany would aid 
a state such defensive relations. This differs greatly from the alliances that were created in the build-up towards World War I, in that Germany did not pledge total support for any state thus navigating the lines of potential conflict that existed in Europe during this time period.

- Who are the creators or architects of the regimes in question?

Germany was able to work within the constraints existing in the international system prior to its ascension to power and to create new international regimes as the source of power and order in Europe. The Franco-Prussian War did not destroy the founding principles of the Congress of Vienna, but rather Bismarck worked within the system of regimes to paint France as the violator and norm breaker. Bismarck's Germany was also able to increase the number and intensity of international regimes present in the European system. Napoleon III's France had tried and failed to create a system of alliances that would function through Europe. Germany during this time period was able to achieve this goal of stabilizing the system through the creation of a defensive system of alliances. The alliance system did not include all of the great powers, but it was known throughout all of the capitals of Europe that violations of status quo international politics would result in balancing led by the Germany state. Bismarck was also able to use the principles of functionalism and brinksmanship to encourage other states in the system to bind themselves to Germany. This binding not only retrained German domestic politics but also allowed Germany to influence the policies of its partners.

\section{The Power Concentration Level}

- Across potential competitors how is population divided?

The numbers bellow are once again drawn from the Correlates of War Project's National Capabilities Data Set and are average scores based on the twenty-five year period of German dominance from 1870 to 1894. 
Table 5-4: Great Power Population Numbers in the German Case

\begin{tabular}{|l|r|}
\hline \multicolumn{1}{|c|}{ State } & \multicolumn{1}{c|}{ Population } \\
\hline Germany & $45,309,280$ \\
\hline Great Britain & $35,076,760$ \\
\hline Russia & $102,952,000$ \\
\hline France & $37,615,200$ \\
\hline Austria - Hungary & $39,541,040$ \\
\hline
\end{tabular}

These population numbers illustrate that the Russian population vastly outnumbered all other competitors in this time period, however these population numbers do not take into account the disparate territorial differences between Russia and the other great powers of the era. The figures do show that if Russia is set aside Germany had the largest population. The historical record supports a conclusion that other factors of power concentration such as economic and military development must also be considered during this era, as Russia at this time still was still dealing with problems of latent power conversion in addition to economic development. The Russian state's only real claim to power at this time was its population, though the state remained isolated to the east. Germany under Bismarck was also able to further marginalize Russian power through close relations during most of his rule.

- How is economic power divided between the target state of each case study and the other great powers in the system?

Table 5-5: Great Power Economic Indicators in the time of Bismarck

\begin{tabular}{|l|r|r|}
\hline \multicolumn{1}{|c|}{ State } & Iron and Steel Production & Energy Consumption \\
\hline Germany & $2,838,680$ & $55,108,080$ \\
\hline Great Britain & $7,288,880$ & $133,736,600$ \\
\hline Russia & 598,366 & $5,022,400$ \\
\hline France & $1,643,120$ & $29,078,120$ \\
\hline Austria - Hungary & 645,000 & $10,048,960$ \\
\hline
\end{tabular}

These numbers better indicate the dominance of Germany during this era. In terms of economic measures Germany was only surpassed by Great Britain, however the numbers alone 
do not tell the complete story. The historical record illustrates that during the period of German dominance the British faced a period of economic decline, and while this decline in no way equalized German and British economic power resources it did mean that Britain, a state already attempting a policy of isolation, was forced to become even more inward looking as it sought to preserve its empire. Bismarck's rule also coincided with rapid economic development and industrialization within Germany. This was fostered through the increased use of railways and the rapid urbanization of the state. The importance of Britain's lack of power projection capabilities to the continent cannot be ignored, as with the case of France Britain during this time period can been seen as ceding dominance to Germany.

This period also witnessed a growth in German banking that provided yet another avenue for the expansion of German economic power, that being through the use of international loans. Germany's two largest client states in this regard were Austria and Russia. These loans allowed for an extension of German influence as well as providing the state the ability to encourage economic stability throughout Europe. Bismarck and his advisors were aware that major economic collapse or recession could have triggered the outbreak of all-out warfare, and thus the state's international loans allowed fostering of increased stability.

- Across potential competitors how is military strength, as measured by either military personnel or military expenditures, divided? (In some cases both measures may be present)

Table 5-6: Great Power Military Comparisons for the German Case

\begin{tabular}{|l|r|r|}
\hline \multicolumn{1}{|c|}{ State } & Military Personnel & Military Expenditures \\
\hline Germany & 487,520 & $24,577,600$ \\
\hline Great Britain & 260,760 & $25,677,960$ \\
\hline Russia & 861,240 & $30,698,840$ \\
\hline France & 560,440 & $34,927,680$ \\
\hline Austria - Hungary & 288,840 & $11,536,880$ \\
\hline
\end{tabular}


The military personnel and military expenditures numbers can be seen as misleading. First, we can see that Germany during this time period outspent only Austria - Hungary and its troop levels are can be seen to have outnumbered Austria - Hungary and Great Britain. This is misleading for several reasons. In regards to Great Britain the small margin by which Germany is outspent can be rationalized by the fact that Britain, as a sea and colonial power, had to spread that money over a larger surface area. Russian numbers are better seen in the context of the lack of modernization and large land mass that corresponded with the Russian state. France must also be seen at this time period to have an inefficient use of military numbers as well as funding, for the state was seen to have been in decline in this period and had recently been defeated by Germany. Finally, the military numbers do not take into account the modernization of the German Army, which will be discussed bellow, nor due the military measures listed above take into account the massive military that Germany was able to call up through its advanced reserve system. This reserve system can also be assumed to have saved the German state in its yearly military expenditures.

- Are any technological or research and design issues present in a given system that could increase the power level of state in question that may not be detected by the previous questions?

First, when considering technological advancements the German railroad boom must be discussed. Germany during this time period saw a rapid development of the use of rail technology, which can be seen to have not only increased the efficiency of transportation in the economic terms but also these developments drastically increased the mobility of the German Army. The increased use of rail systems meant that the German military saw an increase the speed by which it could mobilize its army and transport supplies. Moreover, the use of railways also added to the speed by which the vast German reserves systems could be called into action. 
Another development that must be considered is the German reserve system itself. This was not a reserve army of significantly under-trained troops, but rather a two tiered system of reserves to supplement the already potent fighting force. The first tier had troops that had only been out of regular military service in the past two years, while the second tier had troops that had been out of service for over five years. These reserve tiers were also regularly trained depending on their classification. Such a reserve system added greatly to the already powerful German military.

- If soft power is present in the system, how is such a resource divided between the primary actors?

Germany under Bismarck did not seem to place soft power style power resources at a high premium. Bismarck saw prestige power politics as a potential waste of resources. The state also engaged in policies that would have detracted from their powers of attraction. This can be seen in Bismarck's anti-Catholic policies that drew a great deal of domestic and international attention during this time period. Bismarck created his anti-Catholic policies out of a fear of transnationalism, thus attempting to undercut Catholic loyalties that may have drawn Germans towards the policies of France or revisionist members of Austro-Hungarian government. Such policies certainly did not win the German state many friends throughout the Catholic populations of Europe.

Bismarck's Germany did attempt to play upon its position as an international lender, however this should be considered more of a hard power resource as the German government sought to utilize this resource to coerce states such as Russia to take actions that they other wise would not have taken. One potential source of soft power may have existed within the realm of other European conservative governments, as Bismarck championed such a governmental style 
and questioned the growing liberalization of governments, but such information is not discussed in detail in the historical record.

- Does the dominant state have the political willingness to carry the burden of its position in the system?

The political willingness of the German state under Bismarck cannot be questioned. While, Bismarck sought to avoid warfare and to use it only as a last policy option, however this should not be taken as a lack of political willingness for the German state. Bismarck realized that any war that were to arise in the European system would likely require German action, and that such a war would likely have caused a redistribution of power throughout the system and could have challenged Germany's position of dominance. Germany at this time was willing to undertake war just not if such an outcome could reasonably be avoided. There is also more to consider in terms of political willingness than just a state's willingness to undertake military action, in order to possess a high degree of political will a state must also have a willingness to undertake a leadership role in the international system in which it is dominant.

Germany can be seen as the leader of this system at this time, as it was not only to restrain itself but also to restraint other great powers in the system. The two primary targets of German restraint during this time period were Russia and Austria-Hungary. Germany showed a willingness to restraint Russia and Austria in their relations with each other. The state also showed leadership in its ability to restrain Russia in its relations with Great Britain. Germany was willing to use its power as a deterrent to other states, and thus preserve the status quo distribution of power.

\section{It Worked for a While}

The German case reveals a great deal about the underlying theory of handcuffed hegemony. Germany under the Bismarck government was aware of the problems it would face 
if balancing actions were undertaken by the other great powers of the international system. It is through this case study that we are able to see a great deal of binding through the use of international regimes, particularly through the German alliance system. Germany is demonstrative of a state that was motivated by the preservation of the status quo to bind itself to other actors in the system such as Austrian-Hungary, Russia, and Italy. The state also sought more than just restraint for itself, but was also willing to expend its hegemonic power to restrain other actor in the system, as Bismarck was aware that any war that took place between great powers of the era would have likely changed the power distribution of the international system or required German action as a systemic balancer that could also have resulted in a loss of German dominance. Additionally, the case is critical in its exposure of the powers of domestic politics, especially nationalism, because through Germany we can see the great lengths by which Bismarck attempted to keep public opinion and interest groups on the outside of the German political experience. It is through the decline of German dominance that the case illustrates the importance of domestic politics as the lynchpin variable in the study of hegemonic constraint. Despite the great power of the Chancellor during this period Bismarck still could not hold down the powers of nationalism mobilized through economic interests, and as these domestic forces gained power even Bismarck could not keep Germany upon a status quo path. 


\section{Chapter Six: \\ However, In Conclusion and Moreover}

After reading the case study chapters one might ask her or himself where the success story in the plight of handcuffed hegemony can be found. The truth is that we are able to point to one luck story and two success stories, though the degree and reasons for success vary. Spanish hegemony should be seen as a story of luck in the face of actions that would seem to have led to hegemonic failure. Spain was fortunate in its American discoveries and despite its best efforts was able to parlay its new found riches into a number of years of dominance. The Spanish Empire made few attempts to control its imperialistic, domestic urges and did less to endeavor to guise its power in a more suitable international light. However, in the face of these additional, self-inflicted challenges to its dominance it was able to remain dominant until it ultimately sought to fight a battle it was ill prepared to fight, that being its attempted armada invasion of England. What seems most amazing in the case of Spain was the state's ability to keep moving forward as it witnessed the depletion by overexpansion of its American conquests, in spite of a lack of fiscal discipline and overuse of loans from the banking houses of Europe. This is a testament not only to its exploitation of the Americas but also to the weakness of the other powers present in the international system.

Napoleon III's France had all the right intentions but was still unable to gain a true binding partner, nor was the state able to create much in the way of new international regimes that would have deepened consultation and restraining international norms within the international system. The case of France is most interesting when one considers that traditionally Louis Napoleon's France tends to be seen as a very aggressive international actor as well as a large factor in the downfall of the Concert of Europe. This work depicts France in a different light. Napoleon III, while troubled with the perception of competing domestic political 
forces that sought to pull the state in various directions and with the difficult prospect of navigating a clouded domestic political system, was able to keep France largely out of real balancing opposition until the state's ultimate decline in the Franco-Prussian War. The Crimean War can also be seen as a French and British attempt to preserve the status quo power distribution. Russia during this time period presented the largest danger to the concert system, which also benefited the French power. Moreover, Louis Napoleon sought to further deepen the concert and congress system through continual calls for congress diplomacy and multilateral actions. These calls also did much to soften the appearance of French foreign policy during this time period. However, it is also possible that this form of foreign policy was chosen to best disguise the lack of political willingness present within the state's domestic politics as well as France's lack of a true power asymmetry.

Bismarck's Germany provides the study with a case that is representative of the ideal type of the theory, save for the ultimate nationalistic decline of the German state. Germany during this time period should be seen as a state that sought to restrain itself and bind its power, as well as a state that was willing to take action to restrain other actors in the international system. Bismarck's Germany was very much a status quo state following the conclusion of the Franco-Prussian War, as it was aware that revisionist tendencies would only degrade German power in the long run. However, Germany was also an actor plagued by domestic political concerns, namely the rise in power of nationalism. A telling aspect of the case study was Bismarck's beliefs that such an alliance system could not only convey expectations and norms across governments but also across populations. Still, despite the successes of the alliance system and the centralization of the power within the chancellorship Germany was unable to 
keep its newly created nationalism locked away, as the case illustrates the central role that domestic politics played in the ultimate balancing and downfall of Germany.

The remainder of this concluding chapter will revisit the hypotheses put forth in the theory section of the work. The findings will be discussed in a way that will draw comparative conclusions from the three cases of handcuffed hegemony and the three variable classes used in the project. The chapter then will turn to a lesson drawing framework, so as to attempt to bring potential intelligence from the past to better inform the policies of the United States and other actors that may find themselves as the largest actor in an unbalanced system. This section will also address the limitations and problems that must be admitted in the research and writing process. The work will conclude with a section that details some of the contributions to the larger discipline of Political Science that were hopefully made by this project.

\section{Hypotheses Revisited}

H1: Unbalanced systems have existed with stability and durability over time.

Hypothesis one is supported by all three of the cases in the study. The case study of Spanish hegemony reveals the existence of an unbalanced system for a period of approximately 140 years. This system may be seen as lacking in some regards in the way of stability, yet what is most remarkable is the systems durability. The durability of Spain's period of dominance is underscored by the facts of the case that being the state's inability to take actions that would lessen the number of challenges and challengers that it was forced to face. Spain as a handcuffed hegemon must be seen in the light of the extraordinary environment in which it existed. Spain was blessed with discovery in the Americas and with these good fortunes managed to squander a great deal of its latent power. Still, no other state in the system was able to rise to usurp the power of Spain until such a point that the empire self-destructed from within. 
Both the French and German cases depict approximately 25 years of dominance per state. These systems, considering the unique alignment of power in each regard, are also remarkable in their stability and durability. The French system was marred by the Crimean War, and yet the system of international norms and their underlying power structure were durable enough to allow a high degree of system stability. The instability and ultimate decline of France's dominance arose from an inability to recognize the rising threat in the German territories, as well as France's inability to draw Britain from its cocoon of isolation.

The German system's stability is quite telling in the face of the constant need to keep a revisionist France isolated all the while preventing renewals of conflict between AustriaHungary and Russia. The durability and stability of Bismarck's system should be seen as a testament to the values and care with which the German state approached its international regime policies.

H2: Hegemonic states tend to seek to prevent balancing and thus attempt to function within their constraints under optimal circumstances.

The research provides both reasons to accept the null hypothesis as well as grounds to support the hypothesis. The case of Spain reveals little in the way of a state attempting to prevent balancing. Philip II's Spain did little to make its asymmetrical power more palatable to the other great powers of the era. It did not attempt to provide any real public goods to the system, nor did it attempt to use international regimes to restrain itself. Rather, this case should be seen as one of a hegemonic power acting with total disregard for the consequences of its international actions.

Napoleon III's France should be seen as a case that supports the thoughts behind the hypothesis, as the Emperor was aware of the enormous challenges that international balancing placed at the feet of his uncle earlier in the century. Louis Napoleon did seek the prevention of 
balancing in his foreign policy, as he sought to reform the systems perception of France. The illfated Mexican policy was an attempt to provide public goods to the international system, as the policy began as a multilateral attempt to extend European style property rights to Mexico. Louis Napoleon also attempted to deepen and expand the concert system in Europe with the hopes of making a resurgent France more acceptable, as well as trying to create international norms of alternate conflict resolution and potential European unity.

Germany under Bismarck also sought to prevent the formation of balancing alliances through his foreign policies. Bismarck was aware of the problems that such alliances would cause, not only for Germany but for the European system, particularly since France during this time period was "laying in the high grass" waiting for a chance to avenge its losses to Germany. Thus, Germany made every attempt to keep a revisionist France isolated and without a balancing partner. The German state was also willing to expend energy and resources for the system as it sought to maintain stability, through the prevention of renewed conflicts between AustriaHungary and Russia and Britain and Russia. The preservation of the status quo power distribution and the stability of the system were very much the focus of Bismarck's foreign policy.

H3: Regimes act as a means of conveying norms throughout a system, hence further constraining the actions of hegemonic actors.

The case studies undertaken in this research find mixed support for this hypothesis. When the case of Spain is considered, with its informal international regimes based in marriage diplomacy and international truces, little in the way of conveyance of international norms was found. Spain under Philip II undertook marriage diplomacy as a means of attempting to gain additional power through the extension of his royal bloodlines. Such instances of informal 
international regimes were not undertaken with the motivation of expanding international norms that would seek to further restraint the actions of a hegemonic Spain.

Some support for the hypothesis can be seen in the case of Spain when one considers the Twelve Year Truce with the Netherlands and the non-aggression pact signed with France, as these international regimes conveyed norms of non-violence between system members. However, these agreements must be seen the light of the motivations that underpinned them, that being Spanish motivations to delay further hostilities and quests for power until such a time in which the state was on either a better economic footing or not engaged with another challenger. Spain does not exist as a case that supports the underlying foundation of this hypothesis due to the motivations behind its limited international regime activity.

The case of France is far more interesting when this hypothesis is considered. Napoleon III worked mightily to place his foreign policy within the existing Concert of Europe international regime structure as a means of making French power appear more palatable. The Crimean War which ultimately produced fissures in the structure of the concert was undertaken with the support of the status quo as a motivation. French foreign policy during this time period was restrained by the concert system that followed the Napoleonic Wars, as Louis Napoleon sought to camp his actions directly within the existing structure and went to great lengths to take multilateral actions rather then unilateral actions. Moreover, Napoleon III made constant calls for new congress style meetings of the European great powers when issues of potential conflict arose. Where France falls short in this regard is in its attempts to create new international regimes that would have further restrained French power as well as other powers in the international system. Napoleon III made many attempts to draw Britain out of its policy of splendid isolation so that the state could take a more active role on the European continent and 
act as a binding partner with France. These attempts failed and call into question the real power of the French state, as it can be seen that if France were a more powerful state such overtures for a binding partner may have created more urgency within Britain. The urgency to bind France could have arisen from a British realization that binding was a more efficient form of restraint than balancing.

Germany under Bismarck brings the most "meat to the table" in regards to this hypothesis. Bismarck created his system of alliances to restrain not only the other great powers of the era, as he realized that any great power in Europe would have likely redrawn the power relationships of Europe and decreased German power, but his international regimes were also meant to restraint the German state. Bismarck was aware of the power of German nationalism that he released when unifying the German state and knew that such an alliance system would create a system of expected state behavior, thus placing a constraint upon German power. The Chancellor also knew that the use of international regimes would tie together the populations of the states involved, and not merely bind the governments of the states in question. It was with these realties in mind that Bismarck undertook his international regime actions that sought to covey international norms that encouraged the preservation of the status quo power distribution in the European system, while restraining all parties.

H4: Domestic politics exist as a proximate cause of system and regime stability or instability.

The German case strongly supports this hypothesis. Domestic politics is the lynchpin variable that influenced both the stability of Germany's international regimes and the system as a whole. Bismarck went to great lengths to weaken both political parties and organized interest within the state so as to prevent the derailing of his foreign policy. The Chancellor opposed democracy for the German state, not only as it challenged his power but more to the point 
because he feared the forms of imperialistic policies that a truly democratic Germany would support. He believed that only through an alliance system and the conveyance of international norms could Germany's innate tendencies towards nationalistic imperialism and conquest be avoided. Ultimately, what proved to be the undoing of Bismarck's alliance system and the ultimate spark that ignited the balancing of German power was the states very domestic politics. Once agricultural and industrial interests were able to mobilize the power of the German masses even Bismarck with his centralized constitution could not stand in the way of expansionistic German sentiment.

The first policy shifts that illustrate the road to German balancing can be seen as the result of the state's movement away from free trade based economics towards policies of protectionism as well as Germany's late foray into the world of colonialism. Both of these policies placed the state on the wrong side of British radar. The death toll for Bismarck status quo alliance system was the German state's failure to renew the Reassurance Treaty with Russia, which ultimately allowed Russia to move into the open arms of a revisionist France.

France is an interesting case when one considers the impact of domestic politics. Napoleon III was able to move away from elite corporate opinion in matters of free trade, as he was able to complete a series of reciprocal tariff reduction treaties in the face of perceived opposition from French industry. Moreover, Louis Napoleon's France was forced to take mass public opinion, particularly urban public opinion, kicking and screaming into conflicts such as the Crimean War. It was mass opinion that ultimately forced France to sue for peace in the conflict before the wishes of Britain, which illustrates a lack of political will in the state during this time period. French domestic politics should be seen as a more of a hindrance to the state, as it increased the division between opportunity and willingness in French politics. 
Spain must be seen as a case that did not live up to the hypothesized standards of a state seeking restraint. Still, it was the domestic politics of the Spanish Empire that increased the state's tendencies to squander the promise of its latent power potential. The Catholic Church drew the state towards both actions in the core, the continent, as well as the periphery, in the Americas. The banking interests sought continued expansion in the Americas, as they sought increased revenue streams and the return on investment, all the while Castilian elites sought a lasting historical and nationalistic end. These diverse interests led a poorly organized and governed Spain beyond the limits of its blessed discoveries.

H5: Systems with divided hegemony will be less stable as higher degrees of tension will be found.

Both the case of France under Napoleon III and Germany under the rule of Bismarck can be seen as systems in which divided hegemony existed. These two cases provide reasons to support the hypothesis. Louis Napoleon's France faced a system of divided hegemony due to the unique role that Britain played in the system. The British during this time period sought a policy of isolation from continental affairs, as the state feared that such issues would only drain Britain's resources and serve as a distraction from more economically fruitful actions globally. Thus, Britain sought the role of an off-shore balancer which effectively meant that it forfeited its European dominance to the resurgent France. This reality did nothing to add to the stability of the international system, as a major power attempted to remain on the outskirts of European politics. Moreover, the special systemic place of Britain kept France from creating a natural binding relationship with the most logical power, and it can be seen that Britain's passive balancing of France led to the eventual decline of French power in the fallout of the FrancoPrussian War. 
The case of German dominance under Bismarck is similar to the case of France, in that Britain largely held to the same European policy of isolation. However, Germany was better able to deal with the diffusion of hegemonic power through its binding alliance system that included both Russia and Austria-Hungary. Bismarck was also able to create an informal relationship with Great Britain through its policies of containment in regards to Russian power as well as through the Mediterranean Agreements with Italy. The problems that caused stability troubles for a dominant Germany arose latter in its period, as nationalistic domestic aims placed the German state on the radar of the isolated global power. These policies coincided with Germany's failure to renew the Reassurance Treaty with Russia, which in turn placed Germany under the will of Great Britain. The British could have chosen to formally align with Germany thus stabilizing the system, but such an outcome did not arise and the balancing of German power began.

The case of Spanish dominance does not show a system of divided hegemony, and still it provides little in the way of comparative weight. This lack of comparative value is the result of Spain's inaction when one considers how little the state did to limit balancing challenges. It is safe to argue that systems that exist without divided hegemony should be seen as more easily managed by the given dominant actor, although that is not to say that systems that contain divided hegemony must be unstable. The dominant actor must simply work harder to maintain stability. ${ }^{93}$

\footnotetext{
${ }^{93}$ This theoretical work does open up the potential for future research of the classic Cold War system, as it seems possible to imagine that the environment may be better seen as an unbalanced multipolar system rather than a bipolar system.
} 


\section{Historical Intelligence: Implications for the United States}

A question still remains in this work, that being what can the United States possibly take from such past cases of restrained hegemonic action? The first implication for the United States, as it seeks to lengthen its "unipolar moment" is the foundation of the theory itself. This work contends that dominant actors should seek to make their asymmetrical power as palatable as possible to the other great powers present in the international system, as the prevention of the creation of balancing alliances is the best protector of such handcuffed power. However, the case studies reveal more potential lessons for future handcuffed hegemons than merely the need to restrain and bind oneself to other actors in the international system. This section will briefly delve into five separate lessons that may be drawn from the case study research and will briefly attempt to place their importance within the current international environment.

\section{Lesson One: Bringing the Individual Back In - Avoiding the Perils of Rigid Strategy}

Rigid strategies exist in two of the three cases used in the study of handcuffed hegemony. However, that is not to say that such foreign policies were omens of sound strategy. By rigid strategy in this instance it is meant that the cases of Spain and France in the time periods studied each tended to base their grand strategies around a formalized worldview based on a stark interpretation of the international environment. Adaptability can be seen as a desirable tendency for all great powers, particularly if the state in question is the dominant actor in given system and seeks system stability. Such rigid policies can be seen as the source of both overreaction and under - reaction that can threaten the stability of a system and the dominance of the primary actor. The case of Spain under Philip II exists as a primary example of such a foreign policy.

Philip II's foreign policy strategy was based on traditional Spanish foreign policy goals. First, his policy was based on the belief that the national interest of Spain was to be the first aim 
of any policy undertaken by Spain. This policy goal reflects traditional realist thought, that being that self-interest should be the primary motivation behind the actions of states. Second, Philip believed that the Catholic faith was to be defended by Spanish power. This goal arose from the recommendations of Philip's father, Charles V, and from belief that Spain was a great Catholic state with enough power to defend the church. It also came from the realization that such a defense would grant Spanish policy an air of legitimacy. This policy goal also meant that Spain would have to stand strong against the rising tide of Protestantism and Islam. ${ }^{94}$ (Parker 1998 91-93)

Philip's beliefs were grounded in what Parker calls "messianic imperialism." The author contends that Philip II felt that he, as the monarch of Spain, was charged with a directive from God to protect the Catholic Church. ${ }^{95}$ Thus, Philip is argued to have believed that his actions had the backing and blessing of a supreme being. Philip saw himself as both a monarch and a priest, thus in his dual role it was his belief that his actions were justified by the backing of a higher power. The monarch's deep felt religious beliefs led Spain towards unrealistic goals. Philip believed that it was his calling to do all that was possible in a given policy action and that divine intervention would ensure that the will of God was done. This strategic culture translated into a lack of caution, a lack of planning, and a lack of backup plans in the undertaking of foreign policy. These beliefs can be seen to underlie such policy failures as the 1588 Spanish Armada. (Parker 1998 93-105) Philip's tendency to base the foreign policy actions of Spain on his religious ideology meant that the state tended to take undue risks in the defense of the Catholic Church, and that Philip fully expected that a higher power would intercede on the behalf

\footnotetext{
${ }^{94}$ It is certainly also possible to relate such polices to Philip II's religious beliefs and his potential need to attempt to ensure a place in the afterlife.

${ }^{95}$ Any perceived relationship between the "messianic imperialism" of Philip II and existing views of the impact of religion on the George W. Bush administration is purely coincidental.
} 
of a righteous defender of the faith. This foreign policy also meant that the government of Spain was easily influenced by outside interests that tended to either model or play upon the ideological bias of Philip II.

However, Philip's messianic imperialism is but an extreme example of the rigidification that can arise from such a foreign policy. The rule of Napoleon III also highlights the perils of such a foreign policy. The key portion of French foreign policy that is telling for work's consideration is the emperor's strong belief in self-determination. This is most easily seen in his policies towards Italy. During the height of unrest within Rome and portions of Italy France was called upon to aid the Italian states, particularly since Napoleon III was seen as someone sympathetic to Italian nationalism as a result of his support for national self-determination and his developmental experiences in Italy. Napoleon III's leanings toward national selfdetermination were well know throughout Europe, and it was these leanings that certain elements within Italy were able to play upon in an attempt to secure French support. (Echard 17-18) However, the example of French policy towards Italy only foreshadows a larger use of Louis's leanings by an outside actor.

By 1862, Bismarck had informed the British of his plans to unify Germany through a consolidation of the German territories and a war with Austria (Bresler 336). Moreover, Bismarck had also gained Napoleon's neutrality in a war with Austria. The French granted such neutrality without even a request of territory from the war or a pledge of Franco-German peace. (Bresler 337) This can be argued to have arisen from either of three of Napoleon III's ideals. Bismarck utilized Napoleon III's leanings for national self-determination, as he had long championed this cause. The mindset of Louis Napoleon was used to ensure that France would tolerate greater German advancement. It was also operated upon to allow for the creation of a 
state that should have been seen as a direct challenge to the dominance of France. However, Napoleon must not have counted on the reaches of the German successes, or the fact that such unification would cede the predominance of power to a new, united German state.

Both of the above illustrations depict states that were overly influenced by the power of rigid strategy, and cases in which that influence was played upon by outside actors. One cannot assume that all outside influence can be illuminated, but dominant states can hope to mitigate the effects of such problems. This lesson points to the need for foreign policies that are not rigid in nature. Rather, this lesson shows the value of pragmatic foreign policies to both reduce outside influence and to increase flexibility. The United States should consider this potential pitfall.

A similar bias may also be influencing US relations with Europe. It seems possible to characterize the current conservative nature of US foreign policy as "America first." Yet, this very tactic may weaken US power in the future, as such actions can be seen as moving Europe closer to a more formalized foreign and military policy that could ultimately create another dominant power within the system or at least weaken the soft power stores present within the United States. This lesson illustrates the need to consider pragmatic and flexible policies that can allow the state to see all angles and solutions to future problems, thus preserving traditional power stakes.

\section{Lesson Two: Beware Balancing Through not Bandwagoning}

The case study research that underpins this lesson depicts an interesting form of balancing that appears to be of importance for the United States. Traditionally states tend to concern themselves with overt balancing, that being when a state or group of states allies itself against a dominant or rising power. ${ }^{96}$ However, the Franco - Prussian War and the actions of

\footnotetext{
${ }^{96}$ For more information on traditional forms of balancing see Walt, Stephen M. The Origins of Alliances. Ithaca: Cornell UP, 1990.
} 
Britain point to another possible form of balancing, that being balancing by not bandwagoning. This resembles what Mearsheimer terms "bloodletting," which he contends occurs when a state's rivals begin a war without any attempted baiting by the outside power yet the outside power attempts to ensure that the war is as costly as possible for both rivals. ${ }^{97}$ However, during the Franco - Prussian War the British took no action to ensure that the war was a costly as possible for both of its potential rivals; instead it appears that Britain balanced French power by not bandwagoning with it in its war with Prussia. This form of balancing through inaction appears telling for the current case of US power.

Napoleon III alerted Britain to its situation with the new German territories stating. This can be seen both as a French attempt to make Britain aware of the potential danger that a unified Germany in the heart of Europe posed to stability, and as a means of attempting to convey to the British that it was not the French who sought to further revise the balance of power of Europe. Moreover, this was also an attempt by the government of Napoleon III to draw Britain into any potential conflict as a bandwagoner of French power. (Wawro 21) This is particularly telling when one considers the British hopes of remaining a balancer of last resort for the continent.

As the Congress of Vienna came into fruition Britain came to the conference with a distinct goal in mind. It was the aim of the British to create an international regime that would ensure that the state could implement a policy of isolationism in regards to the continent of Europe. (Chapman 16-17) This would allow Britain to expand its colonial activities and become a balancer of last resort for Europe. Castlereagh saw the politics of the continent as a potential quagmire that could decrease the state's growing power. Thus, it was Britain's aim that the Congress would allow the British to feel safe from attack and unneeded as a day-to-day balancer.

\footnotetext{
${ }^{97}$ For more information of "bloodletting" see Mearsheimer, John J. The Tragedy of Great Power Politics. New York: W. W. Norton \& Company, 2001: 154-155.
} 
It was their hope that the other powers in Europe could be counted on to maintain the status quo distribution of power, hence France was not to be weakened to the point that it could not function in a balancing capacity. This would allow Britain to focus its resources on the development of its colonial holdings. Still Britain felt confident in its abilities to act as a balancer of last resort on the continent, as it sought to ensure that the balance of power did not skew to the point that a continental power could challenge it at home or in the colonies. (Chapman 20) With this in mind it seems likely that Britain sought to balance the power of France through inaction, as it neither joined a balancing coalition with Bismarck nor did it actively bandwagon with France, a state that had attempted to keep close ties with Britain for just such a reason. Rather, it seems Britain attempted to weaken France through inaction.

Such a balancing strategy can also be seen in the actions of Britain in their relationship with post-Bismarck Germany. Bismarck had long had a policy of maintaining close ties to Russia, so as to prevent a Franco-Russian alliance and a war of Franco revenge. Yet, almost immediately after his dismissal Germany broke off its long standing relationship with Russia. It was the hope of Caprivi that Britain could then serve as Germany's bandwagoning partner. However, Britain realized the power position that Germany had placed itself in through the severing of its relationship with Russia and failed to take Germany's invitation to ally with it. (Kagan 121-123)

These acts of balancing by other means appear analogous to the actions of France and Germany prior to the Iraq War. France and Germany can be seen as powers that view with distaste elements of US power, and yet with the case of Iraq and the current power structure of the international system outright balancing was not a potential option for these two states. It was not an option since it is unlikely that both states hoped for a US lose or an Iraqi victory. Rather, 
all that Germany and France could hope for is to somehow degrade the power of the United States. It is possible to argue that by not bandwagoning with the United States in the war with Iraq such an objective was achieved. This is not to say that absence of these states decreased the actual military might of the US, but rather by not bandwagoning through either a token presence or UN blessing these states were able to degrade US credibility. This balancing action did not decrease the hard power stores for the United States, but the action can be seen as a means of decreasing the soft power resources and international regime credibility of a dominant United States.

\section{Lesson Three: A State Scorned - The Importance of Protecting Credibility}

We have long learned that power is key for any state seeking to have both stability and dominance within a given international system, and by power a majority of the international relations literature has concerned itself with military power. The thought being that states must avoid strategic overstretches of power and resources. However, less attention is paid to a states international credibility, not credibility in traditional military thought, but credibility as it relates to international regimes and international trust. The research behind the theory of handcuffed hegemony points to the importance of understanding the memories and perceptions of other states within the system. France under Napoleon III points to a classic illustration of why it is hard to make amends with elephants, as states have memories.

Napoleon III sought to lead Europe, with the gift of French dominance, through the use of a concert style foreign policy and binding international regimes. Louis Napoleon ultimately hoped for the creation of one Europe. Napoleon III realized that a restrained foreign policy and the use of binding regimes were the best means of ensuring the France could exist at its existing power level within the system without triggering the balancing that doomed the rule of previous 
Bonaparte. In short Napoleon III's France appeared to be the perfect case to show the virtues of handcuffed hegemony, and still the Second Empire failed.

The British and the French also cooperated in their policy to open trade with China and in the early phases of the failed Mexican policy (Gilbert et al 1084). Essentially, France sought a permanent alliance with Britain that would allow Britain to monitor and influence the policies of France. Napoleon III had hoped that such a relationship could outlive the issues that he based his British policy around.

The failure of France's concert and binding regime policy must be at least partially attributed to the fear with which the other great powers of the era still held in regards to French power. After all it was France that had attempted previously to dominant the international system, and it was these fears of French power and the Bonaparte name that meant that despite Napoleon III's countless overtures and calls for binding and concert action the other powers rebuffed any long term agreements. (Wright 188-189) This illustrates the difficulty that a state will faces, even a dominant state, in regaining international credibility in the wake of actions that are seen to disrupt the system. Such a case shows the care with which dominant states should protect their credibility within the international system. Louis Napoleon spent his entire rule trying to atone for France's past mistakes. He constantly sought partners and cooperation, but he found few as a result of the memories of those in the system. Certainly any dominant state will be met with some skepticism as to its motivations, but credibility can be built as the United States has shown in the Post - World War II era. Yet, one must now look to see just how damaged US international credibility has become in recent years. This case provides a glimpse into the importance with which such resources should be handled, especially if the state in question can be seen as a dominant state seeking to avoid any and all forms of balancing that 
could challenge its position within the world. The United States should attempt to avoid the label "hyper-power," and should begin to rebuild bridges with states such as France and Germany. This can be done through a reinvigoration of traditional US restraints such as the United Nations and NATO. In a complex system the United States must not be seen as a superpower working to its own beat, but rather as a superpower working for the betterment of the system from within the system.

\section{Lesson Four: Resurrecting Bismarck - A Return to Time Limited Bilateral Alliances}

The case of Germany illustrates that there is something to be said for the preservation of flexibility in foreign policy. Bismarck's alliance strategy was based upon the use of time limits for treaties and alliances. He also utilized bilateral alliances as a means of restraining Germany and extending the influence of Germany throughout Europe. These facts created more flexibility in how the German state could address its foreign policy. The time limits meant that treaties and agreements could be rewritten or nullified if changes occurred in the international system. It also meant that Germany was better able to keep their alliance partners more beholden to Germany, as the threat always existed that the treaty or agreement would not be renewed. This kept states such as Austria-Hungary and Russia looking to please the German state and thus remain on the inside of the dominant state's strategic plans as opposed to being seen as an outsider to the state.

The bilateral nature of the Germany's alliances and agreements also decreased the complexity of the relationships. A number of bilateral agreements created with one state as the dominant actor in that relationships creates a de facto multilateral relationship with the dominant state functioning as a the hub of the international regime. France under Napoleon III further explicates this lesson, as Louis Napoleon attempted to use bilateral agreements to spur deeper multilateral relations. France failed in its attempts because it lacked the power to induce such 
deeper relationships, but Germany was successful in using its Dual Alliance with Austria to reopen the Three Emperor's League with both Austria and Russia. This occurred because Russia feared being isolated, and thus the state was willing to once again resign a time limited treaty which included its rival Austria.

Since the conclusion of the World War II bilateral and time limited agreements have seen as loss of use, as the international system and the United States as a dominant actor have sought to create more permanent and lasting lines of cooperation. NATO and the United Nations exist as two primary international regimes fostered by the United States. However, one must ask if these international bodies have lost their way, either as a function of loss relevance after the conclusion of the Cold War or as a result of a lack of use. This work does not contend that these international regimes should be cast away or replaced, but rather that something must be done to retighten the norms that bind the states together. A series of bilateral alliances could be such a prescription. First, these alliances could be used to place NATO member states on notice that the landmark treaty is in need of repair or rededication, as a series of time limited bilateral agreements could be used by the United States to replace such an agreement. The threat of replacement could be used to induce rapprochement with both France and Germany from the rift created by the Iraq War. This can be seen as a form of brinksmanship-light which ultimately could become more fulfilling than a continued alienation of the two states. The logical targets for the United States in this regard could be both Great Britain and Russia. ${ }^{98}$

Great Britain as a bilateral alliance partner places NATO members on notice of the need to reinvigorate and recast the older body. Britain is also a logical choice because of its reservations with the European Union and because of the tradition of unity that the state holds

\footnotetext{
${ }^{98}$ Still such a policy should not be taken lightly as it would be likely that such bilateral alliances could create hostility and resentment in excluded members, and thus the doors for expansion should be left open and any alliance should also remain transparent in purpose and goals.
} 
with the United States. Russia as an alliance partner serves the deeper purpose of not only casting NATO in a poor light, but it also opens the state for an introduction into new NATO that could be used in a non-Cold War manner. If this seems to risky a proposition one must also remember the vast size of the bureaucracy of the North Atlantic Treaty Organization. This vastness means that the international organization could not be easily destroyed, but that a shock is needed to induce major changes.

A reinvigorated NATO could mean not a mission creep for the body but overall mission change that could deepen the relationship. NATO could remain a system of reassurance and deterrence but also become a global rapid reaction force that could become the teeth for the United Nations bark. A more deeply entrenched NATO could also better restrain the actions of the dominant United States, as any renegotiation of the North Atlantic Treaty would likely be met with additional calls for checks and balances that could constraint the largest actor in the relationship. Moreover, the use of bilateral time limited treaties could also be used outside of Europe, particularly in Asia in the hopes of stemming the tide of nuclear proliferation.

In this area the United States could seek out partners in India, Pakistan, and Japan to reassure, defensively the states of the United State's willingness to offer a nuclear umbrella. Such actions have many potential benefits. First, in the area of Indo-Pakistani relations such treaty arrangements could alleviate pressure between the two fledgling nuclear powers. Moreover, with Japan such a move could further illustrate the lack of need for nuclear escalation in the region and decrease regional fears of Japanese armament, thus acting as a reassurance treaty for a growing China. Essentially, the case of Germany shows that you can never have too many lines of communication, reassurance, and restraint provided that these agreements are made in such a manner so as to be defensive and deterrent forces rather than offensive in nature. 
The Germany model also illustrates the need for transparency in alliance relations to debunk notions of threat construction and alleviate chances of misperception, for even in the so called secret Reassurance Treaty with Russia Bismarck ensured that the agreement was leaked to avoid misperception. Defensive international regimes can be made more palatable if steps are taken to remove chances for misperception.

\section{Lesson Five: Avoiding the Siren Song of Distraction}

Each case in this study shows one distinct commonality, that being the eventual move towards distraction by each state. By this it is meant that such handcuffed hegemons should consider the degree to which they should be risk takers, particularly considering their blessed position within an international system. These moves towards a distracting foreign action can be seen to have arisen from within, as domestic political forces caused each state to take foreign policy actions that were detrimental to their overall strategy and goals. The calls to distraction can also be seen as proximate causes of some form of hegemonic decline. With the case of Spain the distraction in question could be seen as Spain's decision to take its fight to England.

During the reign of Philip II England had become a nuisance in the periphery as the state sought to interrupt Spain's shipments of gold and silver from the Americas. The English state had also begun to ally with factions within the Netherlands that could have become problematic. However, these actions by England may not have called for an outright attempt by Spain to conquer the island state, rather it seems that Spain should have responded by increasing its power in the periphery in an attempt to deter further English aggression and to protect its most valuable resource, the Americas. But, domestic political pressures coupled with the actions of England may have led Spain to distraction, as it began to move, not so secretly, too invade and conquer the Protestant state. These domestic pressures were to two fold. The first pressure was that of 
the Catholic Church. The Church saw Elizabethan England as the Protestant counter-hegemon and thus urged Spain as the dominant Catholic state of the era to rid the system of such a heretical power. The second domestic pressure arose from with Spain, specifically from Castilian nationalism that felt the need to make a lasting impact upon the system through absolute domination of international system. These domestic political interests eventually led the state to its failed armada invasion, and thus revealed the lack of military power that the Spanish superpower had successfully hidden for much of its time of dominance.

The case of France shows again a dominant state that may have moved towards distraction, however in this instance the distraction was in the more normal vein of the periphery. Napoleon III's distraction may be seen in France's failed Mexico policy. The policy began as a joint mission of Spain, Britain, and France in an attempt to force Mexican recognition of European property rights. Such a mission can be seen as a valid use of power as Louis Napoleon could have rebuilt more international credibility and potentially fostered a deeper relationship with Britain, a goal that he had long held as a key to French power. However, Spain and Britain soon defected from the mission and French domestic pressures led the state not only to maintain the mission but change the mission's goals. Napoleon III had used such short and successful military excursions to distract public opinion from his government and to bolster the pride of the French military. Despite the defection of Britain and Spain, France endeavored to stay the course and to bring to power a pro-French monarchy in Mexico in the hopes of building military glory and public support. The policy's eventual failure can be seen as a drain on French power resources and a possible distraction from the growing power to the east, in Prussia/Germany.

Germany under Bismarck is traditionally seen as state that was able to avoid distraction, however not even Bismarck was able to completely lock-out the influences of domestic politics, 
particularly towards the conclusion of his era. Bismarck's possible distraction can be seen in his move towards a policy of colonialism. The Chancellor had long seen colonial action by the German state as a mistake, as he had staked German dominance to an international pledge to maintain the status quo distribution of power. Moreover, he had argued that colonialism for Germany would be foolish, because Germany was a continental power; the state would have been entering the land-grab late; and such actions could bring the German state in direct competition with Great Britain. Still, German agricultural and industrial interests began to mobilize German nationalism to push for just such a policy. These interests had been gaining momentum in the $1880 \mathrm{~s}$ and had already been able to shift Bismarck from free trade to protectionism and colonialism was seen as an extension of these policies that would open more market space for German goods while allowing the state access to additional raw materials. Germany's colonial policy can be seen as a distraction, for the policy moved the state away from its traditional goals of maintaining the status quo and reduced its to a normal state that sought to enter the vogue world of additional territory at the expense of bringing it into direct competition with the isolated Britain.

The intelligence of history shows that the United States should consider avoiding similar mistakes. The Bush Doctrine informs us that it is the United State's primary goal to maintain its position of dominance in the international system, and yet it seems that the state may be allowing distractions to knock it from its policy course. Challenges to the dominance of the US do not appear to be held in Iraq, but rather in great power politics. Thus, the question must be asked, is the United States being distracted from future challengers by this extension of the War on Terror? The rise of Chinese power, both militarily and economically appear to directly challenge the position of US power, while Iraq until the actual invasion may be the equivalent of the 
United State's Mexico. The sounding of alarms can now be heard within the state that a challenger is on the horizon, but one must ask has the United States invested too much in an area where the greatest threat does not lie? Moreover, after taking on the invasion and reconstruction of Iraq the United States would be foolish to leave a task half-done. But, the state should be aware of its weakness during this time period and be on the lookout for challengers and other states that would use this policy action to their benefit. If the United States wishes to extend its period of dominance the mistakes of the past cannot be repeated.

\section{Limitations and Future Lines of Research}

Upon coming to the conclusion of such a work the thoughts of limitations and oversights begin to creep in. Really these thoughts have always been there, but I have attempted to keep the finish line in sight and push through. Still, the admittance of errors and oversights must be undertaken. An oversight exists in the exclusion of the study of both Great Britain and the United States. Britain posses a large challenge to anyone seeking to delve into the realm of hegemonic states, as it has long been considered a predominant hegemonic actor throughout the scope and depth of the hegemonic stability literature. But, when one begins to consider Great Britain's role in continental European affairs from the 1800 s through the conclusion of the World War I a question arises. This question is why did Britain forsake the continent and instead seek to be globally dominant with the exception of the closest land mass to the state? The historical record shows that Great Britain sought to take the role of an off-shore balancer or balancer of last resort in Europe as it sought to preserve its power base and continue to grow economically through the use of its overseas holdings. Great Britain saw Europe as a trap, a trap that could suck it into wars and entanglements that would decrease its powers. These British policies allowed the study to pick-up the cases of France and Germany as states that sought to weld 
hegemonic power in the absence of British power. Moreover, Britain's self isolation from continental politics underscores the potential validity of Mearsheimer's concept of the blocking power of water, as he contends that such a water barrier means that states can only dominant regions and not globally as its power projection wanes if water divides territory. This is highlighted by both the French and German feelings about Britain's lack of power in Europe. However, both states still sought to attract Britain as a binding partner, and thus the special role of Britain in both cases must be taken into consideration.

The state lacked the population and military might to be considered hegemonic or dominant in Europe, but it still was the balancing or binding partner that all other great powers would have wanted. A future work will take a more in depth look at the unique position of Great Britain from both a state level of analysis and the systems level. Such a work could impact not only interpretations of British foreign policy but also the disciplines considerations of hegemony.

The United States exists as another exclusion from the study. The US can be considered to be currently hegemonic, furthermore it is the contention of the author that the United States was hegemonic from the conclusion of World War II and the international system during the Cold War should be seen not as bipolar but as an unbalanced multipolar system. The so called bipolar system can be seen as false systemic and state construction, for if nuclear weapons are seen as non-usable the Soviet Union can be seen as a useful adversary. The concept of the USSR as a useful adversary can be traced to US domestic politics, as the American population required a foil to justify continued military spending and to ensure that the state did not return to a policy of isolation. This does not justify the exclusion of the United States in this study, particularly since it was the United States that first raised the main questions underlying this work. The 
exclusion of the United States in this study and the subsequent transition to a lesson drawing paradigm arose from the unique period of the flux that the state now finds itself.

The attacks on the United States on September 11, 2001 and the subsequent shift in United States' foreign policy justify and exclusion. This time period may very well be seen in future works as the period that triggered the very unlatching of the hegemonic handcuffs that have bound the state since its rise to dominance. The time period in question also raises questions of comparison between cases, as it would be difficult to compare historical cases with their documented and reviewed histories with a case that would require contemporary sources and author biased interpretations. It may have been possible to create an artificial cut-off point for the study of the United States, say 1990, but this would not have captured the case in its entirety and would have introduced additional biases. Still, the case of the United States presents another future line of research that can be undertaken in a deeper methodology than mere lesson drawing.

The problem of power operizationalization also flows throughout the research. This is a problem that faced the majority of this type of research, as it seems that everyone knows power when they see it but has a difficult time actually creating reliable measures of this seemingly simple concept. With the exception of the case of Spain a simplification of the Cline's measure of power has been used in average terms. This provides a decent glimpse of power differences between states in a given time period, but it can easily be biased by outliers and does not show movement over periods of time. Future research may be able to make up for this short-coming through the use of a time series regression analysis, provided that a database of international regime data is found or generated. 
The case studies also show a great deal of the creeping in of the individual. With the creation of the three case studies for this research I found it difficult to cast out the individual leaders and the impacts of their personal make-ups. The problem points to a deeper predicament within the levels of analysis, as there exists much difficulty in excluding this line of research and yet it shows the importance of bringing the individual back into such research and the need to bring all the levels of analysis into focus simultaneously on individual questions for more depth and reliability.

\section{Making a Contribution - Building on the Past}

With this work the writer has truly been building upon the past, as the work is based on previous theoretical contributions as well as numerous historical studies. A primary goal of the work has been to create a path for new theory but also to explore the unification of two distinct levels of analysis. The study of International Relations within the discipline has often been filled with levels of analysis problems and the singular use of one particular level over another. This myopic use of one particular level of analysis over another or over the use of several levels of analysis seems to have limited the gaze and scope of previous research. The work at hand has attempted to utilize both the systems level as well as the state level in unison with the hope that such dual use will provide a more detailed look at hegemonic actors. Previous scholars cannot be faulted for using only one level, as it does lead to a simpler and more easily conveyable work. But, such works appear to limit the scope and breadth of understanding, and thus while sacrificing simplicity (and for that I am truly sorry) this work has delved to marry both of these views of create a more holistic study of the behavior of dominant states.

The use of the systems and the state level allows the work to use both lenses independently and in unison to provide a more detailed look at the cases in question. With the 
case of Spain this dual glimpse has allowed the work to see the interaction of domestic politics with the states power resources. This allowed us to see the role that domestic political concerns played on the power transformation of the Spanish Empire. In the case of France we are able to see the role that domestic politics and power constraints played as the state sought to utilize international regimes to hide its lack of political will. In the German case we see a reversal as Bismarck attempted to use international regimes and external restraints to guide the German population away from policies of expansion and empire. This two-barreled approach allows the research to expose more influences and draw a clearer picture of the past in order to create a more realistic theory of hegemonic state action.

In addition to the use of two levels of analysis this work also points to a more realistic approach to the study of multipolar systems. These international systems are traditionally seen as systems in which power is equally divided between five great powers, however such equal power distributions tends to be impossible to witness as one or more states will tend to possess more power than the remaining members of the system. Still, these models of multipolar systems have persisted due to their educational value and the fact that traditional balance power theory posits that in such systems an enlargement of one pole's power concentration will be balanced by the other great powers in the system or the system will transfer to one of unipolarity or bipolarity. This work points to another sub-form of multipolar systems, that being the unbalanced multipolar system, which was originally described by Mearsheimer. However, he contended that these systems were transient in nature, for if one power made the relationship unbalanced other great powers in the system would quickly reign in this potential threat. But, this work shows with the cases of France under Napoleon III and Germany under Bismarck that 
such systems can exist for some period of time, twenty-two and twenty-five years respectively, without balancing actions taken by the other states in the system.

This unearthing reveals that another form of international system should now be considered. It also highlights the reality that the discipline may need to reconsider how it understands the concepts of hegemony and unipolarity as these concepts are based on systems in which one state possess so much power that it can dominate all other states and thus prevent balancing. However, we can now see that unbalanced multipolar systems may more accurately reflect reality as the dominant state does posses more power but needs to restraint itself to prevent balancing that would return the system to a traditional multipolar system.

The work also extends the foundation of Ikenberry's theory of state binding. He contends that dominant states in the system can essentially make bargains with the other systemic powers so that their preponderance of power will not be balanced by the other powers. His works argue that such binding occurs when the dominant state in question binds itself through international regimes to the maintenance of the status quo power distribution and further reassures the other powers that it will not abandon the system if revisionist states arise. Thus, the larger power binds its fate to the fate of the system and to the other great powers in the system. Ikenberry grounds his theory in the actions of the United States, but the case studies that ground this work show that such behavior predated US dominance as France attempted to create such a bargain and Germany was successful in such binding through the use of its alliance system. This empirical study of binding opens the theory up for additional exploration and deepens the understanding of the concept. The work also points to the notion that such binding actions may not arise out of purely liberal ideals but also out of pragmatic realist concepts of power politics, as cooperation and regime building can be in the best interests of actors. 
Another contribution to literature that is found in this work was literally found, as it was not intended contribution. This is the uncovering of a new form of balancing that may be built into the alliance theory framework. The finding of this potentially new form of balancing is also interesting in that it highlights the importance of the case study methodology because such a methodology can truly find un-researched notions that can lead to additional theory and greater understanding of the past and thus more accurate predictions of the future. The case study work done with both the French and German cases reveals the British tactic of balancing by not bandwagoning. This raises the question as to whether other similar instances of this form of state behavior may exist in the greater historical record. An exploration of this concept from both the internal, state level approach, and the external, systems level approach, can do a great deal to further develop the theory and to explore future situations in which such a policy may be used again. As with each of these contributions to the greater development of Political Science theory more questions are created than are answered, which can lead to productive lines of future research. Moreover, this work also leaves much room for improvement and deeper questions left to be answered. 


\section{Bibliography}

Agulhon, Maurice. The French Republic, 1879-1992. Oxford: Blackwell, 1990.

Anderson M.S. The Rise of Modern Diplomacy 1450-1919. London: Longman Press, 1993.

Anderson M.S. War and Society in the Europe of the Old Regime 1618-1789. London: McGillQueen's UP, 1998.

Anderson, M. S. The Origins of the Modern European State System, 1494-1618. London, Longman Press, 1998.

Ash, Maurice A. "An Analysis of Power, with Special Reference to International Politics." World Politics. 3 (Jan. 1951):218-237.

Baguley, David. Napoleon III and His Regime: An Extravaganza. Baton Rouge: Louisiana State UP, 2000.

Baldwin, David A. "Power Analysis and World Politics: New Trends versus Old Tendencies." World Politics. 31 (Jan. 1979): 161-194.

Bartlett, C. J. Peace, War, and the European Powers, 1814-1914. New York: St. Martin's, 1996.

Berghahn, Volker R. Imperial Germany, 1871-1914: Economy, Soviety, Culture and Politics. Providence: Berghahn Books, 1994.

Blackbourn, David. History of Germany, 1780-1918: The Long Nineteenth Century. New York: Oxford UP, 1998.

Bresler, Fenton. Napoleon III: A Life. New York: Carroll \& Graf Publishers, 1999.

Bridge F. and Bullen. The Great Powers and European States System, 1815-1914. New York, Longman, 1980.

Bury, J. P. T. France 1814-1940. London: Methuen \& Co. Ltd, 1956.

Carr, William. A History of Germany, 1815-1990. London: Arnold, 1991.

Case, Lynn M. "A Voice Crying in the Wilderness." in Samuel M. Osgood (ed.) Napoleon III and the Second Empire. Lexington: D. C. Heath and Company, 1973: 113-121.

Chapman, Tim. The Congress of Vienna: Origins, Processes and Results. New York: Routledge, 1998.

Christensen, Thomas J. and Jack Snyder. "Chain Gangs and Passed Bucks: Predicting Alliance Patterns in Multipolarity." International Organization. 44 (Spring 1990): 137-168. 
Craig, Gordon Alexander. Germany: 1866-1945. New York: Oxford University Press, 1978.

Craig, Gordon Alexander. Europe Since 1815. New York: Holt, Rinehart, and Winston, 1961.

Crankshaw, Edward. Bismarck. New York: Viking Press, 1981.

Croce, Benedetto. History of Europe in the Nineteenth Century. New York: Harcourt, Brace and Company, 1933.

Dill, Marshall Jr. Germany: A Modern History. Ann Arbor: University of Michigan Press, 1961.

Echard, William E. Napoleon III and the Concert of Europe. Baton Rouge: Louisiana State UP, 1983.

Elliott, J. H. Imperial Spain 1469-1716. New York: Mentor Books, 1963.

Feutchtwanger, Edgar. Imperial Germany: 1850-1914. New York: Routledge, 2001.

Fulbrook, Mary. A Concise History of Germany. Cambridge: Cambridge UP, 1990.

George, Alexander L. and Richard Smoke. Deterrence in American Foreign Policy: Theory and Practice. New York: Columbia UP, 1974.

Gilbert, Felix et al. The Norton History of Modern Europe. New York: W. W. Norton \& Company, 1971.

Gildea, Robert. Barricades and Borders: Europe, 1800-1914. New York: Oxford, 1996.

Gilpin, Robert. War and Change in World Politics. Cambridge, UK: Cambridge UP, 1981.

Grun, Bernard. The Timetables of History. New York: Simon \& Schuster, 1991.

Grunberg, Isabelle. "Exploring the 'myth' of Hegemonic Stability." International Organization. 44 (Autumn 1990): 431-477.

Guerard, Albert. "A Forerunner of Woodrow Wilson.” in Samuel M. Osgood (ed.) Napoleon III and the Second Empire. Lexington: D. C. Heath and Company, 1973:100-112.

Hart, Jeffrey. "Three Approaches ton the Measurement of Power in International Relations." International Organization. 30 (Spring 1976): 289-305.

Hass, Ernst B. "Words Can Hurt You: Or Who Said What to Whom About Regimes." in Stephen D. Krasner (ed.) International Regimes. Ithaca: Cornell UP, 1983: 23-59. 
Hazareesingh, Sudhir. From Subject to Citizen: The Second Empire and the Emergence of Modern French Democracy. Princeton: Princeton UP, 1998.

Holborn, Hajo. A History of Modern Germany, 1840-1945. Princeton: Princeton University Press, 1969.

Holsti, Kalevi J. Peace and War: Armed Conflicts and International Order 1648-1989. Cambridge: Cambridge UP, 1998.

Ikenberry, G. John. "Democracy, Institutions, and American Restraint." in G. John Ikenberry America Unrivaled: the Future of the Balance of Power. Ithaca: Cornell UP, 2002: 213-238.

Jervis, Robert. "Realism, Neoliberalism, and Cooperation." International Security . 24 (Summer 1999): 42-63.

Jervis, Robert. "Security Regimes.” in Stephen D. Krasner (ed.) International Regimes. Ithaca: Cornell UP, 1983: 173-194.

Kagan, Donald. On the Origins of War and the Preservation of Peace. New York: Double Day, 1995.

Kaiser, David. Politics and War: European Conflict from Phillip II to Hitler. Cambridge: Harvard UP, 1990.

Kamen, Henry. Empire: How Spain Became a World Power 1492-1763. Hew York: Harper Collins, 2003.

Kaplan, Morton A. System and Process in International Politics. New York: Wiley, 1957.

Kennedy, Paul. The Rise and Fall of Great Powers. New York: Random House, 1987.

Keohane, Robert O. "The Demands for International Regimes." in Stephen D. Krasner (ed.) International Regimes. Ithaca: Cornell UP, 1983: 141-149.

Keohane, Robert O. After Hegemony: Cooperation and Discord in the World and Political Economy. Princeton: Princeton UP, 1984.

Keohane, Robert O. and Joseph S. Nye. Power and Interdependence. New York: Longman, 2001.

Krasner, Stephen D. "Structural Causes and Regime Consequences: Regimes as Intervening Variables." in Stephen D. Krasner (ed.) International Regimes. Ithaca: Cornell UP, 1983: 121.

Kupchan, Charles A. "Hollow Hegemony or Stable Multipolarity?" in G. John Ikenberry America Unrivaled: the Future of the Balance of Power. Ithaca: Cornell UP, 2002: 68-97. 
Kupchan, Charles A. The Vulnerability of Empire. Ithaca: Cornell UP, 1994.

Lake, David. "Beyond Anarchy.” International Security. 23 (Summer 2001): 129-160.

Layne, Christopher. "The Unipolar Illusion: Why New Great Powers Will Rise." in Michael E. Brown et. al. (eds.) The Perils of Anarchy: Contemporary Realism and International Security. Cambridge: MIT Press, 1995: 130-176.

Magraw, Roger. France, 1815-1914. New York: Oxford University Press, 1983.

Mann, Golo, The History of Germany since 1789. New York: Praeger Publishing, 1970.

Mearsheimer, John J. The Tragedy of Great Power Politics. New York: W. W. Norton \& Company, 2001.

Nye, Joseph S. Jr. Soft Power: the Means to Success in World Politics . New York: PublicAffairs, 2004.

Nye, Joseph S. Jr. The Paradox of American Power: Why the World's Only Superpower Can't go it Alone. New York: Oxford UP, 2002.

Olson, Mancur. The Rise and Decline of Nations. New Haven: Yale UP, 1982.

Parker, Geoffrey. The Grand Strategy of Philip II. New Haven: Yale UP, 1998.

Parker, Geoffrey. The Thirty Years’ War. London: Routledge, 1997.

Peters, B. Guy. Comparative Politics: Theory and Methods. New York: New York UP, 1998.

Peterson, Susan. Crisis Bargaining and the State. Ann Arbor: Michigan UP, 1996.

Plessis, A. The Rise and Fall of the Second Empire. New York: Cambridge University Press, 1998.

Puchala, Donald J. and Raymond F. Hopkins. "International Regimes: Lessons from Inductive Analysis.” in Stephen D. Krasner (ed.) International Regimes. Ithaca: Cornell UP, 1983: 6191.

Ramm, Agatha. Germany, 1789-1919: A Political History. London: Methuen, 1967.

Renouvin, Pierre. "Napoleon III, Bismarck, and Cavour." in Samuel M. Osgood (ed.) Napoleon III and the Second Empire. Lexington: D. C. Heath and Company, 1973:94-99.

Rice, Condoleezza. "Promoting the National Interest." Foreign Affairs. 79 (January/February 2000): 45-62. 
Rich, Norman. Great Power Diplomacy, 1814-1914. New York: McGraw-Hill, 1992.

Richardson, James. Crisis Diplomacy: The Great Powers since Mid-19 ${ }^{\text {th }}$ Century. London: Cambridge UP, 1994.

Richter, Werner. Bismarck. New York: G. P. Putnam’s Sons, 1964.

Risse, Thomas. "U.S. Power in a Liberal Security Community." in G. John Ikenberry America Unrivaled: the Future of the Balance of Power. Ithaca: Cornell UP, 2002: 260-283.

Rose, Richard. Lesson - Drawing in Public Policy: A Guide to Learning Across Time and Space. Chatham: Chatham House Publishers, Inc., 1993.

Russett, Bruce. "The Mysterious Case of Vanishing Hegemony; or, Is Mark Twain Really Dead?" International Organization. 39 (Spring 1985): 207-231.

Schulze, Hagen. Germany: A New History. Cambridge: Harvard UP, 1998.

Schweller, Randal L. "Domestic Structure and Preventative War: Are Democracies More Pacific?” World Politics. 44 (January 1992): 235-269.

Schweller, Randall L. "Bandwagoning for Profit: Bringing the Revisionist State Back In." International Security. 19 (Summer 1994): 72-107.

Skocpol, Theda. "Bringing the State Back In." Bringing the State Back In. Eds. Evans et al. 1985.

Snyder, Jack. Myths of Empire: Domestic Politics and International Ambition. Ithaca: Cornell UP, 1994.

Stein, Arthur R. "Coordination and Collaboration: Regimes in the Anarchic World." in Stephen D. Krasner (ed.) International Regimes. Ithaca: Cornell UP, 1983: 115-140.

Stern, Fritz. Gold and Iron: Bismarck, Bleichroder, and the Building of the German Empire. New York: Alfred A. Knopf, 1977.

Sturmer, Michael. The German Empire: 1870-1918. New York: Modern Library, 2000.

Taylor, A. J. P. The Struggle for the Mastery of Europe, 1848-1918. New York: Oxford UP, 1954.

Thomas, Ward. "Norms and Security.” International Security. 25 (Summer 2000): 105-133.

Thomson, J. M. Louis Napoleon and the Second Empire. Oxford: Basil Blackwell Publishing, 1965. 
Tombs, Robert. France 1814-1914. New York: Longman, 1996.

Van Evera, Stephen. Guide to Methods for Students of Political Science. Ithaca: Cornell UP, 1997.

Walt, Stephen M. "Keeping the World Off Balance': Self-Restraint and U.S. Foreign Policy." in G. John Ikenberry America Unrivaled: the Future of the Balance of Power. Ithaca: Cornell UP, 2002: 121-154.

Walt, Stephen M. "Testing Theories of Alliance Formation: The Case of Southwest Asia." International Organization. 42 (Spring 1988): 275-316.

Waltz, Kenneth N. "Structural Realism After the Cold War." International Security. 25 (Summer 2000): 5-41.

Waltz, Kenneth N. Theory of International Politics. Reading: Addison-Wesely, 1979.

Wawro, Geoffrey. The Franco-Prussian War: the German Conquest of France in 1870-1871. Cambridge: Cambridge UP, 2003.

Wehler, Hans-Ulrich The German Empire, 1871-1918. New York: Berg Publishers, 1985.

Wetzel, David. A Duel of Giants: Bismarck, Napoleon III, and the Origins of the FrancoPrussian War. Madison: U of Wisconsin P, 2001.

Wohlforth, William C. "The Stability of a Unipolar World.” International Security. 24 (Summer 1999): 5-41.

Wohlforth, William C. "U.S. Strategy in a Unipolar World." in G. John Ikenberry America Unrivaled: the Future of the Balance of Power. Ithaca: Cornell UP, 2002: 98-118.

Wright, Gordon. France in Modern Times: From Enlightenment to the Present. New York: W. W. Norton and Company, 1987.

Young, Oran R. "Regime Dynamics: The Rise and Fall of International Regimes." in Stephen D. Krasner (ed.) International Regimes. Ithaca: Cornell UP, 1983: 93-113.

Zeldin, Theodore. The Political System of Napoleon III. New York: St. Martin's Press, 1958. 